Final Report

FHWA/IN/JTRP-2005/18

\title{
FLOOD FREQUENCY RELATIONSHIPS FOR INDIANA
}

\author{
by \\ A. Ramachandra Rao \\ Professor Emeritus \\ Principal Investigator \\ School of Civil Engineering \\ Purdue University \\ Joint Transportation Research Program \\ Project No. C-36-62O \\ File No. 9-8-15 \\ SPR-2858
}

Prepared in Cooperation with the

Indiana Department of Transportation and the

Federal Highway Administration

U.S. Department of Transportation

The contents of this report reflect the views of the authors who are responsible for the fats and the accuracy of the data presented herein. The contents do not necessarily reflect the official views or policies of the Federal Highway Administration and the Indiana Department of Transportation. The report does not constitute a standard, specification, or regulation.

\author{
School of Civil Engineering \\ Purdue University \\ March 2006
}




\section{TECHNICAL Summary}

INDOT Research

Technology Transfer and Project Implementation Information

\section{Flood Frequency Relationships for Indiana}

\section{Introduction}

The objective of the research was the development of relationships to estimate flood magnitudes for Indiana streams. In order to achieve this goal several probability distributions were evaluated. The Pearson (3) (LP(3)) and the

\section{Findings}

Relationships were developed for the flood frequencies to be estimated by the LP(3) distributions. The State of Indiana has been divided into regions, seven of which are homogeneous and one heterogeneous. The floods of specific return periods were related to watershed characteristics which are relatively easy to measure by the generalized least squares (GLS) method.

The regional flood estimates based on Lmoments have been developed and presented for all the eight regions. These are based on $\mathrm{P}(3)$, GEV and LP(3) distributions. The GLS based regional regression analysis was used to relate the flood magnitudes based on these distributions and
Generalized Extreme Value (GEV) distributions were found to be the best distributions for Indiana data. Because of the requirement that Log Pearson (3) $(\mathrm{LP}(3))$ distribution must be used in federallyfunded projects, it was retained in the study.

\section{Implementation}

A proposal for an implementation project will be developed by the Principal Investigator, which will include a manual and a CD-ROM to watershed parameters. The L-moment based methods and the regional regression relationships are compared to each other by split sample tests.

Following are the conclusions of this study.

1. The prediction errors were smallest for homogeneous watersheds and highest for heterogeneous watersheds.

2. The L-moment based method is more accurate than the GLS method.

3. The Pearson (3) and generalized extreme value distributions give more accurate predictions than the log Pearson (3) distribution.

\section{Contacts}

For more information:

\section{Prof. A. Ramanchandra Rao}

Principal Investigator

School of Civil Engineering

Purdue University

West Lafayette IN 47907

Phone: (765) 494-2176

Fax: (765) 496-1988

E-mail: rao@purdue.edu use the relationships discussed in the final report. A workshop to train interested engineers in using these relationships will be presented.

\section{Indiana Department of Transportation}

Division of Research 1205 Montgomery Street

P.O. Box 2279

West Lafayette, IN 47906

Phone: (765) 463-1521

Fax: (765) 497-1665

Purdue University

Joint Transportation Research Program

School of Civil Engineering

West Lafayette, IN 47907-1284

Phone: (765) 494-9310

Fax: (765) 496-7996

E-mail: jtrp@ecn.purdue.edu

http://www.purdue.edu/jtrp 
TECHNICAL REPORT STANDARD TITLE PAGE

\begin{tabular}{|c|c|c|}
\hline $\begin{array}{l}\text { 1. Report No. } \\
\text { FHWA/IN/JTRP-2005/18 }\end{array}$ & 2. Government Accession No. & 3. Recipient's Catalog No. \\
\hline \multirow{2}{*}{\multicolumn{2}{|c|}{$\begin{array}{l}\text { 4. Title and Subtitle } \\
\text { Flood Frequency Relationships for Indiana }\end{array}$}} & $\begin{array}{l}\text { 5. } \quad \text { Report Date } \\
\text { March } 2006\end{array}$ \\
\hline & & 6. Performing Organization Code \\
\hline $\begin{array}{l}\text { 7. Author(s) } \\
\text { A. Ramachandra Rao }\end{array}$ & & $\begin{array}{l}\text { 8. Performing Organization Report No. } \\
\text { FHWA/IN/JTRP-2005/18 }\end{array}$ \\
\hline \multirow{2}{*}{\multicolumn{2}{|c|}{$\begin{array}{l}\text { 9. Performing Organization Name and Address } \\
\text { Joint Transportation Research Program } \\
\text { Purdue University } \\
\text { West Lafayette, IN 47907-1284 }\end{array}$}} & 10. Work Unit No. \\
\hline & & $\begin{array}{l}\text { 11. Contract or Grant No. } \\
\text { SPR-2858 }\end{array}$ \\
\hline \multirow{2}{*}{\multicolumn{2}{|c|}{$\begin{array}{l}\text { 12. Sponsoring Agency Name and Address } \\
\text { Indiana Department of Transportation, State Office Bldg, } 100 \text { N Senate Ave., } \\
\text { Indianapolis, IN } 46204\end{array}$}} & $\begin{array}{l}\text { 13. Type of Report and Period Covered } \\
\text { Final Report }\end{array}$ \\
\hline & & 14. Sponsoring Agency Code \\
\hline
\end{tabular}

\section{Abstract}

The objective of the research presented in this report is the development of relationships to estimate flood magnitudes for Indiana streams. In order to achieve this goal several probability distributions were evaluated. The Pearson (3) (LP(3)) and the Generalized Extreme Value (GEV) distributions were found to be the best distributions for Indiana data. Because of the requirement that Log Pearson (3) (LP(3)) distribution must be used in federally-funded projects it was retained in the study.

Relationships were developed for the flood frequencies to be estimated by the LP(3) distributions. The State of Indiana has been divided into regions, seven of which are homogeneous and one heterogeneous. The floods of specific return periods were related to watershed characteristics which are relatively easy to measure by the generalized least squares (GLS) method.

The regional flood estimates based on L-moments have been developed and presented for all the eight regions. These are based on P(3), GEV and LP(3) distributions. The GLS based regional regression analysis was used to relate the flood magnitudes based on these distributions and watershed parameters. The L-moment based methods and the regional regression relationships are compared to each other by split sample tests.

The following conclusions are presented based on this study. (1) Identifying homogeneous regions prior to development of flood frequency relationships substantially reduce the prediction errors. (2) The L-moment based flood frequency relationships are more accurate than those developed by regional regression analysis (3) The Pearson (3) and GEV distributions give more accurate flood flow estimates than the LP(3) distribution.

\begin{tabular}{|l|l|l|l|}
\hline $\begin{array}{l}\text { 17. Key Words } \\
\text { flood frequency analysis, watersheds, generalized least squares }\end{array}$ & $\begin{array}{l}\text { 18. Distribution Statement } \\
\text { No restrictions. This document is available to the public } \\
\text { through the National Technical Information Service, } \\
\text { Springfield, VA 22161 }\end{array}$ \\
\hline \begin{tabular}{l|l|l|} 
19. Security Classif. (of this report) \\
Unclassified
\end{tabular} & $\begin{array}{l}\text { 20. Security Classif. (of this page) } \\
\text { Unclassified }\end{array}$ & $\begin{array}{l}\text { 21. No. of Pages } \\
138\end{array}$ \\
\hline
\end{tabular}




\section{TABLE OF CONTENTS}

Page

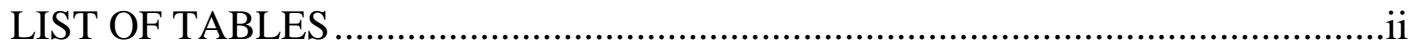

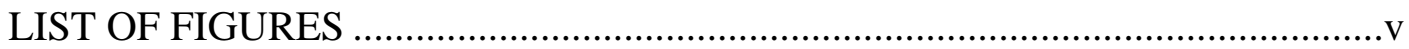

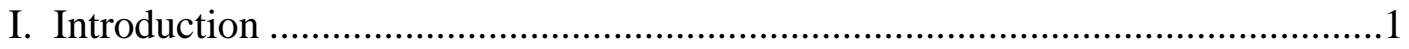

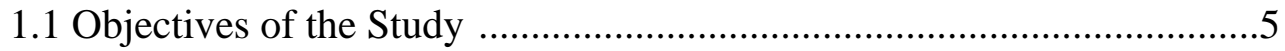

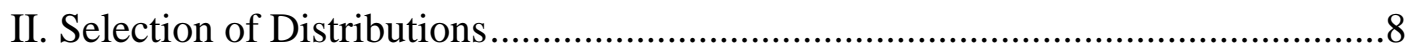

2.1 Parameter and Quantile Estimation ......................................................10

2.2 Parameter Estimation ............................................................................11

2.3 Quantile Estimation .........................................................................12

2.4 Selection of Probability Distributions.................................................12

2.4.1 Chi-Square Test ................................................................13

2.4.2 Kolmogrov-Smirnov Test .......................................................14

2.5 Procedure to Select the Distributions....................................................14

III. Estimation of Peak Discharges by LP(3) Method.........................................27

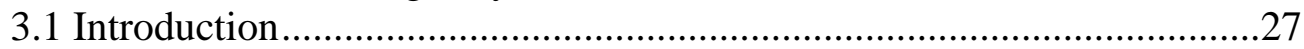

3.2 Development of Flood Prediction Equations ......................................28

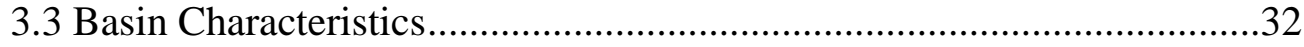

3.4 Generalized Least Squares Regression ..............................................35

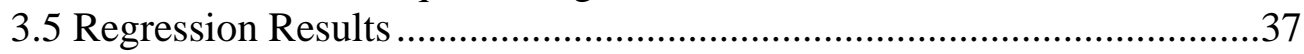

3.6 Evaluation of the Prediction Equations..................................................44

3.7 Split Sample Test .....................................................................49

IV. Regional Flood Estimation Based on L-Moments .........................................54

4.1 L-moments and Parameter Estimation...................................................54

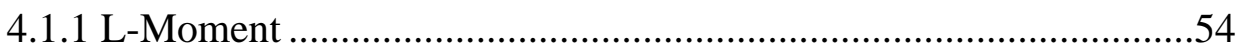

4.1.2 Moments and Parameter Estimation ..............................................55

4.2 Regional Index Flood Method Based on L-Moments............................62

4.2.1 Introduction ........................................................................62

4.2.2 Regional L-moment Method.....................................................62

4.2.3 At-site and regional parameter estimation ....................................64 


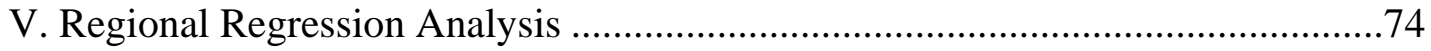

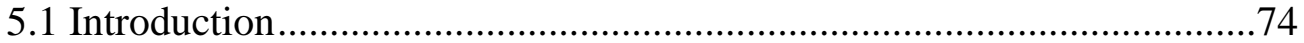

5.2 GLS regional regression results .......................................................74

5.3 Combination of GLS regional regression and L-moment method...........97

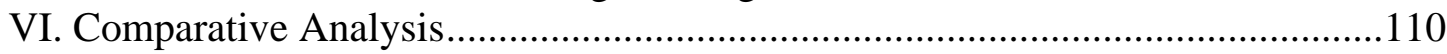

6.1 Split sample test for first method .....................................................111

6.2 Split sample test for the second method ................................................118

6.3 Split sample test for the third method ................................................118

6.4 Comparison of the three approaches..................................................126

VII. Conclusions........................................................ 136

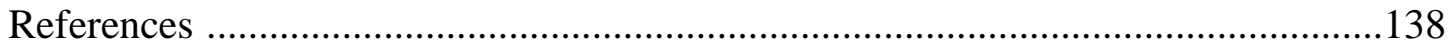




\section{LIST OF TABLES}

Table

Table 2.5.1 Results for Log Pearson III distribution for Region 3 ..........................16

Table 2.5.2 Selection of Best Distribution in each Region .....................................22

Table 2.5.3 Selection of Best Distribution in each Region using stations

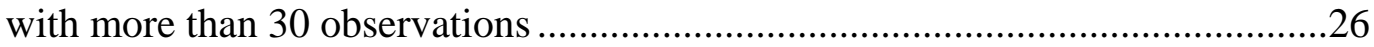

Table 3.3.1 NCLD Land Cover Class Definitions .................................................34

Table 3.5.1 Homogeneity measures for defined regions ......................................38

Table 3.5.2 Regression results for Region 1 ....................................................40

Table 3.5.3 Regression results for Region 2 ...................................................40

Table 3.5.4 Regression results for Region 3 ...................................................41

Table 3.5.5 Regression results for Region 4 .....................................................41

Table 3.5.6 Regression results for Region 5 ....................................................41

Table 3.5.7 Regression results for Region 6 ....................................................42

Table 3.5.8 Regression results for Region 7 ....................................................42

Table 3.5.9 Regression results for Region 8 .....................................................42

Table 3.5.10 Ranges for various watershed characteristics ..................................43

Table 3.7.1 Stations removed from regression for Spilt Sample test.......................50

Table 3.7.2 Spilt Sample error percentages ….....................................................51

Table 4.2.1 Normalized regional quantile estimates...........................................66

Table 4.2.1 Normalized regional quantile estimates (cont.) ................................67

Table 4.2.2 Normalized regional quantile estimates for Region 1 and Region 5 defined by Srinivas and Rao (2003) .........................................69

Table 4.2.3 Determine the optimal probability distributions for regional L-moment flood estimates of the entire series of data. 69

Table 5.2.1 $\mathrm{R}^{2}$ values for the relationship between the individual hydrological attributes and PT3 flood quantile estimates...............................74

Table 5.2.2 $\mathrm{R}^{2}$ values for the relationship between the individual hydrological attributes and GEV flood quantile estimates ..............................75 
Table 5.2.3 GLS Regression coefficients for the drainage areas and PT3

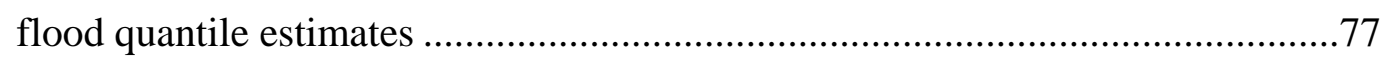

Table 5.2.3 GLS Regression coefficients for the drainage areas and PT3

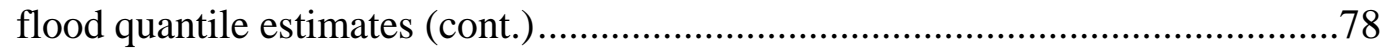

Table 5.2.3 GLS Regression coefficients for the drainage areas and PT3

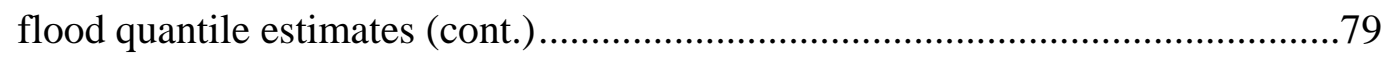

Table 5.2.3 GLS Regression coefficients for the drainage areas and PT3

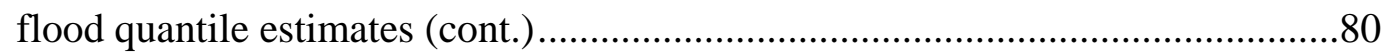

Table 5.2.4 GLS Regression coefficients for the drainage areas and GEV flood quantile estimates .83

Table 5.2.4 GLS Regression coefficients for the drainage areas and GEV flood quantile estimates (cont.)

Table 5.2.4 GLS Regression coefficients for the drainage areas and GEV

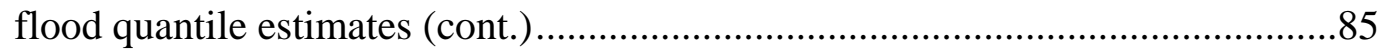

Table 5.2.4 GLS Regression coefficients for the drainage areas and GEV

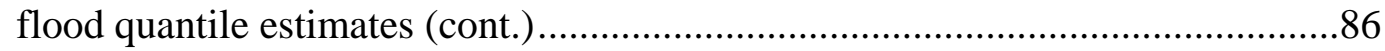

Table 5.2.5 GLS Regression coefficients for the drainage areas and LP3 flood quantile estimates

Table 5.2.5 GLS Regression coefficients for the drainage areas and LP3 flood quantile estimates (cont.) .90

Table 5.2.5 GLS Regression coefficients for the drainage areas and LP3 flood quantile estimates (cont.)

Table 5.2.5 GLS Regression coefficients for the drainage areas and LP3 flood quantile estimates (cont.)

Table 5.2.6 GLS Regression coefficients of mean and logmean annual peak flow for Region 1 and Region 5 derived by Srinivas and Rao (2003) .97

Table 5.2.7 GLS Regression coefficients of PT3 flood quantile estimates for merged area .98

Table 5.2.8 GLS Regression coefficients of GEV flood quantile estimates for merged area .99 
Table 5.2.9 GLS Regression coefficients of LP3 flood quantile estimates

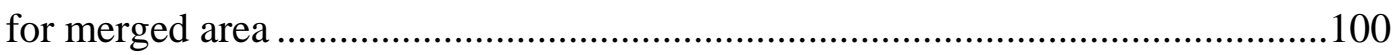

Table 5.3.1 GLS regional regression for mean annual peak flows .............................101

Table 5.3.2 GLS regional regression for mean of logarithms of annual peak flows .102

Table 6.1.1 Optimal probablility distributions for regional flood estimates...............112

Table 6.3.1 Estimation errors of 75\% split samples obtained from three comparative methods for PT3, GEV and LP3 distributions (Region 1 4)...........127

Table 6.3.2 Estimation errors of $75 \%$ split samples obtained from three comparative methods for PT3, GEV and LP3 distributions (Region 5 8)...........128

Table 6.4.3 Estimation errors of 25\% split samples obtained from three comparative methods for PT3, GEV and LP3 distributions (Region 1 4)...........131

Table 6.4.5 Estimation errors of $25 \%$ split samples obtained from three comparative methods for PT3, GEV and LP3 distributions (Region 5 8)...........132

Table 6.4.6 Comparison the estimation errors of the $75 \%$ split samples obtained from three methods for PT3, GEV and LP3 distributions (Merged region $1+7$ and 5+8)

Table 6.4.7 Comparison the estimation errors of the $25 \%$ split samples obtained from three methods for PT3, GEV and LP3 distributions (Merged region 1+7 and 5+8) 135 


\section{LIST OF FIGURES}

Figure

Figure 1.1.1 Percentage error for regional regression estimators of different statistics in the Potomac River basin (after Thomas and Benson (1970) .............2

Figure 1.1.2 Regions by Glatfelter (1984) .....................................................2

Figure 1.1.3 Flood Homogeneous regions of Indiana (Rao et al. (2002)) ...............3

Figure 1.1.4 Flood Homogeneous regions by hybrid cluster method (Srinivas

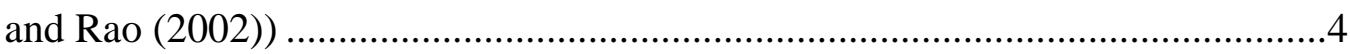

Figure 1.1.5 Flood Homogeneous regions by Fuzzy Cluster Analysis (Srinivas

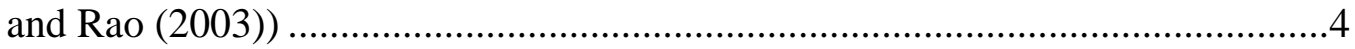

Figure 2.1.1 Homogeneous regions developed by Srinivas and Rao (2002)............10

Figure 2.5.1 Region 1 - Frequency of Rank 1 for selecting the best Distribution ...19

Figure 2.5.2 Region 2 - Frequency of Rank 1 for selecting the best Distribution ...19

Figure 2.5.3 Region 3 - Frequency of Rank 1 for selecting the best Distribution ...20

Figure 2.5.4 Region 4 - Frequency of Rank 1 for selecting the best Distribution ...20

Figure 2.5.5 Region 5 - Frequency of Rank 1 for selecting the best Distribution ...21

Figure 2.5.6 Region 6 - Frequency of Rank 1 for selecting the best Distribution ...21

Figure 2.5.7 Region 1 - Frequency of Rank 1 for selecting the best Distribution with more than 30 observations at each site .23

Figure 2.5.8 Region 2 - Frequency of Rank 1 for selecting the best Distribution with more than 30 observations at each site 23

Figure 2.5.9 Region 3 - Frequency of Rank 1 for selecting the best Distribution with more than 30 observations at each site

Figure 2.5.10 Region 4 - Frequency of Rank 1 for selecting the best Distribution with more than 30 observations at each site .24

Figure 2.5.11 Region 5 - Frequency of Rank 1 for selecting the best Distribution with more than 30 observations at each site .25

Figure 2.5.12 Region 6 - Frequency of Rank 1 for selecting the best Distribution 
with more than 30 observations at each site

Figure 3.1.1 Regions for Indiana as defined by Srinivas and Rao (2003)...............29

Figure 3.1.2 Regions as defined for this analysis ................................................30

Figure 3.6.1 Comparison of 100 year observed discharges and regression model discharges for Region 1

Figure 3.6.2 Comparison of 100 year observed discharges and regression model discharges for Region 2

Figure 3.6.3 Comparison of 100 year observed discharges and regression model discharges for Region 3

Figure 3.6.4 Comparison of 100 year observed discharges and regression model discharges for Region 4

Figure 3.6.5 Comparison of 100 year observed discharges and regression model discharges for Region 5

Figure 3.6.6 Comparison of 100 year observed discharges and regression model discharges for Region 6

Figure 3.6.7 Comparison of 100 year observed discharges and regression model discharges for Region 7

Figure 3.6.8 Comparison of 100 year observed discharges and regression model discharges for Region 8 48

Figure 4.1.1 LCs-LCK moment ratio diagram for the study regions..... .60

Figure 4.1.2 RMSE of L-Moment ratio diagram comparison for different distributions.

Figure 4.1.3 RMSE of L-Moment ratio diagram comparison of the 75\% of data for different distributions

Figure 4.2.1 At-site and regional quantile flood estimates $(\mathrm{T}=100$ year $)$...............70

Figure 4.2.2 Variance of the difference between at-site and regional estimates ......71

Figure 4.2.3 95\% confidence intervals for regional PT3 L-moment estimates ........72

Figure 5.2.1(a) GLS regional regression for PT3 $(\mathrm{T}=10$ years) ...........................81

Figure 5.2.1(b) GLS regional regression for PT3 $(\mathrm{T}=100$ years) ….......................82

Figure 5.2.2(a) GLS regional regression for GEV ( $\mathrm{T}=10$ years) ..........................87 
Figure 5.2.2(b) GLS regional regression for GEV ( $\mathrm{T}=100$ years) ..........................88

Figure 5.2.3(a) GLS regional regression for LP3 $(\mathrm{T}=10$ years) ...........................93

Figure 5.2.3(b) GLS regional regression for LP3 ( $\mathrm{T}=100$ years) ..........................94

Figure 5.3.1(a) At-site observed mean annual peak flows compared with

GLS regression results and the 95\% confidence upper and lower limits for Region 1 4.

Figure 5.3.1(b) At-site observed mean annual peak flows compared with

GLS regression results and the 95\% confidence upper and lower limits for Region 5 8. 105

Figure 5.3.2 Histographs of drainage areas for each region ..... 106

Figure 5.3.3(a) At-site logarithms of mean annual peak flows compared with

GLS regression results and the 95\% confidence upper and lower limits for Region 1 4.

Figure 5.3.3(b) At-site logarithms of mean annual peak flows compared with

GLS regression results and the 95\% confidence upper and lower limits for Region 5 8.

Figure 6.1.1 Flowchart of three comparison methods

Figure 6.1.2(a) Results of at-site and regional quantile floods from method 1

$(\mathrm{T}=50$ year $)$

Figure 6.1.2(b) Results of at-site and regional quantile floods from method 1

$(\mathrm{T}=100$ year $)$

Figure 6.1.2(c) Results of at-site and regional quantile floods from method 1

$$
(\mathrm{T}=200 \text { year })
$$

Figure 6.1.3 Variance of the difference between at-site and regional estimates from method 1

Figure 6.2.1(a) At-site quantile floods and the quantile floods obtained by method 2 for $25 \%$ of the data (PT3)

Figure 6.2.1(b) At-site quantile floods and the quantile floods obtained by method 2 for $25 \%$ of the data (GEV)

Figure 6.2.1(c) At-site quantile floods and the quantile floods obtained by method 2 for $25 \%$ of the data (LP3) 120 
Figure 6.3.1(a) At-site quantile floods and the quantile floods obtained by

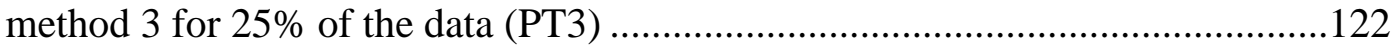

Figure 6.3.1(b) At-site quantile floods and the quantile floods obtained by method 3 for $25 \%$ of the data (GEV)

Figure 6.3.1(c) At-site quantile floods and the quantile floods obtained by method 3 for $25 \%$ of the data (LP3) 


\section{Introduction}

The basic objective of the research reported herein is to analyze Indiana flood data and to develop regional equations to estimate magnitudes of floods corresponding to specified recurrence intervals. The commonly used recurrence intervals of 2, 5, 10, 25, 50 and 100 years are used in this research. In Indiana, the equations which are being used presently to estimate floods were developed by Glatfelter (1984) using data available up to or a few years before 1982. More than 20 years of additional data are available since Glatfelter's work. The additional data offers an incentive to develop more accurate relationships to estimate flood magnitudes.

In addition to the improvements which can be brought about by using the additional data, there are two strong reasons to develop new flood frequency relationships. Both of these are related to the drawbacks in Glatfelter's work. The first of these is that the ordinary least squares (OLS) method was used by him to develop these relationships. This was the standard practice in U.S.G.S. at that time. In fact, all the states followed the same procedure. However, the nature of the flood data is such that, later, the Generalized Least Squares (GLS) method was shown to be better suited for the problem. The GLS was shown to reduce the rather substantial errors in these relationships (Fig. 1.1.1).

The second major drawback in Glatfelter's work is that he used the data from the major river basins in Indiana. These river basins are shown in Fig. 1.1.2. However, as demonstrated by Rao and Hamed (1997), these river basins are not homogeneous in their flood characteristics. Consequently the flood frequency relationships developed by using these data can be improved substantially. 


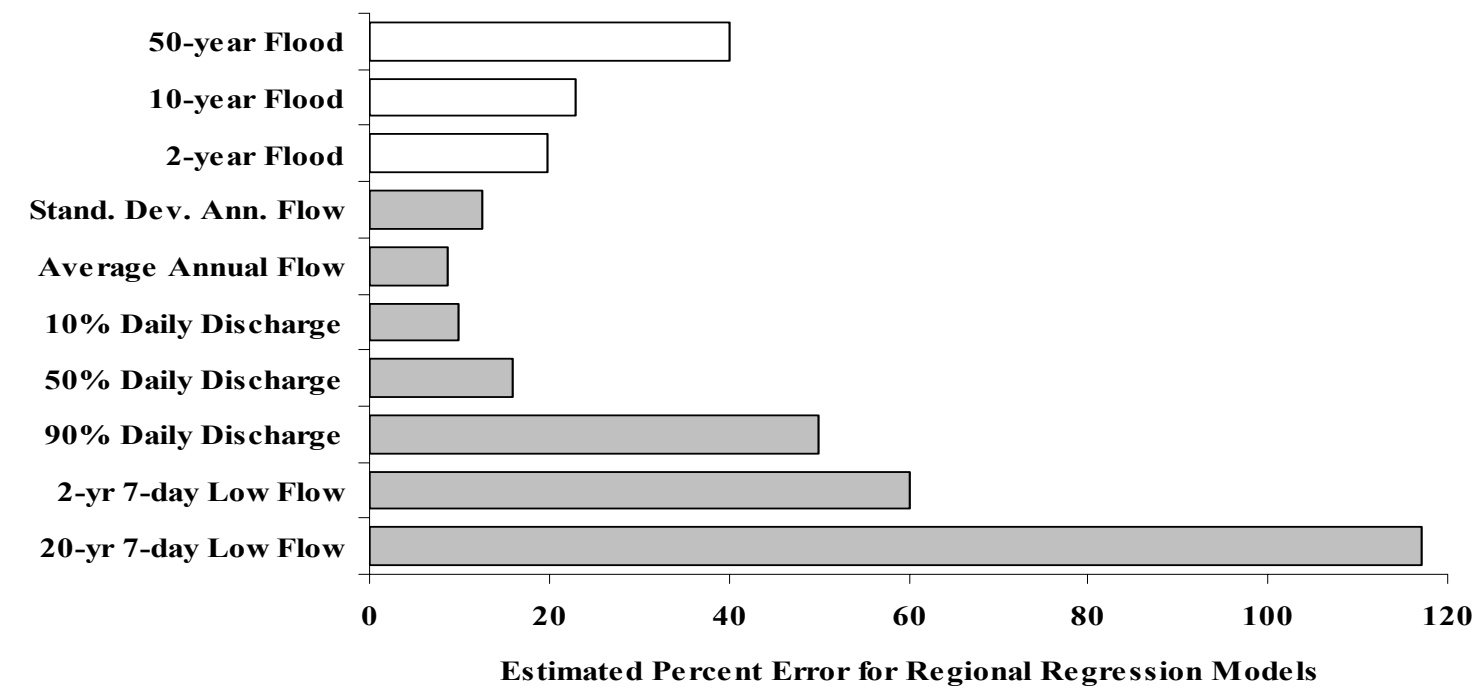

Figure 1.1.1. Percentage error for regional regression estimators of different statistics in the Potomac River basin (after Thomas and Benson (1970))

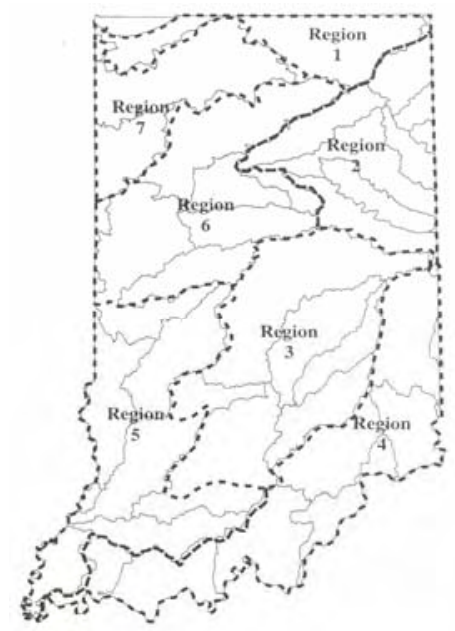

Figure 1.1.2. Regions by Glatfelter (1984)

In order to identify homogeneous regions in Indiana, a JTRP study was conducted at Purdue University. Different methods based on trial and error, clustering algorithms, fuzzy algorithms and neural networks were used to identify homogeneous regions in Indiana [(Rao et al. (2002), Srinivas and Rao (2002), Iblings and Rao (2003), Srinivas and Rao (2003)]. The 
homogeneity of these regions was tested by using the statistics developed by Hosking and Wallis (1993, 1997). Three of these results are shown in figures 1.1.3-1.1.5. A comparison of these regions in Fig. 1.1.2 and Figs. 1.1.3-1.1.5 demonstrates the fact that flood homogeneous regions in Indiana do not correspond to river basin boundaries. The annual maximum flood data from the regions in Figs. 1.1.4 and 1.1.5 or slight modifications are used in the present study. Separate flood frequency relationships are developed for each region.

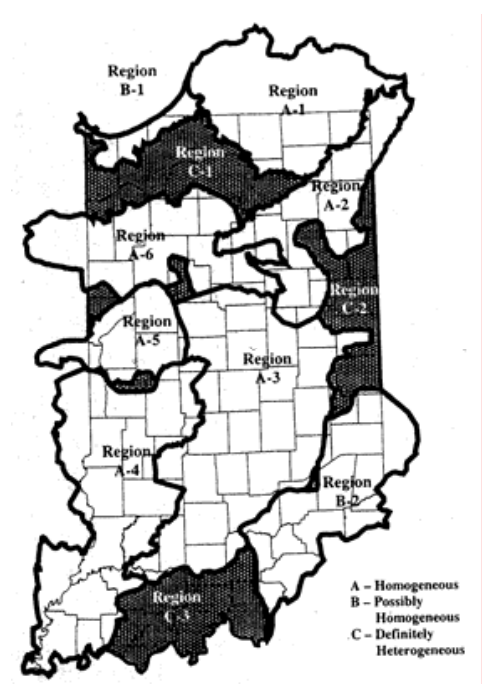

Figure 1.1.3. Flood Homogeneous regions of Indiana (Rao et al. (2002))

The U.S. Water Resources Council mandated the use of log-Pearson (III) (LP(III)) distribution for estimating floods in the U.S whenever Federal funds are used. The LP(III) distribution is very sensitive to skewness coefficients of the annual maximum flood data. These skewness coefficients vary considerably in any given region and hence the flood estimates based on them also vary (McCormick and Rao (1995)). Also, the LP(III) distribution may not be the best distribution to describe the flood data (Wallis and Wood (1985), Rao and Hamed (2000), 


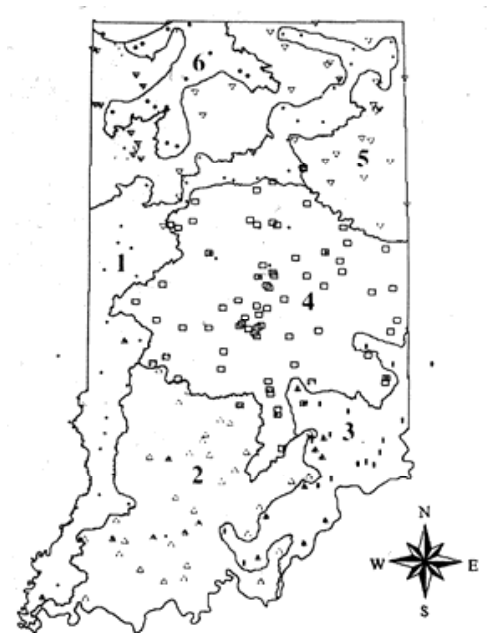

Figure 1.1.4. Flood Homogeneous regions by hybrid cluster method (Srinivas and Rao (2002)).

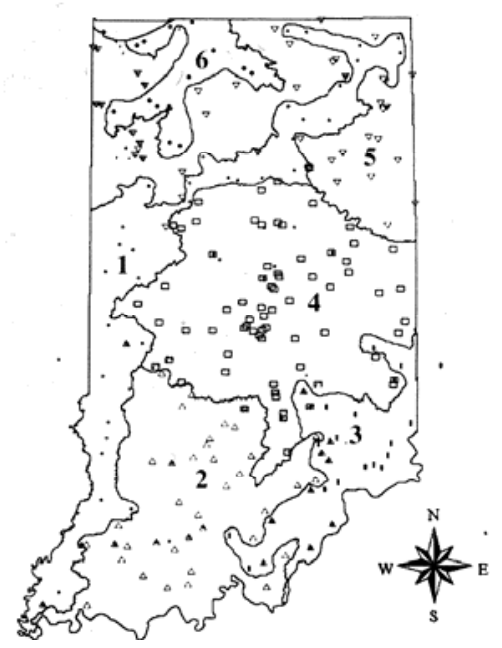

Figure 1.1.5. Flood Homogeneous Regions by Fuzzy Cluster Analysis (Srinivas and Rao (2003))

Rao et al. (2003)). Consequently, two sets of relationships, one based on LP(III) and another one based on a better distribution for a given region are developed for each region. The relationships based on LP(III) distribution are used where it is required. The other set of relationships are designed to be used where the relationships based on LP(III) distributions are not required. 


\subsection{Objectives of the Study}

The optimal statistical distribution which may be used may vary from one region to another. Consequently, data from each region are analyzed to determine the best distribution for each region. The commonly used distributions such as Generalized Extreme Value (GEV), Generalized Logistic, LP(III) and other distributions are selected for this analysis. The tests designed by Hosking and Wallis $(1993,1997)$ as well as other standard tests such as $\chi_{-}^{2}$ or Kolmogorov-Smirnov tests are used to select the best distribution for each region. This is discussed in chapter 2 .

The flood frequency relationships based on LP (III) distribution must be used whenever federal funds are used in any project. Consequently, the flood magnitudes corresponding to the specified frequencies are estimated by using all the available data and the Water Resources Council (WRC) method. These flood values are related to the physiographic and meteorologic variables so that they may be used to estimate the flood magnitudes at locations where flood data are not available. This aspect of the study is discussed in chapter 3.

In developing flood frequency relationships, regression-based relationships are commonly used. However, recent research based on L-moments has demonstrated that the results based on L-moments are as good as or better than those based on other regression relationships. Consequently, L-moment based relationships are developed by using Indiana data. The accuracy of the L-moment based method is tested by using split sample tests. The development of L-Moment based relationships is discussed in chapter 4 .

In order to use the L-moment based approach for ungaged watersheds, the average annual flood or a similar statistic must be estimated from easily measured watershed and meteorological characteristics. These relationships are developed by using GLS techniques. The accuracy of 
these relationships is tested by using split sample tests. Consequently, development of relationships for estimating the average annual maximum flow and testing them are discussed in chapter 5 .

Although the L-moment based methods are supposed to be better than those based purely on regression relationships, the universality of this assertion has not been established. The claims of superiority of the L-moment method compared to the regression relationships are investigated by using a comparison of these methods. Consequently the regression relationships for floods of different return periods are developed for each region. The GLS method is used for developing these relationships. The correlation between the dependent variables are tested and only one of the variables of a pair tested is retained in order to eliminate spurious correlations. Development of these flood frequency regression relationships is discussed in chapter 6 .

In selecting these procedures for flood frequency analysis the accuracies of these methods must be established. The accuracies of L-moment and regression analysis methods are established by using the split sample technique. Part of the data from a region is used to establish these relationships. The remaining part of the data is used to test the accuracy of these relationships. Thus the errors of estimation are determined. This aspect of the study discussed in chapter 7 .

A summary and a set of conclusions are presented in chapter 8 .

The details of much of the work reported herein are found in three reports:

1. Estimation of Peak Discharges of Indiana Streams by Using log Pearson (III) Distribution, Interim Report No. 1, by David Knipe and A.R. Rao, May, 2005. (Knipe and Rao (2005)) 
2. Indiana Flood Data Analysis, Interim Report No. 2, by Shalini Kedia and A. R. Rao, July, 2005. (Kedia and Rao (2005))

3. Flood Estimates for Indiana Steams, Interim Report No. 3, by En-Ching Hsu and A. R. Rao, August, 2005. (Hsu and Rao (2005)).

In order to keep the length of this report within reasonable limits the readers are referred to these reports. They are available from Purdue University libraries. 


\section{Selection of Distributions}

An important problem in hydrology is the estimation of flood magnitudes, especially because planning and design of water resource projects and flood plain management depend on the frequency and magnitude of peak discharges. A flood event can be described as a multivariate event whose main characteristics can be summarized by its peak, volume, and duration, which may be correlated. However, flood frequency analysis has often concentrated on the analysis of flood peaks. Several summaries, discussions and extensive reviews of the field of flood frequency analysis are given by Chow (1964), Yevjevich (1972), Kite (1977), Singh (1987), Potter (1987), Bobee and Ashkar (1991), McCuen (1993), Stedinger et al. (1993), and Rao and Hamed (2000).

In the statistical analysis of floods extreme value probability distributions are fitted to measured peak flows. This method is data intensive and is applicable only to gauged watersheds. Selection of probability distribution is generally arbitrary, as no physical basis is available to rationalize the use of any particular distribution. Several distributions, Log-Normal, Pearson type III, Wiebull, log Pearson Type III, Generalized Extreme Value, to name a few, have been used and these may seem appropriate for a given sample of data. To check the validity of accepting a distribution, goodness-of-fit tests are used.

The U.S. Water Resources Council recommends the use of log-Pearson (III) (LP (III)) distribution for estimating floods in the U.S. Studies by Wallis and Wood (1985), Rao and Hamed (2000), and Rao et al. (2003) show that LP (III) distribution may not be the best distribution for the flood data in U.S. Therefore it is useful to test the adequacy of the distributions to determine the best distribution for a given region. 
Generalized Extreme Value (GEV) distribution is considered to be an appropriate choice for annual peak floods. Stedinger and $\mathrm{Lu}$ (1991) developed critical values and formulas for goodness-of-fit-tests for the GEV distribution. In the past, three tests, namely, KolmogorovSmirnov test, the probability plot correlation test, and sample L moment ratio tests have been investigated. These tests are used to check if data available for a site are consistent with a regional GEV distribution. Zempleni (1991) proposed a test based on the stability property of GEV distributions. It provides a tool for testing the hypothesis of a sample having GEV distribution against any other probability distribution.

To identify the homogeneous regions in Indiana, different methods based on trial and error, clustering algorithms, fuzzy algorithms and neural networks have been used [(Rao et al. (2002), Srinivas and Rao (2002), Iblings and Rao (2003), Srinivas and Rao (2003)]. The homogeneity of these regions is tested by using the statistics developed by Hosking and Wallis (1993, 1997). The study by Srinivas and Rao (2002) yielded six regions shown in Figure 2.1.1. In the present study, the annual maximum flood data from the regions in Figure 2.1.1 are used. Regions 1-5 are found to be homogeneous and region six in Figure 2.1.1, containing the Kankakee River basin, is heterogeneous.

The objective of the research discussed in this chapter is to use Indiana data for a comparative analysis, and determine the best distribution for each region. These distributions include Log Pearson Type III (LP III), Generalized Extreme Value (GEV), Pearson Type III, Log Normal (III), Gamma, Generalized Pareto and Logistic distributions. The method of moments, maximum Likelihood and probability weighted moments are used for parameter estimation. The distributions fitted by using these methods are tested by using the Chi-Square 
and Kolmogorov-Smirnov tests. The results of these goodness-of-fit tests are used to select a distribution for a region.

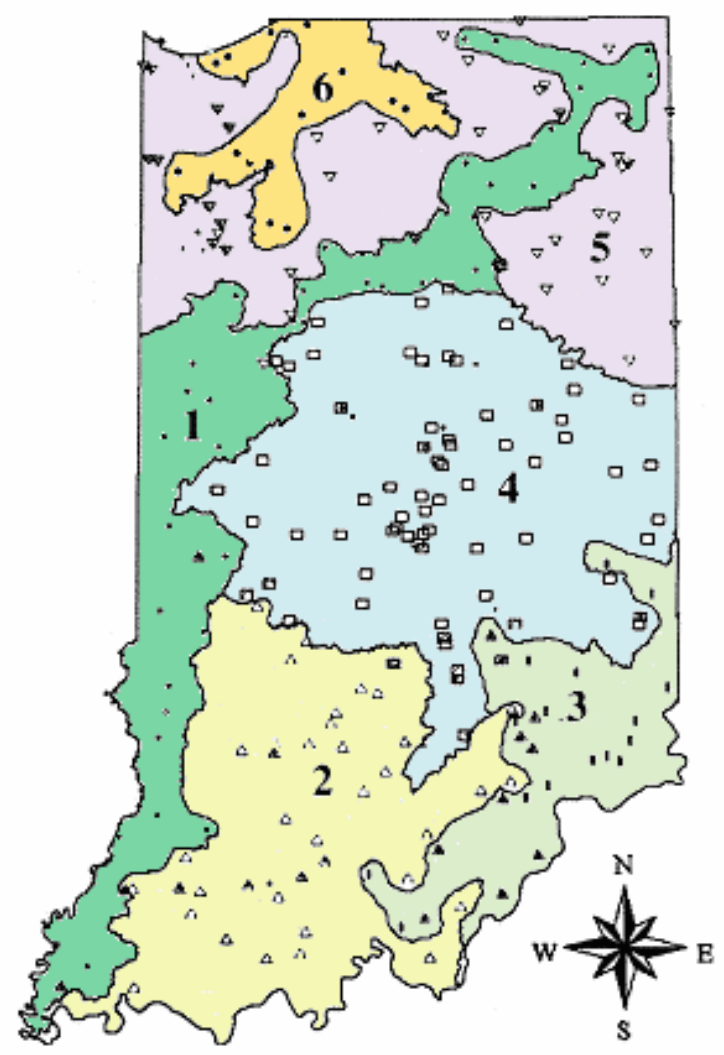

Figure 2.1.1. Homogeneous regions developed by Srinivas and Rao (2002)

\subsection{Parameter and Quantile Estimation}

In flood frequency analysis, an assumed probability distribution is fitted to the available data to estimate the flood magnitude for a specified return period. The choice of an appropriate probability distribution is quite arbitrary, as no physical basis is available to rationalize the use of any particular distribution. The first type of error which is associated with wrong assumption of a particular distribution for the given data can be checked to a certain extent by using goodness-of- 
fit tests. These are statistical tests which provide a probabilistic framework to evaluate the adequacy of a distribution.

Even if an acceptable distribution is selected, proper estimation of parameters is important. Some of the parameter estimation methods may not yield good estimates, or even converge. Therefore, some guidance is needed about the parameter estimation methods.

\subsection{Parameter Estimation}

Several methods can be used for parameter estimation. In this study, the method of moments (MOM), the maximum likelihood method (MLM) and the probability weighted moment method (PWM) are used for parameter estimation.

The maximum likelihood method (MLM) is considered to be the most accurate method, especially for large data sets since it leads to efficient parameter estimators with Gaussian asymptotic distributions. It provides the smallest variance of the estimated parameters, and hence of the estimated quantiles, compared to other methods. However, with small samples the results may not converge.

The method of moments (MOM) is relatively easy and is more commonly used. It can also be used to obtain starting values for numerical procedures involved in ML estimation. However, MOM estimates are generally not as efficient as the ML estimates, especially for distributions with large number of parameters, because higher order moments are more likely to be highly biased for relatively small samples.

The PWM method gives parameter estimates comparable to the ML estimates. Yet, in some cases the estimation procedures are not as complicated as in other methods and the 
computations are simpler. Parameter estimates from samples using PWM are sometimes more accurate than the ML estimates. Further details on this topic are found in Rao and Hamed (2000).

\subsection{Quantile Estimation}

After the parameters of a distribution are estimated, quantile estimates $\left(\mathrm{x}_{\mathrm{T}}\right)$ which correspond to different return periods $\mathrm{T}$ may be computed. The return period is related to the probability of non-exceedence $(\mathrm{F})$ by the relation,

$$
F=1-\frac{1}{T}
$$

where $F=F\left(x_{T}\right)$ is the probability of having a flood of magnitude $\mathrm{x}_{\mathrm{T}}$ or smaller. The problem then reduces to evaluating $\mathrm{x}_{T}$ for a given value of $\mathrm{F}$. In practice, two types of distribution functions are encountered. The first type is that which can be expressed in the inverse form $x_{T}=\phi(F)$. In this case, $\mathrm{x}_{T}$ is evaluated by replacing $\phi(F)$ by its value from equation 2.3.1. In the second type the distribution cannot be expressed directly in the inverse form $x_{T}=\phi(F)$. In this case numerical methods are used to evaluate $\mathrm{x}_{\mathrm{T}}$ corresponding to a given value of $\phi(F)$.

\subsection{Selection of Probability Distributions}

There are many distributions which are used in flood frequency analysis. A few distributions which are commonly used in modeling flood data, are listed below and are used in the present study. 


\section{a. Three-Parameter Lognormal (LN (3)) Distribution}

\section{b. Pearson (3) Distribution \\ c. Log Pearson (3) Distribution \\ d. Generalized Extreme Value (GEV) Distribution}

The choice of distributions to be used in flood frequency analysis has been a topic of interest for a long time. The best probability distribution to be used to fit the observed data cannot be determined analytically. Often, the selection of the distribution is based on an understanding of the underlying physical process. For example, the extreme value distribution might be an appropriate choice for annual peak floods. Many times, the range of the variable in the distribution function, the general shape of the distribution, and descriptors like skewness and kurtosis indicate whether a particular distribution is appropriate to a given situation. If the sample data are insufficient, the reliability in estimating more than two or three parameters may be quite low. So, a compromise has to be made between flexibility of the distribution and reliability of the parameters.

To assess the reasonability of the selected distribution, statistical tests like Chi-Square test, Kolmogrov-Smirnov tests and Akaike's Information Criterion are used. The Chi square test and Kolmogrov-Smirnov tests are discussed below.

\subsubsection{Chi-Square Test}

In the chi-square test, data are first divided into $\mathrm{k}$ class intervals. The statistic $\chi^{2}$ in equation 2.4.1 is distributed as chi-square with $\mathrm{k}-1$ degrees of freedom.

$$
\chi^{2}=\sum_{j=1}^{k} \frac{\left(O_{j}-E_{j}\right)^{2}}{E_{j}}
$$


In equation 2.4.1, $\mathrm{O}_{\mathrm{j}}$ is the observed number of events in the class interval $\mathrm{j}, \mathrm{E}_{\mathrm{j}}$ is the number of events that would be expected from the theoretical distribution, and $\mathrm{k}$ is the number of classes to which the observed data are sorted. If the class intervals are chosen such that each interval corresponds to an equal probability, then $E_{j}=n / k$ where $\mathrm{n}$ is the sample size and $\mathrm{k}$ is the number of class intervals, and equation 2.4.1 reduces to equation 2.4.2.

$$
\chi^{2}=\frac{k}{n} \sum_{j=1}^{k} O_{j}^{2}-n
$$

Class intervals can be computed by using the inverse of the distribution function corresponding to different values of probability $\mathrm{F}$, similar to estimating quantiles.

\subsubsection{Kolmogrov-Smirnov Test}

A statistic based on the deviations of the sample distribution function $F_{N}(x)$ from the completely specified continuous hypothetical distribution function $F_{0}(x)$ is used in this test. The test statistic $\mathrm{D}_{\mathrm{N}}$ is defined in equation 2.4.3.

$$
D_{N}=\max \left|F_{N}(x)-F_{0}(x)\right|
$$

The values of $F_{N}(x)$ are estimated as $N_{j} / N$ where $N_{j}$ is the cumulative number of sample events in class j. $F_{0}(x)$ is then $1 / \mathrm{k}, 2 / \mathrm{k}, \ldots$ etc., similar to the chi-square test. The value of $D_{N}$ must be less than a tabulated value of $\mathrm{D}_{\mathrm{N}}$ at the specified confidence level for the distribution to be accepted.

\subsection{Procedure to Select the Distributions}

The selection of probability distributions by using data from Indiana Watersheds is discussed in this section. The probability distributions included in this study are: Log Pearson Type III (LP III), Generalized Extreme Value (GEV), Pearson Type III, Log Normal (III), 
Gamma, Generalized Pareto and Logistic distributions. The method of moments, maximum Likelihood and probability weighted moments are used for parameter estimation. The distributions fitted by using above mentioned methods of parameter estimation are tested by using the Chi-Square and Kolmogorov-Smirnov tests for goodness-of-fit. Conclusions from these goodness-of-fit tests are used to select the distributions.

The annual peak flows from 279 gaging stations are used in this study. The annual peak flow data, as well as attributes for each gage, are found at the USGS website http://water.usgs.gov/nwis/peak. The USGS site numbers of these gaging stations are included in tables in Kedia and Rao (2005). More information can be found about these sites by using the USGS site number as an input in the USGS website. These gaging stations are divided into 6 regions by Srinivas and Rao (2002) as shown in Figure 2.1.1.

A software package in MATLAB was developed by Khaled Hamed (2001). This package has been used in this research for selecting the best distribution for each region in Indiana.

The following nine distributions are selected as candidates for the best distribution suitable to each region in Indiana: Pearson Type III, Log Pearson Type III, Generalized Extreme Value, Log Normal III, Gamma, Generalized Pareto, Logistic, Gamma and Weibull distribution. Pearson Type I, Extreme Value Type II, and Log Normal II distributions are not considered because the same distributions with three parameters are selected. Some data sets from region 1 were selected to evaluate the nine distributions. The plots of goodness of fit obtained for many of the stations, for Gamma, Generalized Pareto, Logistic and Weibull Distribution showed a very poor fit. Consequently, four distributions (log Normal III, Log Pearson III, Pearson Type III and GEV) are chosen for further investigation. 
Method of moments, maximum likelihood and probability weighted moments were used to estimate the parameters. These parameters are used to calculate the quantiles corresponding to return periods of 10, 20, 50 and 100 years. Standard errors corresponding to the observed values are also obtained. Results of goodness of fit at 95\% confidence limit are tabulated for each gage station in a region corresponding to each distribution and method of parameter estimation. As an example of the results for Log Pearson III distribution fitted to the data from Region 3 are shown in Table 2.5.1.

Table 2.5.1. Results for Log Pearson III distribution for Region 3.

\begin{tabular}{|c|c|c|c|c|c|c|c|c|c|c|c|c|}
\hline 1 & 2 & 3 & 4 & 5 & 6 & 7 & 8 & 9 & 10 & 11 & 12 & 13 \\
\hline \multirow{2}{*}{$\begin{array}{c}\text { station } \\
\text { No. }\end{array}$} & \multirow[t]{2}{*}{ USGS No. } & \multirow{2}{*}{$\begin{array}{l}\text { no. of } \\
\text { Obs. }\end{array}$} & \multirow{2}{*}{$\begin{array}{l}\text { Std Table } \\
\text { Chi Square }\end{array}$} & \multirow{2}{*}{$\begin{array}{l}\text { Std Table } \\
\text { K-Smirnov }\end{array}$} & \multicolumn{2}{|c|}{$\mathrm{ML}$} & \multicolumn{2}{|c|}{ MOM } & \multicolumn{2}{|c|}{ PWM } & \multirow{2}{*}{\begin{tabular}{|c|} 
Ranks of \\
each \\
Distribution
\end{tabular}} & \multirow{2}{*}{$\begin{array}{c}\text { Best Method } \\
\text { of Parameter } \\
\text { estimation }\end{array}$} \\
\hline & & & & & \begin{tabular}{|c|} 
actual \\
chi square
\end{tabular} & $\begin{array}{c}\text { actual } \\
\text { k smirnov }\end{array}$ & \begin{tabular}{|c|} 
actual \\
chi square
\end{tabular} & $\begin{array}{c}\text { actual } \\
\text { k smirnov }\end{array}$ & \begin{tabular}{|c|} 
actual \\
chi square
\end{tabular} & \begin{tabular}{|c|} 
actual \\
k smirnov
\end{tabular} & & \\
\hline 1 & 3242100 & 16 & 9.49 & 0.34 & 3 & 0.14 & 6 & 0.11 & inv & inv & 3131 & MOM \\
\hline 2 & 3262750 & 17 & 9.49 & 0.33 & 9.82 & 0.2 & 9.82 & 0.16 & inv & inv & 3412 & $\mathrm{ML}$ \\
\hline 3 & 3272900 & 17 & 9.49 & 0.33 & inv & inv & 2.29 & 0.08 & inv & inv & 2431 & MOM \\
\hline 4 & 3274950 & 23 & 9.49 & 0.28 & inv & inv & 12.83 & 0.32 & 11.43 & 0.2 & 1324 & MOM \\
\hline 5 & 3275900 & 10 & 9.49 & 0.41 & inv & inv & 2.8 & 0.15 & inv & inv & 3421 & MOM \\
\hline 6 & 3276000 & 47 & 9.49 & 0.20 & inv & inv & 26.36 & 0.15 & 25.68 & 3.45 & 4312 & $\mathrm{ML}$ \\
\hline 7 & 3276640 & 17 & 9.49 & 0.33 & 6.06 & 0.16 & 8.88 & 0.14 & inv & inv & 3231 & MOM \\
\hline 8 & 3276700 & 33 & 9.49 & 0.24 & 4.58 & 0.1 & 6.52 & 0.16 & inv & inv & 4311 & $\mathrm{ML}$ \\
\hline 9 & 3276770 & 10 & 9.49 & 0.41 & 6 & 0.15 & 2.8 & 0.12 & 4.4 & 0.17 & 3321 & MOM \\
\hline 10 & 3276950 & 10 & 9.49 & 0.41 & 9.2 & 0.18 & 10.8 & 0.17 & inv & inv & 3421 & MOM \\
\hline 11 & 3277000 & 41 & 9.49 & 0.21 & inv & inv & 4.07 & 0.09 & inv & inv & 1422 & MOM \\
\hline 12 & 3277250 & 10 & 9.49 & 0.41 & 6 & 0.19 & 9.2 & 0.18 & inv & inv & 2221 & MOM \\
\hline 13 & 3291780 & 33 & 9.49 & 0.24 & inv & inv & 3.61 & 0.07 & inv & inv & 1112 & $\mathrm{ML}$ \\
\hline 14 & 3292350 & 17 & 9.49 & 0.33 & 4.67 & 0.08 & 3 & 0.08 & 3 & 0.08 & 2121 & MOM \\
\hline 15 & 3294000 & 48 & 9.49 & 0.20 & 8.67 & 0.06 & 3.33 & 0.08 & inv & inv & 3311 & $\mathrm{ML}$ \\
\hline 16 & 3302500 & 50 & 9.49 & 0.19 & 5.36 & 0.09 & 12.72 & 0.15 & 27.44 & 3.01 & 2421 & $\mathrm{ML}$ \\
\hline 17 & 3302690 & 10 & 9.49 & 0.41 & 4.4 & 0.2 & 2.8 & 0.14 & inv & inv & 4312 & $\mathrm{ML}$ \\
\hline 18 & 3303000 & 77 & 9.49 & 0.15 & 5.6 & 0.06 & 5.6 & 0.06 & inv & inv & 1111 & $\mathrm{ML}$ \\
\hline 19 & 3364100 & 17 & 9.49 & 0.33 & 4.18 & 0.14 & 2.29 & 0.13 & inv & inv & 1411 & MOM \\
\hline 20 & 3364500 & 56 & 9.49 & 0.18 & 3.71 & 0.08 & 4.57 & 0.08 & inv & inv & 2122 & MOM \\
\hline 21 & 3364570 & 10 & 9.49 & 0.41 & inv & inv & inv & inv & inv & inv & 1110 & MOM \\
\hline 22 & 3366000 & 20 & 9.49 & 0.29 & 1.6 & 0.07 & 5.6 & 0.13 & inv & inv & 4321 & $\mathrm{ML}$ \\
\hline 23 & 3366200 & 34 & 9.49 & 0.23 & inv & inv & 6 & 0.09 & inv & inv & 1111 & MOM \\
\hline 24 & 3366400 & 10 & 9.49 & 0.41 & 9.2 & 0.25 & 9.2 & 0.14 & inv & inv & 1023 & $\mathrm{ML}$ \\
\hline 25 & 3367600 & 10 & 9.49 & 0.41 & 6 & 0.3 & 6 & 0.22 & inv & inv & 4123 & $\mathrm{ML}$ \\
\hline 26 & 3368000 & 47 & 9.49 & 0.20 & 3.55 & 0.07 & 10.02 & 0.11 & inv & inv & 4111 & $\mathrm{ML}$ \\
\hline 27 & 3369000 & 61 & 9.49 & 0.17 & 1.82 & 0.06 & 2.08 & 0.06 & inv & inv & 1222 & $\mathrm{ML}$ \\
\hline 28 & 3369500 & 62 & 9.49 & 0.17 & 5.87 & 0.07 & 4.58 & 0.06 & inv & inv & 1431 & MOM \\
\hline 29 & 3369700 & 10 & 9.49 & 0.41 & inv & inv & inv & inv & inv & inv & 1233 & PWM \\
\hline 30 & 3374455 & 33 & 9.49 & 0.24 & 8.45 & 0.13 & 12.33 & 0.19 & inv & inv & 2412 & $\mathrm{ML}$ \\
\hline
\end{tabular}

ML: Maximum Likelihhood Method

MOM: Method of Moments

PWM: Probability Weighted Moment

Actual K - Smirnov: Computed value using Kolmogorov Smirnov Test.

Actual Chi-Square: Computed value using Chi-Square Test. 
An explanation to each column of Table 2.5.1 is given below.

Column 1: Station Number

Column 2: USGS Site number

Column 3: Number of observations each gauging station

Column 4: Chi Square value using the Standard Tables

Column 5: Kolmogorov Smirnov (K-S) value using Standard Tables

Column 6: Actual Chi Square Value for the data set of the particular gauging station using ML method of parameter estimation.

Column 7: Actual K-S Value for the data set with ML method.

Column 8: Actual Chi Square Value for the data set with MOM method.

Column 9: Actual K-S Value for the data set with MOM method.

Column 10: Actual Chi Square Value for the data set with PWM method.

Column 11: Actual K-S Value for the data set with PWM method.

Column 12: Ranks of each distribution (starting from GEV, followed by Pearson III, Log Normal III and Log Pearson III) for the data set. (Highest Rank 1 to Lowest Rank 4).

Column 13: Best method of parameter estimation.

Note: 'inv' in the table denotes that the results for that particular method of parameter estimation did not converge.

A larger deviation of theoretical quantile estimates from regional quantile estimates is observed for Region 6. After tabulating the results for all the regions, the best distribution is selected by comparing the results from Chi-Square and Kolmogorov-Smirnov tests with the values from standard tables at $95 \%$ confidence limits. For each region and gauging station, all 
four distributions are ranked in order. The distribution with lowest Chi-Square test value and Kolmogorov-Smirnov test are assigned the highest rank, Rank 1. A histogram is plotted to exhibit the frequency of Rank 1 for each frequency distribution (Figure 2.5.1 - Figure 2.5.6). The distribution with highest frequency is selected as the best distribution for that particular region. These rankings are shown in Table 2.5.1 (column 12) for region 3. For other regions the results are included Kedia and Rao (2005).

To select the best method of parameter estimation, the Chi-Square and the KolmogorovSmirnov test values for each distribution and gauging station, are compared with values obtained for the three methods of parameter estimation. The method with the lowest value is given the highest rank, Rank 1. Same procedure is followed for each distribution and gauging station. The method having highest frequency of Rank 1 within each station is selected as the best method of parameter estimation for that particular gauging station. The selected method of parameter estimation for each gauging site in region 3 is shown in Col. 13 of Table 2.5.1. For other regions, the results are found in Kedia and Rao (2005). In most cases, maximum likelihood method is the best one. The final results are tabulated in Table 2.5.2. 


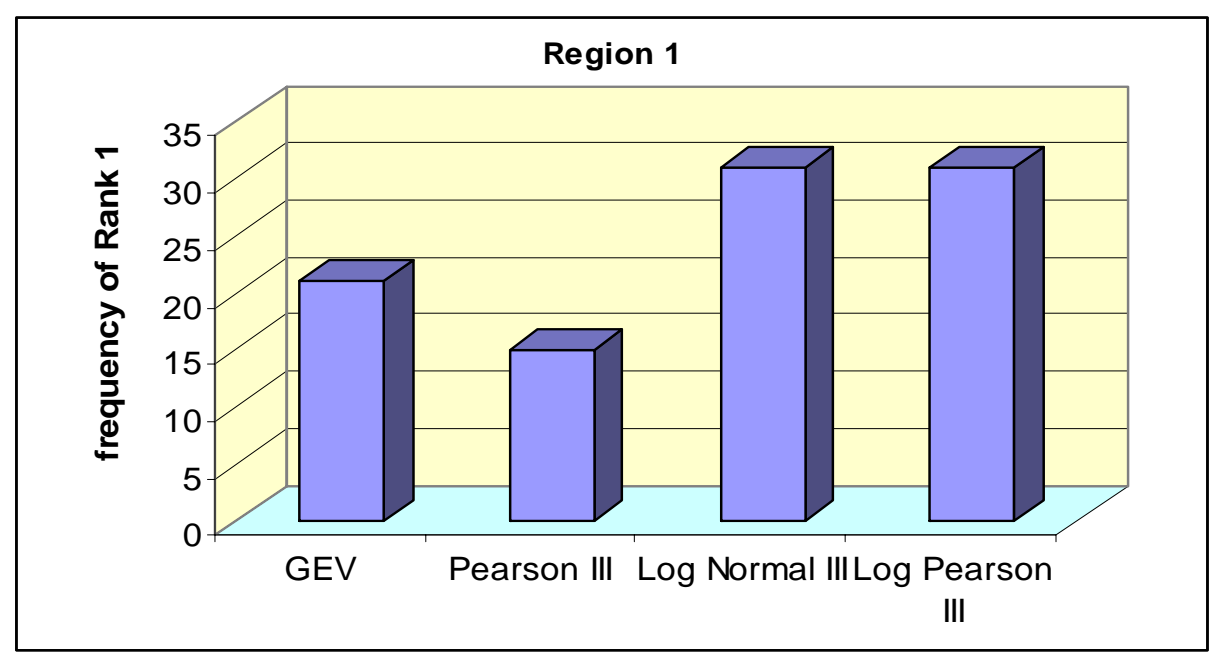

Figure 2.5.1. Region 1- Frequency of Rank 1 for selecting the best Distribution

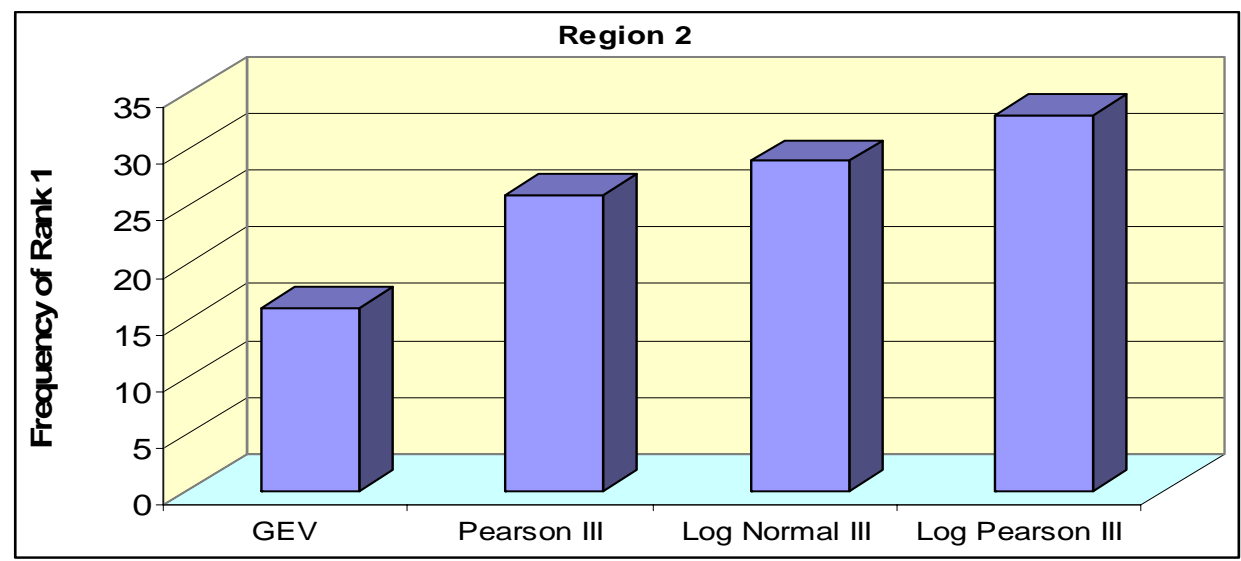

Figure 2.5.2. Region 2- Frequency of Rank 1 for selecting the best Distribution 


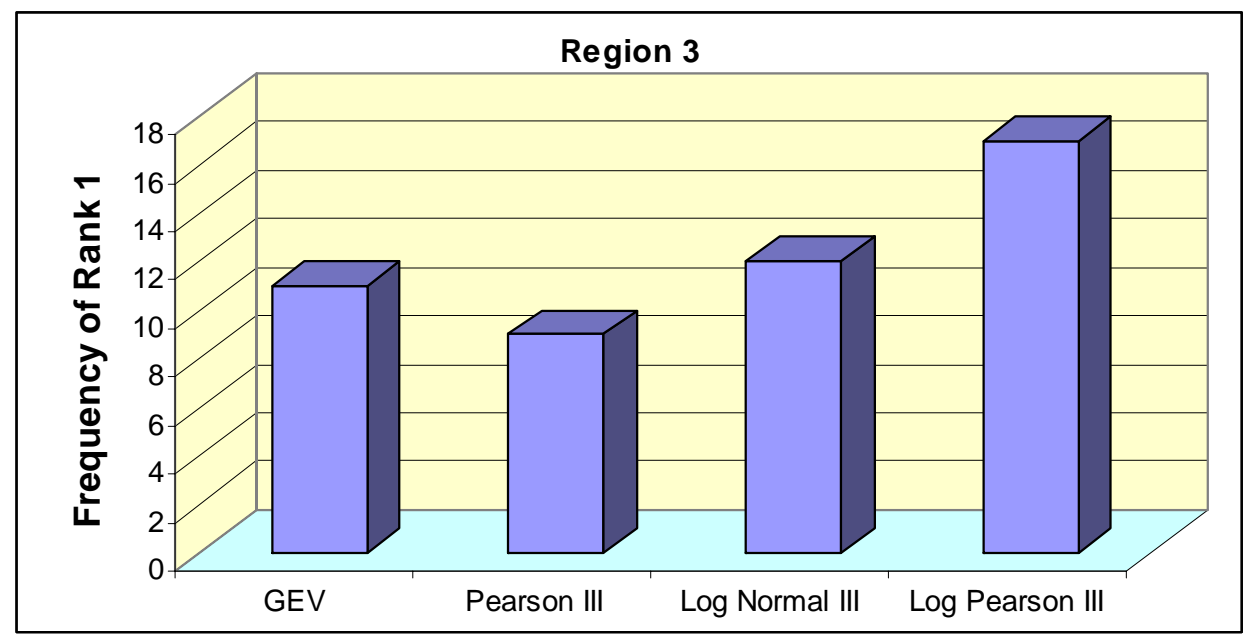

Figure 2.5.3. Region 3- Frequency of Rank 1 for selecting the best Distribution

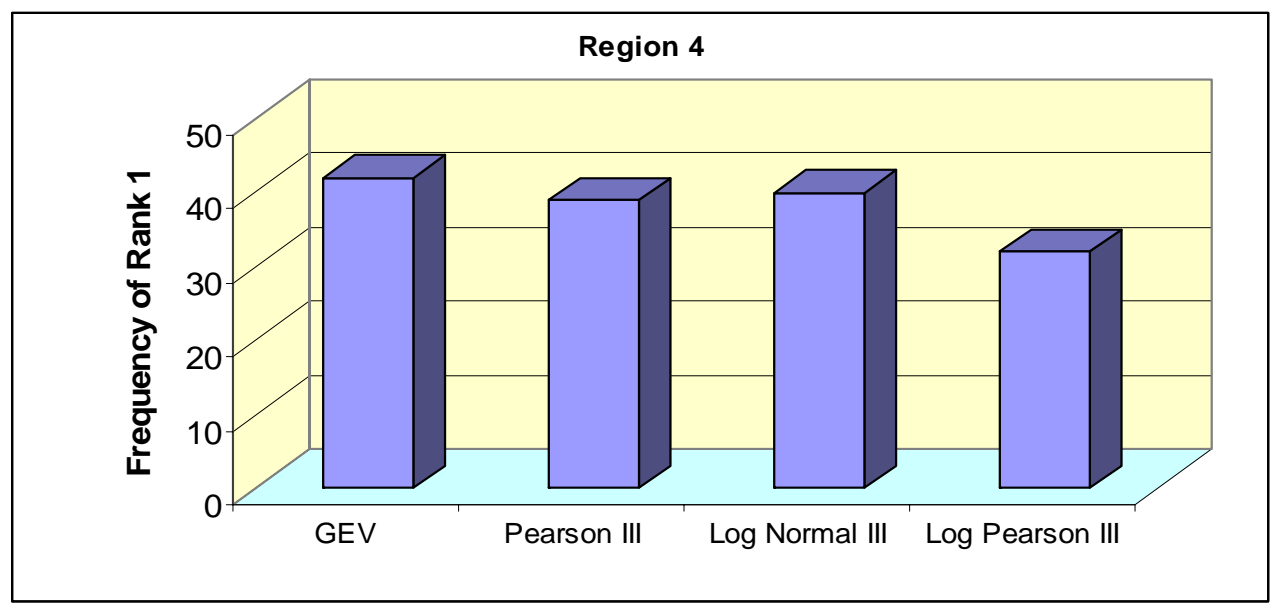

Figure 2.5.4. Region 4- Frequency of Rank 1 for selecting the best Distribution 


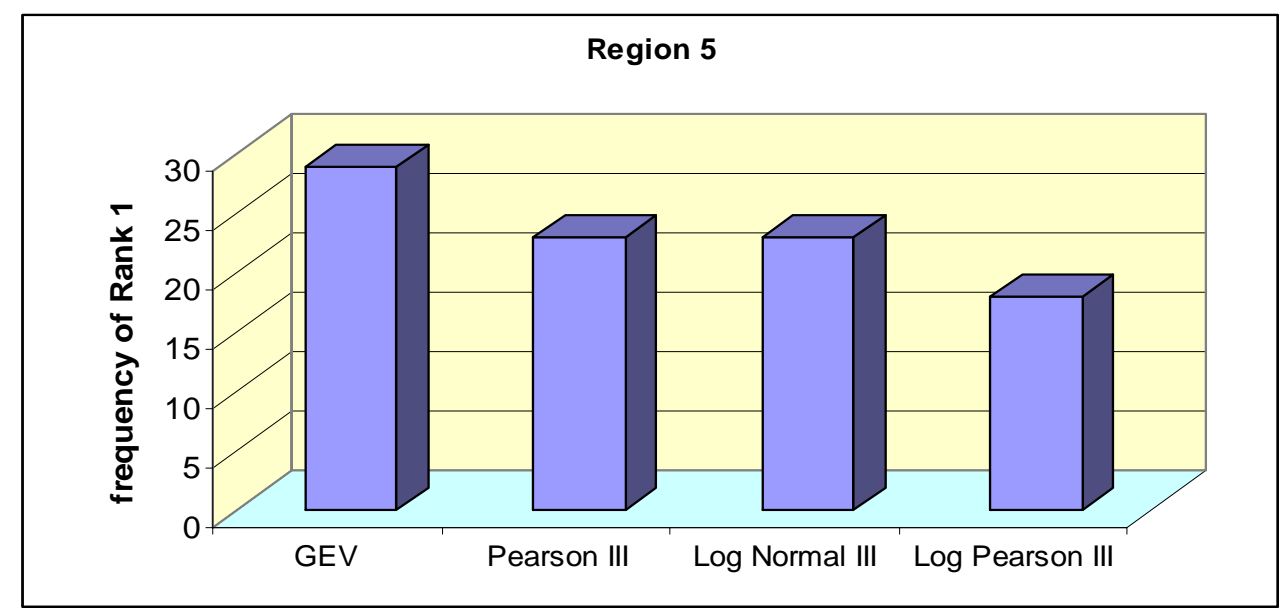

Figure 2.5.5. Region 5- Frequency of Rank 1 for selecting the best Distribution

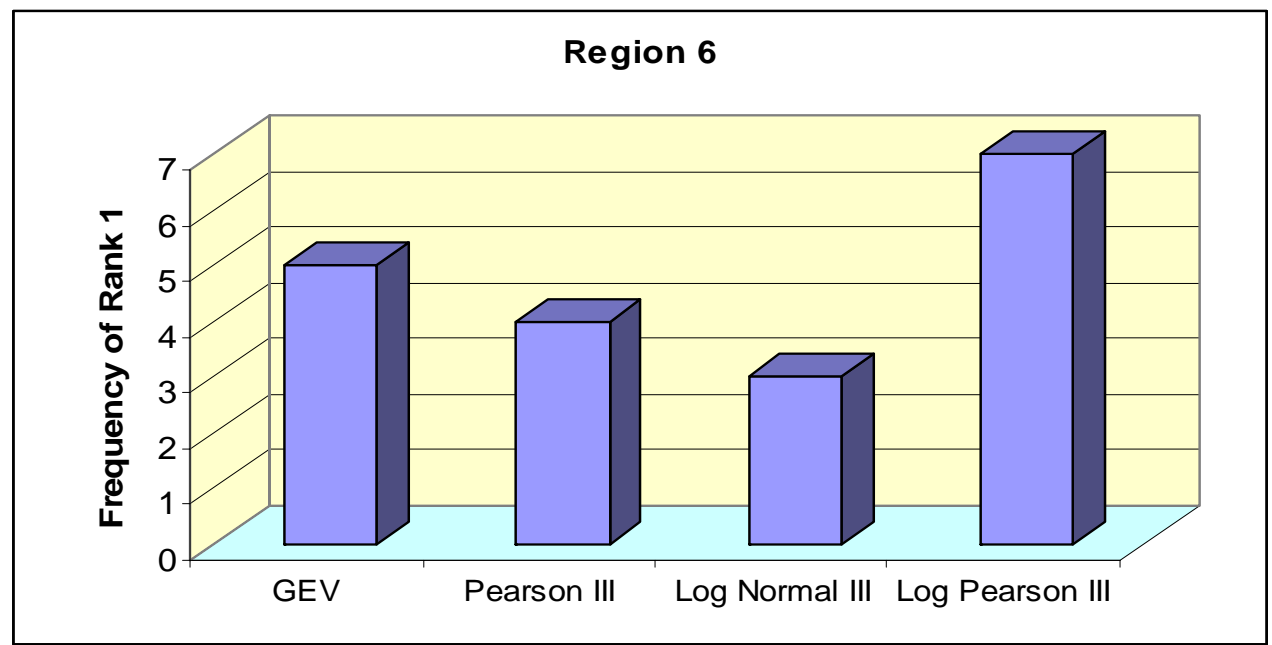

Figure 2.5.6. Region 6- Frequency of Rank 1 for selecting the best Distribution 
Table 2.5.2. Selection of Best Distribution in each Region

\begin{tabular}{|c|c|c|c|c|c|c|}
\hline $\begin{array}{c}\text { Region } \\
\text { Number }\end{array}$ & $\begin{array}{c}\text { Number of } \\
\text { Stations }\end{array}$ & Rank 1 & Rank2 & Rank3 & Rank4 & $\begin{array}{c}\text { Best method } \\
\text { of Parameter } \\
\text { estimation }\end{array}$ \\
\hline $\mathbf{1}$ & 62 & $\begin{array}{c}\text { LP III } \\
\text { LGN III }\end{array}$ & & GEV & P III & ML \\
\hline $\mathbf{2}$ & 58 & LP III & LGN III & PIII & GEV & ML \\
\hline $\mathbf{3}$ & 30 & LPIII & LGN III & GEV & P III & MOM \\
\hline $\mathbf{4}$ & 73 & GEV & LGN III & P III & LP III & ML \\
\hline $\mathbf{5}$ & 42 & GEV & LGN III & P III & LP III & ML \\
\hline $\mathbf{6}$ & 14 & LPIII & GEV & P III & LGN III & ML \\
\hline
\end{tabular}

The results given in Table 2.5.2 are obtained by using observations from all of Indiana watersheds. In many of these watersheds the data are quite short. For example, in Table 2.5.1, the number of observations is less than 20 in 15 out of 30 sites. The goodness-of-fit tests are not reliable for such a small number of observations. Therefore, only those data sets which have more than 30 observations are considered. Same procedures for ranking the four distributions and the method of parameter estimation are adopted and the results are shown in Figure 2.5.7 2.5.12. The new rankings given to the distributions and method of parameter estimation for each region of Indiana watersheds are given in Table 2.5.3. 


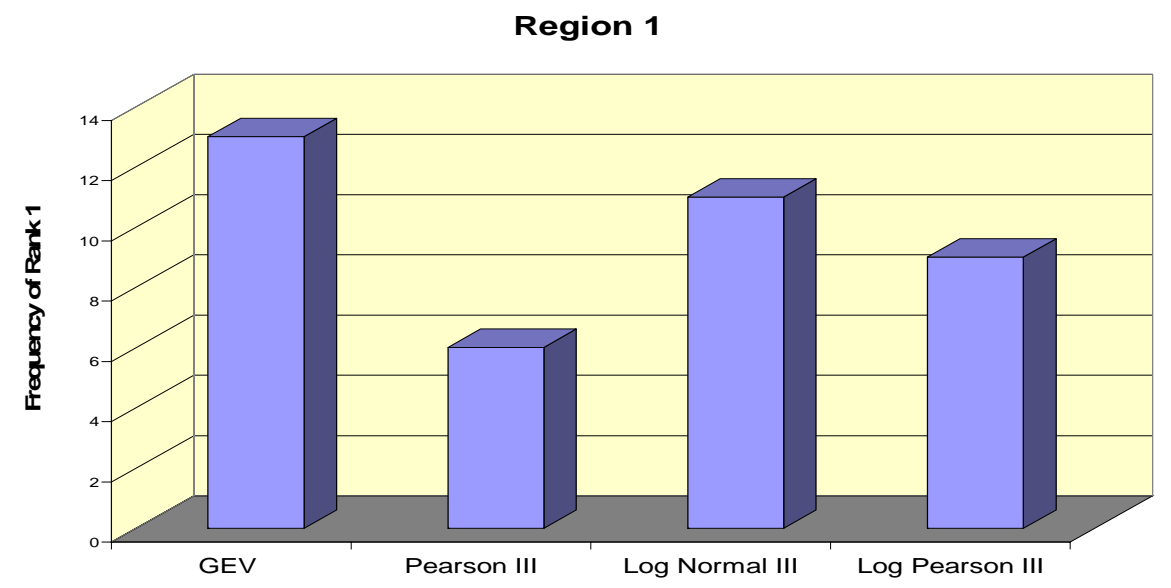

Figure 2.5.7. Region 1- Frequency of Rank 1 for selecting the best Distribution with more than 30 observations at each site.

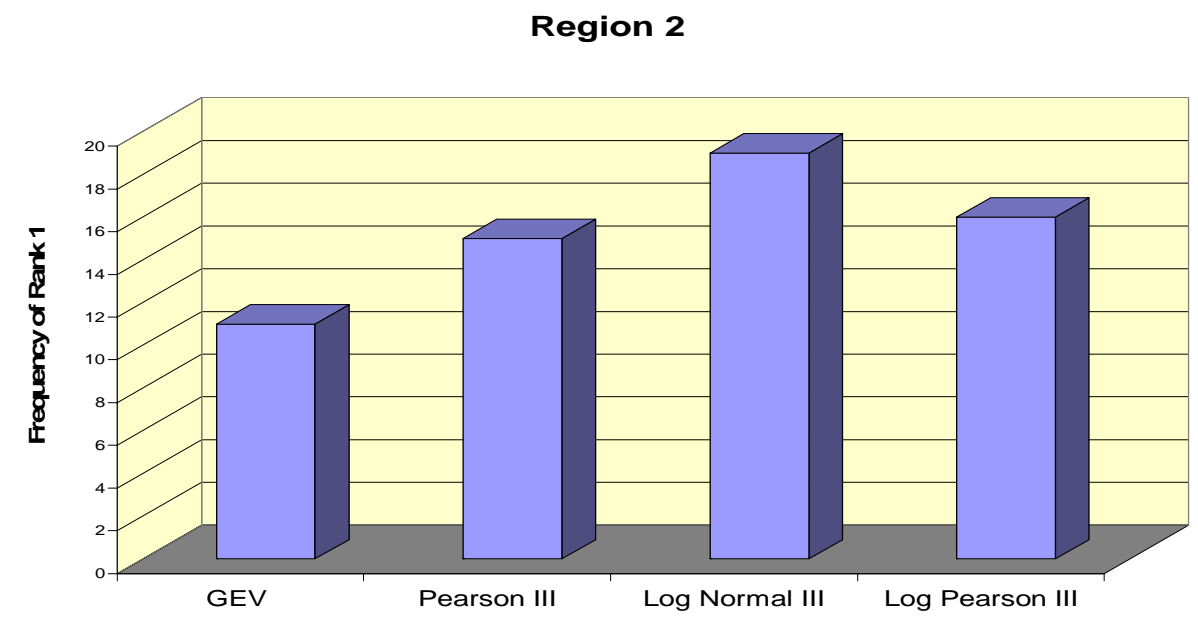

Figure 2.5.8. Region 2- Frequency of Rank 1 for selecting the best Distribution with more than 30 observations at each site. 


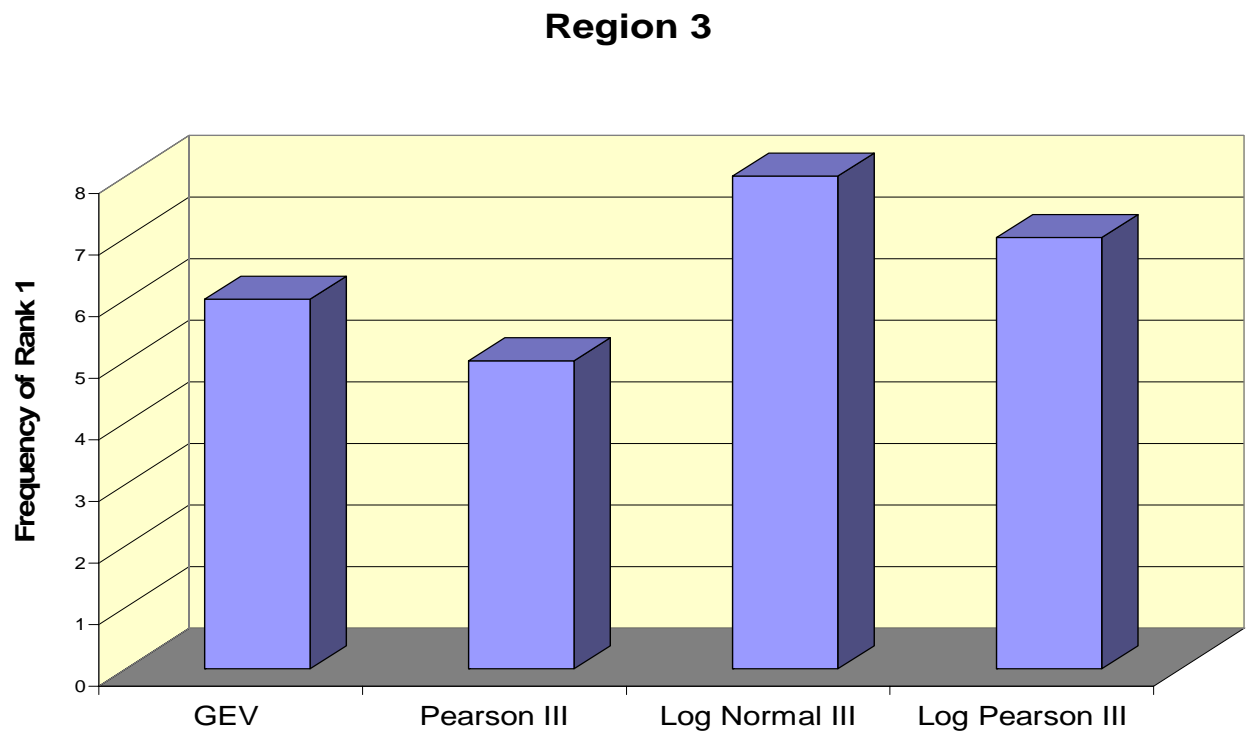

Figure 2.5.9. Region 3- Frequency of Rank 1 for selecting the best Distribution with more than 30 observations at each site.

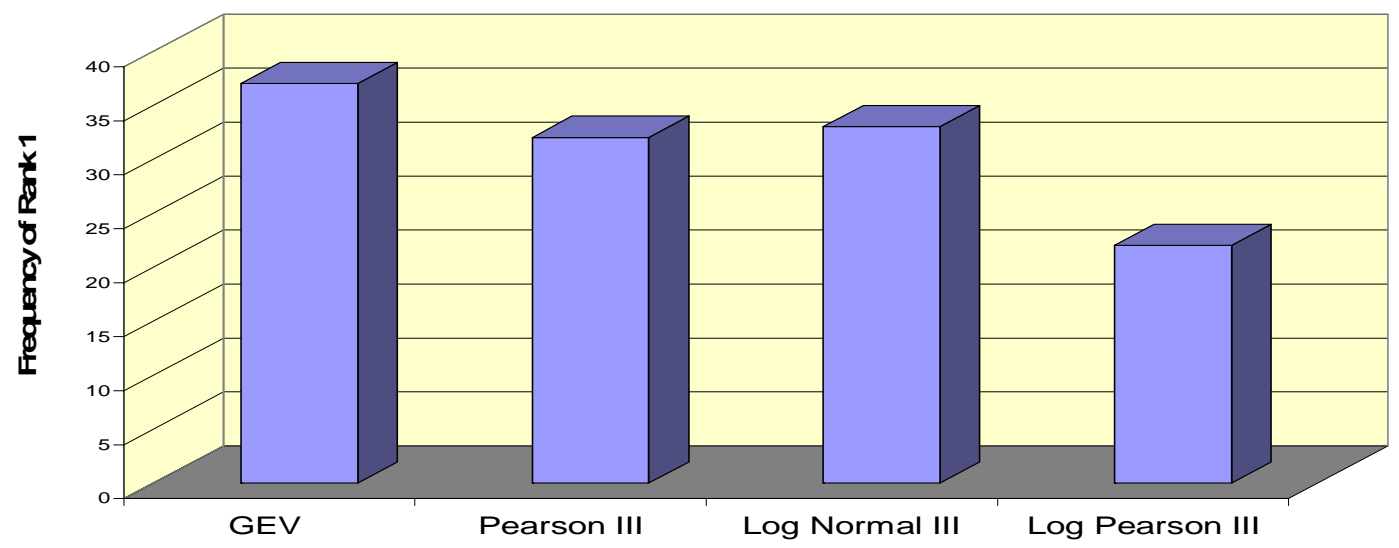

Figure 2.5.10. Region 4- Frequency of Rank 1 for selecting the best Distribution with more than 30 observations at each site. 


\section{Region 5}

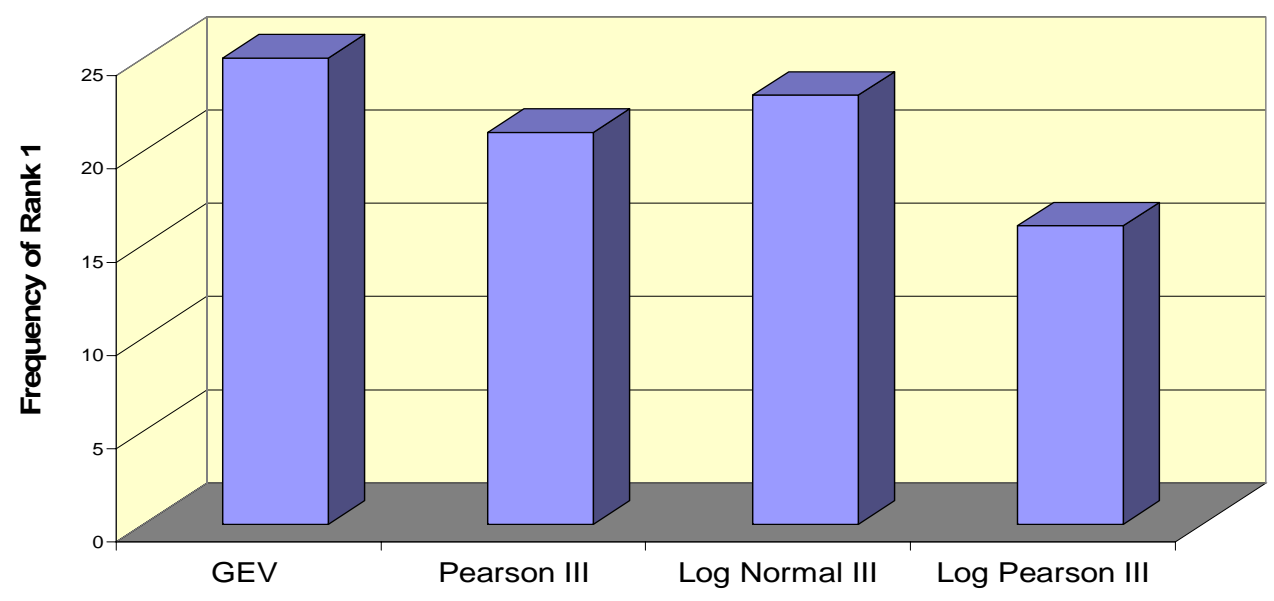

Figure 2.5.11. Region 5- Frequency of Rank 1 for selecting the best Distribution with more than 30 observations at each site.

Region 6

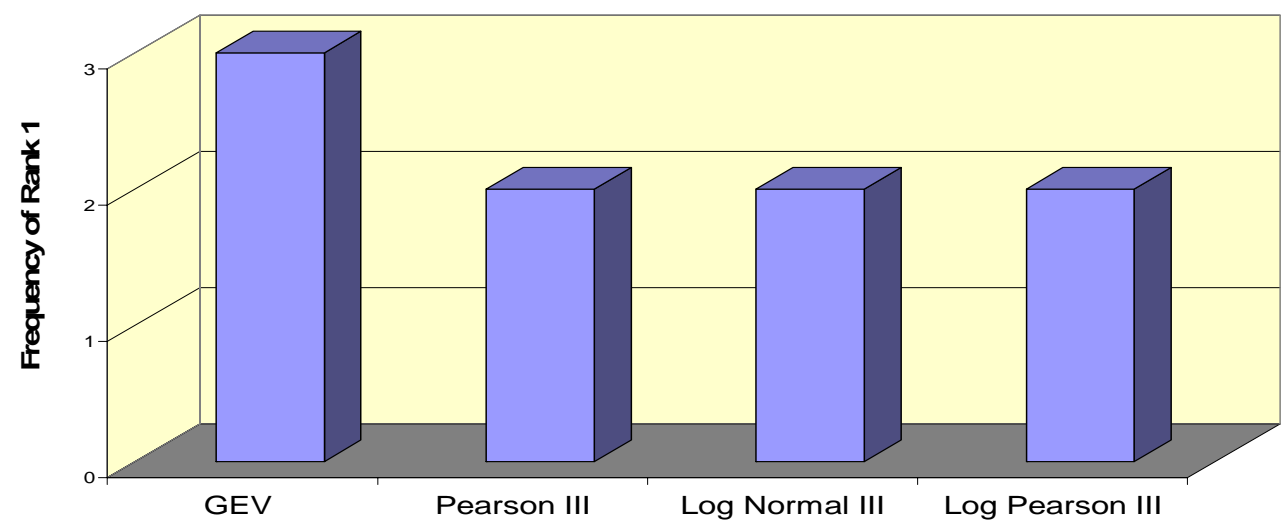

Figure 2.5.12. Region 6- Frequency of Rank 1 for selecting the best Distribution with more than 30 observations at each site. 
Table 2.5.3. Selection of Best Distribution in each Region using stations with more than 30 observations.

\begin{tabular}{|c|c|c|c|c|c|c|}
\hline $\begin{array}{c}\text { Region } \\
\text { Number }\end{array}$ & $\begin{array}{c}\text { Number } \\
\text { of } \\
\text { Stations }\end{array}$ & Rank 1 & Rank2 & Rank3 & Rank4 & $\begin{array}{c}\text { Best } \\
\text { method of } \\
\text { Parameter } \\
\text { estimation }\end{array}$ \\
\hline $\mathbf{1}$ & 21 & GEV & LGN III & LP III & P III & ML \\
\hline $\mathbf{2}$ & 30 & LGN III & $\begin{array}{c}\text { LP III } \\
\text { P III }\end{array}$ & & GEV & ML \\
\hline $\mathbf{3}$ & 13 & LGN III & LP III & GEV & P III & MOM \\
\hline $\mathbf{4}$ & 55 & GEV & $\begin{array}{c}\text { LGN III } \\
\text { P III }\end{array}$ & & LP III & ML \\
\hline $\mathbf{5}$ & 36 & GEV & $\begin{array}{c}\text { LGN III } \\
\text { P III }\end{array}$ & & LP III & ML \\
\hline $\mathbf{6}$ & 07 & GEV & $\begin{array}{c}\text { LP III } \\
\text { P III }\end{array}$ & & & ML \\
\hline
\end{tabular}

The importance of having longer data sequences in goodness-of-fit tests is clearly brought out by the results in Table 2.5.3. The GEV distribution is the best distribution with larger data sets, followed by Log Normal (III) distribution. Log Pearson (III) distribution which was selected as the best distribution in Table 2.5.2 is no longer in the Rank 1 for any region. 


\section{Estimation of Peak Discharges by LP(III) Method}

\subsection{Introduction}

For the regression analysis discussed in this chapter, the regions defined by Srinivas and Rao (2004) are used. However, two of the regions were split into two distinct regions. Region 1 and Region 5 were split based on the presence of a significant amount of natural storage in the northern part of Region 1 and the eastern part of Region 5. These regions are identified as Regions 7 and 8, respectively. The Generalized Least Squares method, which is the regression methodology used here, utilizes the distance between stations as a feature of the algorithm. Regions 1 and 5, as previously defined, extended across the state, resulting in long distances between stations. The regression errors were reduced by splitting these two regions, because of the reduction in the distance between stations and incorporation of the percentage of the basin covered by water or wetlands as a regression parameter.

A minor difficulty in regionalization is that the actual region determinations are often based on large scale maps of the state or region examined. In the regions defined by Srinivas and Rao, the regions were delineated based on the gaging stations only, and followed major basin divides only where it was appropriate to do so (Fig. 3.1.1). However, the scale of the map and ignoring drainage divides make the map difficult to apply in practice, since a site for investigation might lie close to a boundary and determination of the proper region may not be accurate. To eliminate any ambiguity in applying the appropriate equations, the regionalization for this chapter was done by fitting the 14-digit Hydrologic Unit Code (HUC) watersheds for Indiana, as described in DeBroka (1999). The 14-digit HUC watersheds are a nomenclature 
developed and accepted by state and federal water resource agencies for characterizing watersheds.

For the purposes of application, separation of gages into regions as originally determined by Srinivas and Rao has been preserved, but the actual boundaries are modified slightly to follow the 14-digit HUC boundaries whenever possible. This results in a method that is easy to use, since all that is needed to know about a site is the 14-digit HUC basin in which it is located, which is fairly easy to determine. A few 14-digit HUC basins had to be split between regions, but these were kept to a minimum. A CDROM containing a comprehensive listing of the 14digit HUC basins for Indiana, with an indication of the region(s) for each basin is found in Knipe and Rao (2005). The final map of the regions is shown in Figure 3.1.2.

\subsection{Development of Flood Prediction Equations}

The annual peak discharges for each of the gages in the study were reviewed for data consistency and possible errors. The original IDNR peak discharge file used in previous studies was compared with peak flow files obtained from the USGS NWIS website (http://waterdata.usgs.gov/nwis). Staff of the USGS and the IDNR researched the discrepancies between the two data sources and corrected the data where necessary. Many of the differences between the two data sources were due to changes in rating curves developed by the USGS after the initial publication of the discharge in the annual Water Resources Data compilations. Corrections have been made to the USGS peak flow files, which are now the definitive source for peak flow information. 


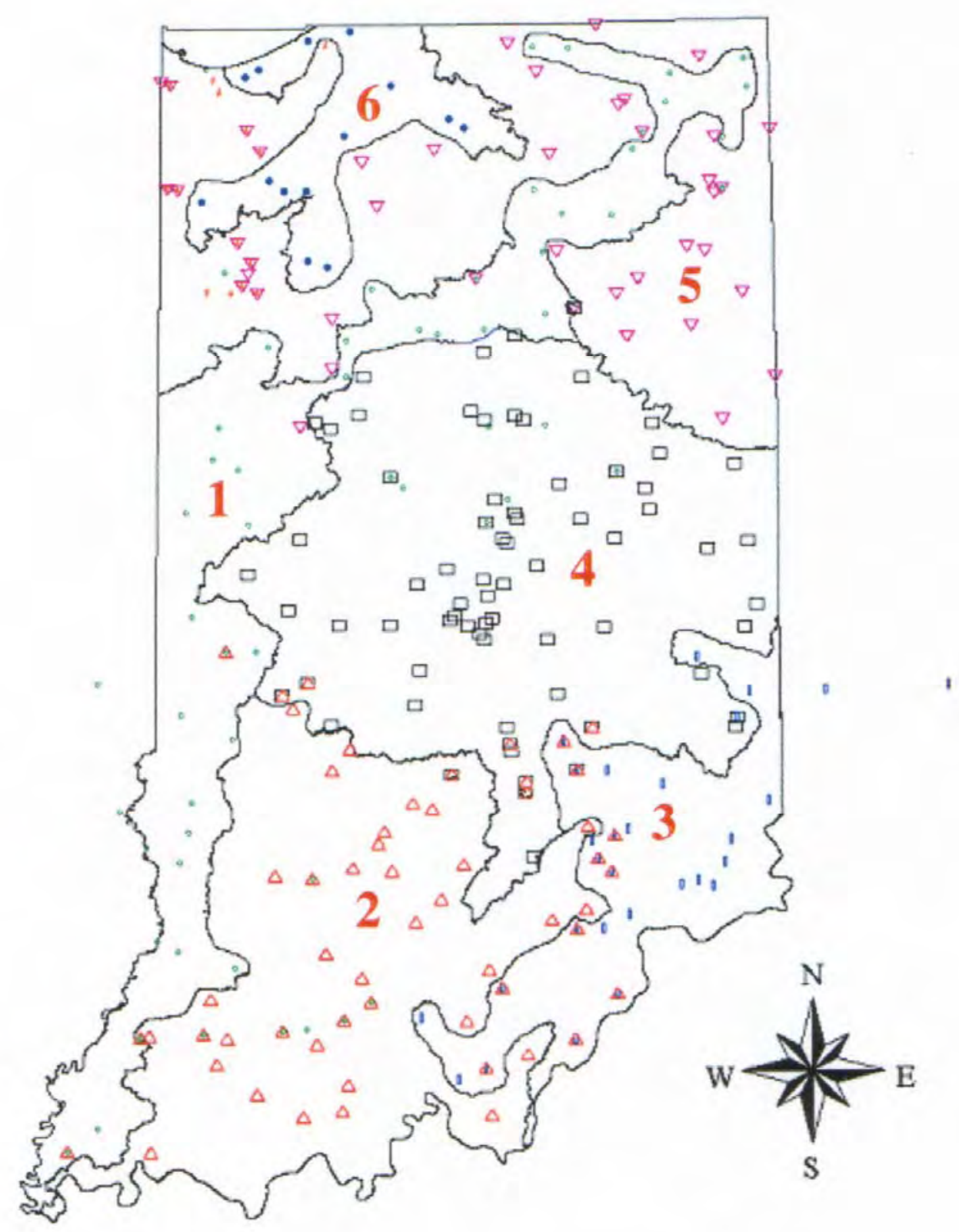

Figure 3.1.1. Regions for Indiana as defined by Srinivas and Rao (2003) 


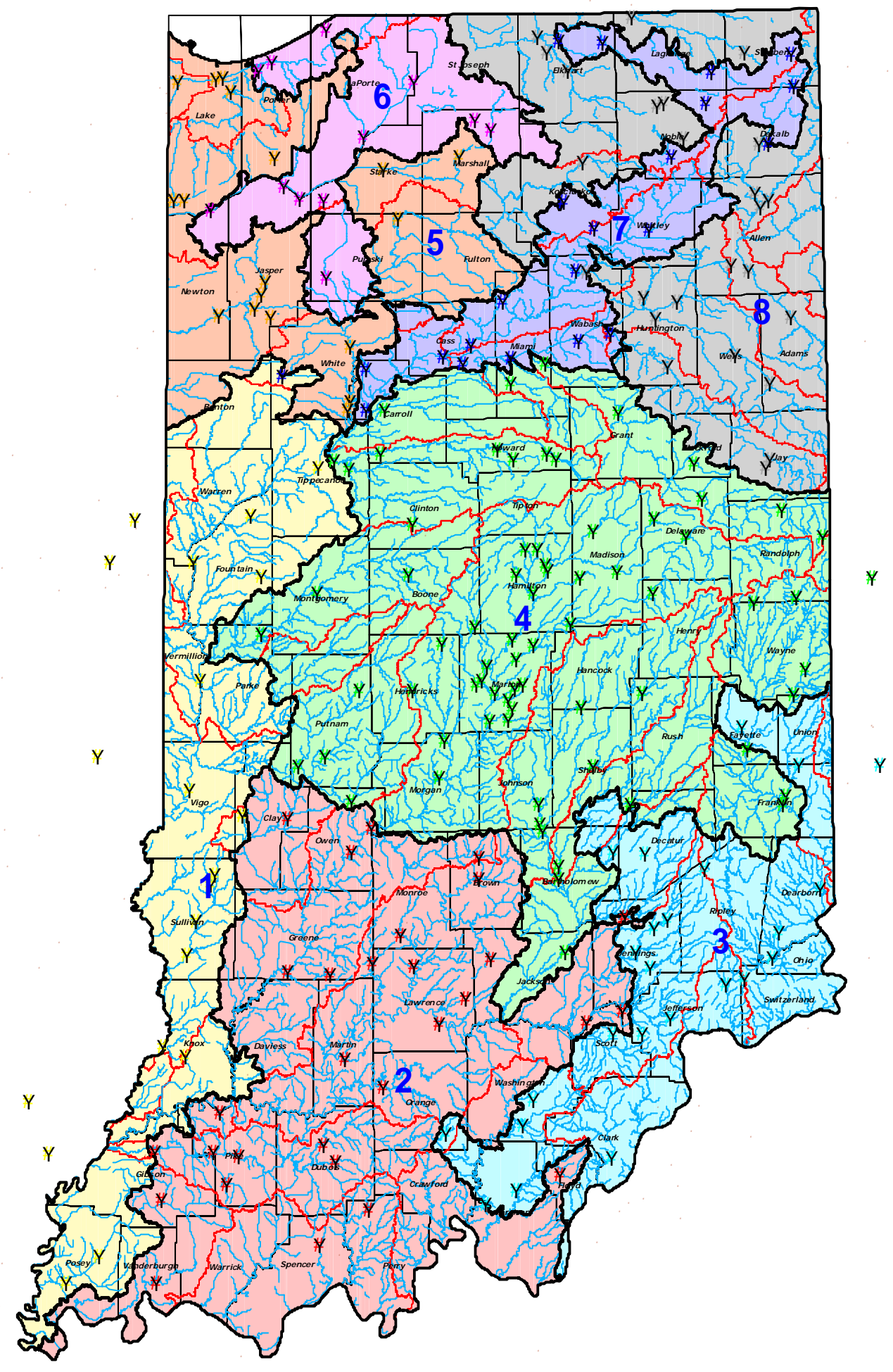

Figure 3.1.2. Regions as defined for the present analysis 
Flood frequency curves for each gaging station were calculated by using standard techniques of the U. S. Water Resources Council (USWRC 1982). The USWRC technique is to fit the annual peak flow data from a station using the log-Pearson III distribution. The discharge values are first transformed by computing the logarithm of each value. The mean, standard deviation (S), and skew coefficient (G) for the logarithmic series are computed by using the following equations, where $\mathrm{X}$ is the logarithmic of the flow and $\mathrm{N}$ is the number of years of record in the annual peak data series:

$$
\begin{gathered}
\bar{X}=\frac{\Sigma X}{N} \\
S=\left[\frac{\Sigma(X-\bar{X})^{2}}{N-1}\right]^{0.5} \\
G=\frac{N \Sigma(X-\bar{X})^{3}}{(N-1)(N-2) S^{3}}
\end{gathered}
$$

The skew coefficient is then weighted by using a regional generalized skew coefficient, in order to eliminate local anomalies that may exist for a particular site. The regional skew coefficient used in this study is -0.2 . This value is the standard value used by the IDNR and has been agreed to by the other federal agencies (USGS, USACE, NRCS).

$$
G_{w}=\frac{M S E_{\bar{G}}(G)+M S E_{G}(\bar{G})}{M S E_{\bar{G}}+M S E_{G}}
$$

The mean square error of the regional skew coefficient is taken from USWRC (1982) to be 0.55 . The mean square error of the station skew coefficient is approximated by

$$
M G E_{G} \cong 10^{\left[A-B\left[\log _{10}(N / 10]\right]\right.}
$$




$$
\begin{gathered}
A=-0.33+0.08|G| \quad \text { if } \quad|G \leq 0.90| \\
-0.52+0.30|G| \text { if } \quad|G>0.90| \\
B=0.94-0.26|G| \text { if }|G| \leq 1.50 \\
0.55 \text { if }|G|>1.50
\end{gathered}
$$

The flood frequency values for each return period are then computed by using the following equation:

$$
\log Q=\bar{X}+K S
$$

where $\mathrm{K}$ is based on the log-Pearson III distribution and is a function of the weighted skew coefficient and the return interval. $\mathrm{K}$ is normally determined from tables published in USWRC (1982). These calculations are performed by using the USGS computer program PEAKFQ.

The gaging stations used for this study and the respective calculated flood frequency discharges are found in Knipe and Rao (2005). The 10, 25, 50, 100, 200 and 500 year return periods are used for data from each station.

\subsection{Basin Characteristics}

Determination of basin characteristics for each of the gaged watersheds is a critical step in a hydrologic regression study. The successful application of the final regression equations will depend on the accurate determination of the basin characteristics by the user. Seven basin characteristics are used in this study.

1. The drainage area of a stream.

2. Slope of a stream is computed by the " $10-85 "$ method using the following equation:

$$
\text { Slope }=\frac{E_{85 \%}-E_{10 \%}}{0.75 * L}
$$


$E_{10}$ and $E_{85}$ are the elevations, in feet, of the thalweg of the stream at $10 \%$ and $85 \%$ of the total length ( $\mathrm{L}$, in miles) of the stream upstream from the determination point, respectively.

3. The 2 year, 24 hour rainfall intensity is taken from TP-40 (NWS, 1960).

4. A runoff coefficient was defined using the STATSGO GIS coverage provided by the NRCS (see http://www.ncgc.nrcs.usda.gov/branch/ssb/products/statsgo/index.html).

The overall soil runoff coefficient is computed by a weighted average of the soil runoff coefficients found in a watershed, based on the aerial extent of each soil complex in a region. Two different soil runoff coefficients were computed, since some soil complexes are defined differently depending on whether the soil is drained or undrained. Accordingly, a drained and undrained soil runoff coefficient is computed.

5-7. The last three variables that are computed are the percentage of the watershed that is covered by water or wetlands $(\% \mathrm{~W})$, by urbanized areas $(\% \mathrm{U})$, and by forested areas $(\% \mathrm{~F})$. These data are derived from the National Land Cover Dataset (NLCD) compiled by the USGS EROS data center. The data were compiled from satellite imagery and has a spatial resolution of 30 meters. This information is based on ground information from the early 1990s.

The NLCD is a raster grid with each grid cell coded with land use classification. The land use classes were taken from a modified Anderson Land Use classification, a standard nomenclature for describing different land use types. The possible values from the NLCD system are listed in Table 3.3.1.

For use in this study, the grid data were converted from a raster dataset to polygons in a ARC shapefile. These polygons were then clipped by using the watershed area polygons for each gaging station. From these shapefiles, the area of the watershed classified by each code can 
be determined. A percentage of the watershed covered by each class is then computed by dividing the incremental areas by the total drainage area. $\% \mathrm{~W}$ is then calculated by adding the percentages for codes $11,12,91$, and $92 . \% \mathrm{U}$ is the sum of the percentages for codes 21,22 , and 23. $\% \mathrm{~F}$ is the sum of codes 41,42 and 43 .

Calculation of these percentages are the most difficult aspect of the application of the final equations. The values could be estimated from a USGS $7 \frac{1}{2} 2$ minute quadrangle map, but practical experience shows that these estimates can vary widely from user to user, and proper application of the method demands that basin characteristics be computed in a similar manner to the methods used to derive the regressed data. Knipe and Rao (2005) include a table of precomputed values of $\% \mathrm{~W}$ and $\% \mathrm{U}$ for each 14-digit $\mathrm{HUC}$ watershed in Indiana.

Table 3.3.1. NCLD Land Cover Class Definitions.

\begin{tabular}{|cl|}
\hline NLCD Code & Description \\
11 & Open Water \\
12 & Perennial Ice/Snow \\
21 & Low Intensity Residential \\
22 & High Intensity Residential \\
23 & Commercial/Industrial/Transportation \\
31 & Bare Rock/Sand/Clay \\
32 & Quarries/Strip Mines/Gravel Pits \\
33 & Transitional \\
41 & Deciduous Forest \\
42 & Evergreen Forest \\
43 & Mixed Forest \\
51 & Shrubland \\
61 & Orchards/Vineyards/Other \\
71 & Grasslands/Herbaceous \\
81 & Pasture/Hay \\
82 & Row Crops \\
83 & Small Grains \\
84 & Fallow \\
85 & Urban/Recreational Grasses \\
91 & Woody Wetlands \\
92 & Emergent Herbaceous Wetlands \\
\hline
\end{tabular}




\subsection{Generalized Least Squares Regression}

Historically, two types of regression analysis have been used for flood frequency analysis. In ordinary least squares the parameters $\mathbf{B}=\left(b_{1}, b_{2}, \ldots b_{n}\right)$ for a model of the response variable $Y_{n}$ (in this case, the log of the discharge for the given return period), given in equation 3.4.1 are estimated,

$$
Y_{n}=b_{0}+b_{1} x_{1}+b_{2} x_{2}+\ldots b_{n} x_{n}+\varepsilon
$$

where $\left(\mathrm{x}_{1}, \mathrm{x}_{2} \ldots \mathrm{x}_{\mathrm{n}}\right)$ are the various predictor or regressor variables (drainage area, slope, etc.), $\mathrm{n}$ is the number of regressor variables in the model and $\varepsilon$ represents the error in the model. The regressor variables may be converted to logarithms, and the prediction equation is expressed as a complex power equation. The scheme for ordinary least squares is to estimate the parameters $\mathbf{B}$ to minimize the sum of the squares of the error term.

While ordinary least squares is a valid model, improvements have been made in the scheme to utilize the unique properties of hydrologic annual maximum flow data. Stedinger and Tasker (1989) have developed and extensively tested a model they have termed generalized least squares (GLS). GLS is an extension of ordinary least squares that incorporates the length of record at each gaging station, differences in the variance at different sites, and any possible cross correlation in the data between stations. The model equation is the same as for ordinary least squares, represented in vector form in equation 3.4.2

$$
\hat{\boldsymbol{Y}}=\boldsymbol{X \beta}+\boldsymbol{e}
$$

where $\mathbf{Y}$ is a $(\mathrm{n} \times 1)$ vector of flow characteristics at $\mathrm{n}$ sites (and $\hat{\mathbf{Y}}$ is an estimate of $\mathbf{Y}), \mathbf{X}$ is an $(n \times p)$ matrix of $(p-1)$ basin characteristics augmented by a column of one's, $\boldsymbol{\beta}$ is a $(p \times 1)$ vector of regression parameters and $\boldsymbol{e}$ is an $(\mathrm{n} \times 1)$ vector of random errors. The GLS estimate of $\boldsymbol{\beta}$ is given by Stedinger and Tasker as 


$$
\boldsymbol{\beta}=\left(\mathbf{X}^{T} \boldsymbol{\Lambda}^{-1} \mathbf{X}\right)^{-1} \mathbf{X}^{T} \boldsymbol{\Lambda}^{-1} \mathbf{Y}
$$

where $\Lambda$ is the covariance of the model. In the GLS model $\Lambda$ is estimated by

$$
\hat{\mathbf{\Lambda}}=\hat{\gamma}^{2} \mathbf{I}+\hat{\mathbf{\Sigma}}
$$

where $\hat{\gamma}^{2}$ is an estimate of the model error variance and $\hat{\boldsymbol{\Sigma}}$ is an $(\mathrm{n} \times \mathrm{n})$ matrix of sampling covariances with elements:

$$
\begin{array}{cc}
\Sigma_{i j}=\hat{\sigma}_{i}^{2}\left[1+K_{T}^{2}\left(\frac{\kappa-1}{4}\right)\right] / n_{i} & \text { for } \mathrm{i}=\mathrm{j} \\
\Sigma_{i j}=\hat{\rho}_{i j} \frac{m_{i j} \hat{\sigma}_{i} \hat{\sigma}_{i}}{n_{i} n_{i}}\left[1+\hat{\rho}_{i j} K_{T}^{2}\left(\frac{\kappa-1}{4}\right)\right] & \text { for } \mathrm{i} \neq \mathrm{j}
\end{array}
$$

where:

$\hat{\sigma}_{\mathrm{i}}$ is an estimate of the standard deviation of flows at site $\mathrm{i}$

$\mathrm{K}_{\mathrm{T}}$ is the T-year frequency factor for the distribution used

$\kappa$ is the kurtosis of the distribution used

$\mathrm{n}_{\mathrm{i}}$ is the record length at site $\mathrm{i}$

$\mathrm{m}_{\mathrm{ij}}$ is the concurrent record length of sites $\mathrm{i}$ and $\mathrm{j}$

$\hat{\rho}_{i j}$ is an estimate of the lag zero correlation of flows between sites $i$ and $j$

There are a number of additional steps that can be applied to improve the estimate of these variables, which are detailed in Stedinger and Tasker's various reports. One is the estimate of the lag-zero cross correlation coefficient, $\rho_{\mathrm{ij}}$. To eliminate data problems and increase the robustness of the overall solution, a non-linear regression model is used to smooth out data problems by relating the cross correlation coefficient to the distance between gaging stations. This regression model is of the form: 


$$
\rho_{i j}=\exp \left\{\left[\frac{d_{i j}}{\alpha d_{i j}+1}\right] \ln \theta\right\}
$$

where $\mathrm{d}_{\mathrm{ij}}$ is the distance between stations $\mathrm{i}$ an $\mathrm{j}$, and $\alpha$ and $\theta$ are model parameters.

The GLS regression scheme is implemented in the USGS computer program GLSNET. This program requires input of the annual maximum flood series for each station, including the adjustments for low and high outliers and historic discharges as appropriate. Each station is also required to have latitude and longitude to compute the cross correlation of each station pair in the regression region. The PEAKFQ program needs to be run on the dataset before GLSNET can be run, since the mean, standard deviation and generalized skew from the flood frequency curve computation and estimation of the flood frequency are part of the GLS method. Basin characteristics are also incorporated into the WDM file as user defined variables, for use as the regressor variables.

\subsection{Regression Results}

The original data set of gaging stations included 439 gages located in Indiana and in the surrounding states of Illinois, Kentucky, Michigan, and Ohio. Through a process of trial and error, this initial set of stations was reduced to 223 based on the homogeneity of certain stations as computed using previous techniques detailed by Srinivas and Rao (2003). The total homogeneity measure of each of the regions with the final station selection is given in Table 3.5.1.

As shown in Table 3.5.1, Regions 1, 3, and 4 are homogeneous, Regions 2, 5, 7, and 8 are possibly homogeneous, and Region 6 is heterogeneous. Region 6 is not a surprise, since all of the previous studies in regionalization had identified that region as heterogeneous. The four 
regions that are possibly homogeneous are a result of the effort to balance the station selection between homogeneity and the regression diagnostics. The selected stations are a compromise

Table 3.5.1. Homogeneity measures for defined regions.

\begin{tabular}{|cccccc|}
\hline $\begin{array}{c}\text { Region } \\
\text { No. }\end{array}$ & \# of gages & $\boldsymbol{H}_{\mathbf{1}}$ & $\boldsymbol{H}_{\mathbf{2}}$ & $\boldsymbol{H}_{3}$ & Region type \\
1 & 21 & 0.66 & -1.83 & -2.40 & Homogeneous \\
2 & 30 & 1.17 & -1.18 & -2.00 & Possible homogeneous \\
3 & 24 & 0.26 & 0.53 & 0.12 & Homogeneous \\
4 & 72 & 0.79 & -0.97 & -1.45 & Homogeneous \\
5 & 18 & 1.18 & -0.30 & -0.09 & Possible homogeneous \\
6 & 12 & 14.68 & 5.42 & 2.47 & Heterogeneous \\
7 & 22 & 1.56 & 0.04 & -0.24 & Possible homogeneous \\
8 & 25 & 1.07 & -0.59 & -0.96 & Possible homogeneous \\
\hline
\end{tabular}

between these two goals. It should be noted, however, that 3 of the regions have $\mathrm{H}_{1}$ values less than 1.2 , meaning that they are fairly close to being considered homogeneous by the common standard. These homogeneity measures do not match the results from previous data sets exactly due to the refinement of the peak flow file performed as a part of this study, and the addition of the 2003 water year data.

The final station selection has 223 stations selected for the 8 regions. The location of the gaging sites is shown in Figure 3.1.2.

The return periods chosen for evaluation in this study are the 10,25, 50, 100, 200 and 500 year frequency flood discharges. The 100-year flood is the basis for most of the regulatory programs in the State of Indiana regarding water resources, while the lower return periods provide information regarding more frequent events that are also helpful in design. The 500-year flood is estimated here even though the length of the period of record for most gages does not support the estimation of the discharge for such a large return period. However, the 500-year flood discharge is a parameter in some of the equations for estimating depth of scour at bridge 
piers and abutments, and therefore it is useful to have an estimate of this discharge. This estimate should be used with extreme caution.

The regression variables for each of the regions were chosen from evaluating the regression results using trial and error. Runoff coefficient, $\mathrm{I}_{2,24}$ and $\% \mathrm{~F}$ did not contribute positively to any of the regional regression models and therefore were not considered in any of the equations. Runoff coefficient, in particular, varied from region to region, but did not vary greatly within a region, meaning that it was of little use in a regression analysis. Given that the regionalization was found to follow geologic and soil type regions throughout the state, this conclusion is not surprising.

All regions have effective drainage area (DA) as factor in the regression, which is expected. Slope is a factor in all regions except Region 8. This may be due to the nature of the stations chosen in those regions, but Glatfelter's study found that slope was not a significant variable in the corresponding region in that area. In this case $\% \mathrm{~W}$ is an indirect measure of the slope of the watershed, since higher water storage in a watershed is an indication of gentler slopes. $\% \mathrm{~W}$ is a factor in Regions 7 and 8 (the lake country) and $\% \mathrm{U}$ is a factor only in Region 4, which is the only region where urban gages (in the Indianapolis metropolitan area) are present in significant numbers. For purposes of the regression analysis, $\% \mathrm{~W}$ and $\% \mathrm{U}$ are expressed as percentages, not decimals, and that a value of one is added to each variable. This was to eliminate $\% \mathrm{~W}$ and $\% \mathrm{U}$ values of zero, which resulted in matrices that could not be inverted.

The average model error is the main regression output used to evaluate the quality of the regression. It is calculated from equation 3.5.1. The percent error is given by Tasker (1995) as in Equation 3.5.1.

$$
\% \text { Error }=100\left[\exp \left(\gamma^{2} * 5.3019\right)-1\right]^{1 / 2}
$$


Average equivalent years of record is a measure developed to express the accuracy of prediction as an equivalent number of years of record required to achieve results of comparable accuracy. It is calculated by equation 3.5.2.

$$
E q Y O R=\frac{\hat{s}_{i}^{2}\left[1+k_{i} g_{i}+\frac{k_{i}^{2}}{2}\left(1+0.75 g_{i}^{2}\right)\right]}{\hat{\gamma}_{i}^{2}+\hat{\Sigma}_{i}}
$$

The form of the prediction equations for Regions 1, 2, and 3 include the effective drainage area and slope as the regressed variables. Table 3.5.2 - 3.5.4 list the values of the regression constant $\mathrm{C}$, and the exponents $\mathrm{a}_{1}$ and $\mathrm{a}_{2}$ for use in determining peak discharges using equation 3.5.3 respectively for regions 1, 2 and 3 .

$$
Q_{\operatorname{Re} t P e r}=(C)(D A)^{a_{1}}(\text { Slope })^{a_{2}}
$$

Table 3.5.2. Regression results for Region 1 .

\begin{tabular}{|ccccccc|}
\hline Return Period & $\begin{array}{c}\text { Constant } \\
(\mathbf{C})\end{array}$ & $\begin{array}{c}\text { DA } \\
\left(\mathbf{a}_{\mathbf{1}}\right)\end{array}$ & $\begin{array}{c}\text { Slope } \\
\left(\mathbf{a}_{\mathbf{2}}\right)\end{array}$ & $\begin{array}{c}\text { Avg Model } \\
\text { Error }\end{array}$ & $\begin{array}{c}\text { Avg Eq } \\
\text { YOR }\end{array}$ & $\begin{array}{c}\text { \%Error } \\
10\end{array}$ \\
47.8 & 0.802 & 0.535 & 0.013 & 4.24 & $27.1 \%$ \\
25 & 55.3 & 0.805 & 0.561 & 0.014 & 5.46 & $27.8 \%$ \\
50 & 61.4 & 0.805 & 0.573 & 0.015 & 6.62 & $28.3 \%$ \\
100 & 67.5 & 0.805 & 0.585 & 0.016 & 6.90 & $29.5 \%$ \\
200 & 74.3 & 0.803 & 0.592 & 0.017 & 7.36 & $30.6 \%$ \\
500 & 83.9 & 0.800 & 0.599 & 0.019 & 7.82 & $32.2 \%$ \\
\hline
\end{tabular}

Table 3.5.3. Regression results for Region 2

\begin{tabular}{|ccccccc|}
\hline Return Period & $\begin{array}{c}\text { Constant } \\
(\mathbf{C})\end{array}$ & $\begin{array}{c}\text { DA } \\
\left(\mathbf{a}_{\mathbf{1}}\right)\end{array}$ & $\begin{array}{c}\text { Slope } \\
\left(\mathbf{a}_{\mathbf{2}}\right)\end{array}$ & $\begin{array}{c}\text { Avg Model } \\
\text { Error }\end{array}$ & $\begin{array}{c}\text { Avg Eq } \\
\text { YOR }\end{array}$ & $\begin{array}{c}\text { \%Error } \\
10\end{array}$ \\
69.6 & 0.798 & 0.473 & 0.022 & 3.12 & $35.5 \%$ \\
25 & 102.4 & 0.777 & 0.441 & 0.023 & 4.23 & $35.6 \%$ \\
50 & 133.1 & 0.762 & 0.417 & 0.023 & 5.01 & $36.0 \%$ \\
100 & 169.5 & 0.748 & 0.394 & 0.024 & 5.70 & $36.8 \%$ \\
200 & 213.3 & 0.734 & 0.371 & 0.025 & 6.24 & $37.7 \%$ \\
500 & 283.3 & 0.716 & 0.341 & 0.027 & 6.80 & $39.4 \%$ \\
\hline
\end{tabular}


Table 3.5.4. Regression results for Region 3

\begin{tabular}{|ccccccc|}
\hline Return Period & $\begin{array}{c}\text { Constant } \\
(\mathbf{C})\end{array}$ & $\begin{array}{c}\text { DA } \\
\left(\mathbf{a}_{\mathbf{1}}\right)\end{array}$ & $\begin{array}{c}\text { Slope } \\
\left.\mathbf{( a}_{2}\right)\end{array}$ & $\begin{array}{c}\text { Avg Model } \\
\text { Error }\end{array}$ & $\begin{array}{c}\text { Avg Eq } \\
\text { YOR }\end{array}$ & \%Error \\
10 & 74.6 & 0.889 & 0.416 & 0.008 & 8.92 & $20.9 \%$ \\
25 & 91.5 & 0.891 & 0.425 & 0.007 & 13.53 & $19.7 \%$ \\
50 & 104.5 & 0.894 & 0.430 & 0.007 & 16.16 & $19.9 \%$ \\
100 & 116.8 & 0.898 & 0.434 & 0.008 & 17.93 & $20.4 \%$ \\
200 & 132.5 & 0.898 & 0.434 & 0.009 & 18.06 & $22.1 \%$ \\
500 & 152.1 & 0.902 & 0.437 & 0.011 & 17.53 & $24.8 \%$ \\
\hline
\end{tabular}

For Region 4, the urbanization factor $\% \mathrm{U}+1$, is added to the equation for the previous regions.

$$
Q_{\text {RetPer }}=(C)(D A)^{a_{1}}(\text { Slope })^{a_{2}}(\% U+1)^{a_{3}}
$$

Table 3.5.5. Regression results for Region 4

\begin{tabular}{|cccccccc|}
\hline $\begin{array}{c}\text { Return } \\
\text { Period }\end{array}$ & $\begin{array}{c}\text { Constant } \\
(\mathbf{C})\end{array}$ & $\begin{array}{c}\text { DA } \\
\left(\mathbf{a}_{\mathbf{1}}\right)\end{array}$ & $\begin{array}{c}\text { Slope } \\
\left(\mathbf{a}_{2}\right)\end{array}$ & $\begin{array}{c}\text { \%U+1 } \\
\left(\mathbf{a}_{3}\right)\end{array}$ & $\begin{array}{c}\text { Avg Model } \\
\text { Error }\end{array}$ & $\begin{array}{c}\text { Avg Eq } \\
\text { YOR }\end{array}$ & $\begin{array}{c}\text { \%Error } \\
10\end{array}$ \\
31.1 & 0.820 & 0.681 & 0.080 & 0.010 & 7.67 & $23.1 \%$ \\
25 & 37.7 & 0.820 & 0.698 & 0.079 & 0.009 & 10.64 & $22.5 \%$ \\
50 & 42.9 & 0.819 & 0.707 & 0.077 & 0.009 & 12.90 & $22.4 \%$ \\
100 & 48.4 & 0.816 & 0.712 & 0.075 & 0.009 & 15.13 & $22.4 \%$ \\
200 & 52.7 & 0.816 & 0.722 & 0.074 & 0.010 & 16.59 & $22.7 \%$ \\
500 & 58.7 & 0.815 & 0.731 & 0.073 & 0.010 & 18.17 & $23.5 \%$ \\
\hline
\end{tabular}

Equations for Region 5 and 6 are similar to the equations for Regions 1, 2 and 3.

$$
Q_{\operatorname{Re} t P e r}=(C)(D A)^{a_{1}}(\text { Slope })^{a_{2}}
$$

Table 3.5.6. Regression results for Region 5

\begin{tabular}{|ccccccc|}
\hline Return Period & $\begin{array}{c}\text { Constant } \\
(\mathbf{C})\end{array}$ & $\begin{array}{c}\text { DA } \\
\left(\mathbf{a}_{\mathbf{1}}\right)\end{array}$ & $\begin{array}{c}\text { Slope } \\
\left(\mathbf{a}_{2}\right)\end{array}$ & $\begin{array}{c}\text { Avg Model } \\
\text { Error }\end{array}$ & Avg Eq YOR & \%Error \\
10 & 35.8 & 0.776 & 0.368 & 0.013 & 2.96 & $26.7 \%$ \\
25 & 45.6 & 0.764 & 0.356 & 0.014 & 3.70 & $27.7 \%$ \\
50 & 53.1 & 0.756 & 0.347 & 0.015 & 4.24 & $28.3 \%$ \\
100 & 60.8 & 0.748 & 0.338 & 0.015 & 4.75 & $28.8 \%$ \\
200 & 68.7 & 0.742 & 0.330 & 0.020 & 5.23 & $33.5 \%$ \\
500 & 79.5 & 0.734 & 0.319 & 0.016 & 5.79 & $30.0 \%$ \\
\hline
\end{tabular}


Table 3.5.7. Regression results for Region 6

\begin{tabular}{|c|c|c|c|c|c|c|}
\hline Return Period & $\begin{array}{l}\text { Constant } \\
\text { (C) }\end{array}$ & $\begin{array}{l}\text { DA } \\
\left(a_{1}\right)\end{array}$ & $\begin{array}{c}\text { Slope } \\
\left(a_{2}\right)\end{array}$ & $\begin{array}{l}\text { Avg Model } \\
\text { Error }\end{array}$ & Avg Eq YOR & $\%$ Error \\
\hline 10 & 22.4 & 0.732 & 0.776 & 0.025 & 2.17 & $37.8 \%$ \\
\hline 25 & 27.9 & 0.709 & 0.858 & 0.026 & 2.77 & $38.7 \%$ \\
\hline 50 & 31.5 & 0.696 & 0.917 & 0.027 & 3.21 & $39.4 \%$ \\
\hline 100 & 34.6 & 0.687 & 0.974 & 0.028 & 3.62 & $40.1 \%$ \\
\hline 200 & 37.3 & 0.681 & 1.029 & 0.029 & 4.01 & $40.8 \%$ \\
\hline 500 & 40.3 & 0.675 & 1.098 & 0.030 & 4.47 & $41.7 \%$ \\
\hline
\end{tabular}

For Region 7 , the factor $\% \mathrm{~W}+1$ is added to the equation

$$
Q_{\operatorname{Re} t P e r}=(C)(D A)^{a_{1}}(\text { Slope })^{a_{2}}(\% W+1)^{a_{3}}
$$

Table 3.5.8. Regression results for Region 7

\begin{tabular}{|c|c|c|c|c|c|c|c|}
\hline Return Period & $\begin{array}{c}\text { Constant } \\
\text { (C) }\end{array}$ & $\begin{array}{l}\text { DA } \\
\left(\mathbf{a}_{1}\right)\end{array}$ & $\begin{array}{c}\text { Slope } \\
\left(\mathbf{a}_{2}\right)\end{array}$ & $\begin{array}{c}\% W+1 \\
\left(a_{3}\right)\end{array}$ & $\begin{array}{l}\text { Avg Model } \\
\text { Error }\end{array}$ & $\begin{array}{c}\text { Avg Eq } \\
\text { YOR }\end{array}$ & \%Error \\
\hline 10 & 65.0 & 0.873 & 0.372 & -0.795 & 0.030 & 2.36 & $41.7 \%$ \\
\hline 25 & 89.0 & 0.858 & 0.361 & -0.801 & 0.034 & 2.84 & $44.4 \%$ \\
\hline 50 & 108.4 & 0.849 & 0.354 & -0.803 & 0.037 & 3.19 & $46.2 \%$ \\
\hline 100 & 129.3 & 0.839 & 0.347 & -0.803 & 0.034 & 3.53 & $44.3 \%$ \\
\hline 200 & 151.1 & 0.831 & 0.343 & -0.802 & 0.041 & 3.82 & $49.4 \%$ \\
\hline 500 & 182.2 & 0.821 & 0.336 & -0.800 & 0.044 & 4.18 & $51.3 \%$ \\
\hline
\end{tabular}

Region 8 is different from the other equations in that the slope is not a factor in the equation.

$\% \mathrm{~W}+1$ is reflected in the final equation.

$$
Q_{\text {Re } t P e r}=(C)(D A)^{a_{1}}(\% W+1)^{a_{2}}
$$

Table 3.5.9. Regression results for Region 8

\begin{tabular}{|ccccccc|}
\hline Return Period & $\begin{array}{c}\text { Constant } \\
(\mathbf{C})\end{array}$ & $\begin{array}{c}\text { DA } \\
\left(\mathbf{a}_{\mathbf{1}}\right)\end{array}$ & $\begin{array}{c}\mathbf{\%} \mathbf{W}+\mathbf{1} \\
\left(\mathbf{a}_{\mathbf{2}}\right)\end{array}$ & $\begin{array}{c}\text { Avg Model } \\
\text { Error }\end{array}$ & Avg Eq YOR & \%Error \\
10 & 106.0 & 0.835 & -0.733 & 0.029 & 1.20 & $41.0 \%$ \\
25 & 118.2 & 0.839 & -0.719 & 0.029 & 1.66 & $40.4 \%$ \\
50 & 126.5 & 0.842 & -0.707 & 0.028 & 2.04 & $39.9 \%$ \\
100 & 134.2 & 0.843 & -0.695 & 0.027 & 2.44 & $39.5 \%$ \\
200 & 141.1 & 0.845 & -0.683 & 0.027 & 2.84 & $39.1 \%$ \\
500 & 149.8 & 0.846 & -0.667 & 0.026 & 3.40 & $38.6 \%$ \\
\hline
\end{tabular}


The ranges of values for each of the watershed parameters in these equations are given in Table 3.5.9. Applying these equations in circumstances where the values of the watershed parameters are outside of the ranges of the data used in the regression study is not recommended, and should be done with caution. The effect of outlier values of the basin characteristics cannot be determined with any certainty, since the data are non existent, and the response of a particular watershed could vary greatly outside the bounds of the variable ranges.

Table 3.5.10. Ranges for various watershed characteristics

\begin{tabular}{|ccccc|}
\hline Region & $\begin{array}{c}\text { DA } \\
\text { (sq mi) }\end{array}$ & $\begin{array}{c}\text { Slope } \\
\text { (ft/mi) }\end{array}$ & $\begin{array}{c}\text { \%W } \\
(\mathbf{\%})\end{array}$ & $\begin{array}{c}\text { \%U } \\
(\mathbf{\%})\end{array}$ \\
1 & $0.27-13,706$ & $1.4-79$ & & \\
2 & $0.15-11,125$ & $1.2-267$ & & \\
3 & $0.07-284$ & $3.8-253$ & & \\
4 & $0.31-2,444$ & $2.7-48.7$ & & $0-83.9$ \\
5 & $5.82-1,869$ & $1.6-8.6$ & & \\
6 & $1.5-1,779$ & $0.9-15.8$ & & \\
7 & $0.17-4,072$ & $2.4-43.7$ & $0-7.2$ & \\
8 & $0.45-3,370$ & & $0-12.1$ & \\
\hline
\end{tabular}

Examining the error results, regions 3 and 4 have the smallest percentage errors and the largest equivalent years of record. This corresponds to the heterogeneity measures, which identified these regions as homogeneous. Region 1, the other homogeneous region, has error values slightly higher than Regions 3 and 4, but still better than four of the other five regions. Errors for the other four regions compare to the errors found in Glatfelter's study. Region 5 has results that are comparable to the three homogenous regions.

Equations for computing confidence limits for each of the predictive equations have also been derived as part of the GLS methodology. A $100(1-\alpha)$ prediction interval is given in Equations 3.5.8 and 3.5.9 for a logarithmic transformation of the prediction variable $\mathrm{q}_{0}$ 


$$
10^{\hat{y}_{0}-T} \leq q_{0} \leq 10^{\hat{y}_{0}+T}
$$

where

$$
T=t_{\frac{\alpha}{2}, n-p^{\prime}} \sqrt{\hat{\gamma}_{0}^{2}+x_{0}\left(X^{\prime} \hat{\Lambda}^{-1} X\right)^{-1} x_{0}^{\prime}}
$$

where $t_{\alpha / 2, n-p^{\prime}}$ is the critical value for a $t$ distribution for n-p' degrees of freedom (Tasker, 1995).

\subsection{Evaluation of the Prediction Equations}

With any study, testing the results with independent methodologies is an important aspect of determining the reliability of the study. The nature of the input data for any hydrologic study is imprecise, and therefore various means of evaluating the study results are warranted. For this study, the results have been tested by using a split sample test, with a comparison to previously determined discharges, and by examining the fit of the regression to the input data points.

As a general examination of the regression results, Figures 3.6.1 through 3.6.8 are plots of the peak 100-year flood frequency discharges for gaging stations in each region (calculated using the USWRC methodology) plotted versus the 100-year frequency flood discharge predicted by the respective regional equation. Given a perfect relationship, these discharges would be equal to each other, and therefore would plot on a straight line at a 45 degree angle. By examining the deviation of the plotted points to this line, the relative strength of the predictive equations can be evaluated.

For these plots, the best fit equations are for Regions 3 and 4, which have the smallest errors from the GLS analysis, and have the lowest homogeneity measures. Other regions do not demonstrate as strong a relationship, but generally show an acceptable relationship between calculated and predicted values for the 100-year discharge. 


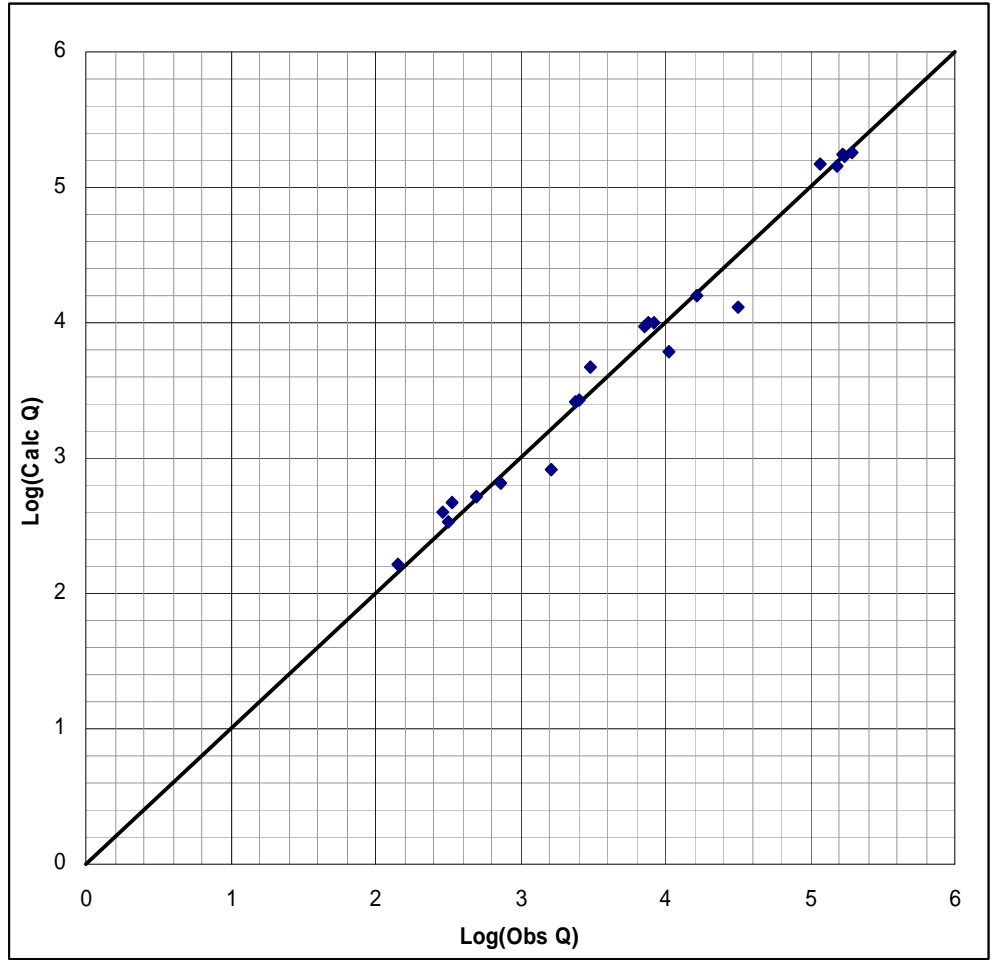

Figure 3.6.1. Comparison of 100 year observed discharges and regression model discharges for Region 1.

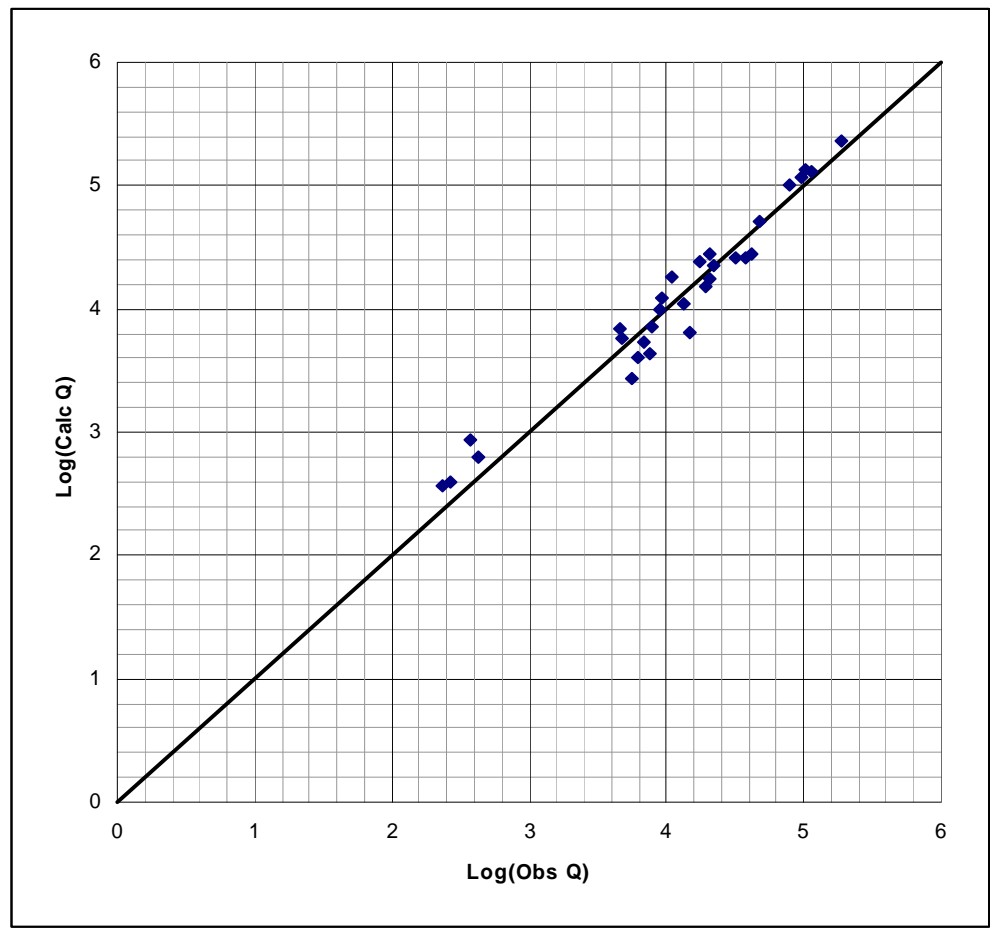

Figure 3.6.2. Comparison of 100 year observed discharges and regression model discharges for Region 2 


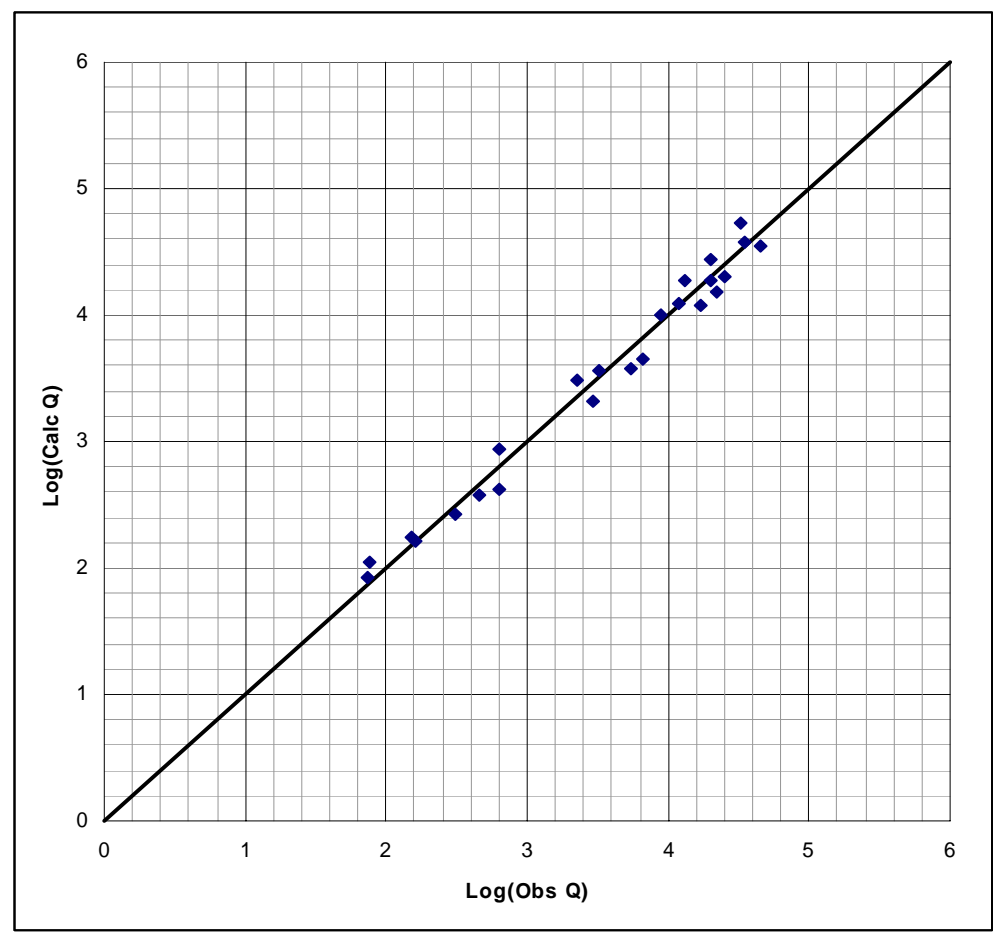

Figure 3.6.3. Comparison of 100 year observed discharges and regression model discharges for Region 3

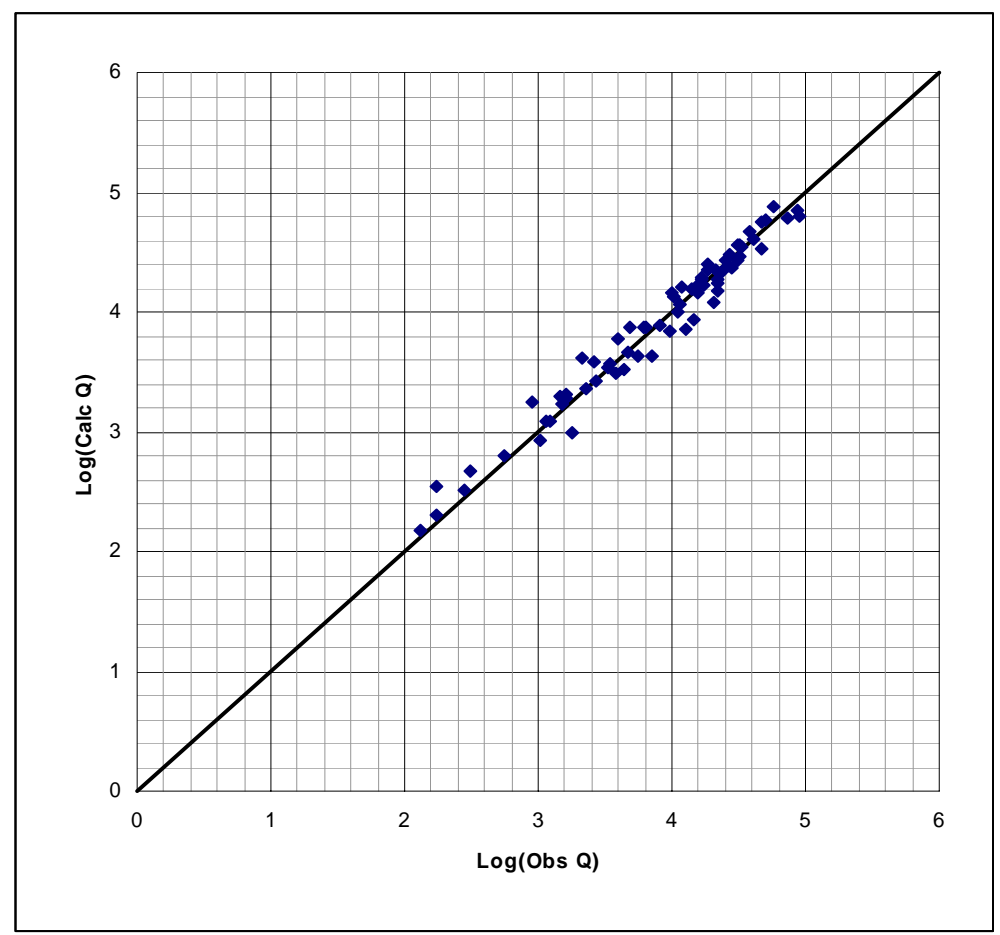

Figure 3.6.4. Comparison of 100 year observed discharges and regression model discharges for Region 4 


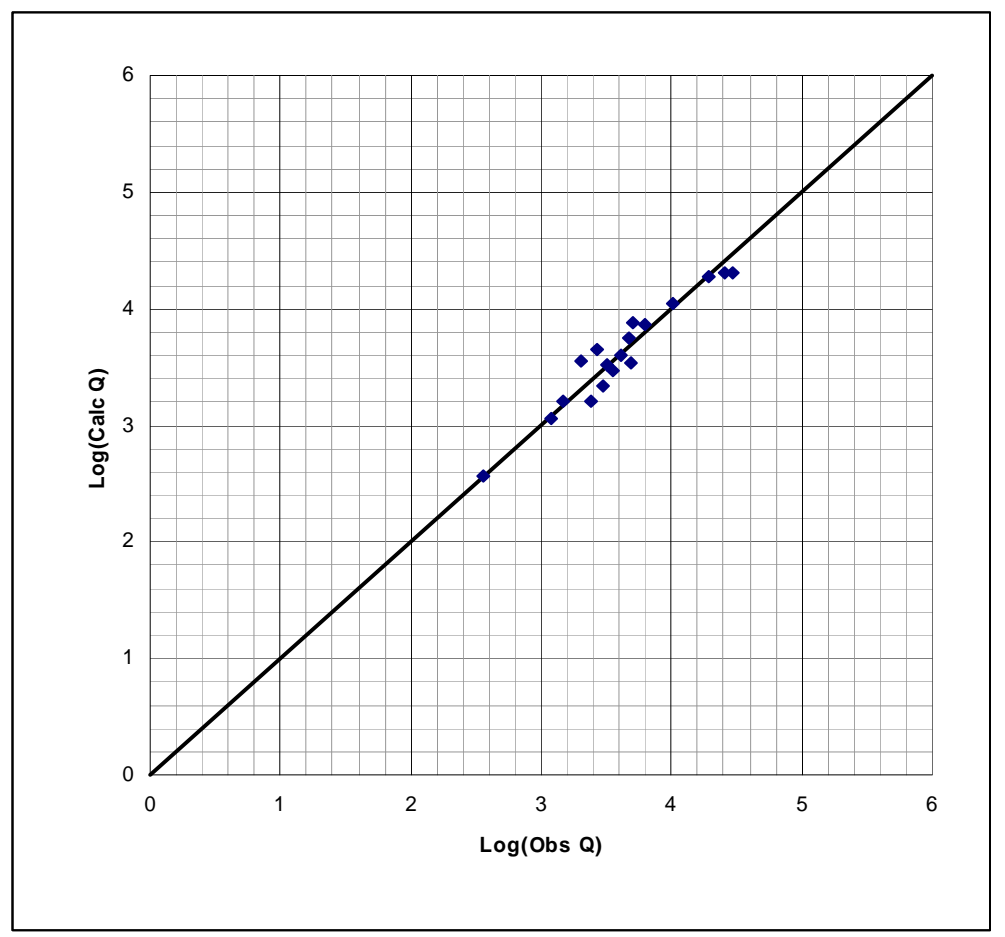

Figure 3.6.5. Comparison of 100 year observed discharges and regression model discharges for Region 5

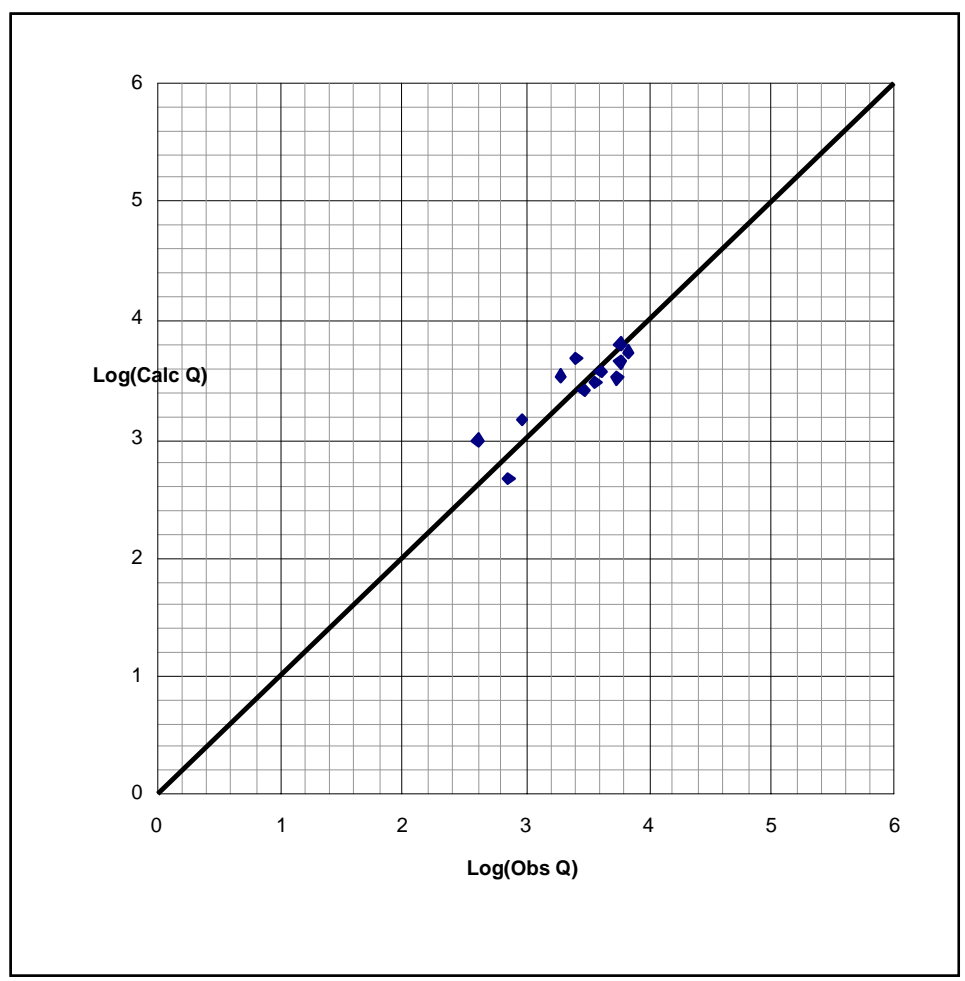

Figure 3.6.6. Comparison of 100 year observed discharges and regression model discharges for Region 6 


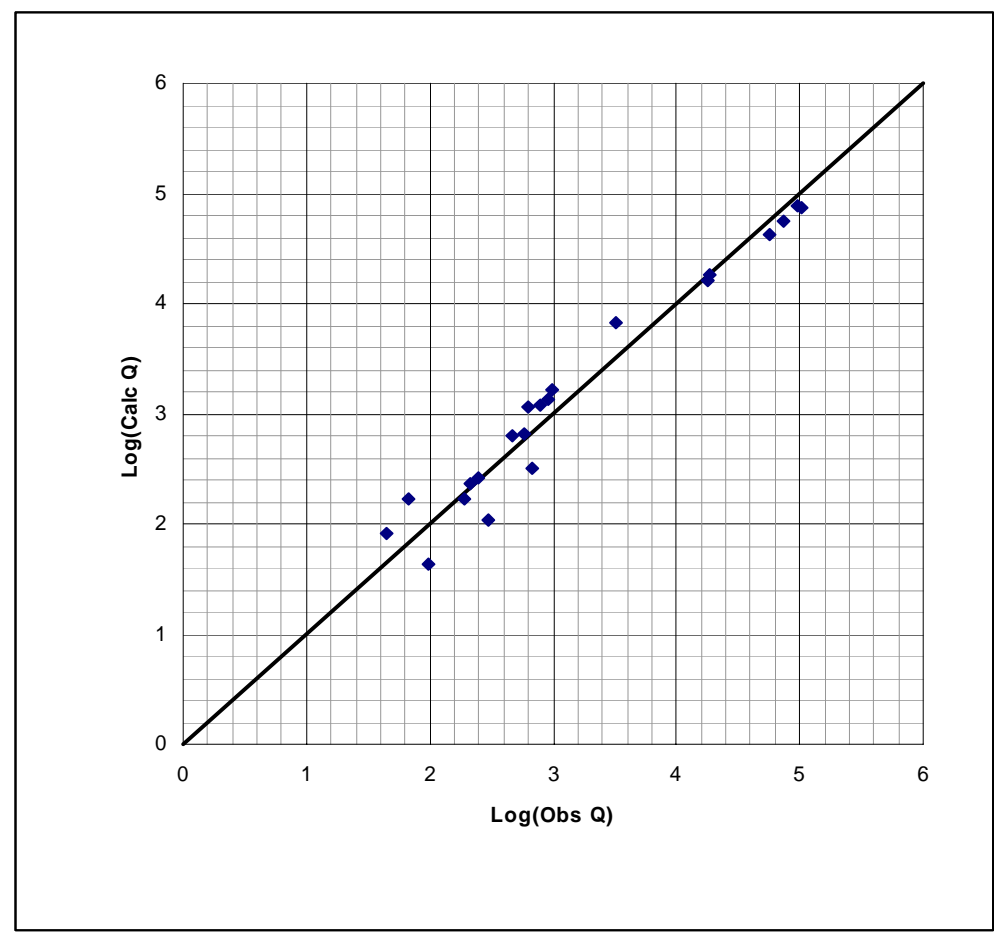

Figure 3.6.7. Comparison of 100 year observed discharges and regression model discharges for Region 7

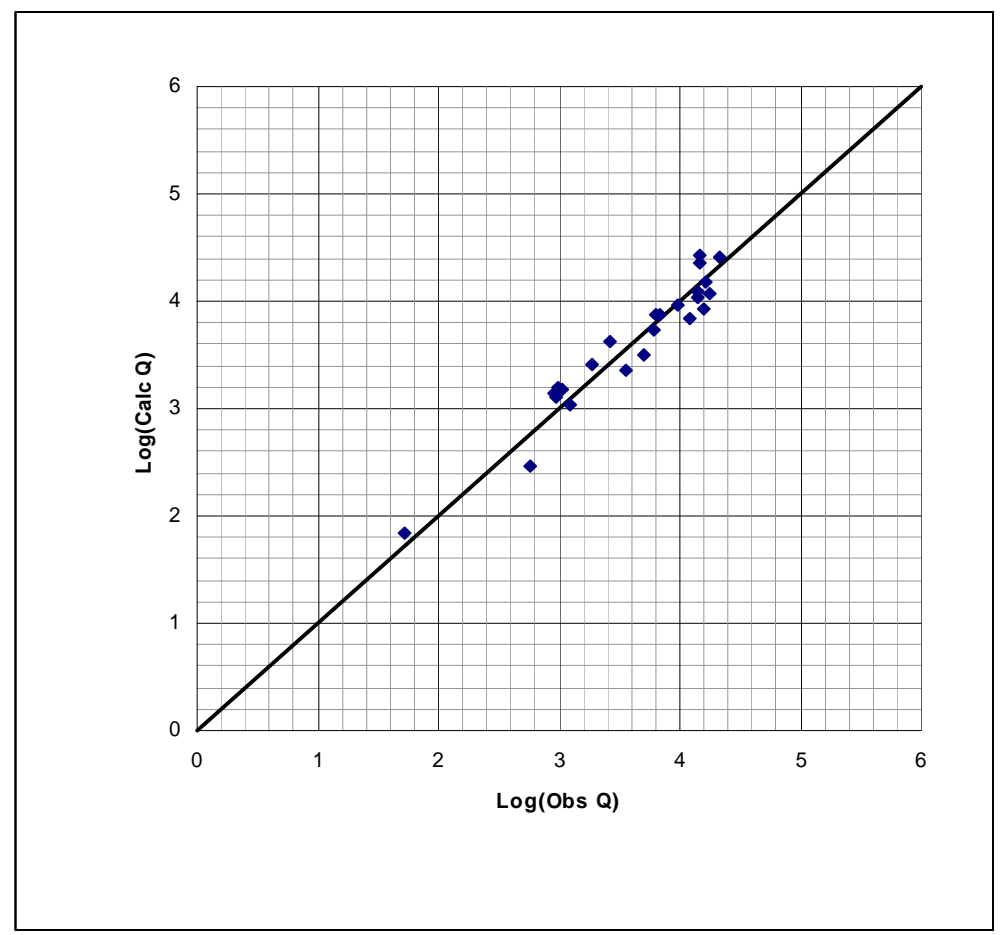

Figure 3.6.8. Comparison of 100 year observed discharges and regression model discharges for Region 8 


\subsection{Split Sample Test}

A split sample test is useful in identifying how stable and reliable a dataset may be. In a truly homogeneous data sample, a regression model on a significant part of the data set should be comparable to a regression model of the entire data set. For the split sample test in this study, the following methodology was used:

- A random number (between 0 and 1) was assigned to each gaging station, using the Microsoft EXCEL rand() function.

- The stations in each region were then sorted using the random number as the sorting key.

- $20 \%$ of the stations in each of the regions were then chosen as the "split" sample, based on the lowest random number generated.

- The GLS regression method was then run using the remaining $80 \%$ of the sample set. The regression variables were kept the same as for the original regression analysis. Only the 100-year flood was used for this test.

- The split sample regression equation was then used to predict the flood flows at the stations removed from the test.

- The percent error of the predicted peak discharge was computed based on the peak discharge computed using flood frequency analysis. This percent error was then compared to the overall percent error in the model (as computed in the GLS methodology), and compared to the percent error at the removed stations in the full regression model.

Table 3.7.1 shows the stations removed for the split sample test with the percent errors noted, and Table 3.7.2 is a summary of the results of the test by region. 
Table 3.7.1. Stations removed from regression for Spilt Sample test

\begin{tabular}{|c|c|c|c|c|c|}
\hline StatNo & 2004Regions & Q100(calc) & Q100 (ss) & $\%$ diff & $\%$ diff (entire sample) \\
\hline 03335500 & 1 & 119,359 & 164,786 & $38.1 \%$ & $24.5 \%$ \\
\hline 03336000 & 1 & 155,856 & 155,410 & $0.3 \%$ & $6.9 \%$ \\
\hline 03360100 & 1 & 142 & 140 & $1.3 \%$ & $16.3 \%$ \\
\hline 03378550 & 1 & 10,666 & 5,326 & $50.1 \%$ & $42.2 \%$ \\
\hline 03302300 & 2 & 7,489 & 4,143 & $44.7 \%$ & $42.2 \%$ \\
\hline 03322100 & 2 & 11,092 & 18,224 & $64.3 \%$ & $62.6 \%$ \\
\hline 03360000 & 2 & 48,371 & 51,158 & $5.8 \%$ & $7.0 \%$ \\
\hline 03366500 & 2 & 37,426 & 25,925 & $30.7 \%$ & $29.3 \%$ \\
\hline 03373700 & 2 & 17,716 & 11,009 & $37.9 \%$ & $34.8 \%$ \\
\hline 03374000 & 2 & 185,277 & 236,515 & $27.7 \%$ & $25.6 \%$ \\
\hline 03276640 & 3 & 462 & 292 & $36.8 \%$ & $19.4 \%$ \\
\hline 03291780 & 3 & 8,825 & 10,208 & $15.7 \%$ & $14.0 \%$ \\
\hline 03302690 & 3 & 75 & 113 & $50.1 \%$ & $49.6 \%$ \\
\hline 03302730 & 3 & 11,916 & 12,709 & $6.7 \%$ & $4.9 \%$ \\
\hline 03369000 & 3 & 19,954 & 19,176 & $3.9 \%$ & $5.8 \%$ \\
\hline 03274880 & 4 & 555 & 633 & $14.1 \%$ & $13.4 \%$ \\
\hline 03275500 & 4 & 21,766 & 16,757 & $23.0 \%$ & $21.0 \%$ \\
\hline 03325500 & 4 & 11,548 & 11,510 & $0.3 \%$ & $2.0 \%$ \\
\hline 03326000 & 4 & 20,639 & 11,888 & $42.4 \%$ & $41.6 \%$ \\
\hline 03333600 & 4 & 1,596 & 2,031 & $27.3 \%$ & $25.9 \%$ \\
\hline 03334500 & 4 & 16,635 & 18,503 & $11.2 \%$ & $14.2 \%$ \\
\hline 03348020 & 4 & 1,633 & 1,952 & $19.5 \%$ & $18.5 \%$ \\
\hline 03348350 & 4 & 6,401 & 7,376 & $15.2 \%$ & $16.3 \%$ \\
\hline 03348700 & 4 & 130 & 153 & $17.6 \%$ & $14.0 \%$ \\
\hline 03349500 & 4 & 4,859 & 7,400 & $52.3 \%$ & $53.5 \%$ \\
\hline 03358000 & 4 & 13,904 & 15,301 & $10.0 \%$ & $12.3 \%$ \\
\hline 03361500 & 4 & 18,305 & 22,121 & $20.9 \%$ & $23.8 \%$ \\
\hline 03364000 & 4 & 73,957 & 58,382 & $21.1 \%$ & $18.3 \%$ \\
\hline 03365500 & 4 & 89,484 & 60,543 & $32.3 \%$ & $30.1 \%$ \\
\hline 03332500 & 5 & 19,452 & 17,480 & $10.1 \%$ & $3.1 \%$ \\
\hline 03333000 & 5 & 25,553 & 18,919 & $26.0 \%$ & $19.7 \%$ \\
\hline 04093500 & 5 & 4,147 & 3,909 & $5.7 \%$ & $3.2 \%$ \\
\hline 05523000 & 5 & 1,201 & 1,156 & $3.8 \%$ & $4.7 \%$ \\
\hline 03332400 & 6 & 2,963 & 2,725 & $8.0 \%$ & $13.2 \%$ \\
\hline 05515500 & 6 & 1,925 & 3,687 & $91.5 \%$ & $74.5 \%$ \\
\hline 03324500 & 7 & 17,952 & 18,948 & $5.6 \%$ & $10.4 \%$ \\
\hline 03327930 & 7 & 666 & 282 & $57.7 \%$ & $52.9 \%$ \\
\hline 03328430 & 7 & 633 & 1,451 & $129.4 \%$ & $80.9 \%$ \\
\hline 03329400 & 7 & 794 & 1,667 & $110.0 \%$ & $50.2 \%$ \\
\hline 03324300 & 8 & 14,066 & 12,770 & $9.2 \%$ & $12.3 \%$ \\
\hline 04099750 & 8 & 2,648 & 3,974 & $50.1 \%$ & $60.0 \%$ \\
\hline 04100220 & 8 & 905 & 1,513 & $67.2 \%$ & $54.1 \%$ \\
\hline 04180000 & 8 & 6,025 & 5,568 & $7.6 \%$ & $12.2 \%$ \\
\hline 04181500 & 8 & 14,822 & 23,385 & $57.8 \%$ & $54.9 \%$ \\
\hline
\end{tabular}


Table 3.7.2. Split Sample error percentages

\begin{tabular}{|ccccc|}
\hline Region & $(1)$ & $(2)$ & $(3)$ & $(4)$ \\
1 & $22.4 \%$ & $22.4 \%$ & $21.8 \%$ & $29.5 \%$ \\
2 & $35.2 \%$ & $33.6 \%$ & $33.8 \%$ & $36.8 \%$ \\
3 & $22.6 \%$ & $18.7 \%$ & $25.0 \%$ & $20.4 \%$ \\
4 & $22.0 \%$ & $21.8 \%$ & $23.0 \%$ & $22.4 \%$ \\
5 & $11.4 \%$ & $7.7 \%$ & $23.5 \%$ & $28.8 \%$ \\
6 & $49.8 \%$ & $43.8 \%$ & $43.7 \%$ & $40.1 \%$ \\
7 & $75.7 \%$ & $48.6 \%$ & $45.0 \%$ & $44.3 \%$ \\
8 & $38.4 \%$ & $38.7 \%$ & $34.7 \%$ & $39.5 \%$ \\
& & & & \\
Total & $30.9 \%$ & $27.2 \%$ & $29.1 \%$ & -- \\
\hline
\end{tabular}

In Table 3.7.2, the columns are as follows:

(1) is the average percent error of the calculated discharge for the split sample using the censored regression equation, compared to the calculated peak discharge using flood frequency analysis

(2) is the average percent error of the calculated peak discharge for the split sample using the full regression equation, compared to the calculated peak discharge using flood frequency analysis.

(3) is the average percent error of the calculated peak discharge for the entire sample using the full regression equation, compared to the calculated peak discharge using flood frequency analysis.

(4) is the average model error as calculated from the GLS regression diagnostics, using equation 3.5.1.

For most regions the percent error as calculated by these various methods are comparable to each other. This is to be expected, since the regions are mainly homogeneous or possibly homogeneous, and therefore errors inherent within the analysis should be consistent for subsets 
of the data. The exceptions to this are Region 5, where the split sample errors are much less then the errors for the entire data set, and Region 7, where they are much greater.

The anomalies for these two regions could be due to a number of reasons. The difference for Region 5 is most likely due to a fortunate selection of stations that fit the data unusually well. Note, for example, that station 03333000, Tippecanoe River near Delphi, is in the split sample, while station 03333050, also named Tippecanoe River near Delphi, is not. The second station is actually a replacement of the first located slightly downstream of the original station, and therefore has similar basin characteristics and a similar flood frequency curve. The reduction in the error for the split sample could be a reason for reevaluating the stations for Region 5 and attempting to further reduce the error for the entire sample. However, since there are only 18 stations in Region 5, eliminating further stations would reduce the diversity of basin characteristics at each of the stations in the region, reducing the predictive qualities of the resulting equation. A balance must be struck between having too many stations in a region; resulting in a heterogeneous region, and too few stations; resulting in equations that are not useful for predicting flood frequency flows for basins that have basin characteristics outside of the range of characteristics in the study.

While the split sample for Region 5 had a lower average error than the entire study, Region 7 had a much higher average error for the split sample than for the entire sample. This may be due to the random nature of the stations chosen for the split sample. Three of the four stations removed from the analysis have drainage areas less than 10 square miles, while 10 of the remaining 16 gages have drainage areas greater than 10 square miles (and mostly much greater than 10 square miles). Also, two of the split sample gages (Weesau Creek near Deadsville and Rattlesnake Creek near Patton) are stations with small drainage areas, but fairly long periods of 
record (31 and 25 years, respectively). This influences the split sample regression to a degree that it is not predicting the peak discharges for the smaller discharges as well as the general model. One of the main advantages of GLS regression over other types of analysis is that the record length is a factor in determining the influence of a station on the model. The nature of the gaging program is such that gaging stations for smaller streams typically do not have as long record lengths as do the stations on larger streams. Therefore, stations such as those two randomly removed from this analysis have a great bearing on defining the lower end of the model, causing the split sample equation to err unacceptably in predicting the peak flows for these stations.

Whether LP (III) distribution gives results with smaller errors than other distributions is not addressed in this chapter. It is considered in the next chapter. 


\section{Regional Flood Estimation Based on L-Moments}

Two sets of data are used in this and the following chapters. The first set is that used in Chapter 2. The second set is the data used in chapter 3. The reason for using the first set is that the division of Indiana to eight regions was rather arbitrary. The effect of this division on flood prediction equations is investigated in this and following chapters.

The objective of the research reported in this chapter is to investigate the L-moment method to obtain the regional normalized flood quantiles. Basic descriptions of L-moments, parameter estimation and probability distribution are introduced first. The regional flood estimation method is discussed later.

\subsection{L-moments and Parameter Estimation}

\subsubsection{L-Moment}

The $r$ th L-moments of a random variable $\mathrm{x}$ have been defined as in equation 4.1.1 (Hosking, 1990):

$$
\lambda_{r}=\int_{0}^{1} x(F) P_{r-1}^{*}(F) d F
$$

in which

$$
P_{r}^{*}=\sum_{k=0}^{r}(-1)^{r-k}\left(\begin{array}{l}
r \\
k
\end{array}\right)\left(\begin{array}{c}
r+k \\
k
\end{array}\right) F^{k}
$$

where $F(x)$ is the cumulative distribution of $x$, and $x(F)$ is the quantile function for the distribution. The first L-moment, $\lambda_{1}$, is the arithmetic mean, while the second L-moment, $\lambda_{2}$, is a 
measure of dispersion analogous to the standard deviation. Hosking found it convenient to standardize the higher L-moments such that the $r$ th L-moment ratio is given by:

$$
\tau_{r}=\lambda_{r} / \lambda_{2}
$$

where $\tau_{3}$ is a measure of the symmetry of the sample and is referred to as L-skewness. $\tau_{4}$ is referred to as L-kurtosis, and $\tau=\lambda_{2} / \lambda_{1}$ is analogous to the conventional coefficient of variation of central moments.

For an ordered random sample, $x_{1} \leq x_{2} \leq \cdots \leq x_{n}$, the $r$ th sample L-moment, $l_{r}$ can be estimated by using equation 4.1.4:

$$
l_{r}=\frac{r !(n-r) !}{n !} \sum_{1 \leq i_{1}<i_{2} \leq} \sum_{<i_{r} \leq n} \frac{1}{r} \sum_{k=0}^{r-1}(-1)^{k}\left(\begin{array}{c}
r-1 \\
k
\end{array}\right) X_{i_{r-k}}, r=1, \cdots, n .
$$

Hosking (1990) points out that it is not necessary to iterate over all subsamples of size $r$, as $l_{r}$ can be written as a linear combination of order statistics.

$$
l_{r}=\sum_{k=0}^{r-1} p_{r-1, k}^{*} b_{k}
$$

where

$$
b_{k}=\frac{1}{n^{k+1}} \sum_{i=1}^{n}(i-1)^{k} x_{i} \text { and } p_{r k}^{*}=(-1)^{r-k}\left(\begin{array}{c}
r \\
k
\end{array}\right)\left(\begin{array}{c}
r+k \\
k
\end{array}\right)
$$

\subsubsection{Moments and Parameter Estimation}

For a distribution with a probability density function $f(x)$, the $r^{\text {th }}$ theoretical moments $\mu_{r}^{\prime}$ and $r^{\text {th }}$ sample moments $m_{r}^{\prime}$ about the origin are given by eq. 4.1 .7 and eq. 4.1.8, respectively. 


$$
\begin{gathered}
\mu_{r}^{\prime}=\int_{-\infty}^{\infty} x^{r} f(x) d x \\
m_{r}^{\prime}=\frac{1}{n} \sum_{i=1}^{n} x_{i}{ }^{r}
\end{gathered}
$$

Parameters of a probability distribution function are estimated by the method of moments (MOM) by equating the moments of samples to the moments of the probability distribution function. The method of moments is a commonly used parameter estimation method. For a distribution with $\mathrm{k}$ parameters, $\alpha_{1}, \alpha_{2}, \cdots, \alpha_{k}$ which are to be estimated, the first $k$ sample moments are set equal to the corresponding population moments that are given in terms of unknown parameters. These $k$ equations are solved simultaneously for the unknown parameters.

For a given probability distribution, its probability weighted moments $M_{p, r, s}$ are defined as

$$
M_{p, r, s}=E\left[X^{p} F^{r}(1-F)^{s}\right]=\int_{0}^{1}[x(F)]^{p} F^{r}(1-F)^{s} d F
$$

where $F=F\left(x, \phi_{1}, \phi_{2}, \cdots, \phi_{k}\right)=P(X \leq x)$ is the cumulative distribution function, $x(F)$ is the inverse cumulative function, and $p, r$ and $s$ are integers. Two particular sets of PWMs $\alpha_{r}$ and $\beta_{r}$ are usually considered:

$$
\begin{gathered}
\alpha_{s} \equiv M_{1,0, s}=\int_{0}^{1} x(F)(1-F)^{s} d F=\int x(1-F)^{s} f(x) d x \\
\beta_{s} \equiv M_{1, r, 0}=\int_{0}^{1} x(F) F^{r} d F=\int x F^{r} f(x) d x
\end{gathered}
$$


where $f(x)=f\left(x, \phi_{1}, \phi_{2}, \cdots, \phi_{k}\right)$ is the probability density function. It can be shown that the set of $\alpha_{s}$ and $\beta_{s}$ are linearly dependent, implying that either definition of PWM may be used for parameter estimation without loss of generality (Hosking, 1986).

To estimate the parameters of a distribution, PWM estimators of the ordered sample $x=\left\{x_{1} \leq x_{2} \leq \cdots \leq x_{n-1} \leq x_{n}\right\}$ are defined as follows, using Haktanir's notation (1997):

$$
\begin{aligned}
& \alpha_{s}^{\prime}=\frac{1}{n} \sum_{i=1}^{n}\left(1-P_{n e x, i}\right)^{s} x_{i} \text { for } s=0,1,2, \ldots, n-1 \\
& \beta^{\prime}{ }_{s}=\frac{1}{n} \sum_{i=1}^{n} P_{n e x, i} x_{i} \text { for } r=0,1,2, \ldots, n-1
\end{aligned}
$$

where $P_{\text {nex }, i}$ is an estimate for the non-exceedance probability of the $i$ th event. Using the unbiased estimators suggested by Landwehr et al. (1979), $P_{n e x, i}^{j}$ is taken as

$$
P_{n e x, i}^{j}=\frac{\left(\begin{array}{c}
i-1 \\
j
\end{array}\right)}{\left(\begin{array}{c}
n-1 \\
j
\end{array}\right)} \text { for } j=0,1,2, \ldots, n-1
$$

The PWM parameter estimates $\phi_{1}{ }^{\prime}, \phi_{2}{ }^{\prime}, \cdots, \phi_{k}{ }^{\prime}$ are defined as those values that make the first $k$ theoretical PWMs equal to the first $k$ sample PWM estimators; i.e. $\phi_{1}{ }^{\prime}, \phi_{2}{ }^{1}, \cdots, \phi_{k}{ }^{\prime}$ are those values such that

$$
\begin{aligned}
& \alpha_{s}^{\prime}=\alpha_{s}\left(\phi_{1}^{\prime}, \phi_{2}^{\prime}, \cdots, \phi_{k}^{\prime}\right) \text { for } s=0,1,2, \ldots, k-1 \\
& \beta_{r}^{\prime}=\beta_{r}\left(\phi_{1}^{\prime}, \phi_{2}^{\prime}, \cdots, \phi_{k}^{\prime}\right) \text { for } r=0,1,2, \ldots, k-1
\end{aligned}
$$


The mathematical solutions or numerical approximations for parameters of different probability distributions by the method of moments and probability weighted moments have been derived by Rao and Hamed (2000). Mainly, the lognormal III, Pearson III and log Pearson III, and the GEV distributions are used in the study.

To select the candidate probability distributions, the statistical characteristics of the data can be investigated by using the L-moment ratio diagram. An important application of summary statistics calculated from an observed random sample is identification of the distribution from which the sample is drawn. This is achieved, particularly for skewed distributions, by using Lmoments. The statistics of L-skewness and L-kurtosis of all sites in each region is shown in Fig. 4.1.1, along with the theoretical lines for some distributions.

The mean square error from the L-moment ratio diagram is the measure used to evaluate the candidate probability distributions. It is calculated by using equation 4.1.17.

$$
R M S E=\sqrt{\frac{\sum_{i=1}^{n}\left(x_{L C K}^{O b s}-x_{L C K}^{T h}\right)^{2}}{n}}
$$

where $x_{L C K}^{O b s}$ refers the fourth L-moment ratio of the observed values and $x_{L C K}^{T h}$ is the theoretical fourth L-moment ratio of a specific distribution corresponding to the same third L-moment of the observations. From the results in Figure 4.1.2, it can be concluded that normal distribution and extreme value type I distribution are inappropriate for these data; the other six distributions, which do not show significant differences in the graph, will be evaluated as candidate distributions in the regional index flood analysis. The candidate distributions are lognormal (LNIII), two-parameter Gamma (GMII), Pearson type 3 (PTIII), log-Pearson type 3 (LPIII), generalized extreme value (GEV), and generalized logistic (GLO) distributions. The method 
used to select the better distribution for regional analysis is to evaluate the distribution which offers better and stable regional estimates than the others.

A split data sample in which the sample is split into $75 \%$ for parameter estimation and $25 \%$ for parameter validation is used. We use the $75 \%$ of data to build the L-moment ratio diagram. Again, the RMSE of L-moment ratio is calculated for each distribution, and the result is shown in Figure 3.1.3. A similar conclusion is indicated as before, in that the sampling statistics of normal distribution (NOR) and extreme value type I (EVI) are not acceptable, so that both of them are not appropriate for further analysis.

Kedia and Rao (2005) performed the goodness-of-fit of the commonly used probability distributions, LP3, GEV, LN3, and PT3, to the regions defined by Sirinivas and Rao (2003). This was discussed in Chapter 2. Their results indicated that GEV and LN3 are better than others in fitting the probability distributions. At a certain significance level, many distributions satisfy the hypothesis and it is not easy to pick up a unique "best" distribution. The results are similar to those in L-moment ratio diagrams. Figure 4.1.1 shows that the data are scattered around theoretical curves, none of them falling on a single curve. The root-mean-square-error (RMSE) values from the L-moment ratio diagram shown in Figures 4.1.2 and Figure 4.1.3 lead to a similar conclusion. 

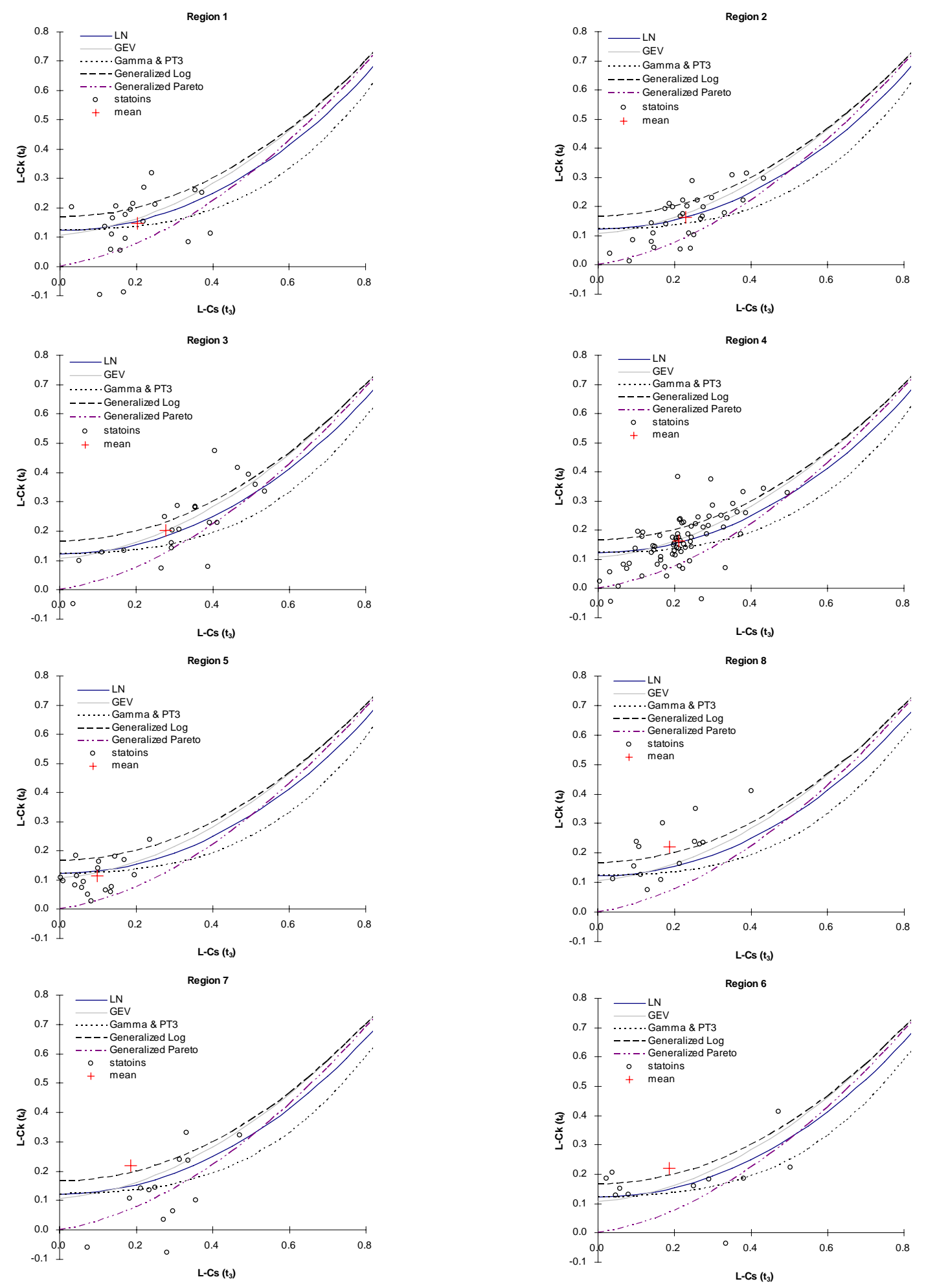

Figure 4.1.1. LCs-LCK moment ratio diagram for the study regions. 


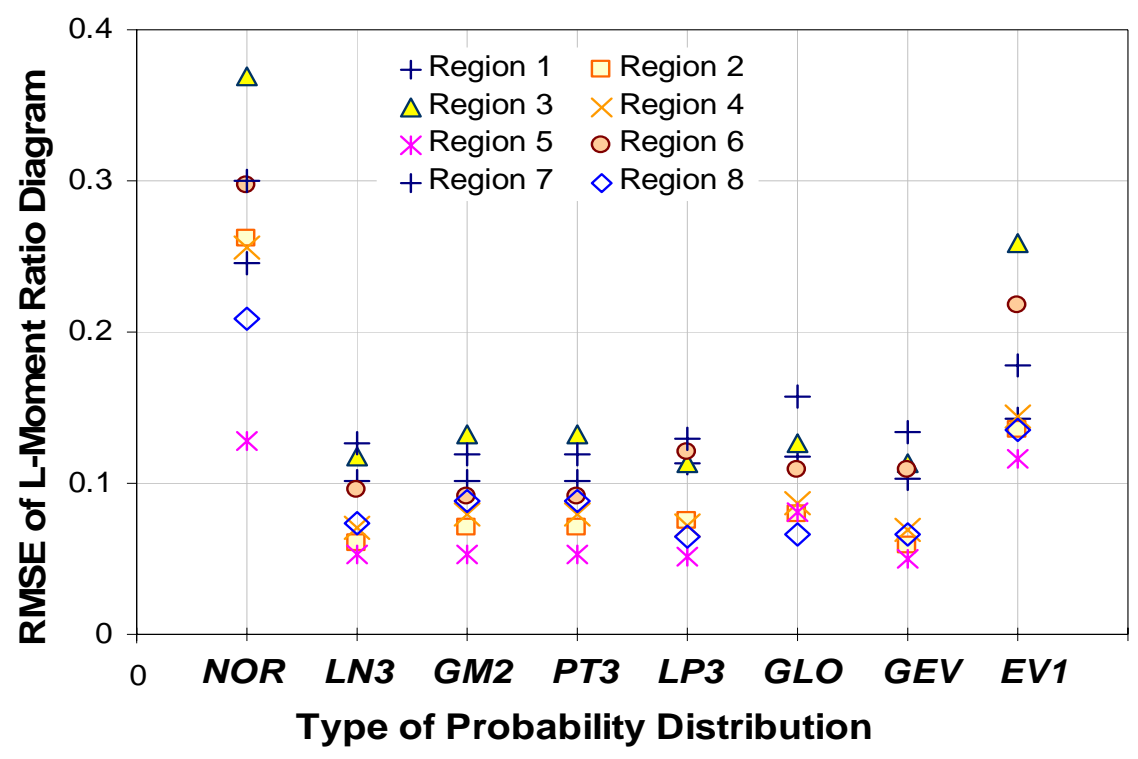

Figure 4.1.2. RMSE of L-Moment ratio diagram comparison for different distributions.

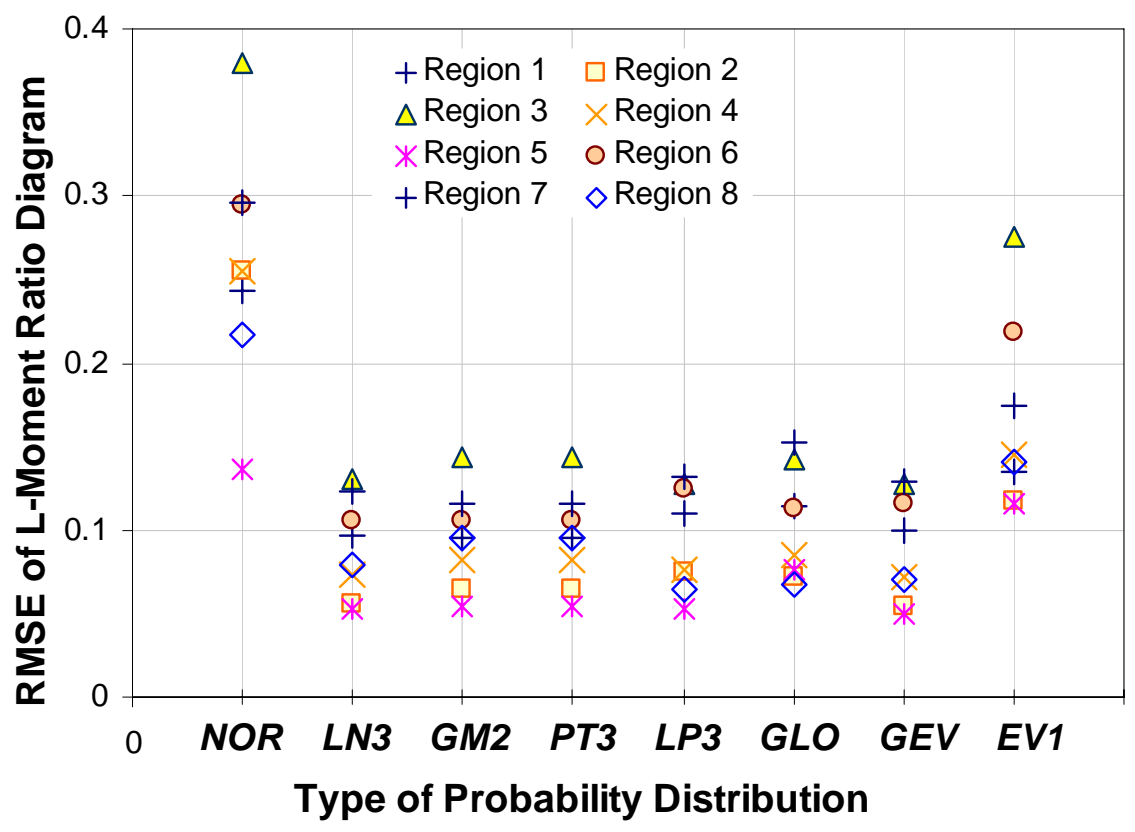

Figure 4.1.3. RMSE of L-Moment ratio diagram comparison of the $75 \%$ of data for different distributions. 


\subsection{Regional Index Flood Method Based on L-Moments}

\subsubsection{Introduction}

The basic idea behind the index flood method, which has been in use for a long time (Dalrymple, (1960)), is that the distributions of floods at different sites in a homogeneous region are similar except for an index-flood parameter. This index flood parameter reflects the important physiographic and meteorologic characteristics of a watershed. The L-moment based index flood method was proposed by Landwehr, Matalas and Wallis and popularized by Wallis and others (Hosking et al. (1985), Wallis (1980), Wallis and Wood (1985)). An important factor in the success of the index flood method is that data from hydrologically similar basins are used (Lettenmaier et al., (1987)).

Regional index flood methods based on probability weighted moments and L-moments have been studied, generally with Generalized Extreme Value (GEV) or Wakeby distributions (Hosking and Wallis (1988), Jin and Stedinger (1989), Landwehr et al. (1987), Potter and Lattenmaeir (1990), Wallis and Wood (1985)). These results, especially with GEV distribution have been demonstrated to be robust. They have been claimed to be more accurate than other procedures based on two or more parameters and short records. This assertion will be tested in this chapter.

\subsubsection{Regional L-moment Method}

Assume that there are $\mathrm{K}$ sites in a region with annual maximum flow records $\left[x_{t}(k)\right.$, $\left.t=1,2, \ldots, n_{k}\right]$ and $k=1,2, \ldots, K$. The first three L-moment estimators $\hat{\lambda}_{1}(k), \hat{\lambda}_{2}(k)$, and $\hat{\lambda}_{3}(k)$ are computed by using the unbiased probability weighted moment (PWM) estimators. The regional 
average of the normalized L-moments of orders 2 and 3 are computed by using equation 4.2.1 and the $1^{\text {st }}$ order normalized L-moment is 1.0 .

$$
\lambda_{r}^{R}=\frac{\sum_{k=1}^{K} w_{k}\left[\hat{\lambda}_{r}(k) / \hat{\lambda}_{1}(k)\right]}{\sum_{k=1}^{K} w_{k}}, \quad r=2,3
$$

In equation 4.2.1, $w_{k}$ are the weights. A simple choice for $w_{k}$ is $N_{k}$ where $N_{k}$ is the number of observations at site $k$. The weighting parameter $w_{k}$ may depend on the heterogeneity of a region (Tasker and Stedinger $(1986,1989))$ and some modification might be required. The normalized parameters for different probability distributions can be calculated by probability weighted moment method based on the first three normalized L-moments. For various recurrence intervals, the quantiles $\hat{x}_{p}^{R}$ of the normalized regional distribution are estimated. The mean of annual maximum flood series is generally used as the index flood. Hence, the estimator of the $100 \mathrm{p}$ percentile of the flood distribution $\hat{x}_{p}(k)$ at any site $k$ is given by equation 4.2.2.

$$
\hat{x}_{p}(k)=\hat{\lambda}_{1}^{k} \hat{x}_{p}^{R}
$$

where $\hat{\lambda}_{1}^{k}$ is the mean for site $k$.

Since $\hat{\lambda}_{1}^{k}$ is the regressor, the confidence limit for the regional L-moment quantile estimate can be calculated by equation 4.2.3.

$$
C L=\hat{x}_{i}(k) \pm t_{\alpha / 2, N-2} \sqrt{\operatorname{MSE}\left(\frac{1}{N}+\frac{\left(\lambda_{i}-\bar{\lambda}\right)^{2}}{S_{\lambda \lambda}}\right)}
$$

Where $\mathrm{N}$ is the total number of observations of the annual peak flow, $\bar{\lambda}$ is the average of $\lambda_{i}^{k}$ values, $S_{\lambda \lambda}$ is the sum of square of $\lambda_{i}^{k}$, MSE is the mean square of the residuals, $\lambda_{i}$ is any 
possible value of $\lambda$ and $\hat{x}_{i}(k)$ is the predicted value of $x$ at $\lambda_{i} . t_{\alpha / 2, N-2}$ is the value of the student's t-distribution for a $100(1-\alpha)$ percent of confidence interval with $\mathrm{N}-2$ degrees of freedom.

An advantage of using the L-moment method is that the $\hat{x}_{p}^{R}$ is estimated directly by using the best distribution for a region. The results about the best distribution for a region are used to estimate $\hat{x}_{p}^{R}$. The importance of using data from a homogeneous region for this analysis is stressed by Lattenmaier et al. (1987). One of the important variables which must be estimated for ungaged locations is $\hat{\lambda}_{1}^{k}$. The usual practice is to estimate this variable by relating it to other variables which are easily available.

\subsubsection{At-site and regional parameter estimation}

The mathematical derivations or numerical approximations for six candidate distributions based on method of moments and probability weighted moments (Rao, A.R. and K.H. Hamed, 2000) are used for parameter estimation. First, for the annual maximum streamflow data at each site, the conventional moments (mean, standard deviation, skewness and kurtosis) and Lmoments $\left(l_{1}, l_{2}, l_{3}, l_{4}, t=l_{2} / l_{1}, t_{3}=l_{3} / l_{2}, t_{4}=l_{4} / l_{2}\right)$ are obtained. These are key statistics for parameter estimation. Once these parameters are calculated, the quantile estimates are calculated for recurrence intervals: $2,5,10,20,25,50,100$, and 200 years.

Following the study approach described previously, the regional average normalized Lmoments can be calculated from the estimates at all sites. A region yields only one set of normalized L-moments, and hence a unique set of parameters is produced. The normalized quantiles for seven distributions with eight different recurrence intervals are summarized in 
Table 4.2.1. Hence, the flood estimate of each site is calculated by multiplying the normalized regional quantile with the at-site first L-moment $\left(l_{1}\right)$.

An estimate of the precision of regional flood quantiles is of interest. It can be evaluated by the variance $v^{2}$, which is the difference between the actual normalized quantiles $x_{p}^{s}$ for different sites in a region and the average regional estimator $x_{p}{ }^{R}$. It is a measure of the heterogeneity of a region. The variance of $\hat{x}_{p}$ is given by equation (4.2.4).

$$
v^{2}=\operatorname{var}\left(\hat{x}_{p}\right)=E\left[\hat{\lambda}_{1} \hat{x}_{p}^{R}-\lambda_{1} \tilde{x}_{p}^{s}\right]^{2}
$$

Higher variance $v^{2}$ refers to high variability within the region and smaller variance indicates strong homogeneity within a region.

The results for Regions 1 8 defined by Knipe and Rao (2004) are given in Table 4.2.1. When GLS regression is used, the regressions in Region 7 and Region 8 do not yield good results. Hence, the region refined by Srinivas and Rao (2003) was considered. Region 1 and Region 7 (by Knipe and Rao, 2004) are merged as one region, which is the Region 1 defined by Srinivas and Rao (2003). Region 5 and Region 8 are merged as one region, which is the Region 5 defined by Srinivas and Rao. The normalized regional quantile estimates of these two regions are listed in Table 4.2.3.

An example of the at-site quantile estimates against the regional quantiles estimates is shown in Fig. 4.2.1. The goodness-of-fit can be observed and the results of GEV, PTIII and LNIII are closely approaching 45 degree line. Log-Pearson type three (LPIII) and two-parameter Gamma distribution are the worst two distributions from this analysis. 
Table 4.2.1. Normalized regional quantile estimates.

\begin{tabular}{|c|c|c|c|c|c|c|c|c|}
\hline & $\mathrm{T}$ (year) & LN3 & G2 & PT3 & LP3 & GEV & GLO & LOG \\
\hline \multirow[t]{8}{*}{ Region 1} & 2 & 0.9098 & 0.8478 & 0.9088 & 1.0036 & 0.6319 & 0.9209 & 1.0000 \\
\hline & 5 & 1.3367 & 1.7612 & 1.3469 & 1.0482 & 1.0522 & 1.3046 & 1.3566 \\
\hline & 10 & 1.6257 & 2.3350 & 1.6353 & 1.0696 & 1.3418 & 1.5809 & 1.5652 \\
\hline & 20 & 1.9066 & 2.8622 & 1.9069 & 1.0863 & 1.6286 & 1.8761 & 1.7574 \\
\hline & 25 & 1.9966 & 3.0252 & 1.9920 & 1.0910 & 1.7214 & 1.9774 & 1.8175 \\
\hline & 50 & 2.2767 & 3.5163 & 2.2513 & 1.1041 & 2.0131 & 2.3162 & 2.0011 \\
\hline & 100 & 2.5599 & 3.9897 & 2.5049 & 1.1153 & 2.3114 & 2.6984 & 2.1821 \\
\hline & 200 & 2.8481 & 4.4501 & 2.7545 & 1.1252 & 2.6177 & 3.1320 & 2.3617 \\
\hline \multirow[t]{8}{*}{ Region 2} & 2 & 0.8761 & 0.8298 & 0.8739 & 1.0023 & 0.5716 & 0.8916 & 1.0000 \\
\hline & 5 & 1.3556 & 1.7468 & 1.3737 & 1.0531 & 1.0362 & 1.3200 & 1.3979 \\
\hline & 10 & 1.7013 & 2.3349 & 1.7194 & 1.0785 & 1.3788 & 1.6438 & 1.6306 \\
\hline & 20 & 2.0512 & 2.8814 & 2.0538 & 1.0988 & 1.7363 & 2.0024 & 1.8451 \\
\hline & 25 & 2.1658 & 3.0514 & 2.1600 & 1.1046 & 1.8561 & 2.1280 & 1.9121 \\
\hline & 50 & 2.5305 & 3.5663 & 2.4871 & 1.1209 & 2.2452 & 2.5580 & 2.1169 \\
\hline & 100 & 2.9100 & 4.0658 & 2.8116 & 1.1353 & 2.6638 & 3.0587 & 2.3188 \\
\hline & 200 & 3.3066 & 4.5544 & 3.1350 & 1.1481 & 3.1156 & 3.6453 & 2.5192 \\
\hline \multirow[t]{8}{*}{ Region 3} & 2 & 0.8456 & 0.8257 & 0.8409 & 0.9989 & 0.4719 & 0.8656 & 1.0000 \\
\hline & 5 & 1.3352 & 1.7433 & 1.3635 & 1.0614 & 0.9369 & 1.2999 & 1.4074 \\
\hline & 10 & 1.7163 & 2.3347 & 1.7477 & 1.0947 & 1.3075 & 1.6479 & 1.6458 \\
\hline & 20 & 2.1217 & 2.8857 & 2.1306 & 1.1226 & 1.7187 & 2.0497 & 1.8654 \\
\hline & 25 & 2.2585 & 3.0573 & 2.2541 & 1.1307 & 1.8619 & 2.1942 & 1.9340 \\
\hline & 50 & 2.7046 & 3.5777 & 2.6393 & 1.1543 & 2.3458 & 2.7019 & 2.1438 \\
\hline & 100 & 3.1859 & 4.0835 & 3.0276 & 1.1756 & 2.8976 & 3.3163 & 2.3505 \\
\hline & 200 & 3.7055 & 4.5787 & 3.4195 & 1.1954 & 3.5287 & 4.0638 & 2.5557 \\
\hline \multirow[t]{8}{*}{ Region 4} & 2 & 0.8824 & 0.8250 & 0.8808 & 1.0040 & 0.6083 & 0.8964 & 1.0000 \\
\hline & 5 & 1.3748 & 1.7426 & 1.3903 & 1.0593 & 1.0885 & 1.3376 & 1.4092 \\
\hline & 10 & 1.7204 & 2.3346 & 1.7355 & 1.0859 & 1.4328 & 1.6648 & 1.6486 \\
\hline & 20 & 2.0642 & 2.8865 & 2.0657 & 1.1069 & 1.7843 & 2.0222 & 1.8691 \\
\hline & 25 & 2.1758 & 3.0584 & 2.1700 & 1.1128 & 1.9004 & 2.1464 & 1.9381 \\
\hline & 50 & 2.5276 & 3.5798 & 2.4898 & 1.1293 & 2.2724 & 2.5678 & 2.1488 \\
\hline & 100 & 2.8893 & 4.0867 & 2.8052 & 1.1435 & 2.6643 & 3.0525 & 2.3564 \\
\hline & 200 & 3.2630 & 4.5832 & 3.1179 & 1.1561 & 3.0785 & 3.6133 & 2.5624 \\
\hline
\end{tabular}


Table 4.2.1. Normalized regional quantile estimates (Cont.)

\begin{tabular}{|c|c|c|c|c|c|c|c|c|}
\hline & $\mathrm{T}$ (year) & LN3 & G2 & PT3 & LP3 & GEV & GLO & LOG \\
\hline \multirow[t]{8}{*}{ Region 5} & 2 & 0.9578 & 0.8657 & 0.9576 & 1.0061 & 0.7422 & 0.9623 & 1.0000 \\
\hline & 5 & 1.3213 & 1.7747 & 1.3235 & 1.0510 & 1.1097 & 1.2938 & 1.3144 \\
\hline & 10 & 1.5387 & 2.3336 & 1.5406 & 1.0713 & 1.3294 & 1.5106 & 1.4983 \\
\hline & 20 & 1.7340 & 2.8411 & 1.7337 & 1.0865 & 1.5242 & 1.7268 & 1.6678 \\
\hline & 25 & 1.7938 & 2.9971 & 1.7925 & 1.0907 & 1.5829 & 1.7979 & 1.7208 \\
\hline & 50 & 1.9725 & 3.4644 & 1.9668 & 1.1019 & 1.7550 & 2.0257 & 1.8827 \\
\hline & 100 & 2.1433 & 3.9118 & 2.1317 & 1.1113 & 1.9135 & 2.2670 & 2.0422 \\
\hline & 200 & 2.3084 & 4.3443 & 2.2894 & 1.1193 & 2.0599 & 2.5242 & 2.2006 \\
\hline \multirow[t]{8}{*}{ Region 6} & 2 & 0.9275 & 0.8831 & 0.9267 & 1.0017 & 0.5879 & 0.9538 & 1.0000 \\
\hline & 5 & 1.2558 & 1.7867 & 1.2645 & 1.0456 & 0.9097 & 1.2459 & 1.2737 \\
\hline & 10 & 1.4809 & 2.3309 & 1.4891 & 1.0677 & 1.1348 & 1.4458 & 1.4338 \\
\hline & 20 & 1.7014 & 2.8196 & 1.7018 & 1.0854 & 1.3600 & 1.6519 & 1.5813 \\
\hline & 25 & 1.7723 & 2.9688 & 1.7686 & 1.0904 & 1.4334 & 1.7210 & 1.6274 \\
\hline & 50 & 1.9940 & 3.4136 & 1.9727 & 1.1048 & 1.6657 & 1.9472 & 1.7684 \\
\hline & 100 & 2.2195 & 3.8366 & 2.1728 & 1.1174 & 1.9057 & 2.1940 & 1.9072 \\
\hline & 200 & 2.4502 & 4.2430 & 2.3703 & 1.1288 & 2.1545 & 2.4650 & 2.0450 \\
\hline \multirow[t]{8}{*}{ Region 7} & 2 & 0.8562 & 0.8262 & 0.8527 & 0.9966 & 0.5123 & 0.8713 & 1.0000 \\
\hline & 5 & 1.3460 & 1.7436 & 1.3704 & 1.0711 & 0.9811 & 1.3060 & 1.4065 \\
\hline & 10 & 1.7163 & 2.3347 & 1.7422 & 1.1121 & 1.3440 & 1.6496 & 1.6444 \\
\hline & 20 & 2.1027 & 2.8853 & 2.1087 & 1.1470 & 1.7376 & 2.0425 & 1.8635 \\
\hline & 25 & 2.2316 & 3.0568 & 2.2262 & 1.1573 & 1.8726 & 2.1830 & 1.9320 \\
\hline & 50 & 2.6482 & 3.5767 & 2.5911 & 1.1874 & 2.3224 & 2.6733 & 2.1413 \\
\hline & 100 & 3.0915 & 4.0818 & 2.9567 & 1.2150 & 2.8243 & 3.2614 & 2.3476 \\
\hline & 200 & 3.5640 & 4.5765 & 3.3240 & 1.2407 & 3.3859 & 3.9705 & 2.5523 \\
\hline \multirow[t]{8}{*}{ Region 8} & 2 & 0.9396 & 0.8722 & 0.9392 & 1.0031 & 0.6683 & 0.9477 & 1.0000 \\
\hline & 5 & 1.2937 & 1.7793 & 1.2989 & 1.0449 & 1.0212 & 1.2678 & 1.2992 \\
\hline & 10 & 1.5207 & 2.3328 & 1.5253 & 1.0651 & 1.2500 & 1.4880 & 1.4742 \\
\hline & 20 & 1.7339 & 2.8332 & 1.7336 & 1.0808 & 1.4662 & 1.7159 & 1.6355 \\
\hline & 25 & 1.8008 & 2.9866 & 1.7980 & 1.0853 & 1.5340 & 1.7925 & 1.6859 \\
\hline & 50 & 2.0055 & 3.4455 & 1.9923 & 1.0977 & 1.7410 & 2.0438 & 1.8399 \\
\hline & 100 & 2.2073 & 3.8837 & 2.1798 & 1.1084 & 1.9435 & 2.3189 & 1.9917 \\
\hline & 200 & 2.4082 & 4.3064 & 2.3622 & 1.1178 & 2.1422 & 2.6221 & 2.1424 \\
\hline
\end{tabular}


An example of the variance of estimation errors in eight regions is shown in Fig. 4.2.2. Pearson Type III (PTIII) has smaller variance than others, especially for longer recurrence intervals. Generalized extreme value (GEV) and three-parameter log-normal distribution (LNIII) yield results which are close to the variance from the PTIII distribution. Overall, GEV, PTIII, and LNIII have good estimates for all regions. Sometimes LNIII cannot yield convergent parameter estimates. The other issue is that although LPIII is not a good candidate for regional index flood estimation, it may have to be used in engineering design. As a result, we will use PTIII, GEV and LPIII for the following analysis.

The $95 \%$ confidence intervals for the regional L-moment flood quantile estimates are shown in Fig. 4.2.3. This is calculated from equation 4.2 .3 based on regression of the mean annual peak discharge, which is the first L-moment. It is plotted in a log-log axis, hence the smaller mean flows look better. A conclusion from Figures 4.2.1 and Figure 4.2.2 is that the LPIII has regional L-moment estimates which are inferior to PTIII and GEV. The confidence intervals for LPIII is much wider than PTIII and GEV from the results in Fig. 4.2.3.

In Table 4.2.3, candidate probability distributions are listed based on the mean-squareerror of L-moment ratio diagram. The order in Table 4.2.3 begins with the one having the minimum MSE. Optimal distributions for regional L-moment estimates are obtained from the variances of regional estimates. It turns out that PTIII, GEV and LNIII are good probability distributions for regional L-moment flood estimates. 
Table 4.2.2. Normalized regional quantile estimates for Region 1 and Region 5 defined by Srinivas and Rao (2003).

\begin{tabular}{|c|c|c|c|c|c|c|c|c|}
\hline & $\mathrm{T}$ (year) & LN3 & G2 & PT3 & LP3 & GEV & GLO & LOG \\
\hline \multirow{8}{*}{$\begin{array}{c}\text { Region } 1 \\
+ \\
\text { Region } 7 \\
= \\
\text { Region } 1\end{array}$} & 2 & 0.8854 & 0.8387 & 0.8836 & 1.0012 & 0.5751 & 0.9529 & 1.0000 \\
\hline & 5 & 1.3401 & 1.7541 & 1.3563 & 1.0595 & 1.0168 & 1.3921 & 1.3775 \\
\hline & 10 & 1.6651 & 2.3351 & 1.6812 & 1.0893 & 1.3395 & 1.7252 & 1.5983 \\
\hline & 20 & 1.9922 & 2.8721 & 1.9943 & 1.1136 & 1.6738 & 2.0948 & 1.8017 \\
\hline & 25 & 2.0991 & 3.0386 & 2.0935 & 1.1206 & 1.7853 & 2.2246 & 1.8653 \\
\hline & 50 & 2.4379 & 3.5416 & 2.3988 & 1.1404 & 2.1459 & 2.6690 & 2.0597 \\
\hline & 100 & 2.7892 & 4.0282 & 2.7012 & 1.1581 & 2.5312 & 3.1876 & 2.2512 \\
\hline & 200 & 3.1549 & 4.5027 & 3.0019 & 1.1741 & 2.9442 & 3.7963 & 2.4413 \\
\hline \multirow{5}{*}{$\begin{array}{c}\text { Region } 5 \\
+ \\
\text { Region } 8 \\
=\end{array}$} & 2 & 0.9473 & 0.8695 & 0.9470 & 1.0041 & 0.7009 & 0.9619 & 1.0000 \\
\hline & 5 & 1.3054 & 1.7775 & 1.3092 & 1.0468 & 1.0601 & 1.2912 & 1.3054 \\
\hline & 10 & 1.5283 & 2.3331 & 1.5316 & 1.0670 & 1.2853 & 1.5140 & 1.4841 \\
\hline & 20 & 1.7337 & 2.8365 & 1.7333 & 1.0825 & 1.4922 & 1.7418 & 1.6487 \\
\hline & 25 & 1.7974 & 2.9909 & 1.7953 & 1.0870 & 1.5560 & 1.8178 & 1.7002 \\
\hline \multirow[t]{3}{*}{ Region 5} & 50 & 1.9905 & 3.4533 & 1.9809 & 1.0990 & 1.7475 & 2.0653 & 1.8574 \\
\hline & 100 & 2.1783 & 3.8952 & 2.1584 & 1.1092 & 1.9300 & 2.3333 & 2.0124 \\
\hline & 200 & 2.3629 & 4.3219 & 2.3301 & 1.1182 & 2.1046 & 2.6254 & 2.1662 \\
\hline
\end{tabular}

Table 4.2.3. Determine the optimal probability distributions for regional L-moment flood estimates of the entire series of data.

\begin{tabular}{ccc}
\hline Region No. & Candidate Probability Distributions & Optimal Distributions for Regional Estimates \\
\hline 1 & PT3, GM2, LN3, GEV, LP3 & PT3, LN3, GEV \\
2 & GEV, LN3, PT3, GM2, GLO & GEV, PT3, LN3 \\
3 & LP3, GEV, LN3, GLO, PT3 & PT3, LN3, GEV \\
4 & GEV, LN3, LP3, PT3, GM2 & PT3, LN3, GEV \\
5 & GEV, LP3, LN3, PT3, GM2 & GEV, PT3, LN3 \\
6 & LN3, PT3, GM2, GLO, GEV & PT3, GEV, LN3 \\
7 & PT3, GM2, LN3, LP3, GEV & PT3, LN3, GEV \\
8 & LP3, GLO, GEV, LN3, PT3 & PT3, LN3, GLO \\
\hline
\end{tabular}

Note: 1). Candidate probability distributions are determined from the mean-square-error of L-moment ratio diagram, and the order is beginning with the one having the minimum MSE. 2). Optimal distributions for regional L-moment flood estimates are obtained from the variances of regional estimates. 

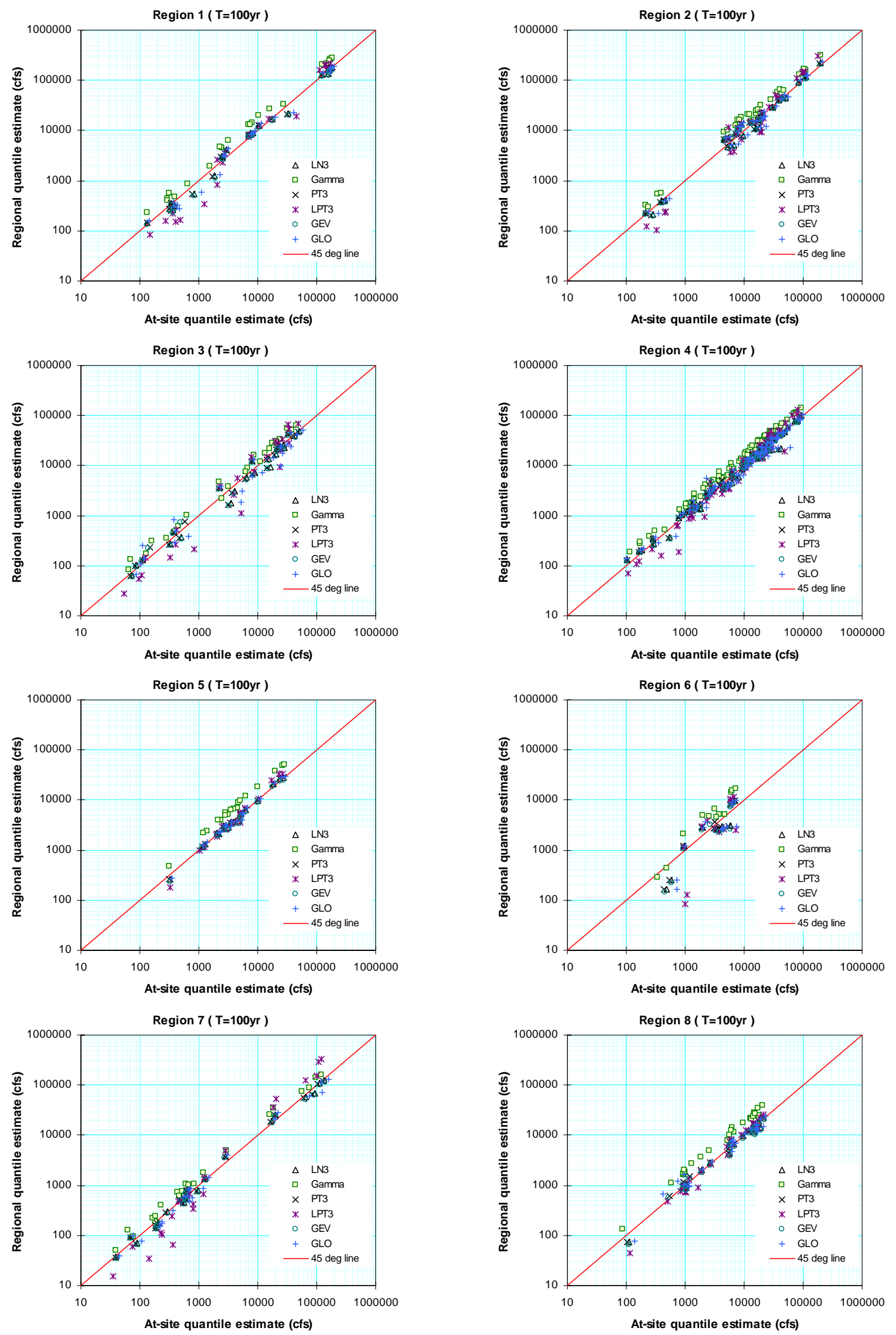

Figure 4.2.1. At-site and regional quantile flood estimates ( $T=100$ year). 

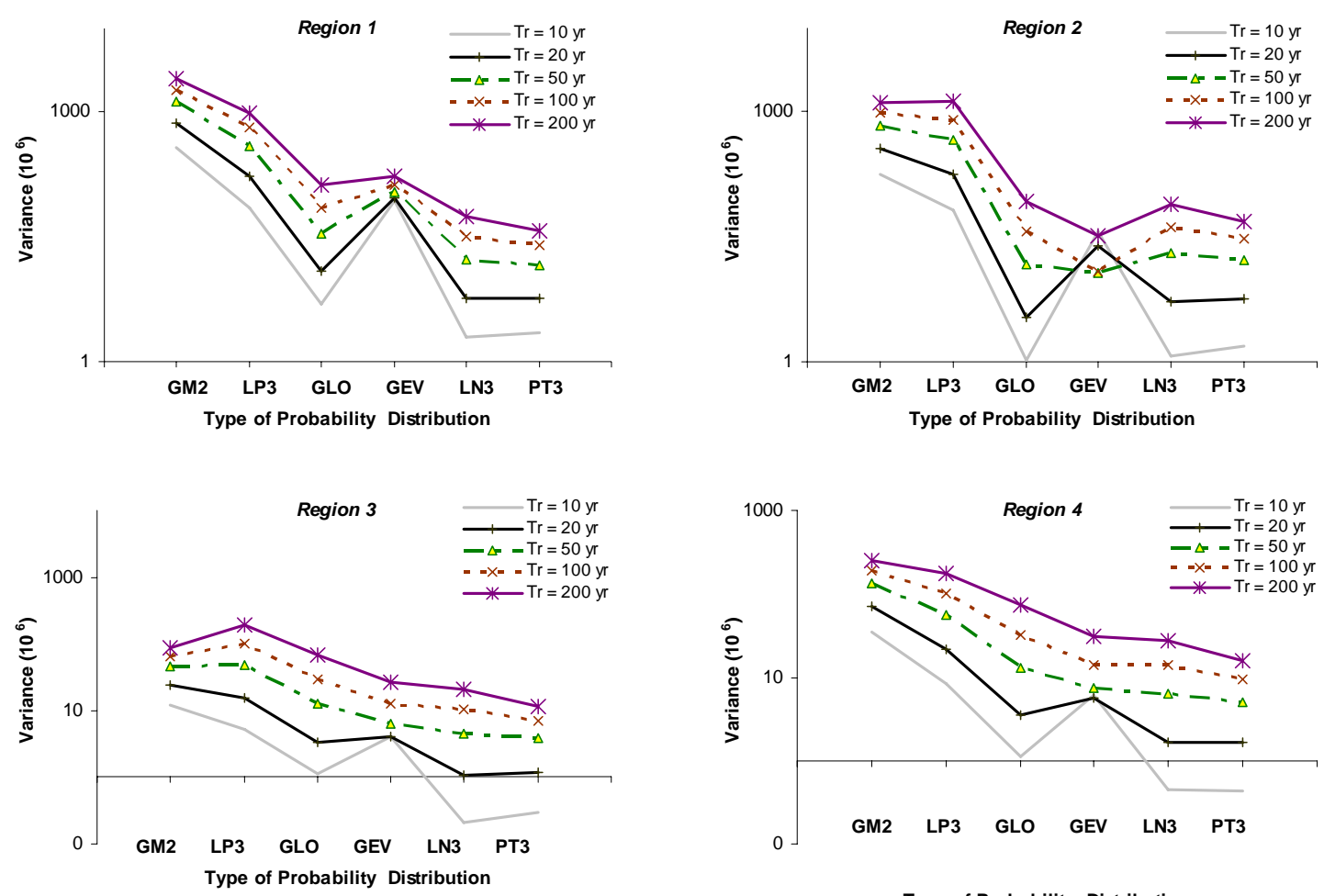

Type of Probability Distribution
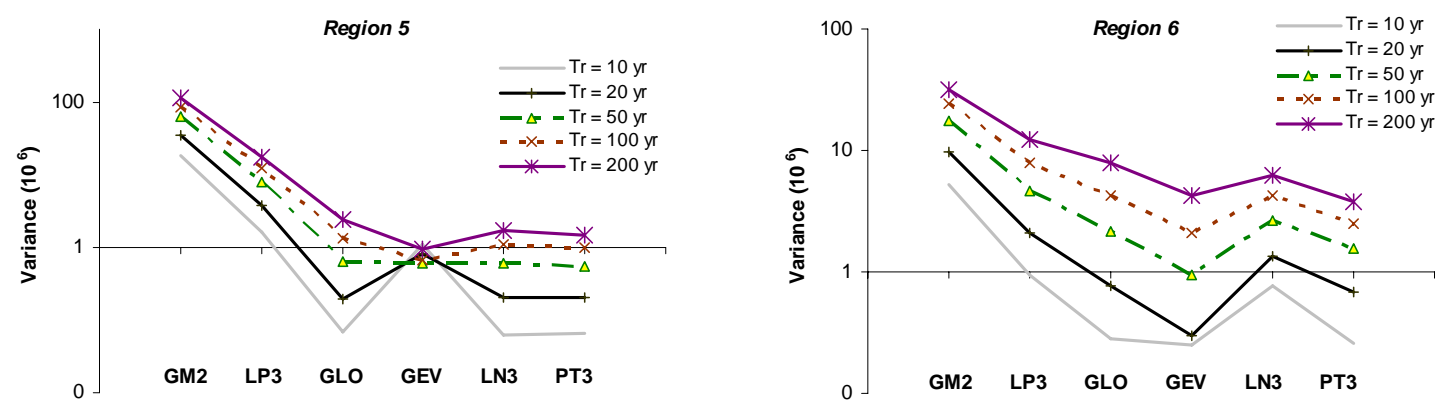

Type of Probability Distribution

Type of Probability Distribution
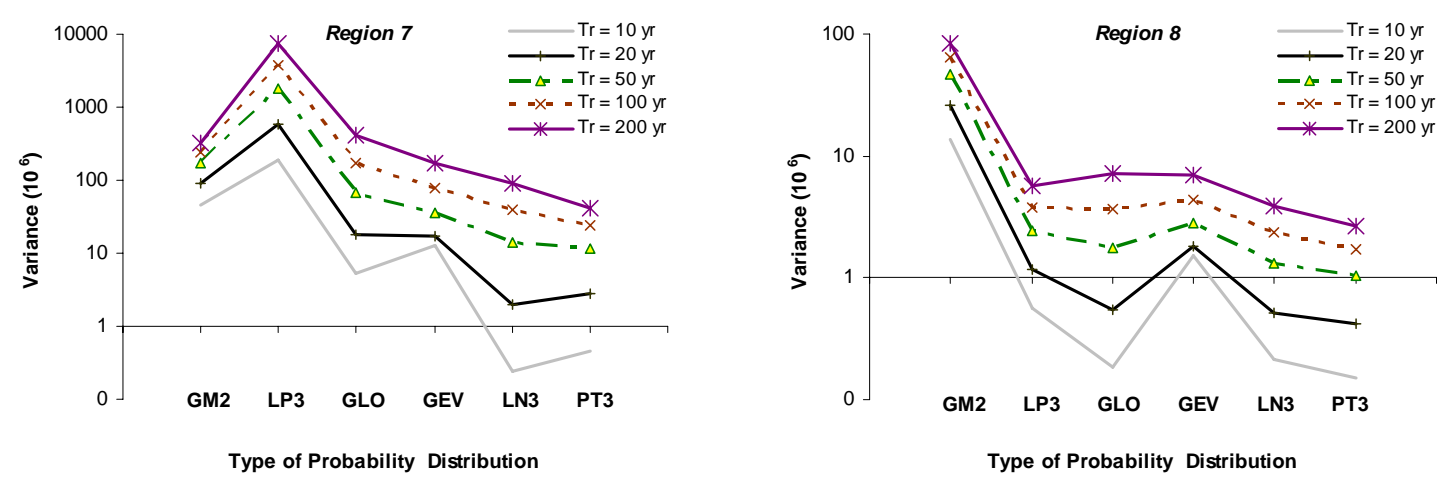

Figure 4.2.2. Variance of the difference between at-site and regional estimates. 

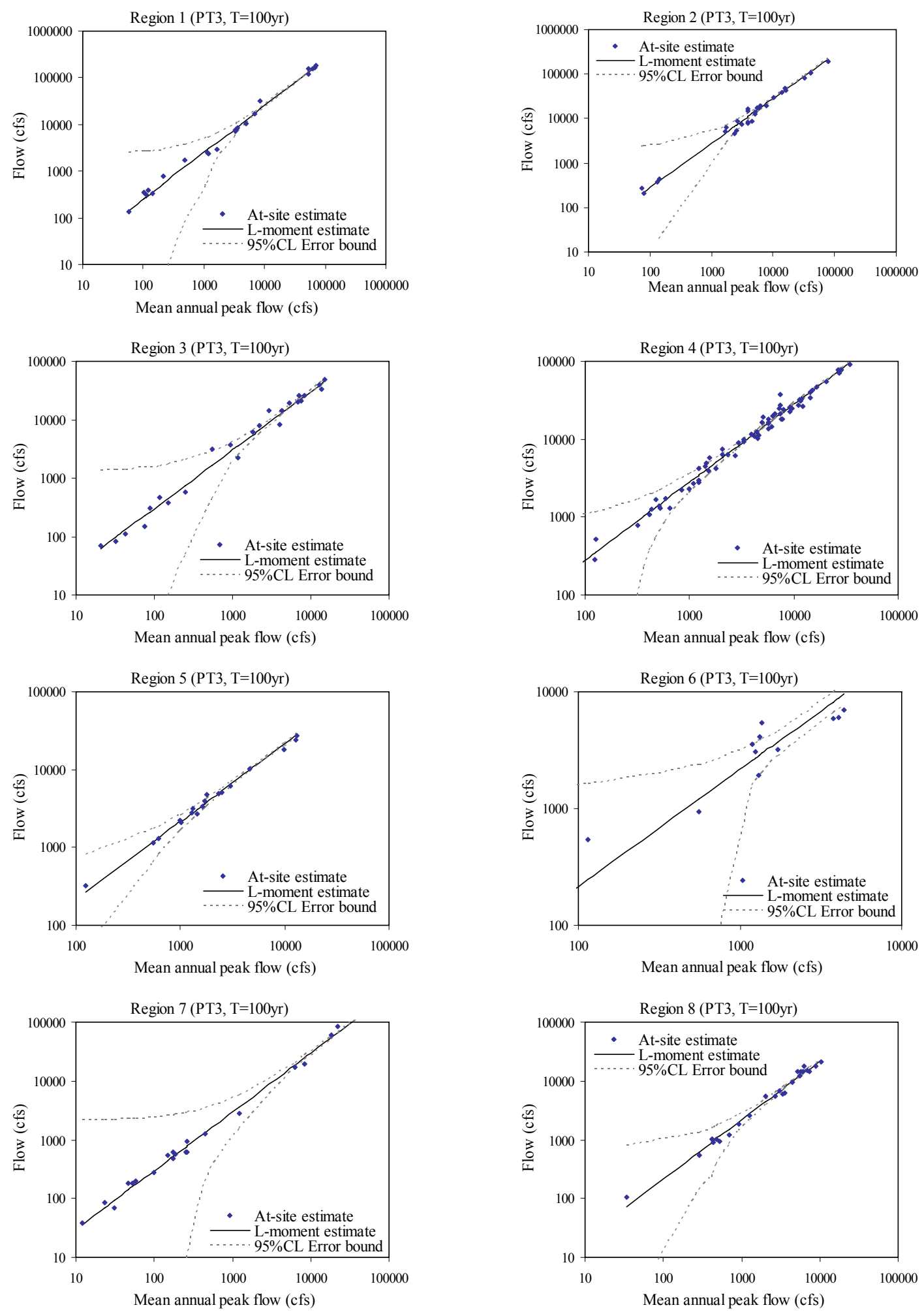

Figure 4.2.3. 95\% confidence intervals for regional PTIII L-moment estimates. 


\section{Regional Regression Analysis}

\subsection{Introduction}

In performing flood frequency analysis for a location of interest, the information about flow measurements is gathered first. However, data may not be available for the location of interest. Regional regression is an idea in which the flood characteristics are related to the geographical or hydrological attributes, which are measurable for any location in a watershed. Generalized least square regression (GLS) discussed in Chapter III is introduced by Stedinger and Tasker (1985) to develop these relationships. It takes the data consistency (lengths of record and correlation) and geographical distance into account. Consequently, the method is physically based. The results from GLS method are presented next.

\subsection{GLS regional regression results}

To investigate the governing hydrological attributes to estimate peak flows the square of the correlation coefficient between each hydrological feature and the at-site quantile estimates are calculated. The result is shown in Table 5.2.1 for PTIII distribution and Table 5.2.2 for GEV distribution. The drainage area (A) and slope (S) are the primary factors. For the secondary factor, wet area $(\% \mathrm{~W})$ is considered. Urbanization factor $(\% \mathrm{U})$ shows smaller correlation and hence it is not taken into further consideration. Therefore, three different models are set up for GLS regional regression. Equation 5.2.1, equation 5.2.2 and equation 5.2.3 are used to fit the quantile floods and hydrological features. The regression parameters, a, b, c, d and squares of the correlation coefficients values are estimated. 
Table 5.2.1. $\mathbf{R}^{2}$ values for the relationship between the individual hydrological attributes and PTIII flood quantile estimates.

\begin{tabular}{|c|c|c|c|c|c|c|}
\hline Region No. & Attriibute & $T=10 y r$ & $T=20 y r$ & $T=50 \mathrm{yr}$ & $T=100 y r$ & $T=200 \mathrm{yr}$ \\
\hline \multirow[t]{4}{*}{ 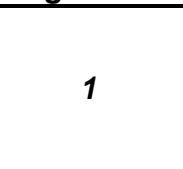 } & Drainage area $\left(\mathrm{mi}^{2}\right)$ & 0.978 & 0.975 & 0.970 & 0.967 & 0.9642 \\
\hline & Slope & 0.856 & 0.850 & 0.841 & 0.836 & 0.8311 \\
\hline & $\% W$ & 0.380 & 0.306 & 0.260 & 0.232 & 0.2108 \\
\hline & $\% U$ & 0.280 & 0.223 & 0.191 & 0.172 & 0.158 \\
\hline \multirow{4}{*}{2} & Drainage area $\left(\mathrm{mi}^{2}\right)$ & 0.935 & 0.935 & 0.933 & 0.931 & 0.9289 \\
\hline & Slope & 0.729 & 0.731 & 0.732 & 0.733 & 0.7331 \\
\hline & $\% W$ & 0.183 & 0.166 & 0.160 & 0.156 & 0.1541 \\
\hline & $\% U$ & 0.288 & 0.230 & 0.196 & 0.175 & 0.160 \\
\hline \multirow{4}{*}{3} & Drainage area $\left(\mathrm{mi}^{2}\right)$ & 0.978 & 0.976 & 0.973 & 0.969 & 0.9662 \\
\hline & Slope & 0.753 & 0.749 & 0.744 & 0.739 & 0.7355 \\
\hline & $\% W$ & 0.096 & 0.067 & 0.054 & 0.046 & 0.0409 \\
\hline & $\% U$ & 0.042 & 0.029 & 0.023 & 0.020 & 0.018 \\
\hline \multirow{4}{*}{4} & Drainage area $\left(\mathrm{mi}^{2}\right)$ & 0.935 & 0.934 & 0.932 & 0.931 & 0.9287 \\
\hline & Slope & 0.397 & 0.394 & 0.390 & 0.388 & 0.3858 \\
\hline & $\% W$ & 0.234 & 0.213 & 0.203 & 0.196 & 0.1923 \\
\hline & $\% U$ & 0.008 & 0.001 & 0.000 & 0.001 & 0.002 \\
\hline \multirow{4}{*}{5} & Drainage area $\left(\mathrm{mi}^{2}\right)$ & 0.939 & 0.938 & 0.937 & 0.936 & 0.9351 \\
\hline & Slope & 0.453 & 0.456 & 0.458 & 0.460 & 0.4609 \\
\hline & $\% W$ & 0.028 & 0.037 & 0.043 & 0.048 & 0.0526 \\
\hline & $\% U$ & 0.150 & 0.165 & 0.170 & 0.173 & 0.175 \\
\hline \multirow{4}{*}{6} & Drainage area $\left(\mathrm{mi}^{2}\right)$ & 0.797 & 0.750 & 0.689 & 0.644 & 0.6005 \\
\hline & Slope & 0.466 & 0.405 & 0.333 & 0.285 & 0.2433 \\
\hline & $\% W$ & 0.074 & 0.091 & 0.112 & 0.127 & 0.141 \\
\hline & $\% U$ & 0.228 & 0.193 & 0.188 & 0.186 & 0.187 \\
\hline \multirow{4}{*}{7} & Drainage area $\left(\mathrm{mi}^{2}\right)$ & 0.907 & 0.903 & 0.899 & 0.896 & 0.8936 \\
\hline & Slope & 0.534 & 0.529 & 0.523 & 0.520 & 0.5166 \\
\hline & $\% W$ & 0.001 & 0.007 & 0.011 & 0.014 & 0.017 \\
\hline & $\% U$ & 0.377 & 0.379 & 0.380 & 0.380 & 0.381 \\
\hline \multirow{4}{*}{8} & Drainage area $\left(\mathrm{mi}^{2}\right)$ & 0.795 & 0.792 & 0.788 & 0.785 & 0.7814 \\
\hline & Slope & 0.674 & 0.677 & 0.680 & 0.682 & 0.6826 \\
\hline & $\% W$ & 0.000 & 0.003 & 0.007 & 0.009 & 0.0115 \\
\hline & $\% U$ & 0.005 & 0.000 & 0.002 & 0.006 & 0.010 \\
\hline
\end{tabular}


Table 5.2.2. $\mathrm{R}^{2}$ values for the relationship between the individual hydrological attributes and GEV flood quantile estimates.

\begin{tabular}{|c|c|c|c|c|c|c|}
\hline Region No. & Attriibute & $T=10 y r$ & $T=20 y r$ & $T=50 \mathrm{yr}$ & $T=100 y r$ & $T=200 y r$ \\
\hline \multirow{4}{*}{1} & Drainage area $\left(\mathrm{mi}^{2}\right)$ & 0.982 & 0.978 & 0.971 & 0.964 & 0.956 \\
\hline & Slope & 0.865 & 0.856 & 0.842 & 0.831 & 0.8175 \\
\hline & $\% W$ & 0.389 & 0.311 & 0.260 & 0.227 & 0.2007 \\
\hline & $\% U$ & 0.284 & 0.226 & 0.191 & 0.169 & 0.153 \\
\hline \multirow{4}{*}{2} & Drainage area $\left(\mathrm{mi}^{2}\right)$ & 0.935 & 0.935 & 0.933 & 0.929 & 0.923 \\
\hline & Slope & 0.723 & 0.728 & 0.732 & 0.733 & 0.7328 \\
\hline & $\% W$ & 0.177 & 0.162 & 0.159 & 0.159 & 0.1602 \\
\hline & $\% U$ & 0.296 & 0.235 & 0.197 & 0.172 & 0.153 \\
\hline \multirow{4}{*}{3} & Drainage area $\left(\mathrm{mi}^{2}\right)$ & 0.975 & 0.978 & 0.974 & 0.967 & 0.9563 \\
\hline & Slope & 0.753 & 0.753 & 0.748 & 0.740 & 0.7298 \\
\hline & $\% W$ & 0.101 & 0.072 & 0.056 & 0.046 & 0.039 \\
\hline & $\% U$ & 0.044 & 0.031 & 0.025 & 0.021 & 0.018 \\
\hline \multirow{4}{*}{4} & Drainage area $\left(\mathrm{mi}^{2}\right)$ & 0.933 & 0.934 & 0.932 & 0.928 & 0.9221 \\
\hline & Slope & 0.398 & 0.393 & 0.387 & 0.382 & 0.3763 \\
\hline & $\% W$ & 0.226 & 0.207 & 0.201 & 0.198 & 0.1961 \\
\hline & $\% U$ & 0.008 & 0.001 & 0.000 & 0.001 & 0.003 \\
\hline \multirow{4}{*}{5} & Drainage area $\left(\mathrm{mi}^{2}\right)$ & 0.939 & 0.939 & 0.938 & 0.936 & 0.9344 \\
\hline & Slope & 0.453 & 0.456 & 0.459 & 0.462 & 0.4641 \\
\hline & $\% W$ & 0.029 & 0.037 & 0.042 & 0.047 & 0.0498 \\
\hline & $\% U$ & 0.152 & 0.166 & 0.168 & 0.169 & 0.168 \\
\hline \multirow{4}{*}{6} & Drainage area $\left(m i^{2}\right)$ & 0.816 & 0.770 & 0.689 & 0.609 & 0.5126 \\
\hline & Slope & 0.511 & 0.441 & 0.336 & 0.250 & 0.165 \\
\hline & $\% W$ & 0.069 & 0.093 & 0.130 & 0.161 & 0.1931 \\
\hline & $\% U$ & 0.228 & 0.199 & 0.207 & 0.216 & 0.227 \\
\hline \multirow{4}{*}{7} & Drainage area $\left(\mathrm{mi}^{2}\right)$ & 0.911 & 0.906 & 0.899 & 0.894 & 0.8888 \\
\hline & Slope & 0.541 & 0.534 & 0.524 & 0.517 & 0.5089 \\
\hline & $\% W$ & 0.001 & 0.006 & 0.011 & 0.014 & 0.0162 \\
\hline & $\% U$ & 0.375 & 0.377 & 0.379 & 0.381 & 0.383 \\
\hline \multirow{4}{*}{8} & Drainage area $\left(\mathrm{mi}^{2}\right)$ & 0.799 & 0.796 & 0.789 & 0.781 & 0.771 \\
\hline & Slope & 0.673 & 0.677 & 0.681 & 0.682 & 0.6816 \\
\hline & $\% W$ & 0.000 & 0.003 & 0.006 & 0.009 & 0.0119 \\
\hline & $\% U$ & 0.006 & 0.000 & 0.002 & 0.007 & 0.013 \\
\hline
\end{tabular}

Model I: $Q_{T}=a A^{b}$

Model II: $Q_{T}=a A^{b} S^{c}$

Model III: $Q_{T}=a A^{b} S^{c}(1+\% W)^{d}$

The probability distributions used for regional regression are generalized extreme value

(GEV), Pearson type III (PTIII) and log-Pearson type III (LPIII). GEV and PTIII distributions fit 
the observed data well and also provide stable results in regional flood index evaluation. Hence they are used further in the analysis. LPIII distribution is used because it may be required to be used in engineering design. However, from the previous analysis, it is not a good distribution to estimate regional flood values and this aspect should be kept in mind.

The coefficients calculated by the GLS method are summarized in Table 5.2.3 for PTIII distribution, Table 5.2.4 for GEV distribution and Table 5.2.5 for LPIII distribution. There are eight sub-tables in each table and they refer to different recurrence intervals of $2,5,10,20,25$, 50, 100 and 200 years. In each sub-table, the coefficients, a, b, c, d and $\mathrm{R}^{2}$, are given for each model and region. The unit for drainage area is square miles, slope is in percentage, wet area is in percentage and the regressed quantile flow is in cubic feet per second (cfs).

Examples of goodness-to-fit of the GLS regression results compared to the at-site quantile estimates are shown in Figure 5.2.1 (for PTIII), Figure 5.2.2 (for GEV), and Figure 5.2.3 (for LPIII) distributions. The model used for each plot is based on the maximum R-square value of the three regression models. They show the best-fitting GLS regional regression results for each distribution for eight hydrological regions. The discharges are plotted against the drainage areas.

We also use the ordinary least square (OLS) regression scheme to fit these data. The results from OLS are shown as dashed lines in Figures 5.2.1 to Figure 5.2.3. Graphically they are very close to the solid lines which are the GLS regression result; however, the result from GLS is slightly better than OLS in goodness-to-fit. Also, the most important part of GLS and its benefit is GLS contains more physical information than OLS, which is simple curve fitting. 
Table 5.2.3. GLS Regression coefficients for the drainage areas and PTIII flood quantile estimates.

\begin{tabular}{|c|c|c|c|c|c|c|}
\hline & Parameter & $a$ & $b$ & $c$ & $d$ & $R^{2}$ \\
\hline & Model I & 149.945 & 0.638 & & & 0.986 \\
\hline \multirow[t]{2}{*}{ Region1 } & Model II & 43.057 & 0.757 & 0.375 & & 0.993 \\
\hline & Model III & 43.529 & 0.756 & 0.375 & -0.001 & 0.993 \\
\hline \multirow{3}{*}{ Region2 } & Model I & 256.676 & 0.594 & & & 0.960 \\
\hline & Model II & 23.476 & 0.847 & 0.569 & & 0.985 \\
\hline & Model III & 71.702 & 0.796 & 0.392 & -0.416 & 0.979 \\
\hline & Model I & 189.646 & 0.736 & & & 0.896 \\
\hline \multirow[t]{2}{*}{ Region3 } & Model II & 40.159 & 0.884 & 0.388 & & 0.921 \\
\hline & Model III & 35.647 & 0.883 & 0.392 & 0.114 & 0.918 \\
\hline \multirow{3}{*}{ Region4 } & Model I & 113.509 & 0.690 & & & 0.902 \\
\hline & Model II & 14.067 & 0.851 & 0.702 & & 0.919 \\
\hline & Model III & 20.346 & 0.868 & 0.677 & -0.361 & 0.936 \\
\hline \multirow{3}{*}{ Region5 } & Model I & 46.832 & 0.706 & & & 0.955 \\
\hline & Model II & 17.384 & 0.814 & 0.409 & & 0.971 \\
\hline & Model III & 24.869 & 0.805 & 0.390 & -0.169 & 0.971 \\
\hline \multirow{3}{*}{ Region6 } & Model I & 55.649 & 0.594 & & & 0.930 \\
\hline & Model II & 11.294 & 0.805 & 0.553 & & 0.951 \\
\hline & Model III & 10.119 & 0.787 & 0.502 & 0.129 & 0.950 \\
\hline \multirow{3}{*}{ Region7 } & Model I & 46.041 & 0.734 & & & 0.975 \\
\hline & Model II & 7.827 & 0.882 & 0.595 & & 0.967 \\
\hline & Model III & 50.878 & 0.885 & 0.505 & -1.163 & 0.980 \\
\hline \multirow{3}{*}{ Region8 } & Model I & 45.274 & 0.704 & & & 0.714 \\
\hline & Model II & 76.124 & 0.649 & -0.173 & & 0.746 \\
\hline & Model III & 113.421 & 0.829 & 0.075 & -0.981 & 0.754 \\
\hline
\end{tabular}

Regional regression for $P T 3$ at $T=5 y r$

\begin{tabular}{lcccccc}
\hline & Parameter & $\boldsymbol{a}$ & $\boldsymbol{b}$ & $\boldsymbol{C}$ & $\boldsymbol{d}$ & $\boldsymbol{R}^{\mathbf{2}}$ \\
\hline \multirow{2}{*}{ Region1 } & Model I & 236.255 & 0.629 & & & 0.986 \\
& Model II & 50.233 & 0.777 & 0.466 & & 0.993 \\
& Model III & 64.427 & 0.773 & 0.428 & -0.116 & 0.994 \\
\hline \multirow{3}{*}{ Region2 } & Model I & 414.755 & 0.587 & & & 0.960 \\
& Model II & 44.143 & 0.824 & 0.534 & & 0.984 \\
& Model III & 109.237 & 0.782 & 0.391 & -0.336 & 0.978 \\
\hline \multirow{3}{*}{ Region3 } & Model I & 314.877 & 0.736 & & & 0.892 \\
& Model II & 55.282 & 0.903 & 0.432 & & 0.934 \\
& Model III & 54.276 & 0.904 & 0.435 & 0.005 & 0.934 \\
\hline \multirow{2}{*}{ Region4 } & Model I & 176.838 & 0.692 & & & 0.907 \\
& Model II & 19.259 & 0.864 & 0.744 & & 0.929 \\
& Model III & 22.998 & 0.873 & 0.734 & -0.182 & 0.937 \\
\hline \multirow{2}{*}{ Region6 } & Model I & 71.136 & 0.689 & & & 0.949 \\
& Model II & 27.561 & 0.792 & 0.388 & & 0.965 \\
& Model III & 34.284 & 0.787 & 0.375 & -0.103 & 0.965 \\
\hline \multirow{2}{*}{ Region7 } & Model I & 146.734 & 0.476 & & & 0.865 \\
& Model II & 18.900 & 0.748 & 0.696 & & 0.902 \\
& Model III & 15.591 & 0.720 & 0.613 & 0.215 & 0.911 \\
\hline \multirow{2}{*}{ Region8 } & Model I & 77.389 & 0.724 & & & 0.980 \\
& Model II & 12.343 & 0.877 & 0.616 & & 0.975 \\
& Model III & 81.087 & 0.882 & 0.526 & -1.173 & 0.987 \\
\hline & Model I & 63.815 & 0.701 & & & 0.705 \\
& Model II & 135.992 & 0.619 & -0.252 & & 0.758 \\
& Model III & 202.458 & 0.798 & -0.005 & -0.976 & 0.750 \\
\hline
\end{tabular}


Table 5.2.3. GLS Regression coefficients for the drainage areas and PTIII flood quantile estimates (Cont.)

\begin{tabular}{|c|c|c|c|c|c|c|}
\hline & Parameter & $a$ & $\boldsymbol{b}$ & c & $d$ & $R^{2}$ \\
\hline & Model I & 296.745 & 0.624 & & & 0.986 \\
\hline \multirow[t]{3}{*}{ Region1 } & Model II & 52.398 & 0.789 & 0.522 & & 0.992 \\
\hline & Model III & 75.826 & 0.783 & 0.465 & -0.171 & 0.993 \\
\hline & Model I & 527.720 & 0.582 & & & 0.960 \\
\hline \multirow[t]{2}{*}{ Region2 } & Model II & 61.815 & 0.809 & 0.512 & & 0.982 \\
\hline & Model III & 135.469 & 0.772 & 0.388 & -0.290 & 0.978 \\
\hline & Model I & 405.407 & 0.739 & & & 0.884 \\
\hline \multirow[t]{3}{*}{ Region3 } & Model II & 63.246 & 0.917 & 0.459 & & 0.935 \\
\hline & Model III & 65.980 & 0.920 & 0.462 & -0.059 & 0.935 \\
\hline & Model I & 217.520 & 0.695 & & & 0.908 \\
\hline \multirow[t]{3}{*}{ Region4 } & Model II & 22.431 & 0.871 & 0.761 & & 0.936 \\
\hline & Model III & 24.246 & 0.876 & 0.758 & -0.087 & 0.939 \\
\hline & Model I & 86.460 & 0.680 & & & 0.946 \\
\hline \multirow[t]{2}{*}{ Region5 } & Model II & 34.119 & 0.782 & 0.377 & & 0.962 \\
\hline & Model III & 39.692 & 0.778 & 0.367 & -0.070 & 0.962 \\
\hline & Model I & 235.108 & 0.420 & & & 0.805 \\
\hline \multirow[t]{3}{*}{ Region6 } & Model II & 21.986 & 0.735 & 0.795 & & 0.860 \\
\hline & Model III & 17.452 & 0.706 & 0.705 & 0.239 & 0.881 \\
\hline & Model I & 97.937 & 0.725 & & & 0.983 \\
\hline \multirow[t]{3}{*}{ Region7 } & Model II & 14.852 & 0.882 & 0.634 & & 0.979 \\
\hline & Model III & 96.520 & 0.888 & 0.544 & -1.170 & 0.991 \\
\hline & Model I & 76.143 & 0.698 & & & 0.700 \\
\hline \multirow[t]{2}{*}{ Region8 } & Model II & 185.371 & 0.602 & -0.297 & & 0.766 \\
\hline & Model III & 275.664 & 0.780 & -0.050 & -0.972 & 0.741 \\
\hline
\end{tabular}

Regional regression for PT3 at T=20yr

\begin{tabular}{lcccccc}
\hline & Parameter & $\boldsymbol{a}$ & $\boldsymbol{b}$ & $\boldsymbol{C}$ & $\boldsymbol{d}$ & $\boldsymbol{R}^{\mathbf{2}}$ \\
\hline Region1 & Model I & 355.567 & 0.620 & & & 0.986 \\
& Model II & 54.017 & 0.799 & 0.568 & & 0.991 \\
& Model III & 85.855 & 0.792 & 0.496 & -0.213 & 0.993 \\
\hline Region2 & Model I & 638.916 & 0.579 & & & 0.960 \\
& Model II & 81.073 & 0.797 & 0.493 & & 0.981 \\
& Model III & 161.046 & 0.764 & 0.385 & -0.253 & 0.977 \\
\hline Region3 & Model I & 494.365 & 0.741 & & & 0.874 \\
& Model II & 69.992 & 0.930 & 0.482 & & 0.932 \\
& Model III & 76.711 & 0.933 & 0.483 & -0.108 & 0.931 \\
\hline Region4 & Model I & 255.045 & 0.697 & & & 0.908 \\
& Model II & 25.322 & 0.876 & 0.772 & & 0.940 \\
& Model III & 25.383 & 0.878 & 0.775 & -0.014 & 0.941 \\
\hline Region5 & Model I & 100.560 & 0.674 & & & 0.944 \\
& Model II & 40.279 & 0.775 & 0.368 & & 0.960 \\
& Model III & 44.488 & 0.771 & 0.360 & -0.043 & 0.960 \\
\hline Region6 & Model I & 339.097 & 0.377 & & & 0.737 \\
& Model II & 23.976 & 0.730 & 0.880 & & 0.819 \\
& Model III & 18.500 & 0.702 & 0.787 & 0.252 & 0.852 \\
\hline Region7 & Model I & 117.108 & 0.727 & & & 0.985 \\
& Model II & 17.006 & 0.888 & 0.649 & & 0.981 \\
& Model III & 108.747 & 0.894 & 0.560 & -1.164 & 0.992 \\
\hline Region8 & Model I & 87.609 & 0.695 & & & 0.694 \\
& Model II & 237.709 & 0.588 & -0.333 & & 0.772 \\
& Model III & 352.797 & 0.765 & -0.087 & -0.967 & 0.730 \\
\hline
\end{tabular}


Table 5.2.3. GLS Regression coefficients for the drainage areas and PTIII flood quantile estimates (Cont.)

\begin{tabular}{lcccccc}
\multicolumn{2}{l}{ Regional regression for PT3 at T=25yr } \\
\hline \multirow{2}{*}{ Region1 } & Parameter & $\boldsymbol{a}$ & $\boldsymbol{b}$ & $\boldsymbol{C}$ & $\boldsymbol{d}$ & $\boldsymbol{R}^{\mathbf{2}}$ \\
& Model I & 374.290 & 0.619 & & & 0.985 \\
& Model II & 54.493 & 0.802 & 0.581 & & 0.991 \\
& Model III & 88.905 & 0.794 & 0.505 & -0.225 & 0.992 \\
\hline \multirow{2}{*}{ Region2 } & Model I & 674.570 & 0.578 & & & 0.960 \\
& Model II & 87.600 & 0.793 & 0.488 & & 0.981 \\
& Model III & 169.212 & 0.762 & 0.385 & -0.242 & 0.977 \\
\hline \multirow{2}{*}{ Region3 } & Model I & 522.800 & 0.742 & & & 0.871 \\
& Model II & 72.001 & 0.933 & 0.488 & & 0.931 \\
& Model III & 80.031 & 0.937 & 0.489 & -0.122 & 0.929 \\
\hline \multirow{2}{*}{ Region4 } & Model I & 266.643 & 0.698 & & & 0.907 \\
& Model II & 26.210 & 0.878 & 0.775 & & 0.941 \\
& Model III & 25.735 & 0.879 & 0.780 & 0.006 & 0.941 \\
\hline \multirow{2}{*}{ Region5 } & Model I & 104.922 & 0.672 & & & 0.943 \\
& Model II & 42.213 & 0.772 & 0.365 & & 0.959 \\
& Model III & 45.949 & 0.769 & 0.357 & -0.035 & 0.959 \\
\hline \multirow{2}{*}{ Region6 } & Model I & 375.840 & 0.365 & & & 0.714 \\
& Model II & 24.475 & 0.729 & 0.905 & & 0.805 \\
& Model III & 18.743 & 0.701 & 0.812 & 0.255 & 0.842 \\
\hline \multirow{2}{*}{ Region7 } & Model I & 123.072 & 0.727 & & & 0.985 \\
& Model II & 17.648 & 0.890 & 0.653 & & 0.981 \\
& Model III & 112.207 & 0.896 & 0.565 & -1.161 & 0.992 \\
\hline & Model I & 91.157 & 0.694 & & & 0.692 \\
& Model II & 255.114 & 0.584 & -0.343 & & 0.774 \\
& Model III & 378.326 & 0.761 & -0.097 & -0.966 & 0.727 \\
\hline
\end{tabular}

\section{Regional regression for $P T 3$ at $T=50 y r$}

\begin{tabular}{lcccccc}
\hline & Parameter & $\boldsymbol{a}$ & $\boldsymbol{b}$ & $\boldsymbol{C}$ & $\boldsymbol{d}$ & $\boldsymbol{R}^{\mathbf{2}}$ \\
\hline Region1 & Model I & 432.021 & 0.615 & & & 0.985 \\
& Model II & 55.905 & 0.810 & 0.617 & & 0.989 \\
& Model III & 97.995 & 0.800 & 0.528 & -0.256 & 0.991 \\
\hline Region2 & Model I & 785.272 & 0.575 & & & 0.960 \\
& Model II & 108.870 & 0.783 & 0.473 & & 0.980 \\
& Model III & 194.494 & 0.755 & 0.382 & -0.213 & 0.976 \\
\hline Region3 & Model I & 610.741 & 0.744 & & & 0.860 \\
& Model II & 77.883 & 0.943 & 0.505 & & 0.925 \\
& Model III & 90.045 & 0.947 & 0.505 & -0.160 & 0.922 \\
\hline Region4 & Model I & 301.516 & 0.700 & & & 0.905 \\
& Model II & 28.869 & 0.882 & 0.783 & & 0.943 \\
& Model III & 26.797 & 0.880 & 0.791 & 0.062 & 0.941 \\
\hline Region5 & Model I & 118.068 & 0.668 & & & 0.941 \\
& Model II & 48.131 & 0.766 & 0.358 & & 0.957 \\
& Model III & 50.312 & 0.764 & 0.350 & -0.012 & 0.956 \\
\hline Region6 & Model I & 500.040 & 0.332 & & & 0.642 \\
& Model II & 25.739 & 0.728 & 0.975 & & 0.767 \\
& Model III & 19.328 & 0.702 & 0.881 & 0.261 & 0.815 \\
\hline Region7 & Model I & 141.101 & 0.730 & & & 0.985 \\
& Model II & 19.528 & 0.895 & 0.665 & & 0.981 \\
& Model III & 121.854 & 0.903 & 0.579 & -1.154 & 0.992 \\
\hline Region8 & Model I & 101.811 & 0.693 & & & 0.686 \\
& Model II & 310.715 & 0.573 & -0.372 & & 0.777 \\
& Model III & 459.468 & 0.749 & -0.126 & -0.961 & 0.717 \\
\hline
\end{tabular}


Table 5.2.3. GLS Regression coefficients for the drainage areas and PTIII flood quantile estimates (Cont.)

\begin{tabular}{lcccccc}
\multicolumn{2}{l}{ Regional regression for $\mathbf{P T 3}$ at $\mathbf{T}=\mathbf{1 0 0} \boldsymbol{y} \boldsymbol{}$} \\
\hline & Parameter & $\boldsymbol{a}$ & $\boldsymbol{b}$ & $\boldsymbol{C}$ & $\boldsymbol{d}$ & $\boldsymbol{R}^{\mathbf{2}}$ \\
\hline Region1 & Model I & 489.317 & 0.613 & & & 0.984 \\
& Model II & 57.265 & 0.817 & 0.648 & & 0.988 \\
& Model III & 106.649 & 0.806 & 0.549 & -0.282 & 0.990 \\
\hline Region2 & Model I & 896.268 & 0.573 & & & 0.959 \\
& Model II & 131.618 & 0.774 & 0.460 & & 0.978 \\
& Model III & 219.760 & 0.750 & 0.380 & -0.187 & 0.975 \\
\hline Region3 & Model I & 698.344 & 0.746 & & & 0.849 \\
& Model II & 83.356 & 0.952 & 0.521 & & 0.919 \\
& Model III & 99.717 & 0.955 & 0.519 & -0.191 & 0.913 \\
\hline Region4 & Model I & 334.991 & 0.702 & & & 0.901 \\
& Model II & 31.407 & 0.886 & 0.789 & & 0.943 \\
& Model III & 27.817 & 0.882 & 0.800 & 0.110 & 0.940 \\
\hline Region5 & Model I & 130.743 & 0.663 & & & 0.939 \\
& Model II & 53.972 & 0.761 & 0.351 & & 0.954 \\
& Model III & 54.480 & 0.758 & 0.343 & 0.008 & 0.954 \\
\hline Region6 & Model I & 639.416 & 0.303 & & & 0.569 \\
& Model II & 26.717 & 0.729 & 1.036 & & 0.732 \\
& Model III & 19.759 & 0.704 & 0.942 & 0.264 & 0.790 \\
\hline Region7 & Model I & 158.534 & 0.733 & & & 0.985 \\
& Model II & 21.273 & 0.901 & 0.676 & & 0.981 \\
& Model III & 130.208 & 0.909 & 0.591 & -1.146 & 0.991 \\
\hline Region8 & Model I & 111.992 & 0.692 & & & 0.679 \\
& Model II & 368.409 & 0.564 & -0.397 & & 0.778 \\
& Model III & 543.001 & 0.739 & -0.152 & -0.956 & 0.707 \\
\hline
\end{tabular}

Regional regression for $P T 3$ at $T=200 y r$

\begin{tabular}{lcccccc}
\hline & Parameter & $\boldsymbol{a}$ & $\boldsymbol{b}$ & $\boldsymbol{C}$ & $\boldsymbol{d}$ & $\boldsymbol{R}^{\mathbf{2}}$ \\
\hline Region1 & Model I & 546.361 & 0.610 & & & 0.983 \\
& Model II & 58.599 & 0.823 & 0.675 & & 0.986 \\
& Model III & 114.985 & 0.810 & 0.566 & -0.304 & 0.989 \\
\hline Region2 & Model I & 1007.864 & 0.570 & & & 0.959 \\
& Model II & 155.814 & 0.766 & 0.448 & & 0.977 \\
& Model III & 245.104 & 0.744 & 0.378 & -0.165 & 0.974 \\
\hline Region3 & Model I & 785.830 & 0.747 & & & 0.838 \\
& Model II & 88.529 & 0.959 & 0.534 & & 0.912 \\
& Model III & 109.137 & 0.962 & 0.531 & -0.218 & 0.905 \\
\hline Region4 & Model I & 367.385 & 0.704 & & & 0.897 \\
& Model II & 33.848 & 0.889 & 0.794 & & 0.942 \\
& Model III & 28.799 & 0.883 & 0.808 & 0.151 & 0.939 \\
\hline Region5 & Model I & 143.074 & 0.660 & & & 0.937 \\
& Model II & 59.790 & 0.756 & 0.344 & & 0.952 \\
& Model III & 58.519 & 0.753 & 0.336 & 0.027 & 0.952 \\
\hline Region6 & Model I & 793.937 & 0.278 & & & 0.500 \\
& Model II & 27.519 & 0.730 & 1.090 & & 0.702 \\
& Model III & 20.111 & 0.706 & 0.997 & 0.266 & 0.768 \\
\hline Region7 & Model I & 175.509 & 0.735 & & & 0.984 \\
& Model II & 22.918 & 0.905 & 0.686 & & 0.980 \\
& Model III & 137.604 & 0.915 & 0.602 & -1.137 & 0.989 \\
\hline Region8 & Model I & 121.778 & 0.691 & & & 0.672 \\
& Model II & 427.940 & 0.556 & -0.419 & & 0.779 \\
& Model III & 628.520 & 0.730 & -0.174 & -0.952 & 0.697 \\
\hline
\end{tabular}



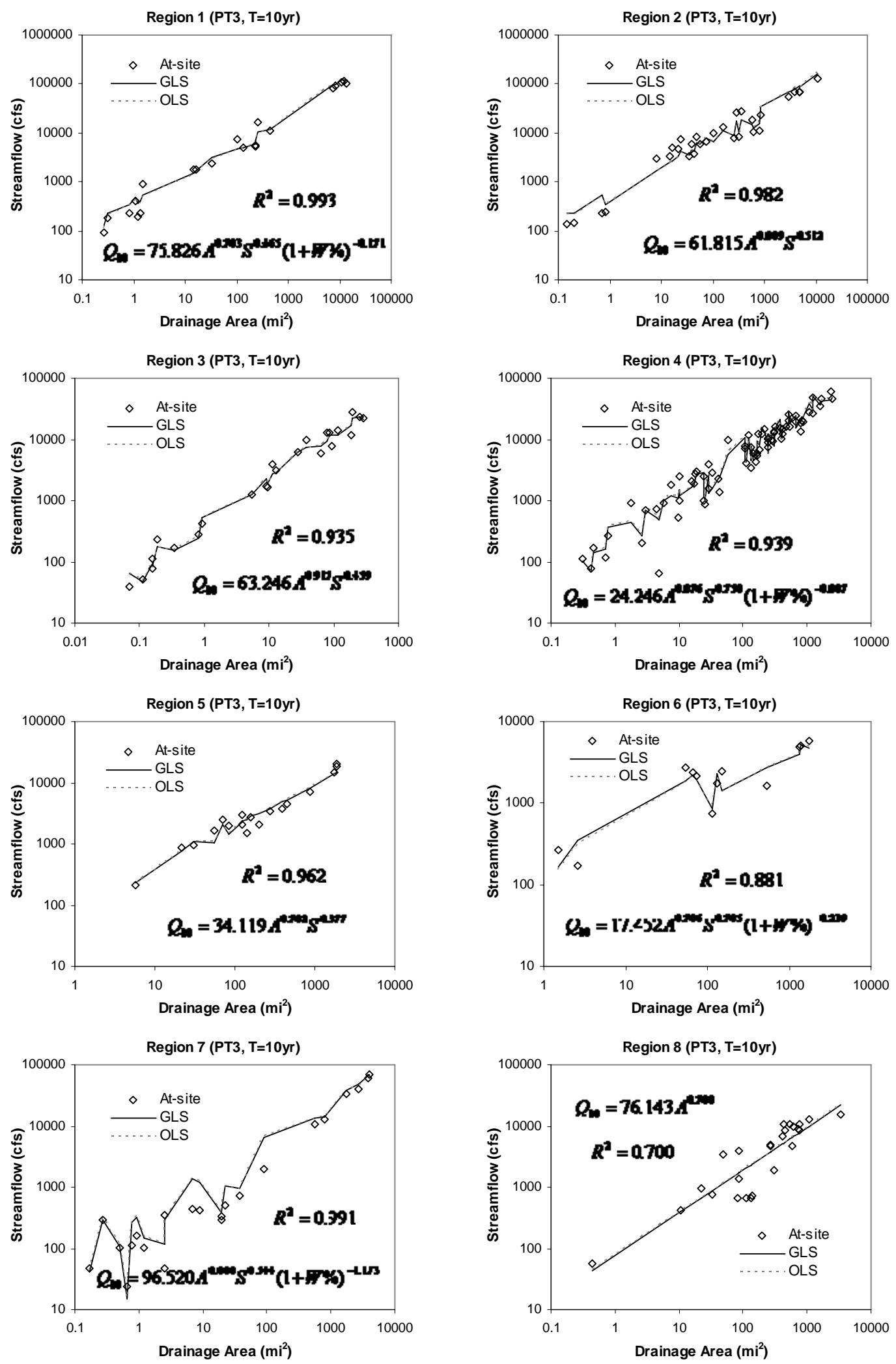

Figure 5.2.1(a). GLS regional regression for PTIII $(T=10$ years) 

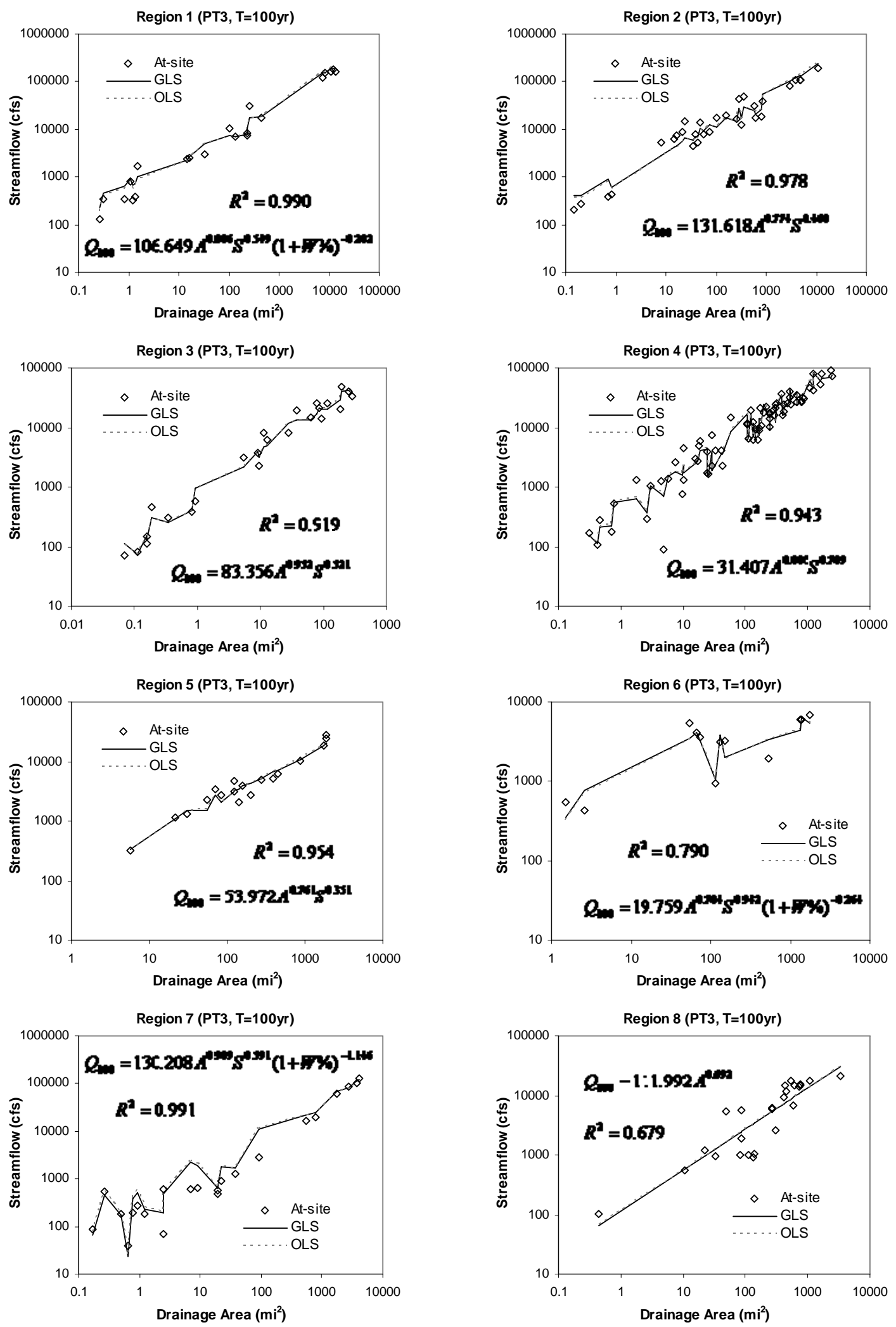

Figure 5.2.1(b). GLS regional regression for PTIII $(T=100$ years) 
Table 5.2.4. GLS Regression coefficients for the drainage areas and GEV flood quantile estimates.

\begin{tabular}{lcccccc}
\multicolumn{2}{l}{ Regional regression for GEV at T=2yr } \\
\hline & Parameter & $\boldsymbol{a}$ & $\boldsymbol{b}$ & $\boldsymbol{C}$ & $\boldsymbol{d}$ & $\boldsymbol{R}^{\mathbf{2}}$ \\
\hline \multirow{3}{*}{ Region1 } & Model I & 140.925 & 0.646 & & & 0.986 \\
& Model II & 47.621 & 0.750 & 0.325 & & 0.992 \\
& Model III & 45.221 & 0.750 & 0.335 & 0.028 & 0.992 \\
\hline \multirow{3}{*}{ Region2 } & Model I & 243.479 & 0.599 & & & 0.960 \\
& Model II & 18.719 & 0.871 & 0.610 & & 0.985 \\
& Model III & 65.081 & 0.814 & 0.413 & -0.464 & 0.978 \\
\hline \multirow{2}{*}{ Region3 } & Model I & 167.474 & 0.728 & & & 0.882 \\
& Model II & 32.504 & 0.884 & 0.410 & & 0.905 \\
& Model III & 25.534 & 0.880 & 0.415 & 0.252 & 0.896 \\
\hline \multirow{2}{*}{ Region4 } & Model I & 111.202 & 0.687 & & & 0.891 \\
& Model II & 15.383 & 0.840 & 0.666 & & 0.903 \\
& Model III & 26.699 & 0.863 & 0.628 & -0.530 & 0.929 \\
\hline \multirow{2}{*}{ Region6 } & Model I & 46.595 & 0.706 & & & 0.955 \\
& Model II & 17.303 & 0.814 & 0.409 & & 0.971 \\
& Model III & 25.007 & 0.805 & 0.389 & -0.174 & 0.971 \\
\hline \multirow{2}{*}{ Region7 } & Model I & 33.428 & 0.676 & & & 0.931 \\
& Model II & 9.398 & 0.840 & 0.480 & & 0.947 \\
& Model III & 7.998 & 0.814 & 0.410 & 0.187 & 0.944 \\
\hline & Model I & 43.693 & 0.734 & & & 0.955 \\
& Model II & 8.200 & 0.874 & 0.561 & & 0.949 \\
& Model III & 51.651 & 0.876 & 0.474 & -1.144 & 0.962 \\
\hline & Model I & 43.710 & 0.710 & & & 0.714 \\
& Model II & 69.677 & 0.660 & -0.156 & & 0.742 \\
& Model III & 103.789 & 0.839 & 0.092 & -0.979 & 0.757 \\
\hline & & & & & &
\end{tabular}

Regional regression for GEV at T=5yr

\begin{tabular}{lcccccc}
\hline & Parameter & $\boldsymbol{a}$ & $\boldsymbol{b}$ & $\boldsymbol{C}$ & $\boldsymbol{d}$ & $\boldsymbol{R}^{\mathbf{2}}$ \\
\hline \multirow{3}{*}{ Region1 } & Model I & 219.915 & 0.637 & & & 0.986 \\
& Model II & 57.278 & 0.766 & 0.404 & & 0.993 \\
& Model III & 67.874 & 0.763 & 0.379 & -0.080 & 0.993 \\
\hline \multirow{3}{*}{ Region2 } & Model I & 387.126 & 0.592 & & & 0.960 \\
& Model II & 35.122 & 0.846 & 0.571 & & 0.984 \\
& Model III & 98.483 & 0.798 & 0.408 & -0.383 & 0.978 \\
\hline \multirow{2}{*}{ Region3 } & Model I & 280.467 & 0.730 & & & 0.887 \\
& Model II & 53.527 & 0.888 & 0.413 & & 0.924 \\
& Model III & 48.053 & 0.887 & 0.416 & 0.107 & 0.922 \\
\hline \multirow{2}{*}{ Region4 } & Model I & 171.392 & 0.690 & & & 0.898 \\
& Model II & 19.863 & 0.856 & 0.725 & & 0.913 \\
& Model III & 27.043 & 0.870 & 0.705 & -0.304 & 0.928 \\
\hline \multirow{2}{*}{ Region6 } & Model I & 70.720 & 0.689 & & & 0.948 \\
& Model II & 27.182 & 0.794 & 0.391 & & 0.965 \\
& Model III & 34.452 & 0.788 & 0.378 & -0.112 & 0.965 \\
\hline \multirow{2}{*}{ Region7 } & Model I & 103.740 & 0.529 & & & 0.887 \\
& Model II & 18.653 & 0.755 & 0.603 & & 0.912 \\
& Model III & 14.859 & 0.721 & 0.509 & 0.255 & 0.918 \\
\hline \multirow{2}{*}{ Region8 } & Model I & 73.201 & 0.721 & & & 0.964 \\
& Model II & 12.901 & 0.866 & 0.582 & & 0.961 \\
& Model III & 83.719 & 0.870 & 0.494 & -1.165 & 0.974 \\
\hline & Model I & 60.632 & 0.708 & & & 0.703 \\
& Model II & 119.005 & 0.635 & -0.225 & & 0.749 \\
& Model III & 177.392 & 0.814 & 0.022 & -0.976 & 0.756 \\
\hline
\end{tabular}


Table 5.2.4. GLS Regression coefficients for the drainage areas and GEV flood quantile estimates (Cont.)

\begin{tabular}{|c|c|c|c|c|c|c|}
\hline & Parameter & $a$ & $b$ & $c$ & $d$ & $R^{2}$ \\
\hline & Model I & 278.174 & 0.631 & & & 0.986 \\
\hline \multirow[t]{2}{*}{ Region1 } & Model II & 58.976 & 0.780 & 0.466 & & 0.993 \\
\hline & Model III & 79.415 & 0.775 & 0.421 & -0.140 & 0.993 \\
\hline \multirow{3}{*}{ Region2 } & Model I & 496.428 & 0.587 & & & 0.960 \\
\hline & Model II & 50.565 & 0.829 & 0.544 & & 0.983 \\
\hline & Model III & 123.245 & 0.787 & 0.403 & -0.330 & 0.977 \\
\hline \multirow{3}{*}{ Region3 } & Model I & 364.046 & 0.736 & & & 0.886 \\
\hline & Model II & 64.232 & 0.902 & 0.431 & & 0.932 \\
\hline & Model III & 61.594 & 0.903 & 0.434 & 0.033 & 0.932 \\
\hline \multirow{3}{*}{ Region4 } & Model I & 211.430 & 0.693 & & & 0.903 \\
\hline & Model II & 22.507 & 0.866 & 0.752 & & 0.922 \\
\hline & Model III & 27.167 & 0.876 & 0.741 & -0.193 & 0.931 \\
\hline \multirow{3}{*}{ Region5 } & Model I & 86.216 & 0.681 & & & 0.945 \\
\hline & Model II & 33.818 & 0.783 & 0.379 & & 0.962 \\
\hline & Model III & 39.903 & 0.779 & 0.369 & -0.077 & 0.962 \\
\hline \multirow{3}{*}{ Region6 } & Model I & 176.101 & 0.463 & & & 0.839 \\
\hline & Model II & 22.526 & 0.735 & 0.710 & & 0.878 \\
\hline & Model III & 16.885 & 0.698 & 0.601 & 0.298 & 0.897 \\
\hline \multirow{3}{*}{ Region7 } & Model I & 93.841 & 0.721 & & & 0.972 \\
\hline & Model II & 15.538 & 0.871 & 0.604 & & 0.969 \\
\hline & Model III & 100.402 & 0.875 & 0.516 & -1.164 & 0.981 \\
\hline \multirow{3}{*}{ Region8 } & Model I & 72.370 & 0.705 & & & 0.699 \\
\hline & Model II & 163.334 & 0.618 & -0.272 & & 0.759 \\
\hline & Model III & 243.387 & 0.795 & -0.025 & -0.972 & 0.749 \\
\hline
\end{tabular}

Regional regression for GEV at $T=20 y r$

\begin{tabular}{lcccccc}
\hline & Parameter & $\boldsymbol{a}$ & $\boldsymbol{b}$ & $\boldsymbol{c}$ & $\boldsymbol{d}$ & $\boldsymbol{R}^{\mathbf{2}}$ \\
\hline Region1 & Model I & 339.463 & 0.626 & & & 0.986 \\
& Model II & 58.344 & 0.794 & 0.530 & & 0.992 \\
& Model III & 88.214 & 0.788 & 0.466 & -0.193 & 0.993 \\
\hline Region2 & Model I & 613.925 & 0.583 & & & 0.960 \\
& Model II & 70.293 & 0.812 & 0.517 & & 0.981 \\
& Model III & 149.811 & 0.776 & 0.397 & -0.279 & 0.977 \\
\hline Region3 & Model I & 453.341 & 0.742 & & & 0.879 \\
& Model II & 73.361 & 0.917 & 0.451 & & 0.934 \\
& Model III & 74.639 & 0.919 & 0.454 & -0.033 & 0.934 \\
\hline Region4 & Model I & 250.053 & 0.697 & & & 0.906 \\
& Model II & 24.820 & 0.876 & 0.774 & & 0.932 \\
& Model III & 26.993 & 0.881 & 0.771 & -0.094 & 0.935 \\
\hline Region5 & Model I & 100.618 & 0.674 & & & 0.943 \\
& Model II & 40.344 & 0.775 & 0.368 & & 0.960 \\
& Model III & 44.761 & 0.771 & 0.359 & -0.045 & 0.959 \\
\hline Region6 & Model I & 275.116 & 0.407 & & & 0.770 \\
& Model II & 24.486 & 0.728 & 0.821 & & 0.835 \\
& Model III & 17.334 & 0.692 & 0.704 & 0.330 & 0.874 \\
\hline Region7 & Model I & 114.570 & 0.723 & & & 0.978 \\
& Model II & 17.687 & 0.879 & 0.628 & & 0.976 \\
& Model III & 112.653 & 0.884 & 0.541 & -1.159 & 0.987 \\
\hline Region8 & Model I & 84.217 & 0.701 & & & 0.694 \\
& Model II & 217.582 & 0.600 & -0.317 & & 0.768 \\
& Model III & 323.533 & 0.776 & -0.071 & -0.967 & 0.736 \\
\hline
\end{tabular}


Table 5.2.4. GLS Regression coefficients for the drainage areas and GEV flood quantile estimates (Cont.)

Regional regression for $G E V$ at $T=25 y r$

\begin{tabular}{|c|c|c|c|c|c|c|}
\hline & Parameter & $a$ & $b$ & c & $d$ & $R^{2}$ \\
\hline & Model I & 360.139 & 0.624 & & & 0.986 \\
\hline \multirow[t]{2}{*}{ Region1 } & Model II & 57.807 & 0.799 & 0.551 & & 0.992 \\
\hline & Model III & 90.587 & 0.792 & 0.481 & -0.209 & 0.993 \\
\hline & Model I & 654.072 & 0.581 & & & 0.960 \\
\hline \multirow[t]{2}{*}{ Region2 } & Model II & 77.818 & 0.806 & 0.508 & & 0.981 \\
\hline & Model III & 158.931 & 0.772 & 0.395 & -0.263 & 0.977 \\
\hline & Model I & 483.849 & 0.744 & & & 0.875 \\
\hline \multirow[t]{2}{*}{ Region3 } & Model II & 76.093 & 0.922 & 0.458 & & 0.933 \\
\hline & Model III & 78.862 & 0.925 & 0.461 & -0.053 & 0.933 \\
\hline \multirow{3}{*}{ Region4 } & Model I & 262.353 & 0.698 & & & 0.907 \\
\hline & Model II & 25.513 & 0.879 & 0.780 & & 0.934 \\
\hline & Model III & 26.878 & 0.883 & 0.780 & -0.063 & 0.937 \\
\hline \multirow{3}{*}{ Region5 } & Model I & 105.085 & 0.672 & & & 0.943 \\
\hline & Model II & 42.458 & 0.772 & 0.364 & & 0.959 \\
\hline & Model III & 46.246 & 0.769 & 0.356 & -0.035 & 0.959 \\
\hline \multirow{3}{*}{ Region6 } & Model I & 314.451 & 0.390 & & & 0.743 \\
\hline & Model II & 24.783 & 0.728 & 0.858 & & 0.819 \\
\hline & Model III & 17.249 & 0.692 & 0.738 & 0.339 & 0.865 \\
\hline \multirow{3}{*}{ Region7 } & Model I & 121.345 & 0.724 & & & 0.980 \\
\hline & Model II & 18.290 & 0.882 & 0.636 & & 0.977 \\
\hline & Model III & 115.773 & 0.888 & 0.549 & -1.156 & 0.989 \\
\hline \multirow{3}{*}{ Region8 } & Model I & 88.116 & 0.700 & & & 0.692 \\
\hline & Model II & 237.672 & 0.594 & -0.331 & & 0.770 \\
\hline & Model III & 353.014 & 0.770 & -0.085 & -0.966 & 0.731 \\
\hline \multicolumn{7}{|c|}{ Regional regression for GEV at $T=50 y r$} \\
\hline & Parameter & $a$ & $\boldsymbol{b}$ & c & $d$ & $R^{2}$ \\
\hline \multirow[t]{3}{*}{ Region1 } & Model I & 427.953 & 0.619 & & & 0.985 \\
\hline & Model II & 55.415 & 0.814 & 0.616 & & 0.990 \\
\hline & Model III & 96.752 & 0.805 & 0.528 & -0.257 & 0.992 \\
\hline \multirow[t]{3}{*}{ Region2 } & Model I & 787.373 & 0.577 & & & 0.960 \\
\hline & Model II & 105.820 & 0.788 & 0.480 & & 0.979 \\
\hline & Model III & 189.496 & 0.761 & 0.388 & -0.214 & 0.976 \\
\hline \multirow[t]{3}{*}{ Region3 } & Model I & 585.435 & 0.751 & & & 0.860 \\
\hline & Model II & 84.115 & 0.938 & 0.479 & & 0.926 \\
\hline & Model III & 92.281 & 0.942 & 0.481 & -0.114 & 0.924 \\
\hline \multirow[t]{3}{*}{ Region4 } & Model I & 300.415 & 0.702 & & & 0.906 \\
\hline & Model II & 27.538 & 0.887 & 0.798 & & 0.941 \\
\hline & Model III & 26.356 & 0.887 & 0.804 & 0.032 & 0.939 \\
\hline \multirow[t]{3}{*}{ Region5 } & Model I & 118.526 & 0.667 & & & 0.940 \\
\hline & Model II & 49.123 & 0.764 & 0.351 & & 0.956 \\
\hline & Model III & 50.688 & 0.761 & 0.344 & -0.006 & 0.956 \\
\hline \multirow[t]{3}{*}{ Region6 } & Model I & 466.918 & 0.340 & & & 0.639 \\
\hline & Model II & 24.868 & 0.731 & 0.975 & & 0.766 \\
\hline & Model III & 16.516 & 0.697 & 0.852 & 0.358 & 0.836 \\
\hline \multirow[t]{3}{*}{ Region7 } & Model I & 142.840 & 0.729 & & & 0.983 \\
\hline & Model II & 19.911 & 0.894 & 0.662 & & 0.981 \\
\hline & Model III & 123.148 & 0.900 & 0.578 & -1.146 & 0.991 \\
\hline \multirow[t]{3}{*}{ Region8 } & Model I & 100.607 & 0.696 & & & 0.684 \\
\hline & Model II & 309.992 & 0.575 & -0.375 & & 0.776 \\
\hline & Model III & 458.217 & 0.751 & -0.130 & -0.960 & 0.712 \\
\hline
\end{tabular}


Table 5.2.4. GLS Regression coefficients for the drainage areas and GEV flood quantile estimates (Cont.)

\begin{tabular}{lcccccc}
\multicolumn{2}{l}{ Regional regression for GEV at T=100yr } \\
\hline & Parameter & $\boldsymbol{a}$ & $\boldsymbol{b}$ & $\boldsymbol{C}$ & $\boldsymbol{d}$ & $\boldsymbol{R}^{\mathbf{2}}$ \\
\hline Region1 & Model I & 502.034 & 0.613 & & & 0.983 \\
& Model II & 52.261 & 0.829 & 0.682 & & 0.987 \\
& Model III & 101.327 & 0.818 & 0.577 & -0.302 & 0.989 \\
\hline Region2 & Model I & 935.570 & 0.572 & & & 0.959 \\
& Model II & 142.691 & 0.770 & 0.450 & & 0.977 \\
& Model III & 224.135 & 0.748 & 0.380 & -0.165 & 0.974 \\
\hline Region3 & Model I & 699.260 & 0.758 & & & 0.837 \\
& Model II & 91.561 & 0.955 & 0.500 & & 0.911 \\
& Model III & 106.380 & 0.959 & 0.501 & -0.174 & 0.905 \\
\hline Region4 & Model I & 338.494 & 0.706 & & & 0.899 \\
& Model II & 29.401 & 0.896 & 0.815 & & 0.942 \\
& Model III & 25.616 & 0.891 & 0.827 & 0.127 & 0.939 \\
\hline Region5 & Model I & 131.386 & 0.662 & & & 0.938 \\
& Model II & 55.997 & 0.756 & 0.338 & & 0.953 \\
& Model III & 54.942 & 0.754 & 0.332 & 0.023 & 0.953 \\
\hline Region6 & Model I & 679.210 & 0.292 & & & 0.508 \\
& Model II & 23.975 & 0.740 & 1.095 & & 0.712 \\
& Model III & 15.343 & 0.708 & 0.971 & 0.367 & 0.803 \\
\hline Region7 & Model I & 165.136 & 0.735 & & & 0.983 \\
& Model II & 21.175 & 0.906 & 0.691 & & 0.980 \\
& Model III & 127.332 & 0.914 & 0.609 & -1.134 & 0.990 \\
\hline Region8 & Model I & 113.807 & 0.691 & & & 0.673 \\
& Model II & 400.359 & 0.556 & -0.420 & & 0.779 \\
& Model III & 587.756 & 0.732 & -0.174 & -0.954 & 0.689 \\
\hline
\end{tabular}

Regional regression for GEV at T=200yr

\begin{tabular}{lcccccc}
\hline & Parameter & $\boldsymbol{a}$ & $\boldsymbol{b}$ & $\boldsymbol{C}$ & $\boldsymbol{d}$ & $\boldsymbol{R}^{\mathbf{2}}$ \\
\hline Region1 & Model I & 583.377 & 0.608 & & & 0.980 \\
& Model II & 48.663 & 0.844 & 0.750 & & 0.982 \\
& Model III & 104.543 & 0.831 & 0.626 & -0.346 & 0.985 \\
\hline Region2 & Model I & 1101.084 & 0.567 & & & 0.957 \\
& Model II & 191.505 & 0.751 & 0.419 & & 0.973 \\
& Model III & 263.778 & 0.736 & 0.370 & -0.117 & 0.971 \\
\hline Region3 & Model I & 827.871 & 0.765 & & & 0.806 \\
& Model II & 98.503 & 0.971 & 0.522 & & 0.886 \\
& Model III & 121.376 & 0.976 & 0.522 & -0.233 & 0.876 \\
\hline Region4 & Model I & 376.795 & 0.711 & & & 0.883 \\
& Model II & 31.130 & 0.904 & 0.830 & & 0.935 \\
& Model III & 24.698 & 0.894 & 0.848 & 0.223 & 0.932 \\
\hline Region5 & Model I & 143.723 & 0.658 & & & 0.936 \\
& Model II & 63.126 & 0.749 & 0.325 & & 0.950 \\
& Model III & 59.066 & 0.746 & 0.318 & 0.051 & 0.949 \\
\hline Region6 & Model I & 975.037 & 0.245 & & & 0.362 \\
& Model II & 22.440 & 0.751 & 1.218 & & 0.667 \\
& Model III & 13.982 & 0.723 & 1.097 & 0.370 & 0.769 \\
\hline Region7 & Model I & 188.332 & 0.741 & & & 0.979 \\
& Model II & 22.107 & 0.920 & 0.721 & & 0.975 \\
& Model III & 128.715 & 0.930 & 0.642 & -1.121 & 0.984 \\
\hline Region8 & Model I & 127.852 & 0.686 & & & 0.657 \\
& Model II & 513.403 & 0.537 & -0.464 & & 0.777 \\
& Model III & 747.139 & 0.712 & -0.218 & -0.948 & 0.662 \\
\hline
\end{tabular}



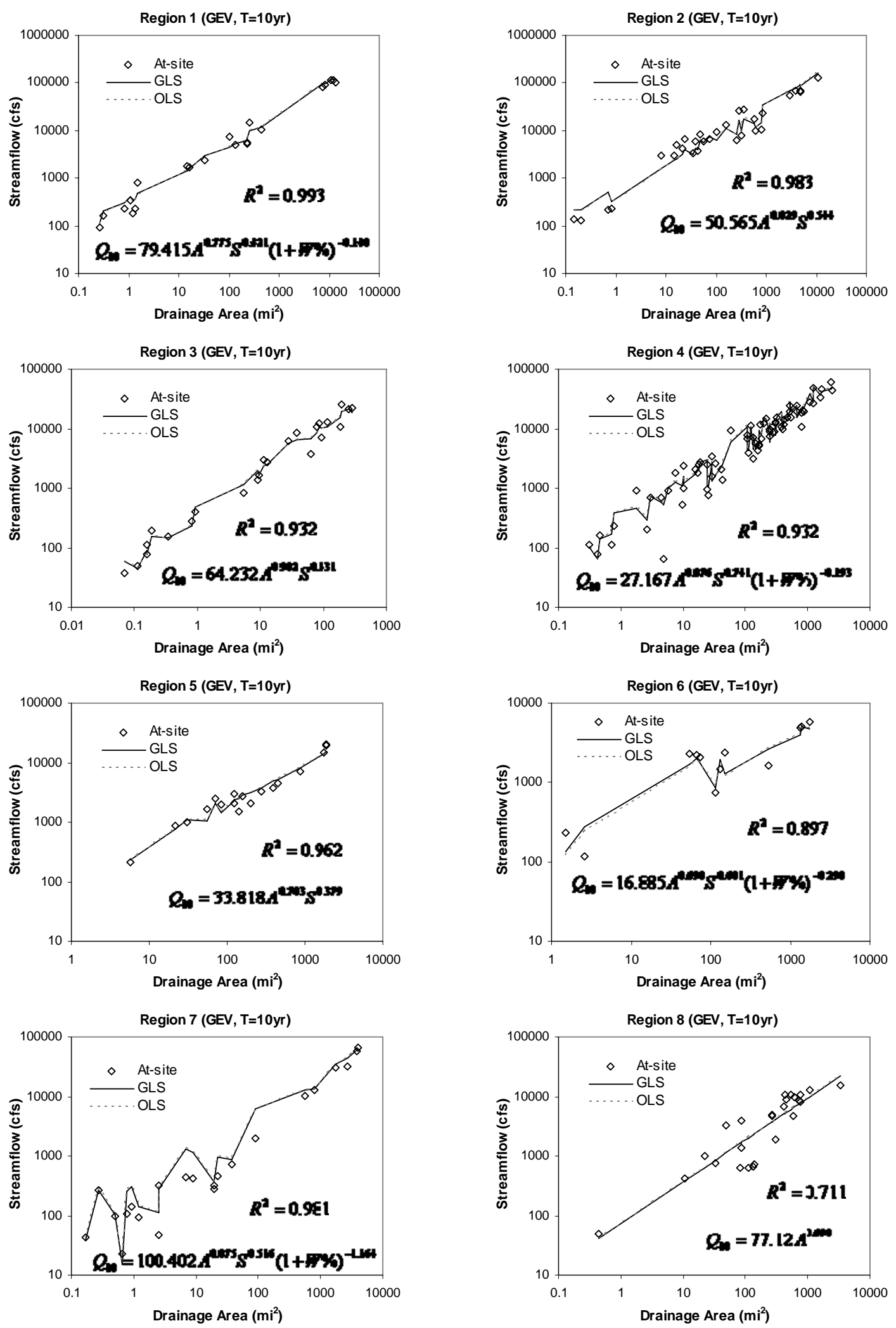

Figure 5.2.2(a). GLS regional regression for $G E V(T=10$ years). 

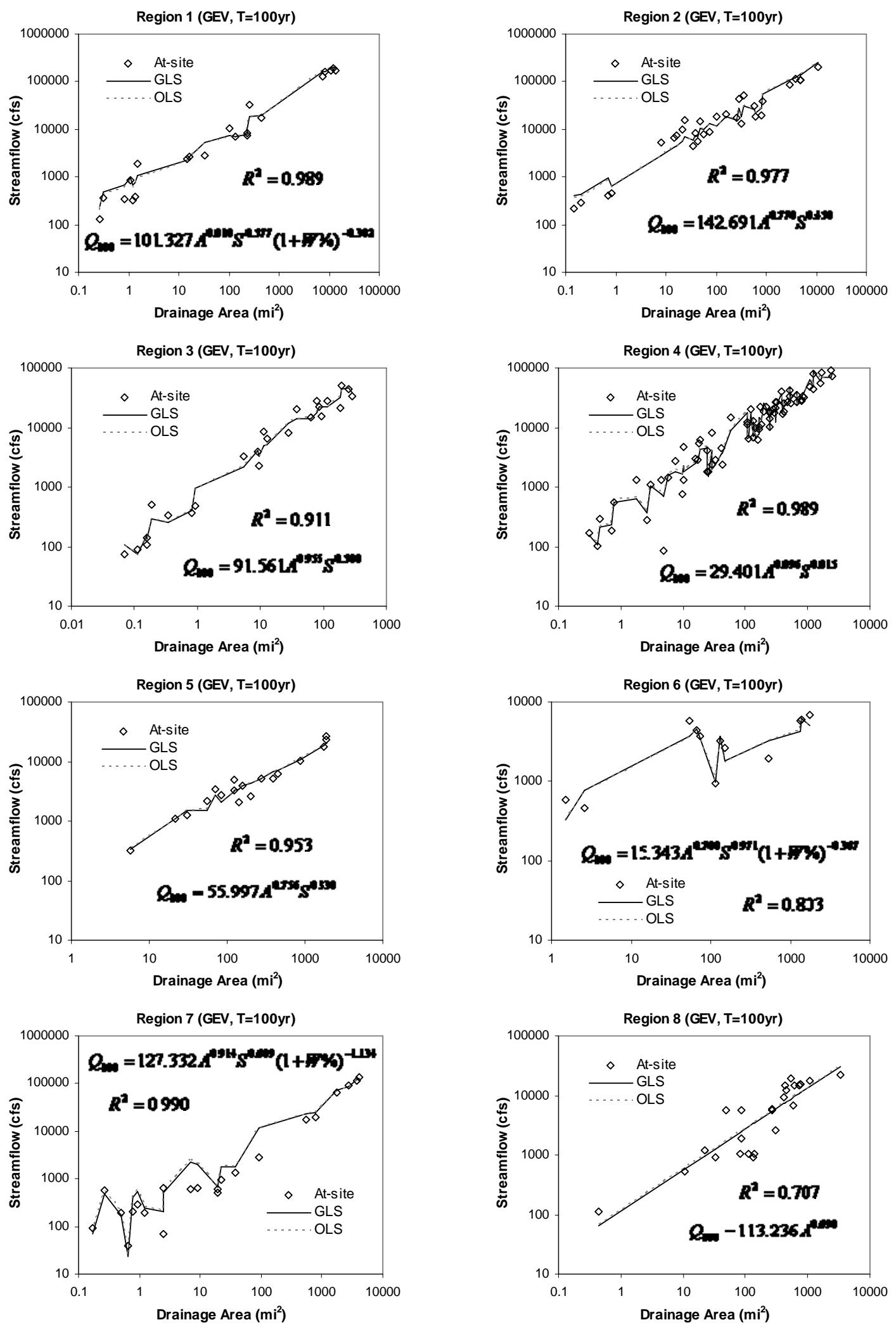

Figure 5.2.2(b). GLS regional regression for GEV $(T=100$ years). 
Table 5.2.5. GLS Regression coefficients for the drainage areas and LPIII flood quantile estimates.

\begin{tabular}{|c|c|c|c|c|c|c|}
\hline & Parameter & $a$ & $b$ & c & $d$ & $R^{2}$ \\
\hline & Model I & 146.884 & 0.640 & & & 0.987 \\
\hline \multirow[t]{2}{*}{ Region1 } & Model II & 37.223 & 0.772 & 0.410 & & 0.994 \\
\hline & Model III & 39.164 & 0.771 & 0.403 & -0.022 & 0.994 \\
\hline & Model I & 287.294 & 0.584 & & & 0.949 \\
\hline \multirow[t]{2}{*}{ Region2 } & Model II & 28.058 & 0.830 & 0.553 & & 0.978 \\
\hline & Model III & 67.892 & 0.789 & 0.414 & -0.329 & 0.972 \\
\hline & Model I & 193.046 & 0.740 & & & 0.896 \\
\hline \multirow[t]{2}{*}{ Region3 } & Model II & 39.770 & 0.890 & 0.396 & & 0.926 \\
\hline & Model III & 36.516 & 0.888 & 0.397 & 0.092 & 0.924 \\
\hline \multirow{3}{*}{ Region4 } & Model I & 115.386 & 0.691 & & & 0.899 \\
\hline & Model II & 14.011 & 0.854 & 0.711 & & 0.919 \\
\hline & Model III & 20.845 & 0.869 & 0.682 & -0.373 & 0.937 \\
\hline & Model I & 46.707 & 0.707 & & & 0.955 \\
\hline \multirow[t]{2}{*}{ Region5 } & Model II & 17.813 & 0.811 & 0.399 & & 0.971 \\
\hline & Model III & 26.121 & 0.802 & 0.379 & -0.180 & 0.971 \\
\hline \multirow{3}{*}{ Region6 } & Model I & 55.398 & 0.598 & & & 0.922 \\
\hline & Model II & 10.451 & 0.818 & 0.574 & & 0.942 \\
\hline & Model III & 9.711 & 0.804 & 0.539 & 0.092 & 0.941 \\
\hline \multirow{3}{*}{ Region7 } & Model I & 44.146 & 0.741 & & & 0.977 \\
\hline & Model II & 7.289 & 0.891 & 0.604 & & 0.968 \\
\hline & Model III & 48.104 & 0.894 & 0.515 & -1.175 & 0.981 \\
\hline \multirow{3}{*}{ Region8 } & Model I & 47.553 & 0.701 & & & 0.724 \\
\hline & Model II & 81.781 & 0.643 & -0.181 & & 0.756 \\
\hline & Model III & 118.870 & 0.811 & 0.052 & -0.919 & 0.767 \\
\hline
\end{tabular}

$\underline{\text { Regional regression for } L P 3 \text { at } T=5 y r}$

\begin{tabular}{lcccccc}
\hline & Parameter & $\boldsymbol{a}$ & $\boldsymbol{b}$ & $\boldsymbol{C}$ & $\boldsymbol{d}$ & $\boldsymbol{R}^{\mathbf{2}}$ \\
\hline \multirow{2}{*}{ Region1 } & Model I & 230.406 & 0.630 & & & 0.985 \\
& Model II & 48.429 & 0.780 & 0.466 & & 0.992 \\
& Model III & 64.032 & 0.777 & 0.423 & -0.135 & 0.993 \\
\hline \multirow{2}{*}{ Region2 } & Model I & 460.726 & 0.575 & & & 0.946 \\
& Model II & 49.685 & 0.811 & 0.530 & & 0.974 \\
& Model III & 105.987 & 0.776 & 0.411 & -0.281 & 0.969 \\
\hline \multirow{2}{*}{ Region3 } & Model I & 311.620 & 0.736 & & & 0.889 \\
& Model II & 61.061 & 0.891 & 0.407 & & 0.931 \\
& Model III & 59.102 & 0.890 & 0.408 & 0.032 & 0.931 \\
\hline \multirow{2}{*}{ Region4 } & Model I & 180.331 & 0.691 & & & 0.899 \\
& Model II & 19.209 & 0.863 & 0.755 & & 0.922 \\
& Model III & 24.870 & 0.874 & 0.737 & -0.249 & 0.933 \\
\hline \multirow{2}{*}{ Region6 } & Model I & 72.273 & 0.688 & & & 0.947 \\
& Model II & 28.531 & 0.789 & 0.381 & & 0.964 \\
& Model III & 35.827 & 0.783 & 0.369 & -0.107 & 0.964 \\
\hline \multirow{2}{*}{ Region7 } & Model I & 141.277 & 0.483 & & & 0.869 \\
& Model II & 19.246 & 0.747 & 0.677 & & 0.902 \\
& Model III & 16.183 & 0.720 & 0.602 & 0.198 & 0.910 \\
\hline \multirow{2}{*}{ Region8 } & Model I & 76.881 & 0.720 & & & 0.977 \\
& Model II & 12.134 & 0.875 & 0.619 & & 0.971 \\
& Model III & 84.255 & 0.879 & 0.528 & -1.209 & 0.985 \\
\hline & Model I & 65.529 & 0.700 & & & 0.712 \\
& Model II & 138.783 & 0.620 & -0.250 & & 0.763 \\
& Model III & 201.844 & 0.787 & -0.019 & -0.914 & 0.771 \\
\hline
\end{tabular}


Table 5.2.5. GLS Regression coefficients for the drainage areas and LPIII flood quantile estimates (Cont.)

\begin{tabular}{|c|c|c|c|c|c|c|}
\hline & Parameter & $a$ & $\boldsymbol{b}$ & $c$ & $d$ & $R^{2}$ \\
\hline & Model I & 294.188 & 0.622 & & & 0.982 \\
\hline \multirow[t]{2}{*}{ Region1 } & Model II & 50.433 & 0.791 & 0.528 & & 0.990 \\
\hline & Model III & 77.185 & 0.787 & 0.462 & -0.206 & 0.991 \\
\hline & Model I & 597.250 & 0.567 & & & 0.946 \\
\hline \multirow[t]{2}{*}{ Region2 } & Model II & 72.813 & 0.789 & 0.502 & & 0.973 \\
\hline & Model III & 150.543 & 0.755 & 0.387 & -0.268 & 0.968 \\
\hline & Model I & 396.151 & 0.740 & & & 0.882 \\
\hline \multirow[t]{3}{*}{ Region3 } & Model II & 75.108 & 0.898 & 0.415 & & 0.929 \\
\hline & Model III & 73.933 & 0.899 & 0.417 & 0.010 & 0.929 \\
\hline & Model I & 222.117 & 0.692 & & & 0.899 \\
\hline \multirow[t]{3}{*}{ Region4 } & Model II & 21.547 & 0.872 & 0.785 & & 0.929 \\
\hline & Model III & 25.522 & 0.880 & 0.774 & -0.169 & 0.936 \\
\hline & Model I & 87.923 & 0.679 & & & 0.944 \\
\hline \multirow[t]{2}{*}{ Region5 } & Model II & 35.139 & 0.779 & 0.373 & & 0.960 \\
\hline & Model III & 39.813 & 0.776 & 0.365 & -0.057 & 0.960 \\
\hline & Model I & 249.432 & 0.409 & & & 0.805 \\
\hline \multirow[t]{3}{*}{ Region6 } & Model II & 25.015 & 0.715 & 0.768 & & 0.859 \\
\hline & Model III & 19.615 & 0.684 & 0.676 & 0.253 & 0.883 \\
\hline & Model I & 102.550 & 0.712 & & & 0.983 \\
\hline \multirow[t]{3}{*}{ Region7 } & Model II & 14.355 & 0.876 & 0.659 & & 0.977 \\
\hline & Model III & 103.024 & 0.881 & 0.567 & -1.232 & 0.990 \\
\hline & Model I & 77.120 & 0.698 & & & 0.711 \\
\hline \multirow[t]{2}{*}{ Region8 } & Model II & 184.753 & 0.605 & -0.292 & & 0.774 \\
\hline & Model III & 268.128 & 0.771 & -0.061 & -0.908 & 0.769 \\
\hline
\end{tabular}

Regional regression for $L P 3$ at $T=20 y r$

\begin{tabular}{lcccccc}
\hline & Parameter & $\boldsymbol{a}$ & $\boldsymbol{b}$ & $\boldsymbol{C}$ & $\boldsymbol{d}$ & $\boldsymbol{R}^{\mathbf{2}}$ \\
\hline Region1 & Model I & 362.225 & 0.614 & & & 0.979 \\
& Model II & 49.654 & 0.804 & 0.595 & & 0.986 \\
& Model III & 86.990 & 0.798 & 0.508 & -0.269 & 0.988 \\
\hline Region2 & Model I & 744.503 & 0.558 & & & 0.946 \\
& Model II & 104.190 & 0.765 & 0.470 & & 0.972 \\
& Model III & 212.958 & 0.732 & 0.357 & -0.263 & 0.968 \\
\hline Region3 & Model I & 482.516 & 0.745 & & & 0.867 \\
& Model II & 88.017 & 0.908 & 0.423 & & 0.918 \\
& Model III & 87.416 & 0.909 & 0.427 & -0.006 & 0.918 \\
\hline Region4 & Model I & 260.735 & 0.694 & & & 0.896 \\
& Model II & 23.201 & 0.881 & 0.812 & & 0.934 \\
& Model III & 25.426 & 0.886 & 0.807 & -0.097 & 0.938 \\
\hline Region5 & Model I & 101.687 & 0.672 & & & 0.940 \\
& Model II & 41.066 & 0.772 & 0.367 & & 0.957 \\
& Model III & 42.425 & 0.770 & 0.361 & -0.009 & 0.957 \\
\hline Region6 & Model I & 414.003 & 0.341 & & & 0.709 \\
& Model II & 29.747 & 0.694 & 0.863 & & 0.797 \\
& Model III & 21.750 & 0.661 & 0.756 & 0.299 & 0.846 \\
\hline Region7 & Model I & 129.909 & 0.706 & & & 0.987 \\
& Model II & 15.710 & 0.883 & 0.709 & & 0.981 \\
& Model III & 116.037 & 0.889 & 0.614 & -1.253 & 0.994 \\
\hline Region8 & Model I & 88.137 & 0.696 & & & 0.711 \\
& Model II & 235.569 & 0.591 & -0.328 & & 0.785 \\
& Model III & 340.265 & 0.756 & -0.099 & -0.901 & 0.764 \\
\hline
\end{tabular}


Table 5.2.5. GLS Regression coefficients for the drainage areas and LPIII flood quantile estimates (Cont.)

Regional regression for $L P 3$ at $T=25 y r$

\begin{tabular}{lcccccc}
\hline & Parameter & $\boldsymbol{a}$ & $\boldsymbol{b}$ & $\boldsymbol{C}$ & $\boldsymbol{d}$ & $\boldsymbol{R}^{\mathbf{2}}$ \\
\hline \multirow{2}{*}{ Region1 } & Model I & 385.335 & 0.611 & & & 0.977 \\
& Model II & 49.037 & 0.809 & 0.618 & & 0.985 \\
& Model III & 89.581 & 0.802 & 0.523 & -0.288 & 0.987 \\
\hline \multirow{2}{*}{ Region2 } & Model I & 794.626 & 0.555 & & & 0.946 \\
& Model II & 116.487 & 0.758 & 0.459 & & 0.972 \\
& Model III & 237.777 & 0.724 & 0.347 & -0.263 & 0.967 \\
\hline \multirow{2}{*}{ Region3 } & Model I & 511.157 & 0.747 & & & 0.859 \\
& Model II & 91.988 & 0.911 & 0.426 & & 0.912 \\
& Model III & 91.518 & 0.913 & 0.430 & -0.010 & 0.912 \\
\hline \multirow{2}{*}{ Region4 } & Model I & 272.681 & 0.694 & & & 0.893 \\
& Model II & 23.633 & 0.884 & 0.820 & & 0.935 \\
& Model III & 25.307 & 0.888 & 0.817 & -0.075 & 0.938 \\
\hline \multirow{2}{*}{ Region5 } & Model I & 105.803 & 0.671 & & & 0.940 \\
& Model II & 42.872 & 0.770 & 0.364 & & 0.956 \\
& Model III & 43.075 & 0.768 & 0.360 & 0.006 & 0.955 \\
\hline \multirow{2}{*}{ Region7 } & Model I & 482.603 & 0.321 & & & 0.670 \\
& Model II & 31.024 & 0.689 & 0.893 & & 0.773 \\
& Model III & 22.181 & 0.656 & 0.783 & 0.312 & 0.831 \\
\hline \multirow{2}{*}{ Region8 } & Model I & 139.131 & 0.705 & & & 0.988 \\
& Model II & 16.000 & 0.886 & 0.725 & & 0.982 \\
& Model III & 119.188 & 0.892 & 0.631 & -1.260 & 0.994 \\
\hline & Model I & 91.624 & 0.695 & & & 0.711 \\
& Model II & 253.144 & 0.586 & -0.339 & & 0.789 \\
& Model III & 364.903 & 0.751 & -0.110 & -0.899 & 0.761 \\
\hline
\end{tabular}

\section{Regional regression for $L P 3$ at $T=50 y r$}

\begin{tabular}{lcccccc}
\hline & Parameter & $\boldsymbol{a}$ & $\boldsymbol{b}$ & $\boldsymbol{C}$ & $\boldsymbol{d}$ & $\boldsymbol{R}^{\mathbf{2}}$ \\
\hline Region1 & Model I & 461.583 & 0.603 & & & 0.972 \\
& Model II & 46.397 & 0.823 & 0.689 & & 0.979 \\
& Model III & 96.152 & 0.813 & 0.574 & -0.346 & 0.982 \\
\hline Region2 & Model I & 959.847 & 0.546 & & & 0.945 \\
& Model II & 163.181 & 0.733 & 0.424 & & 0.970 \\
& Model III & 333.100 & 0.699 & 0.312 & -0.263 & 0.965 \\
\hline Region3 & Model I & 603.822 & 0.753 & & & 0.826 \\
& Model II & 103.885 & 0.922 & 0.437 & & 0.879 \\
& Model III & 103.635 & 0.925 & 0.442 & -0.021 & 0.879 \\
\hline Region4 & Model I & 308.622 & 0.696 & & & 0.880 \\
& Model II & 24.740 & 0.892 & 0.844 & & 0.934 \\
& Model III & 24.768 & 0.893 & 0.846 & -0.010 & 0.934 \\
\hline Region5 & Model I & 117.769 & 0.666 & & & 0.937 \\
& Model II & 48.243 & 0.764 & 0.358 & & 0.952 \\
& Model III & 44.677 & 0.763 & 0.355 & 0.050 & 0.952 \\
\hline Region6 & Model I & 758.207 & 0.260 & & & 0.525 \\
& Model II & 34.208 & 0.677 & 0.988 & & 0.685 \\
& Model III & 22.836 & 0.644 & 0.868 & 0.349 & 0.773 \\
\hline Region7 & Model I & 169.157 & 0.702 & & & 0.989 \\
& Model II & 16.530 & 0.896 & 0.780 & & 0.981 \\
& Model III & 126.182 & 0.904 & 0.685 & -1.279 & 0.993 \\
\hline Region8 & Model I & 102.412 & 0.693 & & & 0.710 \\
& Model II & 312.159 & 0.573 & -0.372 & & 0.797 \\
& Model III & 446.450 & 0.737 & -0.143 & -0.891 & 0.751 \\
\hline
\end{tabular}


Table 5.2.5. GLS Regression coefficients for the drainage areas and LPIII flood quantile estimates (Cont.)

\begin{tabular}{lcccccc}
\multicolumn{2}{l}{ Regional regression for $\mathbf{L} \mathbf{P}$ at $\mathbf{T}=\mathbf{1 0 0} \boldsymbol{y} \boldsymbol{}$} \\
\hline & Parameter & $\boldsymbol{a}$ & $\boldsymbol{b}$ & $\boldsymbol{C}$ & $\boldsymbol{d}$ & $\boldsymbol{R}^{\mathbf{2}}$ \\
\hline Region1 & Model I & 545.593 & 0.594 & & & 0.965 \\
& Model II & 43.115 & 0.837 & 0.762 & & 0.971 \\
& Model III & 100.881 & 0.825 & 0.627 & -0.400 & 0.976 \\
\hline Region2 & Model I & 1140.736 & 0.537 & & & 0.942 \\
& Model II & 225.895 & 0.707 & 0.388 & & 0.966 \\
& Model III & 462.830 & 0.674 & 0.276 & -0.264 & 0.962 \\
\hline Region3 & Model I & 703.266 & 0.760 & & & 0.771 \\
& Model II & 115.414 & 0.934 & 0.447 & & 0.823 \\
& Model III & 115.061 & 0.937 & 0.455 & -0.031 & 0.822 \\
\hline Region4 & Model I & 343.147 & 0.699 & & & 0.857 \\
& Model II & 25.572 & 0.900 & 0.866 & & 0.923 \\
& Model III & 24.071 & 0.899 & 0.872 & 0.051 & 0.923 \\
\hline Region5 & Model I & 128.672 & 0.662 & & & 0.933 \\
& Model II & 53.337 & 0.759 & 0.352 & & 0.948 \\
& Model III & 45.829 & 0.759 & 0.350 & 0.091 & 0.948 \\
\hline Region6 & Model I & 1154.568 & 0.202 & & & 0.358 \\
& Model II & 36.271 & 0.671 & 1.082 & & 0.588 \\
& Model III & 22.666 & 0.639 & 0.955 & 0.381 & 0.703 \\
\hline Region7 & Model I & 201.377 & 0.700 & & & 0.983 \\
& Model II & 16.612 & 0.909 & 0.838 & & 0.973 \\
& Model III & 129.619 & 0.918 & 0.741 & -1.296 & 0.984 \\
\hline Region8 & Model I & 113.236 & 0.690 & & & 0.707 \\
& Model II & 378.588 & 0.560 & -0.403 & & 0.804 \\
& Model III & 536.122 & 0.723 & -0.175 & -0.883 & 0.739 \\
\hline
\end{tabular}

$\underline{\text { Regional regression for } L P 3 \text { at } T=200 y r}$

\begin{tabular}{lcccccc}
\hline & Parameter & $\boldsymbol{a}$ & $\boldsymbol{b}$ & $\boldsymbol{C}$ & $\boldsymbol{d}$ & $\boldsymbol{R}^{\mathbf{2}}$ \\
\hline Region1 & Model I & 638.605 & 0.585 & & & 0.954 \\
& Model II & 39.569 & 0.851 & 0.835 & & 0.959 \\
& Model III & 104.145 & 0.837 & 0.681 & -0.452 & 0.966 \\
\hline Region2 & Model I & 1338.893 & 0.528 & & & 0.937 \\
& Model II & 309.724 & 0.682 & 0.352 & & 0.959 \\
& Model III & 637.815 & 0.648 & 0.239 & -0.267 & 0.956 \\
\hline Region3 & Model I & 810.942 & 0.766 & & & 0.690 \\
& Model II & 126.844 & 0.945 & 0.458 & & 0.737 \\
& Model III & 126.029 & 0.950 & 0.468 & -0.038 & 0.736 \\
\hline Region4 & Model I & 376.568 & 0.701 & & & 0.818 \\
& Model II & 26.199 & 0.908 & 0.886 & & 0.899 \\
& Model III & 23.286 & 0.903 & 0.896 & 0.110 & 0.899 \\
\hline Region5 & Model I & 138.683 & 0.659 & & & 0.930 \\
& Model II & 58.230 & 0.755 & 0.345 & & 0.944 \\
& Model III & 46.684 & 0.755 & 0.344 & 0.131 & 0.944 \\
\hline Region6 & Model I & 1713.317 & 0.148 & & & 0.199 \\
& Model II & 37.354 & 0.668 & 1.175 & & 0.498 \\
& Model III & 21.930 & 0.639 & 1.042 & 0.409 & 0.629 \\
\hline Region7 & Model I & 235.898 & 0.699 & & & 0.968 \\
& Model II & 16.371 & 0.922 & 0.896 & & 0.957 \\
& Model III & 130.285 & 0.933 & 0.798 & -1.312 & 0.966 \\
\hline & Model I & 124.222 & 0.686 & & & 0.701 \\
& Model II & 453.553 & 0.547 & -0.432 & & 0.808 \\
& Model III & 634.820 & 0.710 & -0.205 & -0.874 & 0.724 \\
\hline
\end{tabular}



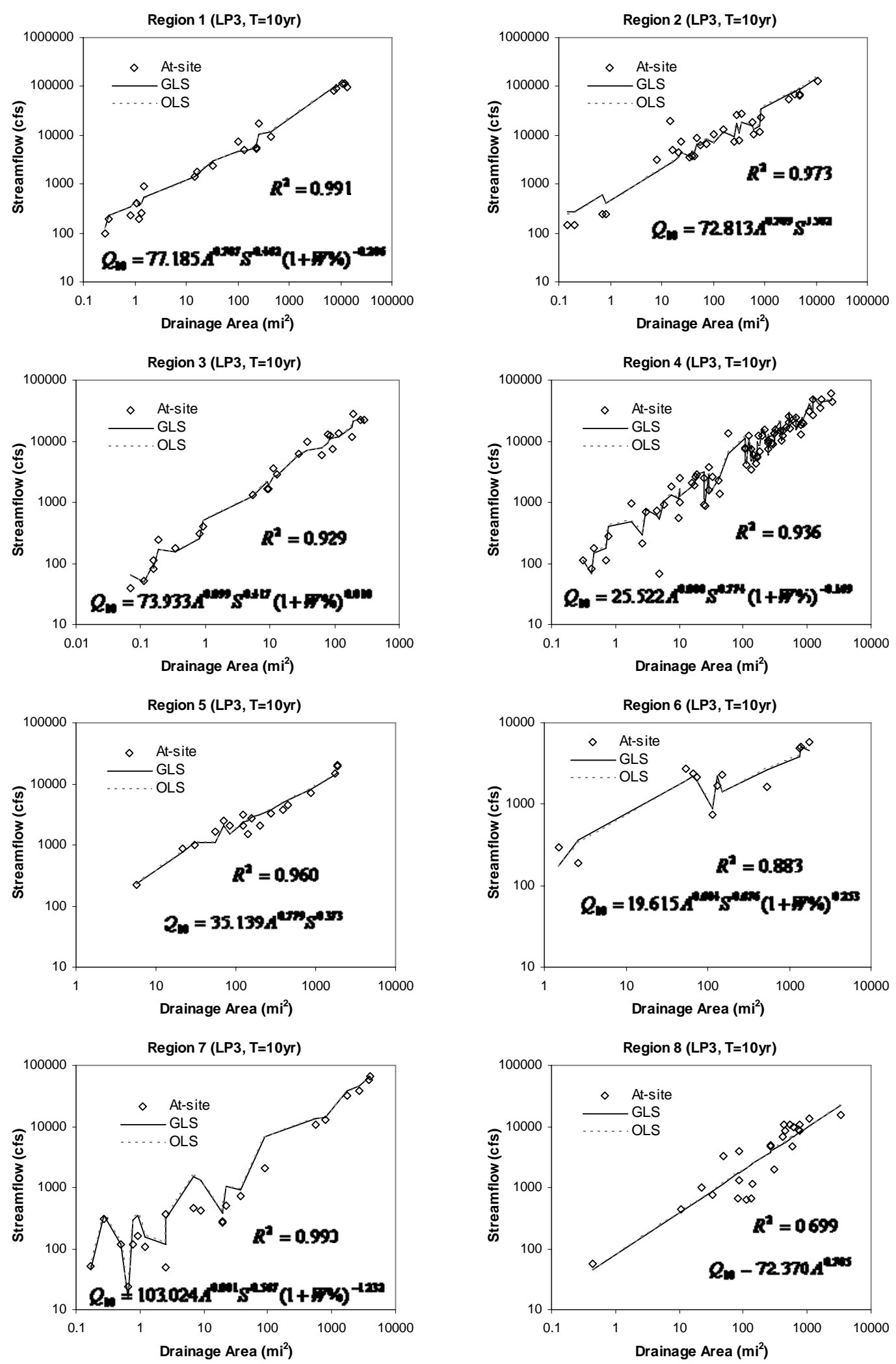

Figure 5.2.3(a). GLS regional regression for LPIII $(T=10$ years) 

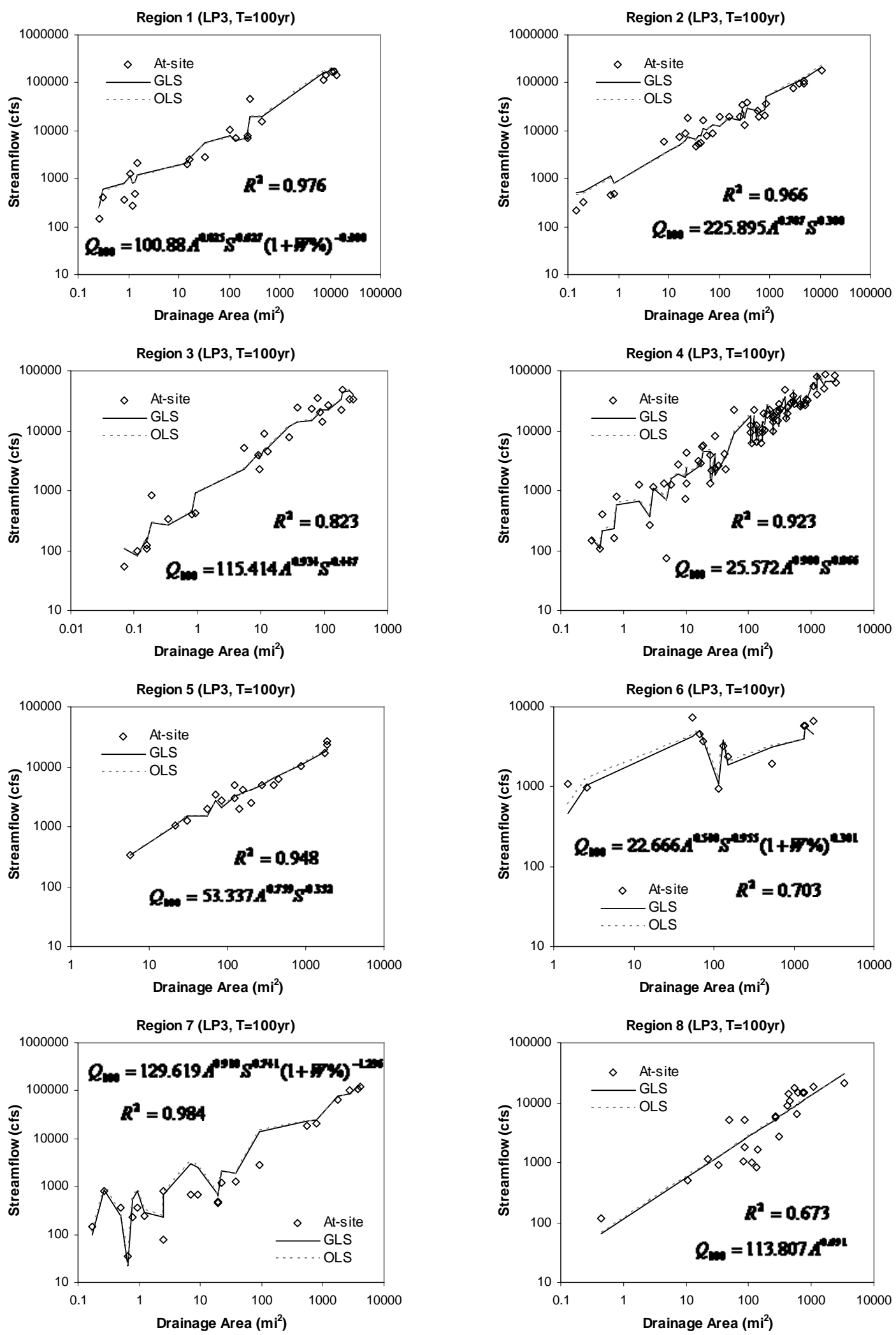

Figure 5.2.3(b). GLS regional regression for LPIII $(T=100$ years $)$ 
From Table 5.2.3 to Table 5.2.5, we can see that for most of cases, adding W\% increases the accuracy of regression; however, it does not yield a significantly better prediction result. Therefore it is easier to only take drainage area and slope into consideration. Also, including only area and slope is better since the more detailed attributes of most ungaged sites are unavailable. Drainage area and stream slope are the basic information which are easily available.

Ideally, the slope should be proportional to the quantile floods. But, region 8 has the opposite behavior with negative coefficients for the slope term. To avoid this unreasonable situation, only drainage area is considered for region 8. As for other regions, the factors contributing to the best fit in region 1, 4, 6 and 7 are area (A), slope (S) and percentage wet area $(\% \mathrm{~W})$; factors in region 2 and region 3 are area and slope. Region 5 could have area and slope or area, slope and percent wet area.

Additionally, the regional regression is performed for regions 1 and 5 by using the data used by Srinivas and Rao (2003). The results for region 2, 3, 4, and 6 are kept because both Srinivas and Rao (2003, Figure 3.1.1) and Knipe and Rao (2004, Figure 3.1.2) have the same definition for these four regions. Merging region 1 and region 7 in Figure 3.1.2, results in region 1 in Figure 3.1.1, and merging region 5 and region 8 in Figure 3.1.2 yields region 5 in Figure 3.1.1. The coefficients of generalized least square regression for the mean annual peak flow and log-mean peak flow for these six regions are shown in Table 5.2.6 (a) and Table 5.2.6(b), respectively. The GLS regression is also performed for PTIII, GEV, and LPIII distributions for region 1 and 5 in Figure 3.1.1 and the results are listed in Table 5.2.7, Table 5.2.8 and Table 5.2 .9 , respectively. 
Taking region 5 (Figure 3.1.1) for example, the $\mathrm{R}^{2}$ values in Table 5.2.7 to Table 5.2.8 compared to the $\mathrm{R}^{2}$ values in Table 5.2.3 to Table 5.2.5, the $\mathrm{R}^{2}$ is lower than the $\mathrm{R}^{2}$ in region 5 (Figure 3.1.2) but higher than region 8 (Figure 3.1.2). For instance, in Table 5.2.7 for PTIII distribution with 100 -year recurrence interval, the $\mathrm{R}^{2}$ value is 0.856 , which is between 0.707 (Table 5.2.3 for PTIII, 100-year in Region 8) and 0.954 (Table 5.2.3 for PTIII, 100-year in Region 5). For Region 1, it is better to keep using the equation derived from Knipe and Rao (2004) since it yields a better fit than that obtained by considering the merged area. Further analysis of data from region 8 did not yield better results than the equation derived from the merged area. The reason is that several validated stations in region 8 have poor correlation between flood magnitudes and drainage areas. Consequently, it is not possible to derive a reasonable regression among these variables. This leads to the high prediction error in region 8 . As for region 1 and region 7, in Table 5.2.7 for PTIII distribution with 100-year recurrence interval, the $\mathrm{R}^{2}$ value is 0.982 , which is lower than both 0.990 (Table 5.2.3 for PTIII, 100-year in Region 1) and 0.991 (Table 5.2.3 for PTIII, 100-year in Region 7). Therefore, for region 1 it is also better to use the equation derived from Knipe and Rao (2004), which contains eight regions.

\subsection{Combination of GLS regional regression and L-moment method.}

To use the regional L-moment method, the first moment (the mean annual peak flow) is the statistic of interest. However, this is usually not available for an ungauged location. In such situations, GLS regression is one approach to obtain the quantile floods for various recurrence intervals. However, the hydrological or geographical information may be combined with the Lmoment method simply by developing equations for the mean (or logarithm of mean annual) flows with the GLS method. At each site, the mean and the mean of logarithms are calculated 
from the data. The mean of the logarithms of the annual maximum flows are calculated because it is needed in LPIII.

\section{Table 5.2.6. GLS regression coefficients of mean and logmean annual peak flow for Region 1 and Region 5 derived by Srinivas and Rao (2003).}

(a) Mean peak flow

\begin{tabular}{ccccccc}
\hline & Parameter & $\boldsymbol{a}$ & $\boldsymbol{b}$ & $\boldsymbol{c}$ & $\boldsymbol{d}$ & $\boldsymbol{R}^{\mathbf{2}}$ \\
\hline \multirow{2}{*}{ Region1 + } & Model I & 89.4602 & 0.6951 & & & 0.983 \\
Region7 & Model II & 9.5021 & 0.8995 & 0.7122 & & 0.991 \\
& Model III & 40.9509 & 0.8911 & 0.5377 & -0.7661 & 0.995 \\
\hline \multirow{2}{*}{ Region5 + } & Model I & 49.2186 & 0.7021 & & & 0.823 \\
Region8 & Model II & 44.3388 & 0.7132 & 0.0387 & & 0.818 \\
& Model III & 130.5746 & 0.7560 & 0.0413 & -0.7623 & 0.882 \\
\hline
\end{tabular}

(b) Log-mean peak flow

\begin{tabular}{ccccccc}
\hline & Parameter & $\boldsymbol{a}$ & $\boldsymbol{b}$ & $\boldsymbol{c}$ & $\boldsymbol{d}$ & $\boldsymbol{R}^{\mathbf{2}}$ \\
\hline \multirow{2}{*}{ Region1 + } & Model I & 4.5137 & 0.0985 & & & 0.918 \\
Region7 & Model II & 3.5134 & 0.1191 & 0.0883 & & 0.924 \\
& Model III & 4.1319 & 0.1189 & 0.0729 & -0.0942 & 0.931 \\
\hline \multirow{2}{*}{ Region5 + } & Model I & 4.4142 & 0.0989 & & & 0.844 \\
Region8 & Model II & 3.9897 & 0.1098 & 0.0340 & & 0.841 \\
& Model III & 4.5339 & 0.1158 & 0.0447 & -0.0975 & 0.920 \\
\hline
\end{tabular}

The GLS regression equation is constructed by using the drainage area, slope and wet area percentage. Three models are constructed. Model I is based only on the area, which is $Q_{\text {mean }}=a A^{b}$, where $\mathrm{Q}_{\text {mean }}$ is the estimated mean flow, A is drainage area, and $a, b$ are GLS regression coefficients. Similarly, Model II considers area and slope, which is $Q_{\text {mean }}=a A^{b} S^{c}$, and Model III considers area, slope and wet area percentage, which is $Q_{\text {mean }}=a A^{b} S^{c}(1+W \%)^{d}$. The coefficients for each region and each model are listed in Table 5.3.1. For the logarithms of peak flows, the results are listed in Table 5.3.1. For the logarithms of peak flows, the unit for drainage area is square miles, slope is percentage, wet area is percentage and if the regressed value is $Q$, then the quantile flow is $\exp (Q)$ which is in unit of cubic feet per second (cfs). 
Table 5.2.7. GLS Regression coefficients of PTIII flood quantile estimates for merged area.

PT3 GLS regional regression for (Region $1+$ Region 7$)$

\begin{tabular}{|c|c|c|c|c|c|c|}
\hline$T$ (years) & Parameter & $a$ & $\boldsymbol{b}$ & $c$ & $d$ & $R^{2}$ \\
\hline \multirow{3}{*}{2} & Model I & 77.039 & 0.699 & & & 0.983 \\
\hline & Model II & 9.567 & 0.889 & 0.663 & & 0.989 \\
\hline & Model III & 39.963 & 0.880 & 0.490 & -0.744 & 0.992 \\
\hline \multirow{3}{*}{5} & Model I & 125.150 & 0.689 & & & 0.982 \\
\hline & Model II & 14.441 & 0.886 & 0.686 & & 0.989 \\
\hline & Model III & 65.052 & 0.877 & 0.505 & -0.784 & 0.994 \\
\hline \multirow{3}{*}{10} & Model I & 158.127 & 0.686 & & & 0.979 \\
\hline & Model II & 17.127 & 0.889 & 0.707 & & 0.987 \\
\hline & Model III & 79.761 & 0.879 & 0.521 & -0.802 & 0.993 \\
\hline \multirow{3}{*}{20} & Model I & 189.808 & 0.684 & & & 0.974 \\
\hline & Model II & 19.471 & 0.891 & 0.725 & & 0.984 \\
\hline & Model III & 92.791 & 0.882 & 0.537 & -0.815 & 0.991 \\
\hline \multirow{3}{*}{25} & Model I & 199.830 & 0.684 & & & 0.972 \\
\hline & Model II & 20.179 & 0.892 & 0.730 & & 0.983 \\
\hline & Model III & 96.739 & 0.882 & 0.541 & -0.818 & 0.990 \\
\hline \multirow{3}{*}{50} & Model I & 230.586 & 0.682 & & & 0.967 \\
\hline & Model II & 22.275 & 0.895 & 0.744 & & 0.978 \\
\hline & Model III & 108.428 & 0.885 & 0.554 & -0.828 & 0.986 \\
\hline \multirow{3}{*}{100} & Model I & 260.939 & 0.681 & & & 0.961 \\
\hline & Model II & 24.253 & 0.897 & 0.757 & & 0.973 \\
\hline & Model III & 119.424 & 0.888 & 0.566 & -0.835 & 0.982 \\
\hline \multirow{3}{*}{200} & Model I & 291.035 & 0.680 & & & 0.954 \\
\hline & Model II & 26.144 & 0.899 & 0.768 & & 0.968 \\
\hline & Model III & 129.886 & 0.890 & 0.577 & -0.841 & 0.977 \\
\hline \multicolumn{7}{|c|}{ PT3 GLS regional regression for (Region $5+$ Region 8) } \\
\hline$T$ (years) & Parameter & $a$ & $\boldsymbol{b}$ & $c$ & $\boldsymbol{d}$ & $R^{2}$ \\
\hline \multirow{3}{*}{2} & Model I & 45.243 & 0.707 & & & 0.817 \\
\hline & Model II & 39.260 & 0.723 & 0.052 & & 0.810 \\
\hline & Model III & 117.116 & 0.765 & 0.053 & -0.767 & 0.880 \\
\hline \multirow{3}{*}{5} & Model I & 65.254 & 0.700 & & & 0.813 \\
\hline & Model II & 65.315 & 0.699 & 0.001 & & 0.813 \\
\hline & Model III & 187.308 & 0.743 & 0.008 & -0.753 & 0.879 \\
\hline \multirow{3}{*}{10} & Model I & 78.017 & 0.696 & & & 0.810 \\
\hline & Model II & 83.033 & 0.689 & -0.022 & & 0.813 \\
\hline & Model III & 232.255 & 0.734 & -0.008 & -0.747 & 0.876 \\
\hline \multirow{3}{*}{20} & Model I & 89.698 & 0.693 & & & 0.807 \\
\hline & Model II & 100.009 & 0.681 & -0.038 & & 0.812 \\
\hline & Model III & 273.589 & 0.727 & -0.019 & -0.742 & 0.872 \\
\hline \multirow{3}{*}{25} & Model I & 93.287 & 0.692 & & & 0.805 \\
\hline & Model II & 105.372 & 0.678 & -0.043 & & 0.812 \\
\hline & Model III & 286.342 & 0.726 & -0.022 & -0.741 & 0.870 \\
\hline \multirow{3}{*}{50} & Model I & 104.015 & 0.690 & & & 0.800 \\
\hline & Model II & 121.813 & 0.672 & -0.056 & & 0.809 \\
\hline & Model III & 324.647 & 0.721 & -0.031 & -0.736 & 0.864 \\
\hline \multirow{3}{*}{100} & Model I & 114.215 & 0.688 & & & 0.795 \\
\hline & Model II & 138.017 & 0.667 & -0.067 & & 0.804 \\
\hline & Model III & 361.380 & 0.717 & -0.038 & -0.731 & 0.856 \\
\hline \multirow{3}{*}{200} & Model I & 123.992 & 0.687 & & & 0.788 \\
\hline & Model II & 154.068 & 0.663 & -0.076 & & 0.799 \\
\hline & Model III & 396.924 & 0.714 & -0.045 & -0.726 & 0.849 \\
\hline
\end{tabular}


Table 5.2.8. GLS Regression coefficients of GEV flood quantile estimates for merged area.

GEV GLS regional regression for (Region $1+$ Region 7)

\begin{tabular}{|c|c|c|c|c|c|c|}
\hline$T$ (years) & Parameter & $a$ & $b$ & $c$ & $d$ & $R^{2}$ \\
\hline \multirow{3}{*}{2} & Model I & 72.863 & 0.704 & & & 0.980 \\
\hline & Model II & 10.240 & 0.882 & 0.623 & & 0.986 \\
\hline & Model III & 41.071 & 0.874 & 0.455 & -0.723 & 0.988 \\
\hline \multirow{3}{*}{5} & Model I & 117.387 & 0.693 & & & 0.982 \\
\hline & Model II & 15.517 & 0.877 & 0.643 & & 0.987 \\
\hline & Model III & 67.285 & 0.868 & 0.466 & -0.765 & 0.991 \\
\hline \multirow{3}{*}{10} & Model I & 149.787 & 0.689 & & & 0.981 \\
\hline & Model II & 18.356 & 0.880 & 0.667 & & 0.988 \\
\hline & Model III & 82.611 & 0.871 & 0.486 & -0.785 & 0.993 \\
\hline \multirow{3}{*}{20} & Model I & 183.474 & 0.686 & & & 0.978 \\
\hline & Model II & 20.558 & 0.885 & 0.696 & & 0.987 \\
\hline & Model III & 95.386 & 0.876 & 0.511 & -0.802 & 0.993 \\
\hline \multirow{3}{*}{25} & Model I & 194.749 & 0.685 & & & 0.977 \\
\hline & Model II & 21.149 & 0.887 & 0.706 & & 0.986 \\
\hline & Model III & 99.012 & 0.878 & 0.521 & -0.807 & 0.992 \\
\hline \multirow{3}{*}{50} & Model I & 231.436 & 0.683 & & & 0.969 \\
\hline & Model II & 22.647 & 0.895 & 0.740 & & 0.980 \\
\hline & Model III & 108.840 & 0.885 & 0.552 & -0.822 & 0.987 \\
\hline \multirow{3}{*}{100} & Model I & 271.042 & 0.681 & & & 0.955 \\
\hline & Model II & 23.670 & 0.903 & 0.777 & & 0.968 \\
\hline & Model III & 116.572 & 0.894 & 0.587 & -0.837 & 0.977 \\
\hline \multirow{3}{*}{200} & Model I & 314.032 & 0.680 & & & 0.933 \\
\hline & Model II & 24.260 & 0.913 & 0.816 & & 0.950 \\
\hline & Model III & 122.302 & 0.904 & 0.625 & -0.852 & 0.960 \\
\hline \multicolumn{7}{|l|}{ GEV GLS re } \\
\hline$T$ (years) & Parameter & $a$ & $b$ & c & $d$ & $R^{2}$ \\
\hline \multirow{3}{*}{2} & Model I & 44.189 & 0.711 & & & 0.817 \\
\hline & Model II & 37.975 & 0.727 & 0.056 & & 0.810 \\
\hline & Model III & 112.978 & 0.769 & 0.056 & -0.763 & 0.880 \\
\hline \multirow{3}{*}{5} & Model I & 63.126 & 0.704 & & & 0.811 \\
\hline & Model II & 62.460 & 0.705 & 0.005 & & 0.811 \\
\hline & Model III & 179.037 & 0.748 & 0.011 & -0.749 & 0.880 \\
\hline \multirow{3}{*}{10} & Model I & 75.581 & 0.700 & & & 0.810 \\
\hline & Model II & 79.713 & 0.694 & -0.018 & & 0.813 \\
\hline & Model III & 222.955 & 0.739 & -0.006 & -0.744 & 0.878 \\
\hline \multirow{3}{*}{20} & Model I & 87.595 & 0.697 & & & 0.808 \\
\hline & Model II & 97.253 & 0.685 & -0.037 & & 0.813 \\
\hline & Model III & 266.073 & 0.731 & -0.020 & -0.739 & 0.874 \\
\hline \multirow{3}{*}{25} & Model I & 91.430 & 0.695 & & & 0.806 \\
\hline & Model II & 103.052 & 0.682 & -0.042 & & 0.812 \\
\hline & Model III & 280.066 & 0.729 & -0.023 & -0.737 & 0.872 \\
\hline \multirow{3}{*}{50} & Model I & 103.347 & 0.692 & & & 0.799 \\
\hline & Model II & 121.725 & 0.674 & -0.058 & & 0.808 \\
\hline & Model III & 324.438 & 0.721 & -0.035 & -0.732 & 0.861 \\
\hline \multirow{3}{*}{100} & Model I & 115.359 & 0.688 & & & 0.787 \\
\hline & Model II & 141.619 & 0.665 & -0.072 & & 0.798 \\
\hline & Model III & 370.810 & 0.714 & -0.047 & -0.726 & 0.845 \\
\hline \multirow{3}{*}{200} & Model I & 127.550 & 0.684 & & & 0.770 \\
\hline & Model II & 162.989 & 0.657 & -0.086 & & 0.782 \\
\hline & Model III & 419.860 & 0.706 & -0.059 & -0.720 & 0.822 \\
\hline
\end{tabular}


Table 5.2.9. GLS Regression coefficients of LPIII flood quantile estimates for merged area.

LP3 GLS regional regression for (Region $1+$ Region 7)

\begin{tabular}{|c|c|c|c|c|c|c|}
\hline$T$ (years) & Parameter & $a$ & $\boldsymbol{b}$ & $c$ & $d$ & $R^{2}$ \\
\hline \multirow{3}{*}{2} & Model I & 75.280 & 0.702 & & & 0.983 \\
\hline & Model II & 8.581 & 0.900 & 0.690 & & 0.990 \\
\hline & Model III & 37.428 & 0.891 & 0.512 & -0.769 & 0.993 \\
\hline \multirow{3}{*}{5} & Model I & 123.321 & 0.688 & & & 0.981 \\
\hline & Model II & 13.966 & 0.887 & 0.692 & & 0.988 \\
\hline & Model III & 66.194 & 0.878 & 0.505 & -0.814 & 0.993 \\
\hline \multirow{3}{*}{10} & Model I & 160.587 & 0.680 & & & 0.978 \\
\hline & Model II & 16.544 & 0.887 & 0.722 & & 0.987 \\
\hline & Model III & 82.744 & 0.877 & 0.529 & -0.842 & 0.993 \\
\hline \multirow{3}{*}{20} & Model I & 200.511 & 0.672 & & & 0.972 \\
\hline & Model II & 18.207 & 0.891 & 0.763 & & 0.982 \\
\hline & Model III & 95.758 & 0.881 & 0.564 & -0.870 & 0.990 \\
\hline \multirow{3}{*}{25} & Model I & 214.075 & 0.670 & & & 0.968 \\
\hline & Model II & 18.584 & 0.892 & 0.777 & & 0.980 \\
\hline & Model III & 99.294 & 0.883 & 0.577 & -0.879 & 0.988 \\
\hline \multirow{3}{*}{50} & Model I & 258.755 & 0.663 & & & 0.955 \\
\hline & Model II & 19.340 & 0.899 & 0.825 & & 0.969 \\
\hline & Model III & 108.432 & 0.889 & 0.620 & -0.906 & 0.979 \\
\hline \multirow{3}{*}{100} & Model I & 307.767 & 0.656 & & & 0.933 \\
\hline & Model II & 19.582 & 0.906 & 0.877 & & 0.950 \\
\hline & Model III & 115.116 & 0.897 & 0.667 & -0.933 & 0.963 \\
\hline \multirow{3}{*}{200} & Model I & 361.705 & 0.649 & & & 0.901 \\
\hline & Model II & 19.433 & 0.915 & 0.931 & & 0.922 \\
\hline & Model III & 119.741 & 0.905 & 0.717 & -0.961 & 0.937 \\
\hline \multicolumn{7}{|c|}{ LP3 GLS regional regression for (Region $5+$ Region 8 ) } \\
\hline$T$ (years) & Parameter & $a$ & $b$ & $c$ & $\boldsymbol{d}$ & $R^{2}$ \\
\hline \multirow{3}{*}{2} & Model I & 46.618 & 0.706 & & & 0.823 \\
\hline & Model II & 39.250 & 0.724 & 0.063 & & 0.815 \\
\hline & Model III & 110.705 & 0.764 & 0.063 & -0.726 & 0.886 \\
\hline \multirow{3}{*}{5} & Model I & 66.826 & 0.699 & & & 0.815 \\
\hline & Model II & 66.022 & 0.700 & 0.005 & & 0.815 \\
\hline & Model III & 177.884 & 0.741 & 0.012 & -0.708 & 0.885 \\
\hline \multirow{3}{*}{10} & Model I & 79.279 & 0.695 & & & 0.815 \\
\hline & Model II & 83.580 & 0.689 & -0.018 & & 0.818 \\
\hline & Model III & 218.152 & 0.731 & -0.005 & -0.696 & 0.885 \\
\hline \multirow{3}{*}{20} & Model I & 90.592 & 0.692 & & & 0.815 \\
\hline & Model II & 100.006 & 0.681 & -0.034 & & 0.820 \\
\hline & Model III & 253.678 & 0.724 & -0.017 & -0.686 & 0.884 \\
\hline \multirow{3}{*}{25} & Model I & 94.065 & 0.691 & & & 0.815 \\
\hline & Model II & 105.134 & 0.679 & -0.039 & & 0.820 \\
\hline & Model III & 264.400 & 0.722 & -0.021 & -0.682 & 0.882 \\
\hline \multirow{3}{*}{50} & Model I & 104.475 & 0.689 & & & 0.812 \\
\hline & Model II & 120.747 & 0.673 & -0.051 & & 0.819 \\
\hline & Model III & 296.133 & 0.717 & -0.029 & -0.672 & 0.876 \\
\hline \multirow{3}{*}{100} & Model I & 114.441 & 0.686 & & & 0.806 \\
\hline & Model II & 136.061 & 0.667 & -0.060 & & 0.814 \\
\hline & Model III & 326.092 & 0.712 & -0.037 & -0.661 & 0.866 \\
\hline \multirow{3}{*}{200} & Model I & 124.093 & 0.684 & & & 0.797 \\
\hline & Model II & 151.280 & 0.662 & -0.069 & & 0.806 \\
\hline & Model III & 354.926 & 0.707 & -0.045 & -0.650 & 0.853 \\
\hline
\end{tabular}


The $95 \%$ confidence interval are calculated for all the measurements in each region. The results for annual peak flow is shown in Figure 5.3.1. There are four series of data plotted: observed mean annual peak flow, GLS-regressed mean annual peak flow, 95\% confidence interval upper limit and 95\% confidence limits. Simple linear fitting is applied for each of them in order to show the trend of each data set. The observed and estimated means are very close to each other. Except for Region 4 and Region 6, the two trend lines in the other six regions are almost overlapping. Figure 5.3.2 shows the histograms of the distribution of the drainage area. In Regions 4 and 6 most of the drainage areas are greater than 100 square miles and there are few small drainage areas with high variability flow than in the other regions.

Table 5.3.1. GLS regional regression for mean annual peak flows.

\begin{tabular}{lcccccc}
\hline & Parameter & $\boldsymbol{a}$ & $\boldsymbol{b}$ & $\boldsymbol{c}$ & $\boldsymbol{d}$ & $\boldsymbol{R}^{2}$ \\
\hline \multirow{3}{*}{ Region 1 } & Model I & 173.4825 & 0.6309 & & & 0.9881 \\
& Model II & 37.3649 & 0.7779 & 0.4602 & & 0.9951 \\
& Model III & 42.5792 & 0.7763 & 0.4406 & -0.0627 & 0.9953 \\
\hline \multirow{2}{*}{ Region 2 } & Model I & 299.5047 & 0.5894 & & & 0.961 \\
& Model II & 32.1958 & 0.8256 & 0.5314 & & 0.9846 \\
& Model III & 81.8451 & 0.7822 & 0.3841 & -0.3468 & 0.9793 \\
\hline \multirow{3}{*}{ Region 3 } & Model I & 226.0649 & 0.7443 & & & 0.8972 \\
& Model II & 41.8274 & 0.9055 & 0.4197 & & 0.9335 \\
& Model III & 40.0037 & 0.9065 & 0.4231 & 0.0339 & 0.9333 \\
\hline \multirow{3}{*}{ Region 4 } & Model I & 145.918 & 0.6712 & & & 0.9091 \\
& Model II & 21.6708 & 0.8161 & 0.6508 & & 0.937 \\
& Model III & 34.0161 & 0.8328 & 0.6172 & -0.4202 & 0.9524 \\
\hline \multirow{3}{*}{ Region 5 } & Model I & 50.2466 & 0.7005 & & & 0.9556 \\
& Model II & 19.3921 & 0.8038 & 0.3927 & & 0.9709 \\
& Model III & 25.7894 & 0.7971 & 0.3779 & -0.1358 & 0.971 \\
\hline \multirow{3}{*}{ Region 6 } & Model I & 94.6589 & 0.5154 & & & 0.9026 \\
& Model II & 12.9361 & 0.7811 & 0.6608 & & 0.9352 \\
& Model III & 11.5316 & 0.7621 & 0.6054 & 0.1367 & 0.9378 \\
\hline \multirow{2}{*}{ Region 7 } & Model I & 53.8668 & 0.7342 & & & 0.9845 \\
& Model II & 8.2252 & 0.8914 & 0.6306 & & 0.9765 \\
& Model III & 52.7069 & 0.896 & 0.539 & -1.1561 & 0.9892 \\
\hline \multirow{3}{*}{ Region 8 } & Model I & 49.8341 & 0.6986 & & & 0.7204 \\
& Model II & 96.4878 & 0.6277 & -0.2204 & & 0.7637 \\
& Model III & 143.2239 & 0.8076 & 0.0277 & -0.9783 & 0.7449 \\
\hline
\end{tabular}


Table 5.3.2. GLS regional regression for mean of logarithms of annual peak flows.

\begin{tabular}{ccccccc}
\hline & Parameter & $\boldsymbol{a}$ & $\boldsymbol{b}$ & $\boldsymbol{c}$ & $\boldsymbol{d}$ & $\boldsymbol{R}^{2}$ \\
\hline \multirow{3}{*}{ Region 1 } & Model I & 5.3345 & 0.0779 & & & 0.9645 \\
& Model II & 5.0811 & 0.0824 & 0.0152 & & 0.9639 \\
& Model III & 4.7038 & 0.0857 & 0.033 & 0.0223 & 0.9645 \\
\hline \multirow{2}{*}{ Region 2 } & Model I & 5.7749 & 0.0728 & & & 0.894 \\
& Model II & 4.6272 & 0.0944 & 0.0557 & & 0.9063 \\
& Model III & 5.896 & 0.0811 & 0.0178 & -0.0796 & 0.9101 \\
\hline \multirow{2}{*}{ Region 3 } & Model I & 5.2372 & 0.1085 & & & 0.9546 \\
& Model II & 3.6401 & 0.1458 & 0.087 & & 0.9694 \\
& Model III & 3.5076 & 0.1467 & 0.0896 & 0.0287 & 0.9703 \\
\hline \multirow{3}{*}{ Region 4 } & Model I & 5.2189 & 0.0874 & & & 0.9264 \\
& Model II & 4.1978 & 0.1041 & 0.073 & & 0.9517 \\
& Model III & 4.5072 & 0.1075 & 0.0679 & -0.0693 & 0.9583 \\
\hline \multirow{3}{*}{ Region 5 } & Model I & 4.7561 & 0.0868 & & & 0.9472 \\
& Model II & 3.7632 & 0.1137 & 0.079 & & 0.9603 \\
& Model III & 3.9458 & 0.1149 & 0.08 & -0.0316 & 0.9677 \\
\hline \multirow{3}{*}{ Region 6 } & Model I & 4.8775 & 0.0708 & & & 0.881 \\
& Model II & 3.4816 & 0.1175 & 0.0924 & & 0.9253 \\
& Model III & 3.4933 & 0.1174 & 0.0899 & -0.0017 & 0.9242 \\
\hline \multirow{2}{*}{ Region 7 } & Model I & 3.6987 & 0.1276 & & & 0.9461 \\
& Model II & 2.9408 & 0.1448 & 0.0874 & & 0.9532 \\
& Model III & 3.9225 & 0.1416 & 0.0891 & -0.1828 & 0.979 \\
\hline \multirow{2}{*}{ Region 8 } & Model I & 4.0622 & 0.1119 & & & 0.7936 \\
& Model II & 4.2363 & 0.1072 & -0.013 & & 0.795 \\
& Model III & 4.6362 & 0.1228 & 0.0269 & -0.1297 & 0.9148 \\
\hline
\end{tabular}

In all regression methods high variations in small drainage areas is not reflected. Also, the $95 \%$ confidence intervals are added to the logarithms of mean annual peak flow and these are shown in Figure 5.3.3. Regions 3, 5, 7 and 8 have perfect match and Regions 1, 2, 4 and 6 are not as close.

By the using the GLS regression, we can obtain the mean (or logmean) for the location of interest. Furthermore, we need to use the information of regional normalized quantile $\hat{x}_{T}$, which is presetned in Chapter 4. It is based on regional L-moment method and ends up with a parameter $\hat{x}_{T}$ for a specific recurrence interval $\mathrm{T}$ years. Once the first L-moment $\lambda_{k}(\mathrm{mean})$ at site 
$k$ is available, it is multiplied by $\hat{x}_{T}$. In other words, the estimated T-year quantile flood is $\hat{x}_{T}^{k}(=$ $\lambda_{k} \cdot \hat{x}_{T}$ in unit cfs). For LPIII distribution, the first L-moment should be replaced by the mean of the logarithms of the flows $\lambda_{k}{ }^{\prime}$, and the estimated T-year quantile flood is $\hat{x}_{T}^{k}\left(=10^{\lambda_{1} x_{7}}\right)$ in unit cfs). 

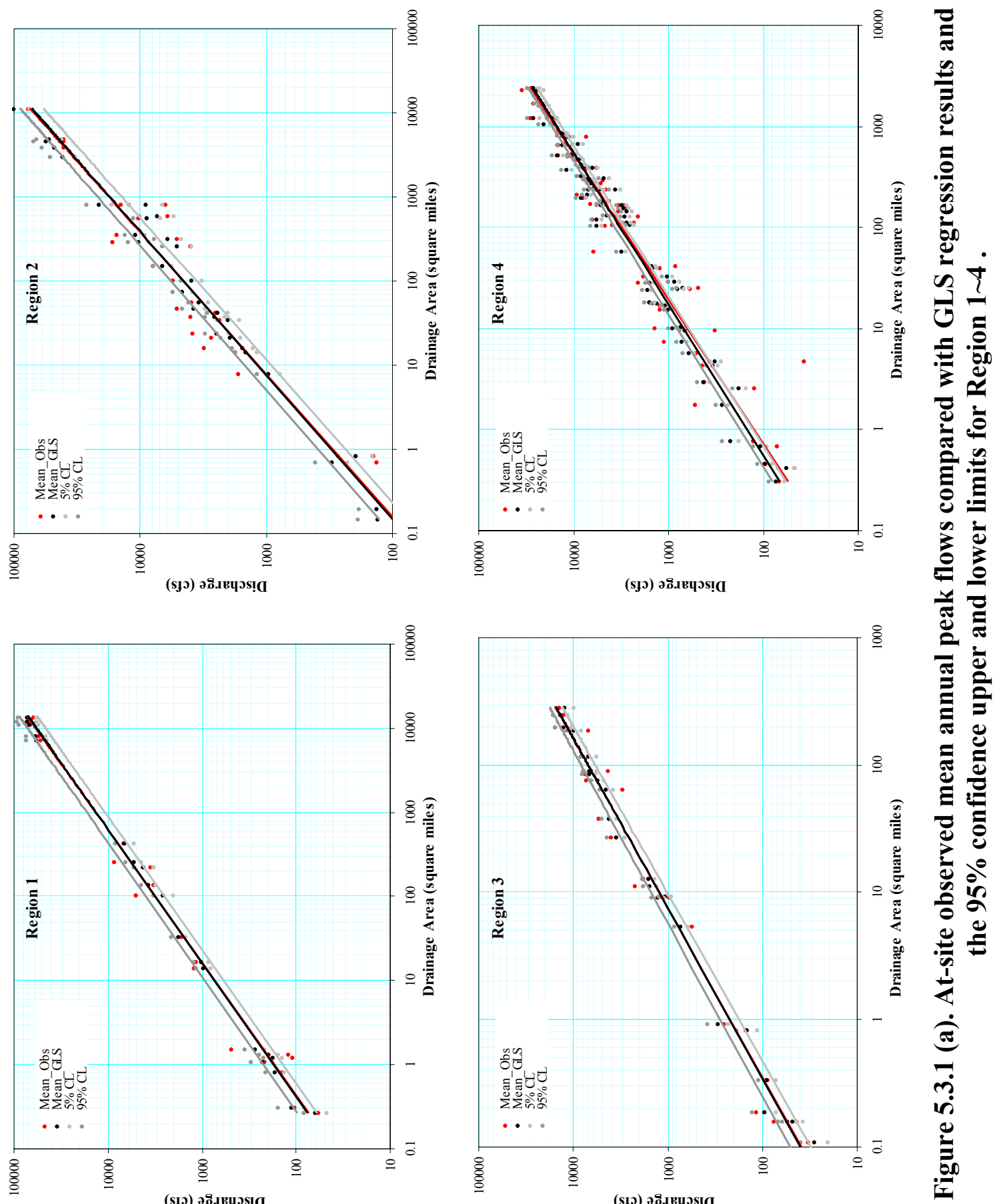

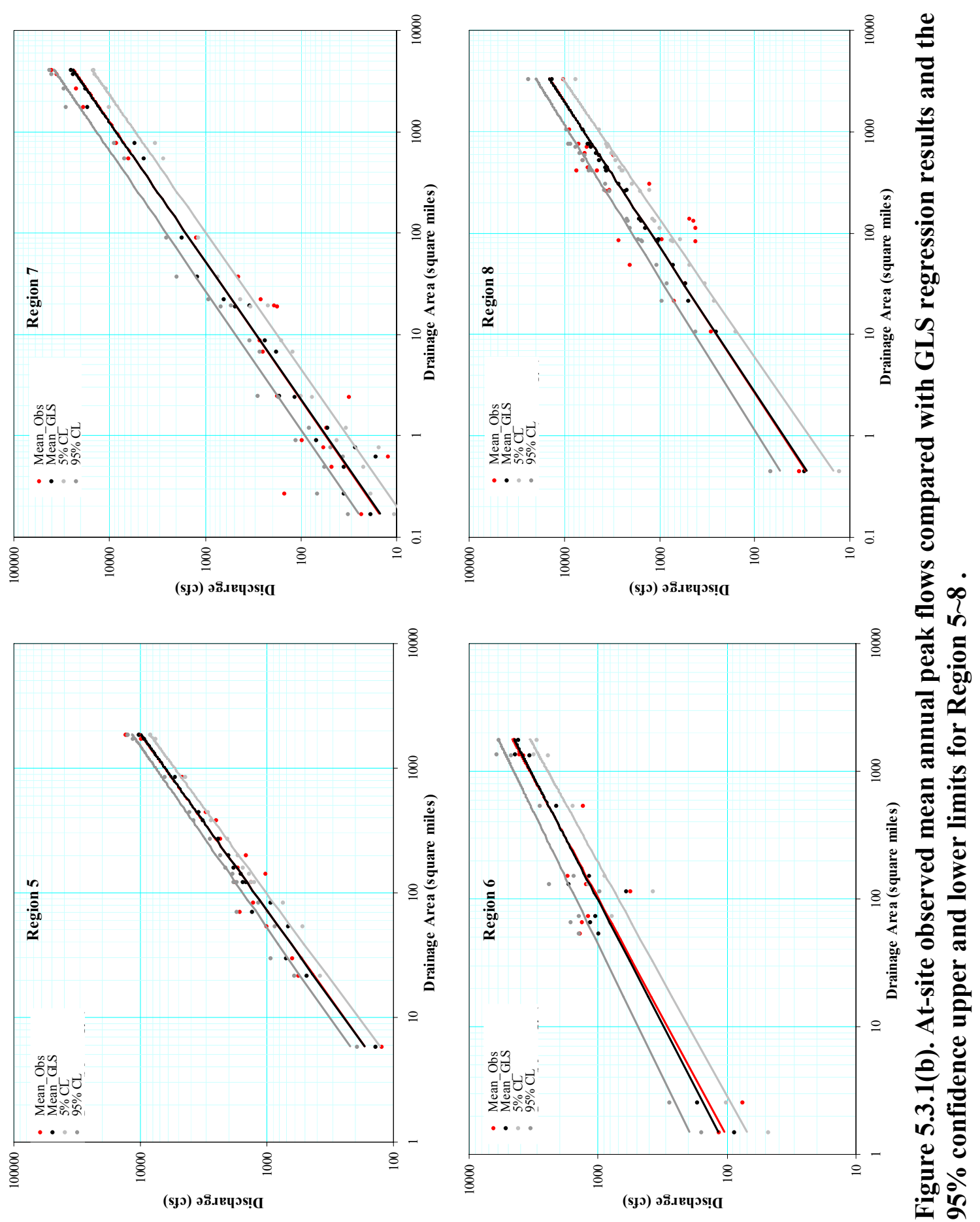

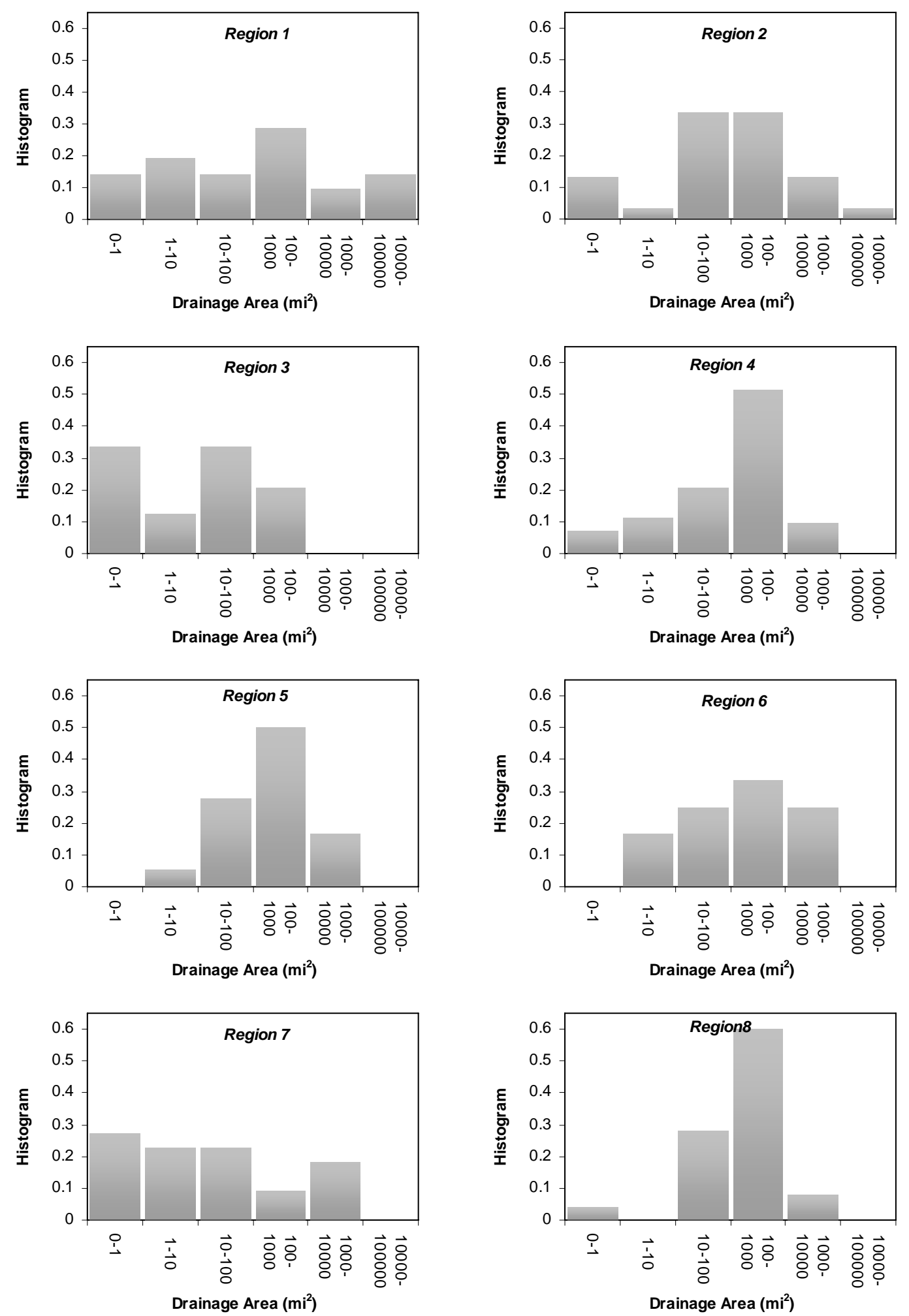

Figure 5.3.2. Histographs of drainage areas for each region. 

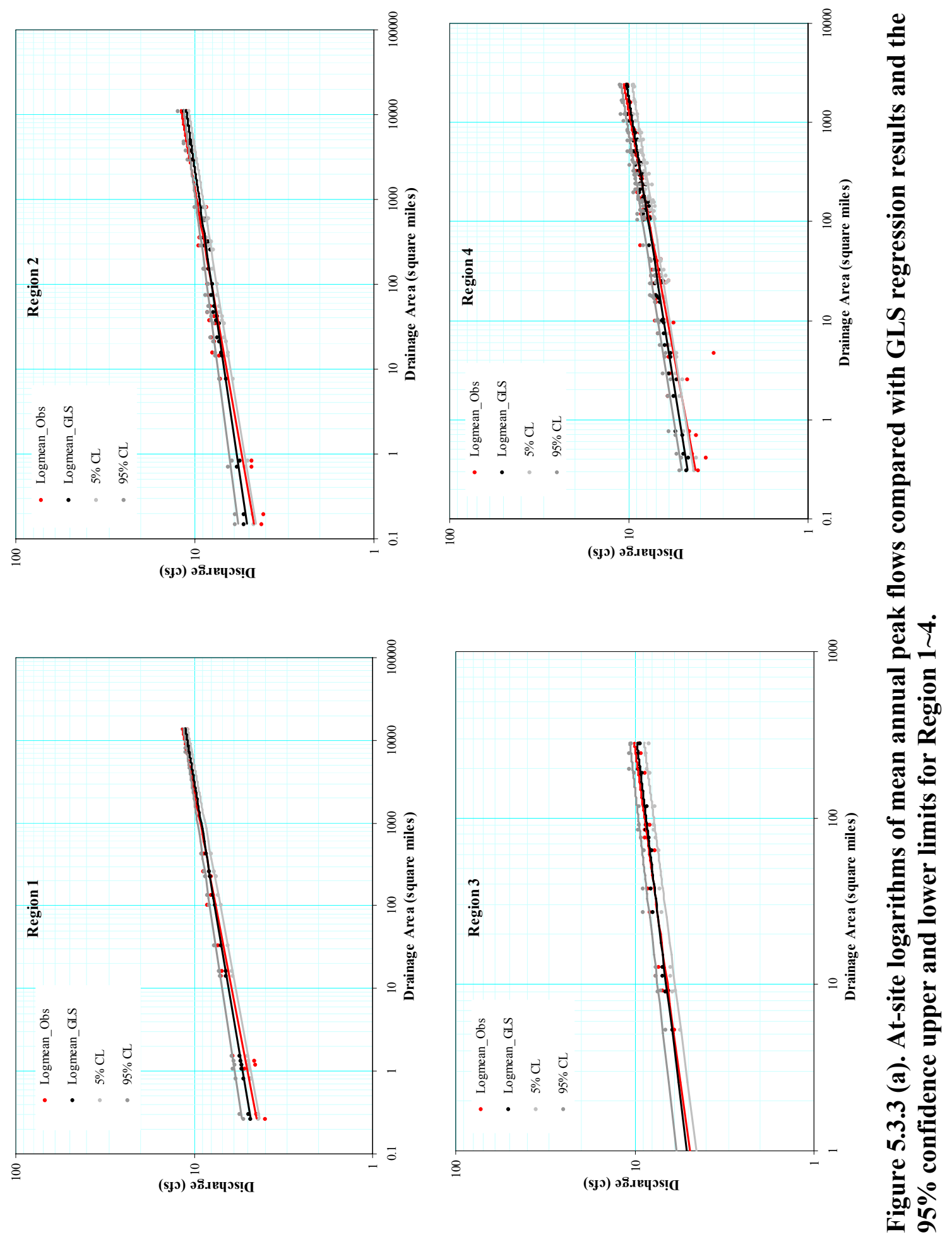

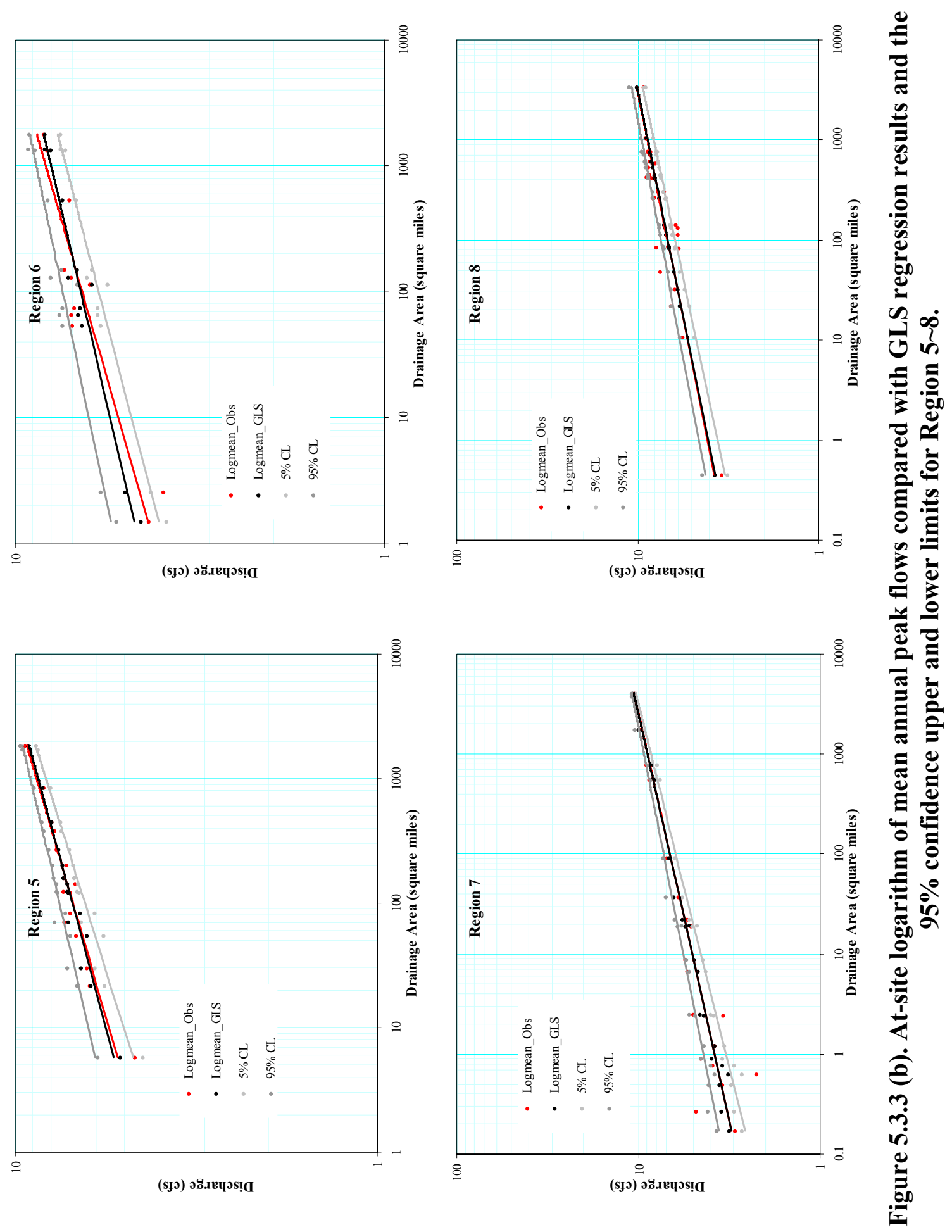


\section{Comparative Analysis}

There are three methods by which the equations derived in this study can be used. In the first method, the normalized regional quantiles can be used with the observed mean value of annual maximum flows at a site to compute the flood frequencies at specific recurrence intervals. In the second method, the mean values are estimated by using hydrological characteristics at a site, such as the watershed area and stream slope and these mean values are used with the normalized regional quantiles to estimate the flood magnitudes. In the third method, the equations for quantiles derived by the GLS method are used directly to obtain flood magnitudes.

The accuracies of these methods differ. The first method should give the smallest error because only the normalized quantiles are used with the observed means of annual maximum flows. In the second method, the mean peak flows are estimated by using the regression relationships along with the normalized regional quantiles. The third method is based entirely on regression relationships. The errors associated with the second and third methods may depend on the regions to which the equations apply.

Before these procedures, especially the second and third methods, are recommended for use the errors associated with their use must be quantified. This is achieved by using split sample tests. The data from each region is divided into two parts, each containing $75 \%$ and $25 \%$ of the data. The $25 \%$ of the data is selected to reflect the distribution of the watershed areas so that the test involves a range of areas. The $75 \%$ of the data is used to estimate the parameters of the equations used for that method. The data in $25 \%$ of the sample are used to estimate the floods

and these are compared to the observed quantiles. This analysis would enable us to estimate the errors. The procedures used in the three methods are schematically shown in Figure 6.1.1. 


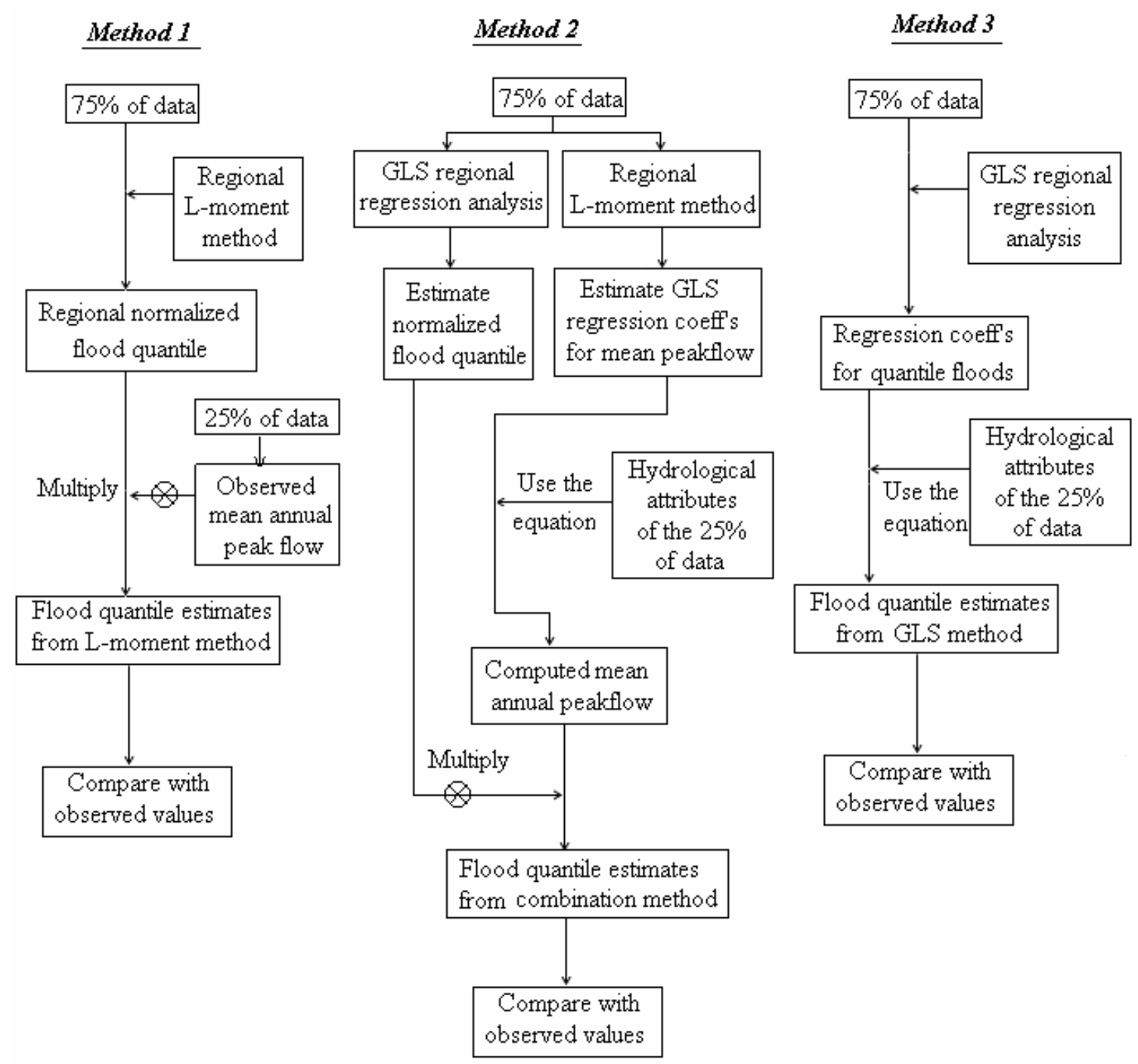

Figure 6.1.1. Flowchart of three comparison methods.

\subsection{Split sample test for first method}

The mean annual peak flow in this method is calculated from $25 \%$ of the data. The observed mean annual peak flow computed from observed data is multiplied by the normalized regional quantiles and compared to at-site quantiles of observed data. The measure to evaluate the error is the variance calculated by Eqn.3.2.4. The total number of stations in each region are 
$21,30,24,72,18,12,22$ and 25 ; hence, $25 \%$ of the observations are $5,8,6,18,5,3,6$ and 6 , respectively, and they are selected based on their drainage areas. This analysis is valid only in homogeneous or possibly homogeneous regions. The data from region 6 , which is heterogeneous, is included only for the sake of completion.

The validated results are plotted in Figure 6.1.2 and the variances are shown in Figure 6.1.3. The recurrence intervals of 50,100 and 200 years are shown as examples. The $x$-axis has the at-site quantile estimates and $y$-axis is quantile estimates calculated from the regional Lmoment method. These results show that Gamma distribution mostly overestimates the floods while LPIII distribution underestimates them. PTIII, LNIII and GEV produce consistent and better estimates. Also, results from Figure 6.1.3 indicate that Gamma and LPIII distribution are not good candidates for regional flood estimation. Results from PTIII are better than the others and hence PTIII is the best distribution according to this test. The optimal probability distributions for regional flood estimates from this test are summarized in Table 6.1.1. It is a two step selection. The results show that PTIII is the favored distribution to Regions 3, 4, 5 and 7, LP3 is preferred for Regions 1 and 8, and GEV is good for Regions 2 and 6. PTIII is acceptable for regions 1, 2, 6 and 8 as the second best distribution.

All these homogeneous or possible homogeneous regions $(1,2,3,4,5,7$, and 8$)$ have estimates close to 45 degree lines; the estimates in region 6, which is the heterogeneous region, is further away the 45 degree line. It indicates that flood estimates from a heterogeneous region are not accurate. Hence, once a region fails homogeneity tests, stable regional estimation is not possible. 
As the recurrence interval increases, the estimates deviate more from the 45-degree line, especially for 200 year floods. This behavior is caused by extrapolation errors. Also, we find that the prediction result is less stable for low flows which are mostly from small drainage areas. The hydrological responses from small watersheds are easily affected by local events. Higher value of streamflow corresponds to larger drainage areas which follow the regional properties well and are less influenced by local events. Similar conclusion is seen in Method 2 and Method 3.

\section{Table 6.1.1. Optimal probability distributions for regional flood estimates.}

\begin{tabular}{ccc}
\hline Region No. & Candidate Probability Distributions & Optimal Distributions for Regional Estimates \\
\hline 1 & PT3, GM2, LN3, GEV, LP3 & LP3, PT3, LN3 \\
2 & GEV, LN3, PT3, GM2, GLO & GEV, PT3, LN3 \\
3 & GEV, LN3, LP3, GLO, PT3 & PT3, LN3, GEV \\
4 & GEV, LN3, LP3, PT3, GM2 & PT3, LN3, GEV \\
5 & GEV, LN3, LP3, PT3, GM2 & PT3, LN3, GEV \\
6 & LN3, PT3, GM2, GLO, GEV & GEV, PT3, LN3 \\
7 & PT3, GM2, LN3, GEV, LP3 & PT3, LN3, GEV \\
8 & LP3, GLO, GEV, LN3, PT3 & LP3, PT3, LN3 \\
\hline
\end{tabular}

Note: 1). Candidate probability distributions are determined from the mean-square-error of Lmoment ratio diagram of the $75 \%$ of data, and the order is beginning with the one having the minimum MSE. 2). Optimal distributions for regional estimates are obtained from the variances of L-moment regional estimates from the $25 \%$ of data. 

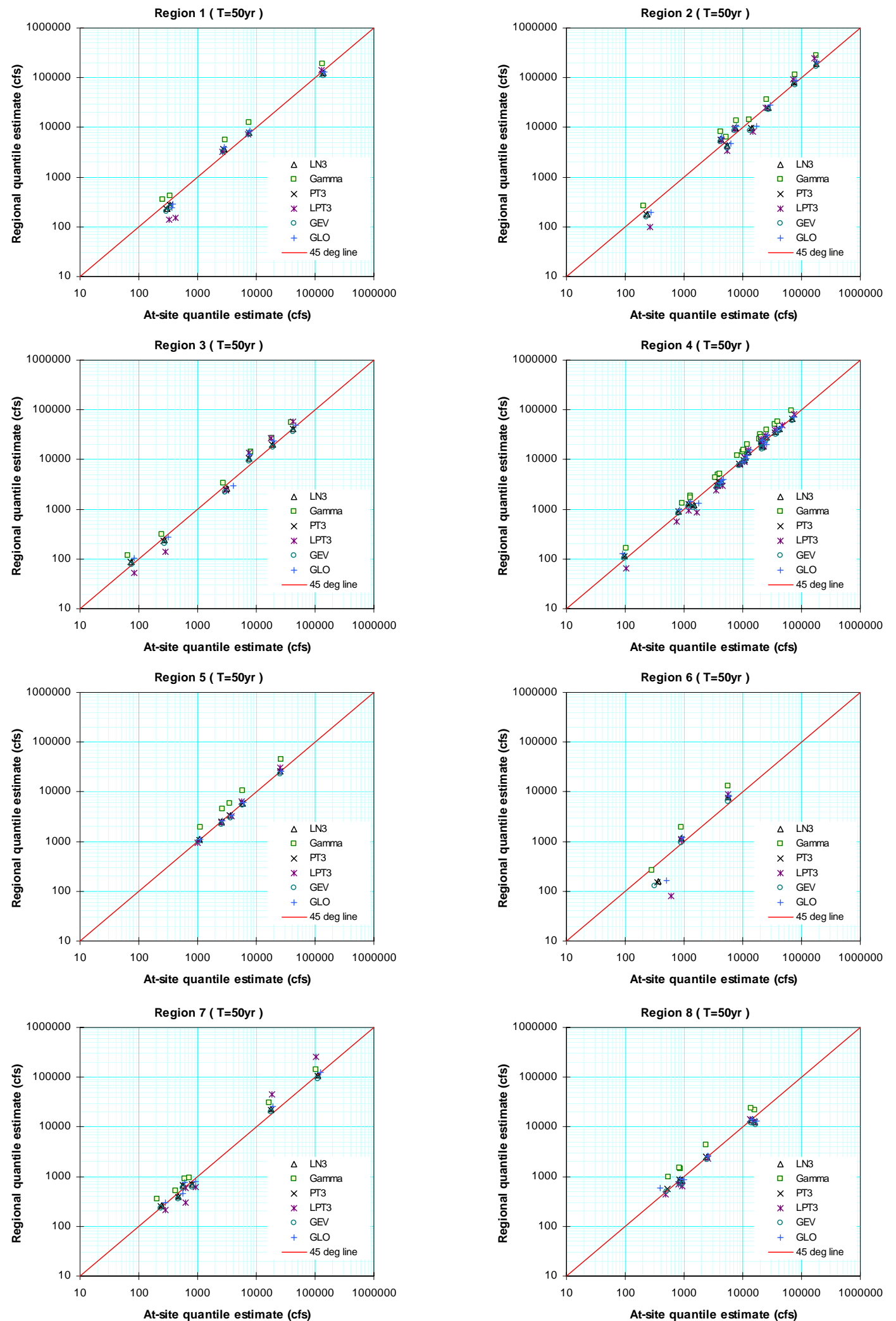

Figure 6.1.2(a) Results of at-site and regional quantile floods from method 1 ( $T=50$ year). 

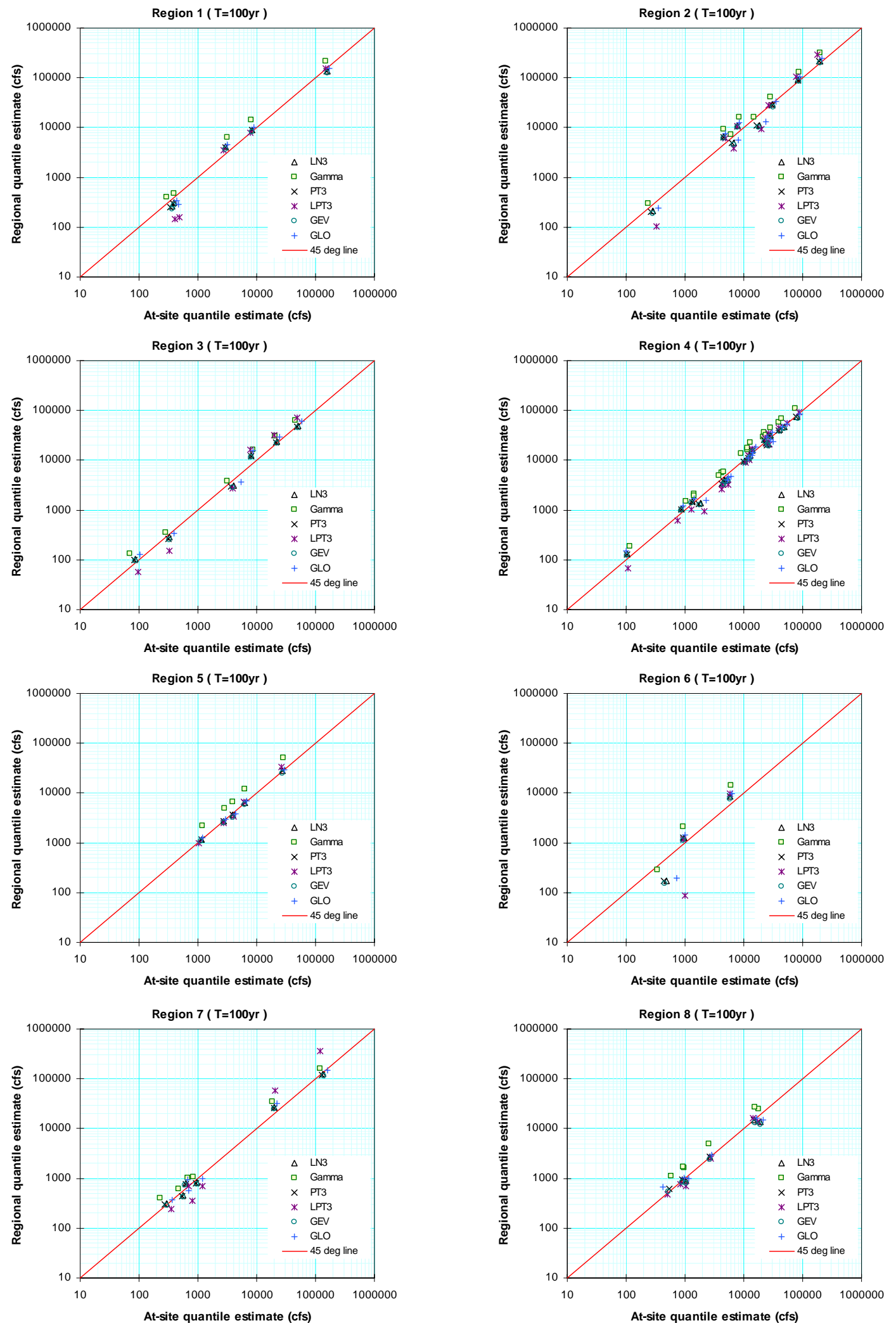

Figure 6.1.2(b) Results of at-site and regional quantile floods from method 1 ( $T=100$ year). 

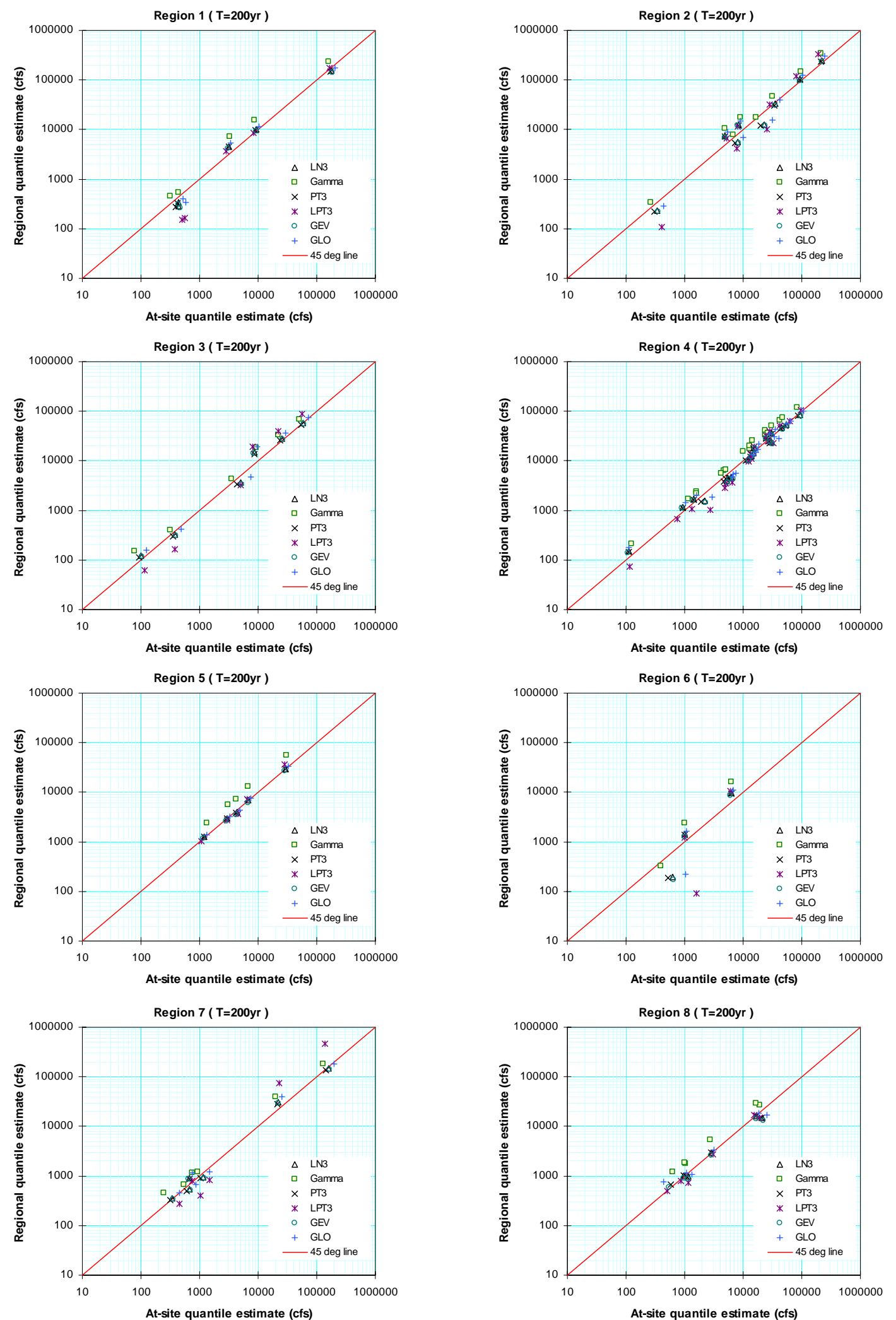

Figure 6.1.2(c) Results of at-site and regional quantile floods from method 1 ( $T=200$ year). 

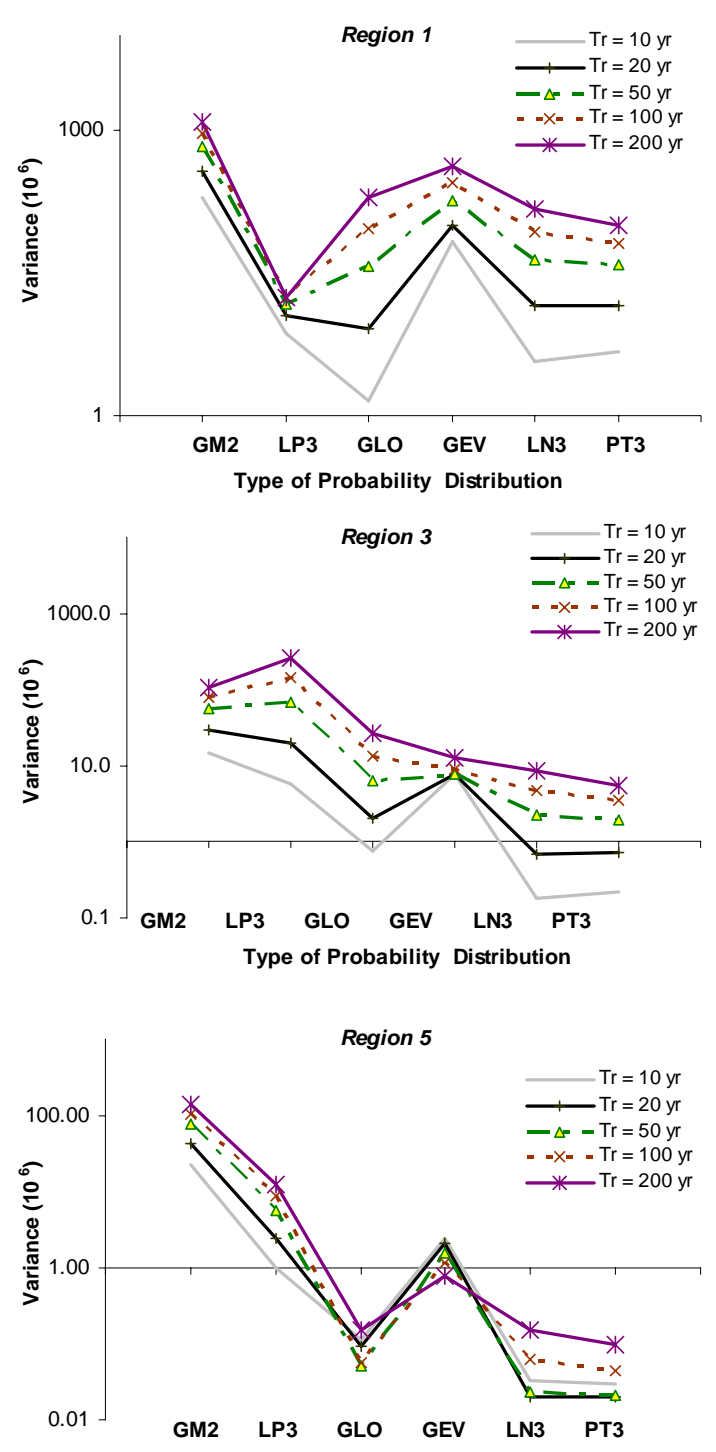

Type of Probability Distribution

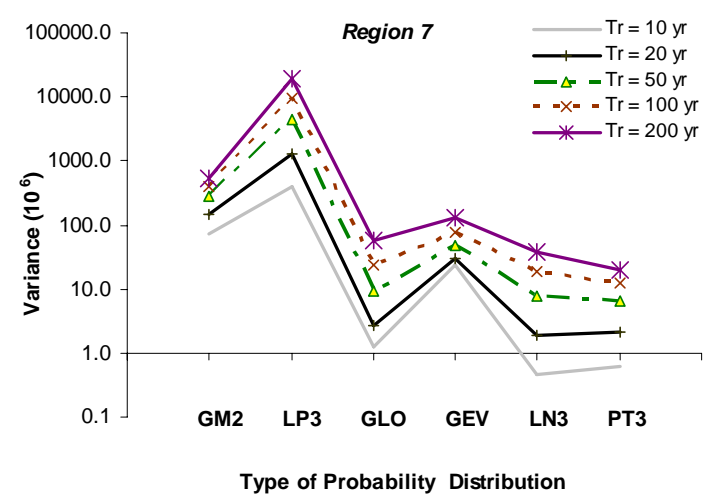

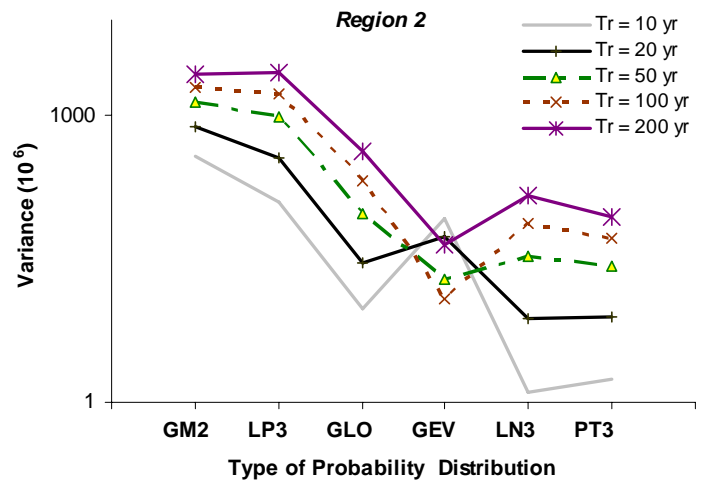
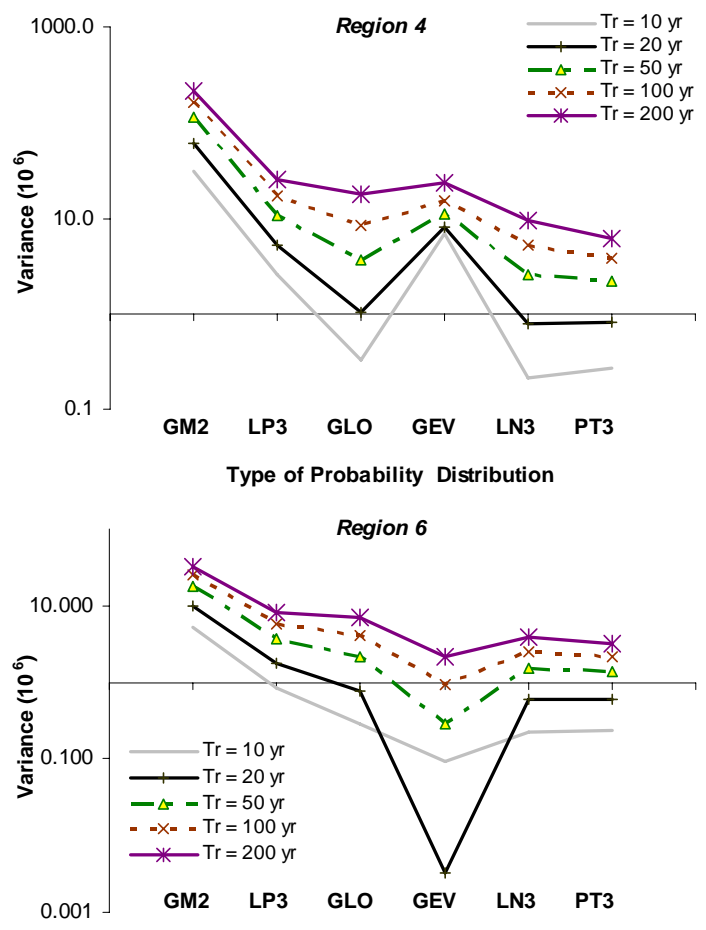

Type of Probability Distribution

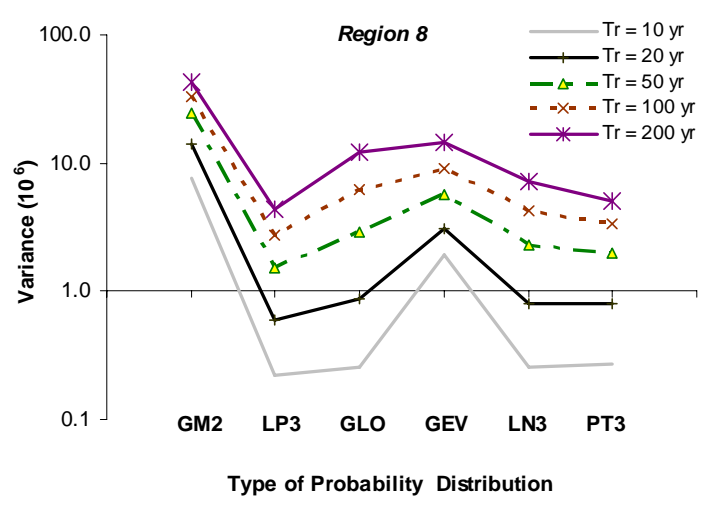

Figure 6.1.3. Variance of the difference between at-site and regional estimates from method 1. 


\subsection{Split sample test for the second method}

The second comparative method is the combination of GLS and L-moment methods. The concepts of regional index flood and GLS regional regression are used to test the prediction accuracy. The normalized regional flood quantile is established from the $75 \%$ data. The GLS regional regression is used to estimate the mean annual peakflows from the $75 \%$ data.

The at-site and regional flood quantile estimations are calculated by Method 2 by using 25\% of data. Results from Figure 6.2.1(a), Region 3 and Region 5 have best accuracy for PTIII distribution. The best estimates for region 1 are from GEV distribution (Figure 6.2.1(b)) and LPIII distribution gives the best estimates for region 3 (Figure 6.2.1(c)). Results from region 6, 7 and 8 are not good; Region 6 and 7 have poor results for small drainage areas. The results in Table 6.2.1 explain these poor results because of the small correlation coefficient between hydrological attributes and qunatile floods. The correlation between drainage area and quantile flood in Region 8 is the poorest one, reflecting the poor results for region 8 .

\subsection{Split sample test for the third method}

To examine the accuracy flood estimated from GLS regional regression, the estimated parameters are directly applied with the hydrological attributes. $75 \%$ of data is used to calculate the GLS regional regression in order to obtain the coefficients and exponents (for example, $a^{\prime}$, $b^{\prime}, c^{\prime}, d^{\prime}$ from equation $\left.Q_{T}=a^{\prime} A^{b^{\prime}} S^{c^{\prime}}(1+W \%)^{d^{\prime}}\right)$, are used to estimate floods from the $25 \%$ of data. 

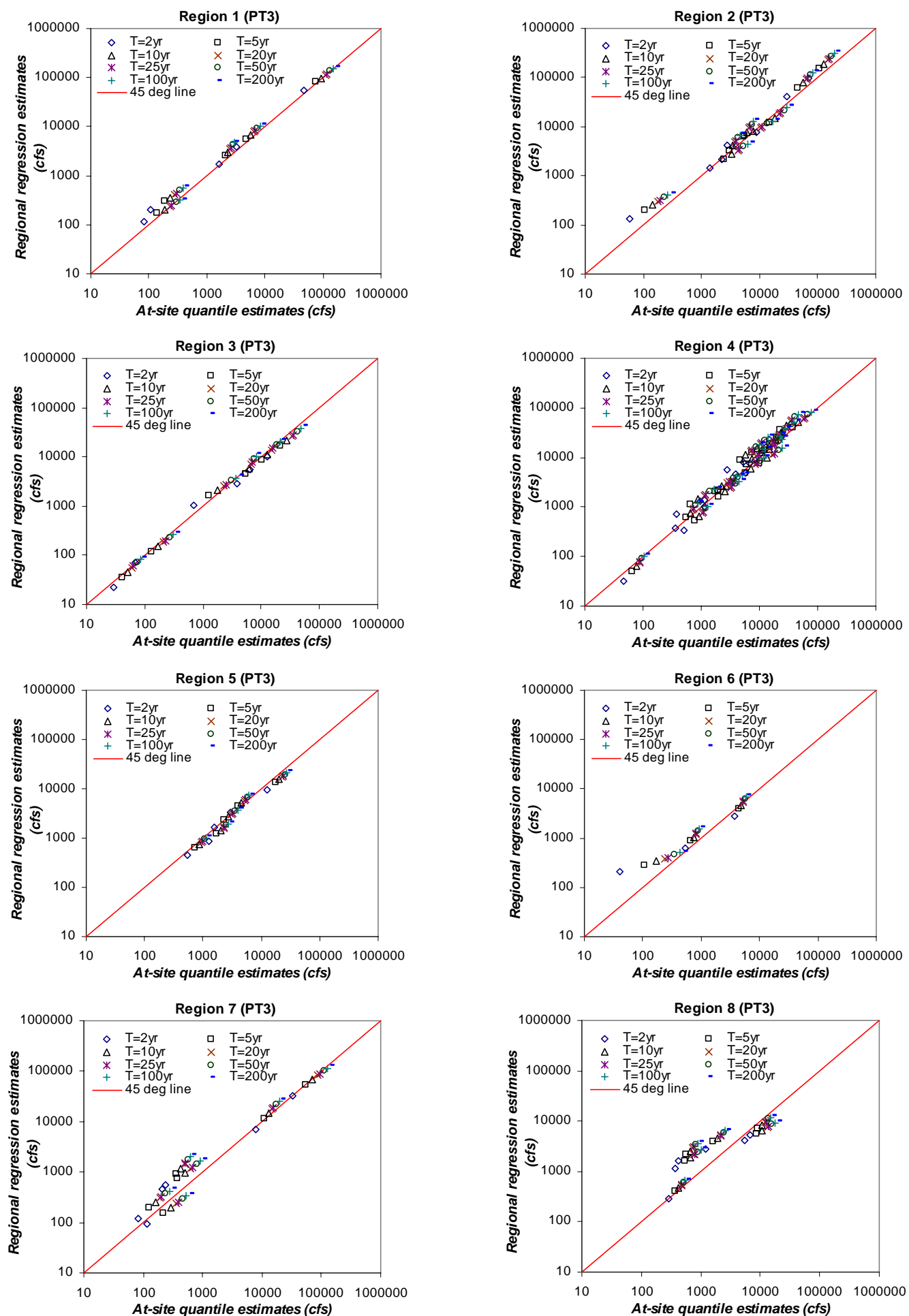

Figure 6.2.1(a). At-site quantile floods and the quantile floods obtained by Method 2 for $25 \%$ of the data (PTIII). 

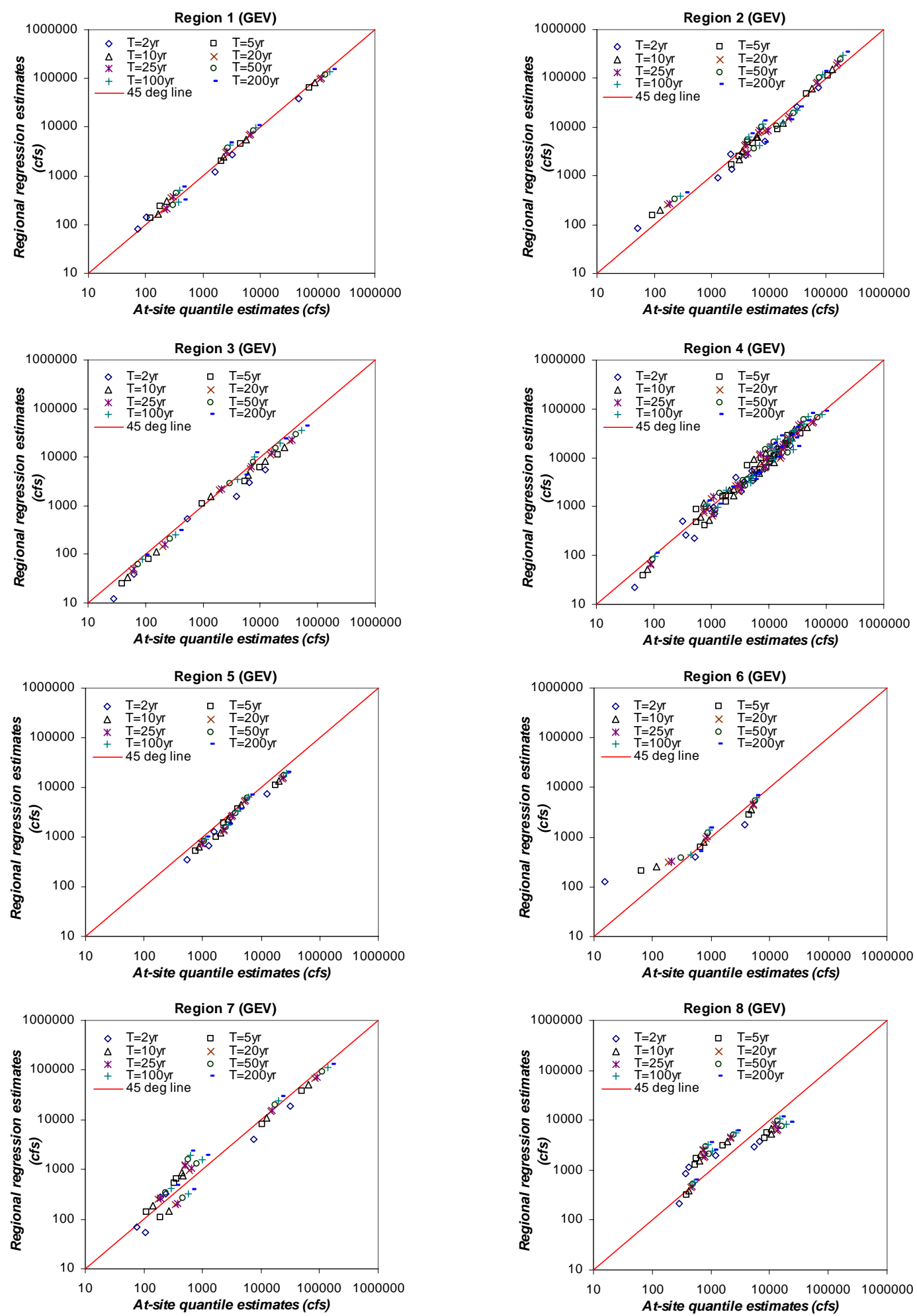

Figure 6.2.1(b). At-site quantile floods and the quantile floods obtained by Method 2 for $25 \%$ of the data (GEV). 

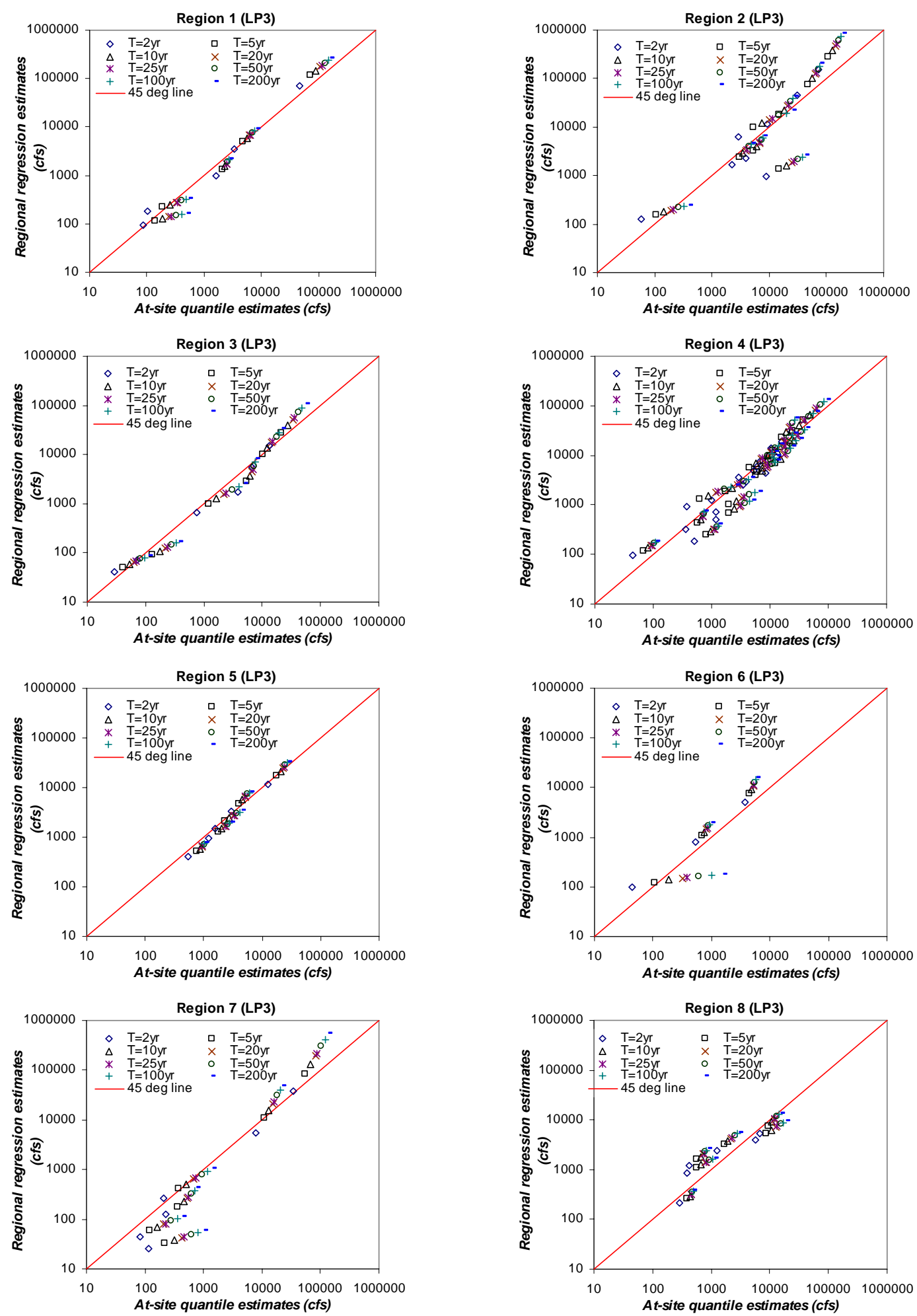

Figure 6.2.1(c). At-site quantile floods and the quantile floods obtained by Method 2 for $25 \%$ of the data (LPIII). 
The validation results are shown in Figure 6.3.1(a), 6.3.1(b) and 6.3.1(c) for PTIII, GEV, and LPIII distributions, respectively. The y-axis is the value calculated from using the drainage area, slope and percentage wet area of $25 \%$ of the data with the GLS regression equation which is built from the $75 \%$ data; the $\mathrm{x}$-axis is the at-site quantile flood estimates for these $25 \%$ data. Flood estimates for eight recurrence intervals at each site are plotted in the same figure. If they are approaching 45-degree line, it indicates a better capability to predict. Most cases in Figure 6.3.1(a) shows that GLS regression and PTIII quantile floods are in good agreement, except for some outlier points in Region 6,7 and 8. Similarly, the same situation occurs to the fitting of GEV floods in Figure 6.3.1(b). For LPIII floods (in Figure 6.3.1(c)), besides the outlier in Region 6, 7 and 8, there are more errors in Region 2 than PTIII and GEV.

In summary, Figure 6.3.1 shows the average errors of at-site and regional quantile floods to the third test case (simply considering the GLS regression), and Figure 6.2.1 is to the second test case (combination of regional index flood and GLS regression). The third method does not indicate too many differences among PTIII, GEV and LPIII probability distributions because the result of GLS regression is dominated by the correlation between hydrologic attributes and quantile floods. The second case shows PTIII and GEV having similar response, but LP3 yields worst result. The reason is the same as we have described in Chapter 3 that LPIII is not a good candidate for regional L-moment method of flood estimation. Except for Region 6, the results from either GLS regression or combination method are quite reliable and follow the trend well. Region 7 may have more estimation errors for small drainage areas (less than 1000 square miles) and Region 8 has more error for the drainage areas in the range of 500 5000 square miles. 

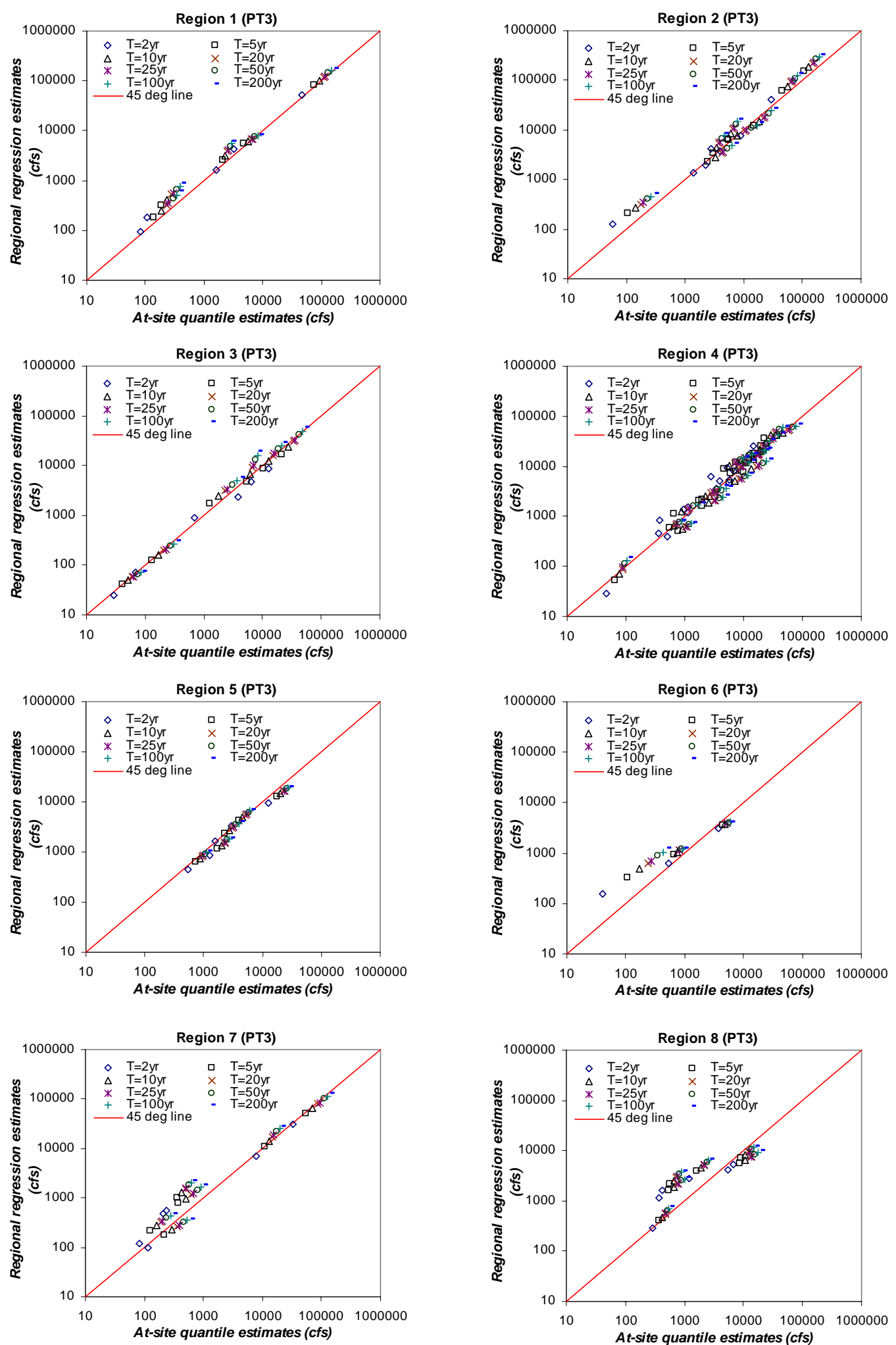

Figure 6.3.1(a). At-site quantile floods and the quantile floods obtained by Method 3 for $25 \%$ of the data (PTIII). 

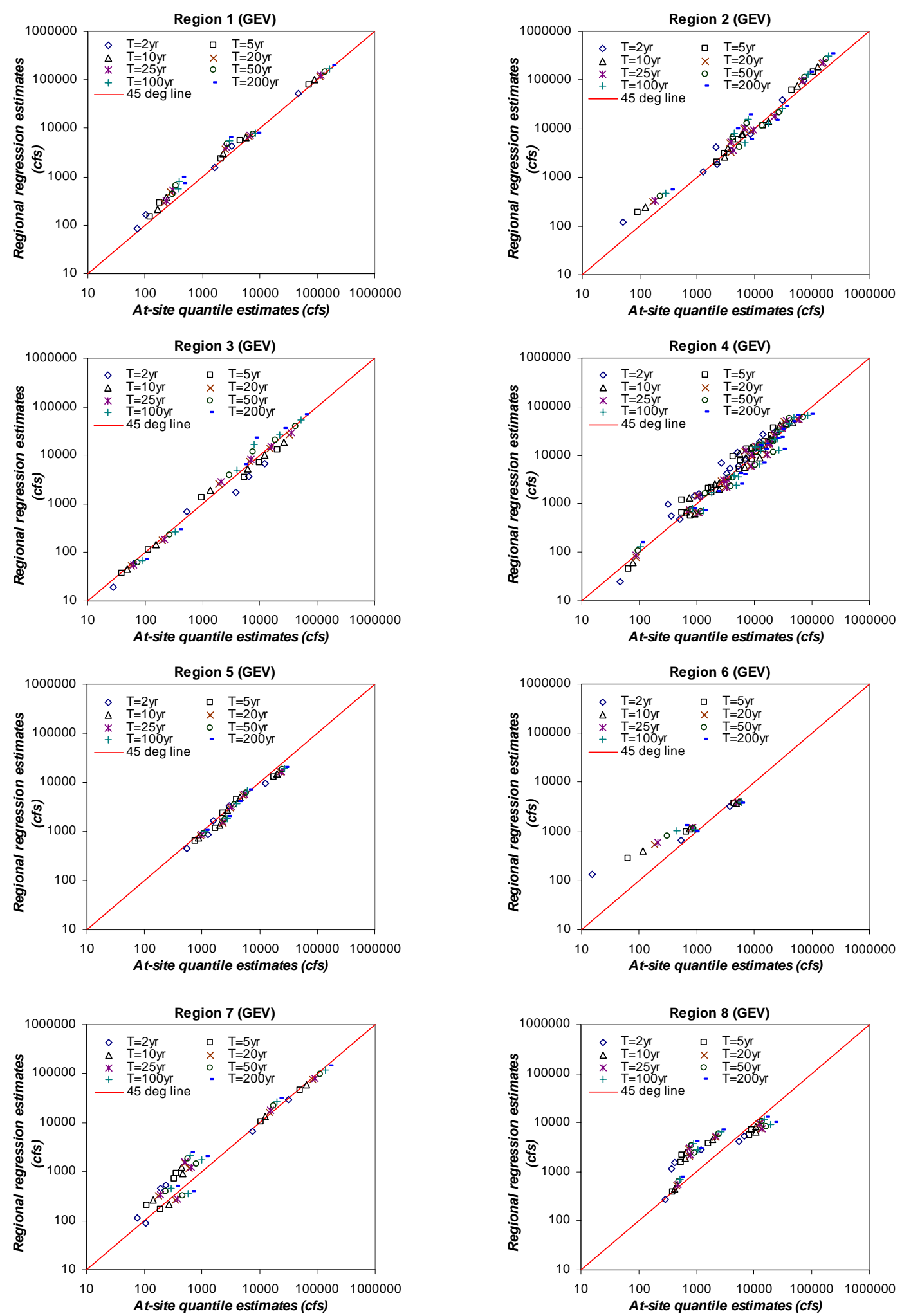

Figure 6.3.1(b). At-site quantile floods and the quantile floods obtained by Method 3 for $25 \%$ of the data (GEV). 

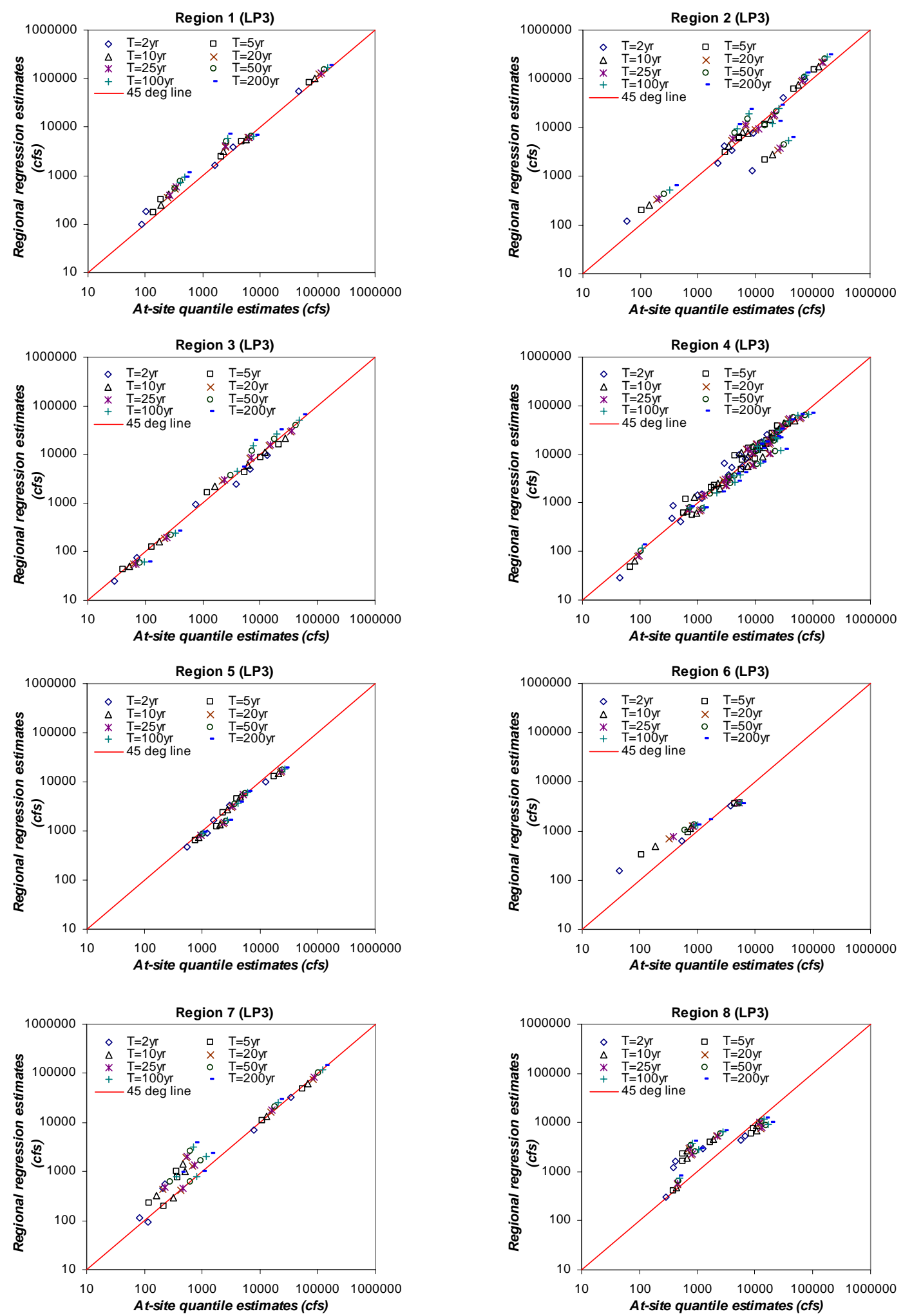

Figure 6.3.1(c). At-site quantile floods and the quantile floods obtained by Method 3 for $25 \%$ of the data (LPIII). 


\subsection{Comparison of the three approaches}

To quantify the errors, the estimation errors between at-site quantile estimates and Lmoment estimates are calculated for the quantile floods. The percentage error for Region $j$ for the L-moment method is calculated by equation (6.4.1).

$$
e_{D, T}(\%)=\sum_{i=1}^{N} \frac{\left|x_{A S}^{D, T}(i)-x_{M 1}^{D, T}(i)\right|}{x_{A S}^{D, T}(i)} \cdot D A R(i)
$$

Where $e_{D, T}$ is the average error percentage for Region $j$ with probability distribution $D$ (PTIII, GEV or LPIII), and recurrence interval $T(2,5,10,20,25,50,100$ and 200 years). $i=1, \ldots, \mathrm{N}$. N is the number of stations in Region $j . x_{A S}^{D, T}(i)$ is the quantile flood of distribution $D$ and return period $T$ at site $i(\mathrm{AS}) x_{M 1}^{D, T}(i)$ is the quantile flood obtained by method 1 (M1, L-moment method) of distribution $D$ and return period $T$ at site $i . D A R(\mathrm{i})$ is the drainage area ratio, which is ratio of the area at site $i$ divided by the sum of drainage areas in the sample.

A similar expression for calculating error percentage is applied to Method 2 (M2) and Method $3(M 3)$, with the change that $x_{M 1}^{D, T}(i)$ is replaced by $x_{M 2}^{D, T}(i)$ and $x_{M 3}^{D, T}(i)$, respectively. The average is calculated by weighting by the drainage area instead of simply by the arithmetical average, because it is not reasonable to give same weightings for data from small and large drainage areas and flood magnitudes. The percent errors from small drainage areas are always larger and lead to misinterpretation.

The error percentages are calculated for the $75 \%$ of data, which is used for establishing the model parameters, and $25 \%$ of data, which is used for validation. The results of the $75 \%$ of data for Region 1 4 are listed in Table 6.3.1 and of Region 5 8 are listed in Table 6.3.2. Dark 
shaded box indicates the minimum prediction error in that region. As expected, most of the regions have a more accurate prediction by the L-moment method than GLS and combination method. PTIII has flood better estimates than GEV and LPIII, but PTIII and GEV are close to each other. If we only look at the shaded boxes, except region 6 , all the regions have less than $10 \%$ average errors. The poor result in region 6 is expected, because it is a heterogeneous region. The error percentage of L-moment method for GEV in most regions is around $15 \%$, and for LPIII distribution is around $20 \%$ for most regions. The error percentage of L-moment method for LPIII in region 3 and region 7 is even as high as $30 \%$ and $42 \%$, so that LPIII is not preferred for these regions.

As for the GLS regional regression, PTIII distribution is still the preferred distribution and GEV is quite close to it. However, deriving mean flow magnitudes from geographical attributes produce more error than the L-moment method. The best results we see in Table 6.3.1 and Table 6.3.2 are from region 1, 4, 5, and 7, which have error percentage around 10 20\%. Region 2 has error as high as 45\%, region 3 and region 6 have error around $30 \%$ and region 8 has error about 40\%. Basically, Table 6.3.1 and Table 6.3.2 give us an idea of residual standard deviation.

The results for $25 \%$ of data, which is used for validation, for Region $1 \sim 4$ are listed in Table 6.4.3 and of Region 5 8 are listed in Table 6.4.4. Dark shaded box indicates the minimum prediction error for that region. Most of the regions show more accurate prediction by L-moment method than GLS and combination method. The other comparison of distribution, PTIII has better estimates than GEV and LPIII. If we only look at the shaded boxes, except region 6, all the regions have less than $10 \%$ average errors, which is very good prediction for hydrological analysis. The error percentage of L-moment for GEV in most regions is around $10 \sim 20 \%$, and for 
Table 6.3.1. Estimation errors of $75 \%$ split samples obtained from three comparative methods for PTIII, GEV and LPIII distributions (Region 1 4).

\begin{tabular}{|c|c|c|c|c|c|c|c|c|c|c|}
\hline \multicolumn{2}{|c|}{ Method } & \multicolumn{3}{|c|}{ Method 1} & \multicolumn{3}{|c|}{ Method 2} & \multicolumn{3}{|c|}{ Method 3} \\
\hline Region & $\mathrm{T}(\mathrm{yrs})$ & PT3 & LP3 & GEV & PT3 & LP3 & GEV & PT3 & LP3 & GEV \\
\hline \multirow{10}{*}{1} & 2 & 1.23 & 1.8 & 31.52 & 11.4 & 20.31 & 23.94 & 8.09 & 8.33 & 7.01 \\
\hline & 5 & 1.58 & 9.4 & 22.07 & 11.29 & 13.85 & 13.42 & 12.39 & 13.06 & 9.66 \\
\hline & 10 & 1.74 & 15.1 & 18.25 & 11.4 & 26.33 & 9.24 & 14.54 & 17.19 & 12.46 \\
\hline & 20 & 2 & 19.8 & 15.5 & 11.54 & 34.77 & 6.95 & 16.14 & 21.33 & 14.86 \\
\hline & 25 & 2.22 & 21.1 & 14.76 & 11.59 & 36.96 & 6.82 & 16.46 & 22.66 & 15.68 \\
\hline & 50 & 2.83 & 25.2 & 12.77 & 11.73 & 42.63 & 6.28 & 17.56 & 26.85 & 18 \\
\hline & 100 & 3.37 & 28.9 & 11.15 & 11.87 & 47.07 & 5.6 & 18.39 & 30.97 & 20.19 \\
\hline & 200 & 3.85 & 32.3 & 9.8 & 12.01 & 50.66 & 5.12 & 19.04 & 35.06 & 22.49 \\
\hline & Average & 2.35 & 19.2 & 16.98 & 11.60 & 34.07 & 9.67 & 15.33 & 21.93 & 15.04 \\
\hline & Stdev & 0.92 & 10.2 & 7.06 & 0.25 & 13.01 & 6.35 & 3.62 & 8.99 & 5.23 \\
\hline \multirow{10}{*}{2} & 2 & 2.02 & 2.0 & 35.38 & 43.58 & 59.52 & 9.74 & 41.79 & 38.61 & 38.67 \\
\hline & 5 & 1.24 & 9.5 & 23.14 & 45.81 & 15.37 & 15.31 & 45.59 & 41.77 & 42.29 \\
\hline & 10 & 2.24 & 15.9 & 17.89 & 47.27 & 9.18 & 21.79 & 47.49 & 45.2 & 44.5 \\
\hline & 20 & 3.14 & 21.8 & 13.98 & 48.5 & 19.68 & 27.23 & 48.76 & 49.01 & 46.64 \\
\hline & 25 & 3.49 & 23.7 & 12.92 & 48.86 & 22.74 & 28.76 & 49.13 & 50.38 & 47.41 \\
\hline & 50 & 4.45 & 29.4 & 9.97 & 49.88 & 30.62 & 33.09 & 50.09 & 54.61 & 49.55 \\
\hline & 100 & 5.29 & 35.0 & 7.49 & 50.78 & 36.79 & 37.01 & 50.81 & 59.14 & 51.96 \\
\hline & 200 & 6.03 & 40.6 & 5.37 & 51.59 & 41.75 & 40.66 & 51.47 & 63.92 & 54.47 \\
\hline & Average & 3.49 & 22.2 & 15.77 & 48.28 & 29.46 & 26.70 & 48.14 & 50.33 & 46.94 \\
\hline & Stdev & 1.67 & 12.9 & 9.75 & 2.66 & 16.30 & 10.61 & 3.18 & 8.61 & 5.14 \\
\hline \multirow{10}{*}{3} & 2 & 6.82 & 5.4 & 45.18 & 27.64 & 30.94 & 49.06 & 27.73 & 27.16 & 41.39 \\
\hline & 5 & 1.87 & 13.1 & 25.97 & 22.5 & 26.5 & 30.74 & 21.9 & 23.41 & 29.84 \\
\hline & 10 & 5.08 & 23.1 & 18.24 & 19.99 & 33.22 & 26.63 & 20.71 & 20.62 & 24.46 \\
\hline & 20 & 8.33 & 33.2 & 14.06 & 18.2 & 44.27 & 23.26 & 23.85 & 21.93 & 19.93 \\
\hline & 25 & 9.29 & 36.5 & 13 & 17.7 & 47.12 & 22.34 & 25.13 & 23.81 & 19.5 \\
\hline & 50 & 11.95 & 47.6 & 14.52 & 18.12 & 54.45 & 19.51 & 28.8 & 32.42 & 25.92 \\
\hline & 100 & 14.23 & 60.0 & 18.08 & 19.92 & 60.07 & 19.08 & 31.96 & 41.84 & 33.49 \\
\hline & 200 & 16.22 & 73.1 & 22.16 & 21.53 & 64.48 & 23.32 & 34.79 & 52.01 & 42.52 \\
\hline & Average & 9.22 & 36.5 & 21.40 & 20.70 & 45.13 & 26.74 & 26.86 & 30.40 & 29.63 \\
\hline & Stdev & 4.77 & 23.1 & 10.55 & 3.28 & 14.04 & 9.77 & 4.90 & 11.16 & 8.92 \\
\hline \multirow{10}{*}{4} & 2 & 4.36 & 3.4 & 31.64 & 25.27 & 35.01 & 27.67 & 30.05 & 31.34 & 42.25 \\
\hline & 5 & 1.77 & 8.9 & 19.21 & 23.71 & 16.21 & 17.09 & 22.29 & 25.86 & 28.56 \\
\hline & 10 & 3.45 & 14.5 & 14.15 & 22.71 & 25.4 & 14.13 & 18.45 & 22.37 & 23.11 \\
\hline & 20 & 5.48 & 20.0 & 11.21 & 22.32 & 34.84 & 13.77 & 15.66 & 19.22 & 18.59 \\
\hline & 25 & 6.07 & 21.9 & 10.56 & 22.44 & 37.4 & 13.76 & 14.98 & 18.35 & 17.26 \\
\hline & 50 & 7.68 & 27.5 & 9.76 & 22.78 & 43.94 & 14.27 & 13.42 & 16.58 & 13.86 \\
\hline & 100 & 9.07 & 32.9 & 9.72 & 23.08 & 48.94 & 15.61 & 12.8 & 15.8 & 12.2 \\
\hline & 200 & 10.31 & 38.1 & 11.19 & 23.75 & 52.91 & 17.16 & 12.48 & 16.48 & 12.51 \\
\hline & Average & 6.02 & 20.9 & 14.68 & 23.26 & 36.83 & 16.68 & 17.52 & 20.75 & 21.04 \\
\hline & $\overline{S t d e v}$ & 2.88 & 11.8 & 7.54 & 0.97 & 12.07 & 4.65 & 6.04 & 5.47 & 10.24 \\
\hline
\end{tabular}


Table 6.4.2. Estimation errors of $75 \%$ split samples obtained from three comparative methods for PTIII, GEV and LPIII distributions (Region 5 8).

\begin{tabular}{|c|c|c|c|c|c|c|c|c|c|c|}
\hline \multicolumn{2}{|c|}{ Method } & \multicolumn{3}{|c|}{ Method 1} & \multicolumn{3}{|c|}{ Method 2} & \multicolumn{3}{|c|}{ Method 3} \\
\hline Region & $\mathrm{T}(\mathrm{yrs})$ & PT3 & LP3 & GEV & PT3 & LP3 & GEV & PT3 & LP3 & GEV \\
\hline \multirow{10}{*}{5} & 2 & 3.25 & 2.9 & 24.81 & 17.86 & 17.31 & 28.54 & 17.26 & 17.49 & 17.4 \\
\hline & 5 & 1.15 & 8.4 & 16.4 & 16.18 & 26.06 & 23.12 & 17.2 & 18.12 & 17.73 \\
\hline & 10 & 3.56 & 14.1 & 12.22 & 14.59 & 32.28 & 20.5 & 16.38 & 16.95 & 16.8 \\
\hline & 20 & 5.7 & 19.3 & 8.74 & 13.01 & 36.94 & 18.2 & 15.45 & 15.43 & 15.54 \\
\hline & 25 & 6.35 & 20.9 & 7.71 & 13.04 & 38.2 & 17.5 & 15.25 & 15.02 & 15.15 \\
\hline & 50 & 8.26 & 25.6 & 4.81 & 13.26 & 41.5 & 15.46 & 14.65 & 13.79 & 14.28 \\
\hline & 100 & 10.14 & 30.1 & 6.99 & 13.45 & 44 & 13.53 & 14.08 & 12.58 & 13.35 \\
\hline & 200 & 11.98 & 34.5 & 9.88 & 13.76 & 45.96 & 12.66 & 13.5 & 12.97 & 13.17 \\
\hline & Average & 6.30 & 19.5 & 11.45 & 14.39 & 35.28 & 18.69 & 15.47 & 15.29 & 15.43 \\
\hline & Stdev & 3.68 & 10.7 & 6.45 & 1.76 & 9.69 & 5.28 & 1.39 & 2.09 & 1.77 \\
\hline \multirow{10}{*}{6} & 2 & 7.54 & 1.7 & 40.14 & 23.13 & 20.36 & 41.69 & 17.00 & 15.25 & 15.80 \\
\hline & 5 & 8.49 & 20.0 & 22.13 & 18.48 & 25.91 & 31.39 & 23.28 & 22.89 & 23.35 \\
\hline & 10 & 18.1 & 33.1 & 10.57 & 20.78 & 28.19 & 25.58 & 24.97 & 26.26 & 25.76 \\
\hline & 20 & 26.72 & 45.3 & 4.67 & 25.75 & 30.55 & 19.61 & 25.81 & 28.57 & 26.95 \\
\hline & 25 & 29.38 & 49.0 & 8.21 & 28.22 & 31.18 & 19.37 & 25.98 & 29.16 & 27.19 \\
\hline & 50 & 37.48 & 60.9 & 20.36 & 35.56 & 32.82 & 21.23 & 26.3 & 30.52 & 27.43 \\
\hline & 100 & 45.1 & 72.7 & 33.04 & 42.48 & 34.09 & 29.11 & 26.43 & 31.36 & 27.09 \\
\hline & 200 & 52.35 & 84.2 & 46.32 & 49.08 & 35.11 & 41.19 & 26.44 & 31.75 & 26.29 \\
\hline & Average & 28.15 & 45.9 & 23.18 & 30.44 & 29.78 & 28.65 & 24.53 & 26.97 & 24.98 \\
\hline & Stdev & 16.37 & 27.3 & 15.38 & 10.92 & 4.86 & 9.00 & 3.22 & 5.56 & 3.94 \\
\hline \multirow{10}{*}{7} & 2 & 6.18 & 3.0 & 31.38 & 18.56 & 36.05 & 25.22 & 16.18 & 14.87 & 23.64 \\
\hline & 5 & 2.67 & 38.3 & 17.66 & 15.46 & 11.09 & 17.61 & 11.53 & 11.91 & 17.55 \\
\hline & 10 & 3.21 & 61.1 & 14.48 & 12.37 & 27.75 & 12.88 & 9.27 & 9.28 & 13.5 \\
\hline & 20 & 5.93 & 81.9 & 13.68 & 9.88 & 41.12 & 9.76 & 7.76 & 7.27 & 9.74 \\
\hline & 25 & 6.66 & 88.3 & 13.73 & 9.2 & 44.68 & 8.85 & 7.37 & 6.7 & 8.58 \\
\hline & 50 & 8.61 & 108.1 & 14.73 & 8.37 & 53.97 & 10.54 & 8.01 & 10.79 & 5.99 \\
\hline & 100 & 10.17 & 127.6 & 17.01 & 9.76 & 61.23 & 13.82 & 9.65 & 15.15 & 9.29 \\
\hline & 200 & 11.45 & 147.3 & 19.79 & 10.91 & 67.02 & 17.47 & 11.03 & 19.55 & 13.72 \\
\hline & Average & 6.86 & 81.9 & 17.81 & 11.81 & 42.86 & 14.52 & 10.10 & 11.94 & 12.75 \\
\hline & Stdev & 3.10 & 47.3 & 5.89 & 3.52 & 18.26 & 5.43 & 2.88 & 4.38 & 5.70 \\
\hline \multirow{10}{*}{8} & 2 & 2.06 & 2.2 & 27.77 & 39.91 & 40.12 & 28.95 & 40.84 & 39.02 & 41.39 \\
\hline & 5 & 2.35 & 6.4 & 19.97 & 39.76 & 31.07 & 32.3 & 39.85 & 38.5 & 40.63 \\
\hline & 10 & 4.09 & 8.8 & 17.09 & 39.89 & 28.7 & 33.82 & 39.41 & 37.38 & 39.56 \\
\hline & 20 & 5.48 & 11.2 & 15.24 & 40.29 & 31.74 & 34.91 & 39.3 & 37.02 & 39.39 \\
\hline & 25 & 5.86 & 12.0 & 14.79 & 40.39 & 33.66 & 35.2 & 39.24 & 36.85 & 39.31 \\
\hline & 50 & 6.91 & 14.2 & 14.22 & 40.6 & 38.77 & 35.95 & 39.04 & 36.25 & 38.98 \\
\hline & 100 & 7.84 & 16.2 & 14.22 & 40.77 & 42.91 & 36.52 & 38.86 & 35.71 & 38.69 \\
\hline & 200 & 8.67 & 18.0 & 14.43 & 41.02 & 46.35 & 36.93 & 38.79 & 35.14 & 38.55 \\
\hline & Average & 5.41 & 11.1 & 17.22 & 40.33 & 36.67 & 34.32 & 39.42 & 36.98 & 39.56 \\
\hline & Stdev & 2.43 & 5.2 & 4.70 & 0.45 & 6.29 & 2.63 & 0.67 & 1.32 & 0.98 \\
\hline
\end{tabular}


LPIII distribution is as high as $6 \sim 114 \%$ for all regions. It can be concluded that LPIII is not preferable.

From the results of GLS regional regression, PTIII is the preferred distribution and GEV is quite close to it. Region 1 and region 7 have less than $10 \%$ error, region 3, 4, 5, 6 and 7 have error around $16 \sim 30 \%$, region 2 has $45 \%$ error and region 8 has error as high as $75 \%$. The error from region 8 is from the poor correlation between flood magnitude and drainage area and it makes the regression equation not as reliable as in other regions.

As for Method 2, which is using GLS regression to estimate the mean flow, i.e., the first L-moment, and then applying the L-moment method to calculate the flood magnitude, the error percentages are between the method 1 (L-moment) and method 3 (GLS) or higher than both of them. LPIII is still the less preferred distribution since it embeds the error from both models and makes the result not reliable. Method 2 can be a good substitute for the regions that have higher error in Method 3 but lower error in Method 2.

The same error percentages are calculated for the regions defined by Srinivas and Rao (2003); again, we only put the result for region 1 and region 5 since the other regions are the same as Knipe and Rao (2004). For the $75 \%$ of data, which are used to build model parameters, are listed in Table 5.6, and for the $25 \%$ of data, which are used to validate the model, are listed in Table 5.7. For the percentage error, we can find out that the values is between the two merged regions. For example, the error for L-moment, PTIII in region 1 is $2.35 \%$ and $6.86 \%$ in region 7 (Table 6.4.1 and Table 6.4.2), and the error is 5.9\% for the merged region. We also have tried to apply the equation for the merged area to region 8 individually, but no significant improvement 
is got for region 8 . 
Table 6.4.3. Estimation errors of $25 \%$ split samples obtained from three comparative methods for PTIII, GEV and LPIII distributions (Region 1 4).

\begin{tabular}{|c|c|c|c|c|c|c|c|c|c|c|}
\hline \multicolumn{2}{|c|}{ Method } & \multicolumn{3}{|c|}{ Method 1} & \multicolumn{3}{|c|}{ Method 2} & \multicolumn{3}{|c|}{ Method 3} \\
\hline Region & $\mathrm{T}(\mathrm{yrs})$ & PT3 & LP3 & GEV & PT3 & LP3 & GEV & PT3 & LP3 & GEV \\
\hline \multirow{10}{*}{1} & 2 & 4.4 & 2.1 & 27.2 & 15.07 & 25.33 & 20.61 & 11.84 & 12.48 & 10.63 \\
\hline & 5 & 2.0 & 5.6 & 21.1 & 10.34 & 13.71 & 11.74 & 10.35 & 11.22 & 10.11 \\
\hline & 10 & 5.2 & 6.5 & 20.0 & 7.89 & 28.04 & 9.69 & 9.11 & 11.46 & 9.32 \\
\hline & 20 & 7.6 & 6.8 & 20.1 & 5.97 & 37.64 & 9.31 & 7.99 & 12.23 & 8.21 \\
\hline & 25 & 8.3 & 6.7 & 20.3 & 5.44 & 40.12 & 9.36 & 7.55 & 12.55 & 7.88 \\
\hline & 50 & 10.2 & 6.6 & 21.2 & 3.97 & 46.53 & 9.93 & 6.56 & 13.66 & 6.73 \\
\hline & 100 & 11.8 & 6.3 & 22.6 & 2.74 & 51.53 & 10.94 & 5.72 & 14.8 & 5.62 \\
\hline & 200 & 13.2 & 5.8 & 24.1 & 1.68 & 55.56 & 12.26 & 4.9 & 15.94 & 4.51 \\
\hline & Average & 7.8 & 5.8 & 22.1 & 6.64 & 37.31 & 11.73 & 8.00 & 13.04 & 7.88 \\
\hline & Stdev & 3.8 & 1.6 & 2.5 & 4.39 & 14.22 & 3.75 & 2.35 & 1.64 & 2.15 \\
\hline \multirow{10}{*}{2} & 2 & 4.3 & 3.9 & 36.8 & 33.42 & 52.36 & 14.99 & 37.03 & 36.06 & 36.12 \\
\hline & 5 & 1.0 & 10.5 & 24.5 & 44.24 & 10.58 & 11.52 & 40.15 & 37.21 & 37.67 \\
\hline & 10 & 2.7 & 20.4 & 18.3 & 50.89 & 7.64 & 23.19 & 42.49 & 40.02 & 40.02 \\
\hline & 20 & 4.6 & 30.5 & 13.0 & 56.64 & 17.04 & 33.89 & 44.71 & 43.84 & 42.91 \\
\hline & 25 & 5.4 & 33.8 & 11.3 & 58.38 & 19.38 & 37.31 & 45.37 & 45.28 & 44.1 \\
\hline & 50 & 7.4 & 44.4 & 6.4 & 63.34 & 25.25 & 47.85 & 47.2 & 49.79 & 47.95 \\
\hline & 100 & 9.3 & 55.1 & 2.0 & 67.74 & 29.62 & 58.49 & 48.74 & 54.62 & 52.31 \\
\hline & 200 & 11.0 & 66.3 & 6.7 & 71.71 & 32.97 & 69.43 & 50.19 & 59.71 & 56.98 \\
\hline & Average & 5.7 & 33.1 & 14.9 & 55.80 & 24.36 & 37.08 & 44.49 & 45.82 & 44.76 \\
\hline & Stdev & 3.4 & 21.5 & 11.4 & 12.64 & 14.31 & 20.58 & 4.43 & 8.40 & 7.25 \\
\hline \multirow{10}{*}{3} & 2 & 2.6 & 4.8 & 44.8 & 17.79 & 7.83 & 47.48 & 29.67 & 27.69 & 44.49 \\
\hline & 5 & 1.7 & 9.2 & 29.2 & 17.78 & 35.6 & 37.11 & 19.03 & 23.28 & 33.37 \\
\hline & 10 & 3.7 & 19.9 & 22.2 & 17.36 & 46.8 & 32.69 & 12.3 & 16.59 & 24.59 \\
\hline & 20 & 5.4 & 30.9 & 16.5 & 17.58 & 54.53 & 29.33 & 11.14 & 12.48 & 16.52 \\
\hline & 25 & 5.8 & 34.5 & 15.7 & 17.86 & 56.52 & 28.38 & 11.29 & 12.55 & 14.68 \\
\hline & 50 & 7.2 & 46.3 & 14.0 & 18.67 & 61.65 & 26.4 & 11.88 & 12.81 & 12.36 \\
\hline & 100 & 8.5 & 58.7 & 13.0 & 19.61 & 65.63 & 27.09 & 16.18 & 20.56 & 16.71 \\
\hline & 200 & 9.6 & 71.7 & 13.7 & 20.55 & 68.81 & 28.19 & 22.36 & 35.5 & 33.3 \\
\hline & Average & 5.6 & 34.5 & 21.1 & 18.40 & 49.67 & 32.08 & 16.73 & 20.18 & 24.50 \\
\hline & Stdev & 2.8 & 23.5 & 11.0 & 1.13 & 19.97 & 7.14 & 6.64 & 8.33 & 11.49 \\
\hline \multirow{10}{*}{4} & 2 & 2.8 & 2.1 & 29.2 & 26.93 & 37.76 & 20.45 & 38.4 & 38.47 & 50.96 \\
\hline & 5 & 1.4 & 5.9 & 19.2 & 29.19 & 17.38 & 17.94 & 25.27 & 28.86 & 32.75 \\
\hline & 10 & 3.0 & 9.0 & 15.6 & 30.21 & 25.24 & 19.3 & 20.99 & 22.87 & 25.21 \\
\hline & 20 & 4.3 & 11.3 & 13.2 & 31 & 33.95 & 21.38 & 20.58 & 22.11 & 22.16 \\
\hline & 25 & 4.7 & 12.0 & 12.6 & 31.23 & 36.51 & 22.07 & 20.5 & 22.05 & 21.86 \\
\hline & 50 & 5.7 & 13.7 & 11.3 & 31.86 & 43.57 & 24.15 & 20.3 & 21.95 & 21.23 \\
\hline & 100 & 6.7 & 15.0 & 12.4 & 32.41 & 49.02 & 26.15 & 20.2 & 21.96 & 21.05 \\
\hline & 200 & 7.6 & 16.1 & 13.7 & 32.89 & 53.37 & 28.11 & 20.23 & 22.06 & 21.01 \\
\hline & Average & 4.5 & 10.7 & 15.9 & 30.72 & 37.10 & 22.44 & 23.31 & 25.04 & 27.03 \\
\hline & Stdev & 2.1 & 4.8 & 5.9 & 1.93 & 11.89 & 3.47 & 6.33 & 5.92 & 10.45 \\
\hline
\end{tabular}


Table 6.4.5. Estimation errors of $25 \%$ split samples obtained from three comparative methods for PTIII, GEV and LPIII distributions (Region 5 8).

\begin{tabular}{|c|c|c|c|c|c|c|c|c|c|c|}
\hline \multicolumn{2}{|c|}{ Method } & \multicolumn{3}{|c|}{ L-Moment } & \multicolumn{3}{|c|}{ Method 2} & \multicolumn{3}{|c|}{ Method 3} \\
\hline Region & $\mathrm{T}(\mathrm{yrs})$ & PT3 & LP3 & GEV & PT3 & LP3 & GEV & PT3 & LP3 & GEV \\
\hline \multirow{10}{*}{5} & 2 & 1.7 & 1.4 & 24.3 & 20.9 & 20.12 & 33.11 & 20.42 & 20.7 & 20.69 \\
\hline & 5 & 2.2 & 5.5 & 18.6 & 21.02 & 34.58 & 27.92 & 22.55 & 23.48 & 22.98 \\
\hline & 10 & 2.0 & 9.6 & 15.7 & 20.74 & 41.51 & 26.5 & 23.07 & 24.08 & 23.39 \\
\hline & 20 & 1.6 & 13.3 & 13.4 & 20.57 & 45.76 & 25.62 & 23.39 & 24.41 & 23.59 \\
\hline & 25 & 1.4 & 14.3 & 12.6 & 20.51 & 46.79 & 25.36 & 23.48 & 24.44 & 23.61 \\
\hline & 50 & 1.1 & 17.7 & 10.6 & 20.29 & 49.29 & 24.59 & 23.62 & 24.4 & 23.54 \\
\hline & 100 & 1.9 & 20.8 & 8.7 & 20.06 & 51.03 & 23.86 & 23.72 & 24.59 & 23.36 \\
\hline & 200 & 2.6 & 23.7 & 6.9 & 19.82 & 52.25 & 23.17 & 23.76 & 25.02 & 23.09 \\
\hline & Average & 1.8 & 13.3 & 13.8 & 20.49 & 42.67 & 26.27 & 23.00 & 23.89 & 23.03 \\
\hline & Stdev & 0.5 & 7.6 & 5.6 & 0.41 & 10.74 & 3.14 & 1.12 & 1.36 & 0.97 \\
\hline \multirow{10}{*}{6} & 2 & 6.8 & 0.2 & 41.2 & 22.30 & 19.13 & 47.86 & 15.49 & 13.56 & 13.06 \\
\hline & 5 & 7.8 & 19.4 & 22.5 & 16.49 & 26.82 & 36.78 & 22.08 & 21.17 & 20.01 \\
\hline & 10 & 16.9 & 31.3 & 10.9 & 12.93 & 30.53 & 30.43 & 25.02 & 26.14 & 23.91 \\
\hline & 20 & 25.2 & 42.0 & 1.3 & 9.75 & 33.83 & 25.21 & 27.11 & 30.24 & 27.07 \\
\hline & 25 & 27.7 & 45.3 & 4.4 & 8.79 & 34.74 & 23.72 & 27.68 & 31.41 & 28 \\
\hline & 50 & 35.1 & 55.3 & 15.6 & 5.95 & 37.13 & 19.14 & 29.18 & 34.54 & 30.49 \\
\hline & 100 & 42.0 & 64.9 & 27.3 & 3.3 & 39.05 & 14.67 & 30.42 & 37.15 & 32.66 \\
\hline & 200 & 48.5 & 74.2 & 39.5 & 5.81 & 40.63 & 10.2 & 31.47 & 39.28 & 34.62 \\
\hline & Average & 26.2 & 41.6 & 20.3 & 10.67 & 32.73 & 26.00 & 26.06 & 29.19 & 26.23 \\
\hline & Stdev & 15.3 & 24.3 & 15.1 & 6.31 & 7.09 & 12.22 & 5.22 & 8.60 & 7.08 \\
\hline \multirow{10}{*}{7} & 2 & 3.7 & 2.8 & 38.0 & 3.18 & 11.54 & 33.35 & 5.96 & 7.46 & 8.9 \\
\hline & 5 & 1.8 & 38.8 & 22.6 & 4.68 & 23.14 & 22.7 & 7.42 & 8.68 & 9.36 \\
\hline & 10 & 3.0 & 70.5 & 17.0 & 8.47 & 36.12 & 20.06 & 9.33 & 8.48 & 10.02 \\
\hline & 20 & 5.2 & 104.1 & 13.5 & 11.5 & 45.24 & 19.26 & 10.66 & 7.73 & 11.64 \\
\hline & 25 & 5.8 & 115.4 & 13.6 & 12.34 & 47.69 & 19.25 & 11.03 & 7.36 & 12.14 \\
\hline & 50 & 7.5 & 152.6 & 14.7 & 14.67 & 54.13 & 20.84 & 11.98 & 5.65 & 13.59 \\
\hline & 100 & 9.0 & 193.3 & 16.5 & 16.63 & 59.25 & 23.7 & 12.81 & 5.11 & 15.04 \\
\hline & 200 & 10.4 & 237.9 & 18.7 & 18.31 & 63.44 & 26.82 & 13.49 & 9.58 & 16.45 \\
\hline & Average & 5.8 & 114.4 & 19.3 & 11.22 & 42.57 & 23.25 & 10.34 & 7.51 & 12.14 \\
\hline & Stdev & 3.0 & 78.5 & 8.1 & 5.45 & 17.98 & 4.83 & 2.62 & 1.51 & 2.73 \\
\hline \multirow{10}{*}{8} & 2 & 3.3 & 1.3 & 26.9 & 68.64 & 70.06 & 61.28 & 68.22 & 68.86 & 67.8 \\
\hline & 5 & 2.4 & 3.9 & 22.0 & 73.1 & 65.75 & 66.4 & 72.13 & 71.66 & 70.71 \\
\hline & 10 & 4.6 & 6.7 & 20.5 & 75.43 & 63.86 & 69.28 & 74.28 & 73.18 & 72.79 \\
\hline & 20 & 6.4 & 9.2 & 19.8 & 77.29 & 62.45 & 71.87 & 75.97 & 74.48 & 74.85 \\
\hline & 25 & 6.8 & 10.0 & 19.6 & 77.81 & 62.06 & 72.68 & 76.44 & 74.86 & 75.5 \\
\hline & 50 & 8.2 & 12.3 & 19.3 & 79.29 & 61.02 & 75.13 & 77.72 & 76.02 & 77.54 \\
\hline & 100 & 9.2 & 14.4 & 19.2 & 80.58 & 60.16 & 77.48 & 78.8 & 77.09 & 79.57 \\
\hline & 200 & 10.2 & 16.4 & 19.3 & 81.73 & 59.44 & 79.75 & 79.72 & 78.13 & 81.62 \\
\hline & Average & 6.4 & 9.3 & 20.8 & 76.73 & 63.10 & 71.73 & 75.41 & 74.29 & 75.05 \\
\hline & Stdev & 2.8 & 5.1 & 2.6 & 4.28 & 3.46 & 6.02 & 3.79 & 3.01 & 4.58 \\
\hline
\end{tabular}


As a result, the error percentage is obtained by averaging the errors from two regions and by merging the regions still hardly helps to modify the region with bad regression results. Overall, for three methods, the best recommended method is L-moment method. However, if a watershed lacks flow measurements and requires performing regional regression, it is better to compare the accuracy between GLS and combination methods for the region of interest and decide using which model. For three distributions, the order of best-fit distribution is PT3 followed by GEV and finally the LP3 distribution. 
Table 6.4.6. Comparison the estimation errors of the $75 \%$ split samples obtained from three methods for PTIII, GEV and LPIII distributions (Merged regions: $1+7$ and 5+8).

\begin{tabular}{|c|c|c|c|c|c|c|c|c|c|c|}
\hline \multicolumn{2}{|c|}{ Method } & \multicolumn{3}{|c|}{ Method 1} & \multicolumn{3}{|c|}{ Method 2} & \multicolumn{3}{|c|}{ Method 3} \\
\hline Region & $\mathrm{T}(\mathrm{yrs})$ & PT3 & LP3 & GEV & PT3 & LP3 & GEV & PT3 & LP3 & GEV \\
\hline \multirow{10}{*}{$1+7$} & 2 & 4.8 & 6.2 & 32.7 & 20.5 & 33.1 & 25.3 & 20.5 & 15.0 & 24.7 \\
\hline & 5 & 1.2 & 17.2 & 22.1 & 19.1 & 10.3 & 13.1 & 16.6 & 12.0 & 19.3 \\
\hline & 10 & 2.5 & 27.5 & 17.9 & 18.6 & 22.3 & 7.4 & 15.7 & 13.1 & 16.0 \\
\hline & 20 & 5.0 & 38.3 & 15.0 & 18.4 & 31.9 & 4.8 & 15.6 & 15.7 & 13.1 \\
\hline & 25 & 5.7 & 41.9 & 14.3 & 18.5 & 34.4 & 5.6 & 15.8 & 16.8 & 12.5 \\
\hline & 50 & 7.7 & 53.1 & 12.2 & 19.1 & 40.7 & 8.3 & 16.4 & 21.5 & 11.4 \\
\hline & 100 & 9.4 & 65.3 & 11.4 & 20.0 & 45.5 & 12.9 & 17.4 & 28.2 & 11.8 \\
\hline & 200 & 11.0 & 78.8 & 13.0 & 21.3 & 49.3 & 17.6 & 18.6 & 35.7 & 14.2 \\
\hline & Average & 5.9 & 41.0 & 17.3 & 19.4 & 33.4 & 11.9 & 17.1 & 19.7 & 15.4 \\
\hline & Stdev & 3.3 & 24.3 & 7.1 & 1.1 & 12.6 & 6.9 & 1.7 & 8.3 & 4.6 \\
\hline \multirow{10}{*}{$5+8$} & 2 & 3.1 & 7.6 & 27.2 & 31.1 & 34.9 & 22.8 & 32.6 & 31.3 & 32.8 \\
\hline & 5 & 2.2 & 8.1 & 18.6 & 33.4 & 19.2 & 18.7 & 32.3 & 30.9 & 32.6 \\
\hline & 10 & 4.2 & 13.7 & 14.9 & 35.0 & 24.5 & 20.9 & 32.0 & 31.3 & 31.5 \\
\hline & 20 & 6.2 & 21.2 & 12.2 & 36.7 & 28.5 & 22.9 & 32.2 & 32.4 & 30.3 \\
\hline & 25 & 6.8 & 24.5 & 11.5 & 37.2 & 29.6 & 23.8 & 32.4 & 32.8 & 30.2 \\
\hline & 50 & 8.6 & 36.7 & 10.0 & 38.8 & 32.7 & 27.2 & 32.8 & 34.4 & 29.7 \\
\hline & 100 & 10.2 & 50.7 & 11.3 & 40.3 & 35.4 & 30.5 & 33.2 & 36.0 & 30.0 \\
\hline & 200 & 11.6 & 67.1 & 13.1 & 41.6 & 37.6 & 33.6 & 33.8 & 38.1 & 30.4 \\
\hline & Average & 6.6 & 28.7 & 14.8 & 36.7 & 30.3 & 25.1 & 32.6 & 33.4 & 30.9 \\
\hline & Stdev & 3.4 & 21.3 & 5.7 & 3.5 & 6.2 & 5.0 & 0.6 & 2.6 & 1.2 \\
\hline
\end{tabular}


Table 6.4.7. Comparison the estimation errors of the $25 \%$ split samples obtained from three methods for PTIII, GEV and LPIII distributions (Merged regions: 1+7 and 5+8).

\begin{tabular}{|c|c|c|c|c|c|c|c|c|c|c|}
\hline \multicolumn{2}{|c|}{ Method } & \multicolumn{3}{|c|}{ Method 1} & \multicolumn{3}{|c|}{ Method 2} & \multicolumn{3}{|c|}{ Method 3} \\
\hline Region & $\mathrm{T}$ (yrs) & PT3 & LP3 & GEV & PT3 & LP3 & GEV & PT3 & LP3 & GEV \\
\hline \multirow{10}{*}{$1+7$} & 2 & 3.6 & 2.8 & 38.9 & 25.2 & 37.8 & 21.0 & 39.7 & 19.3 & 25.0 \\
\hline & 5 & 1.8 & 19.1 & 24.7 & 29.1 & 2.4 & 5.6 & 41.5 & 21.6 & 24.9 \\
\hline & 10 & 4.7 & 33.5 & 18.1 & 31.0 & 13.0 & 6.2 & 41.7 & 26.0 & 24.1 \\
\hline & 20 & 7.1 & 47.6 & 13.0 & 32.5 & 22.1 & 11.7 & 41.6 & 31.8 & 23.0 \\
\hline & 25 & 7.8 & 52.2 & 11.5 & 32.9 & 24.5 & 13.2 & 41.5 & 33.9 & 22.7 \\
\hline & 50 & 9.6 & 66.7 & 7.3 & 34.1 & 30.7 & 17.4 & 41.1 & 41.1 & 21.5 \\
\hline & 100 & 11.3 & 81.8 & 6.8 & 35.1 & 35.5 & 21.1 & 41.5 & 49.2 & 20.4 \\
\hline & 200 & 12.7 & 97.5 & 6.8 & 35.9 & 39.4 & 24.6 & 44.1 & 58.2 & 19.3 \\
\hline & Average & 7.3 & 50.1 & 15.9 & 32.0 & 25.7 & 15.1 & 41.6 & 35.1 & 22.6 \\
\hline & Stdev & 3.8 & 31.7 & 11.2 & 3.5 & 13.0 & 7.1 & 1.2 & 13.6 & 2.1 \\
\hline \multirow{10}{*}{$5+8$} & 2 & 1.5 & 1.7 & 23.0 & 53.1 & 61.2 & 25.3 & 55.3 & 55.1 & 53.1 \\
\hline & 5 & 2.0 & 4.6 & 17.3 & 52.6 & 41.2 & 26.2 & 51.3 & 49.5 & 49.1 \\
\hline & 10 & 2.6 & 7.1 & 15.0 & 53.3 & 38.7 & 27.5 & 50.0 & 48.4 & 46.6 \\
\hline & 20 & 2.9 & 9.3 & 13.3 & 54.3 & 37.1 & 28.7 & 49.4 & 48.6 & 44.4 \\
\hline & 25 & 3.0 & 10.0 & 12.8 & 54.6 & 36.9 & 29.1 & 49.2 & 48.7 & 43.8 \\
\hline & 50 & 3.1 & 12.2 & 11.6 & 55.7 & 36.8 & 30.1 & 48.8 & 49.6 & 42.0 \\
\hline & 100 & 3.5 & 14.5 & 10.9 & 56.8 & 36.6 & 31.1 & 48.6 & 50.8 & 40.5 \\
\hline & 200 & 4.1 & 16.7 & 10.3 & 57.8 & 36.5 & 31.9 & 48.5 & 52.2 & 39.3 \\
\hline & Average & 2.8 & 9.5 & 14.3 & 54.8 & 40.6 & 28.7 & 50.2 & 50.4 & 44.8 \\
\hline & Stdev & 0.8 & 5.0 & 4.2 & 1.8 & 8.5 & 2.3 & 2.3 & 2.3 & 4.6 \\
\hline
\end{tabular}




\section{Conclusions}

On the basis of the research presented in this report, the following conclusions are presented.

1. One of the objectives of the study is to select the probability distribution which best fits the data in each of the six regions in Indiana. Based on the results presented in Chapter II, distributions in each region are ranked. In general, for region 4, 5 and 6, Generalized Extreme Value distribution is the best distribution. For regions 2 and 3, Log Normal (III) distribution is the best. Log Pearson (III) distribution is not the best distribution for any region. The Maximum likelihood method is the best parameter estimation method.

2. The equations developed for different regions may be used by the results in Chapter III when LP(III) distributions must be used. If a region is homogeneous the prediction error can be quite small. Otherwise, it may be large. However, the results presented in Chapter II indicate that the LP(III) distribution is inferior to other distributions.

3. The tables needed for the L-moment flood estimates for Indiana watersheds have been presented. The prediction accuracies of three distributions are compared. The LP(III) distribution is the least accurate distribution. If a region is homogeneous, the L-moment method gives quite accurate estimates.

4. The parameters for quantile flood estimation by regression relationships are presented. By using these equations, the flood magnitude is directly calculated. The 
GLS regression equations developed for mean and mean of logarithms of annual peak flows are also presented. These equations may be used with L-moment method.

5. Results are presented for the L-moment and GLS methods to estimate flood frequencies. These methods give similar results but the results from L-moment method are slightly superior. Once again the accuracy depends on the homogeneity of regions. The results are quite inferior for heterogeneous watersheds. The LP(III) distribution does not perform as well as other distributions. 


\section{Index}

Bobee, B., and F. Ashkar (1991). "The Gamma Family and Derived Distributions Applied in Hydrology", Water Resources Publications, Littleton, CO.

Chow, V.T. (1964). Editor-in-Chief, Handbook of Applied Hydrology, McGraw-Hill, New York, NY.

Glatfelter, Dale (1984). "Techniques for Estimating Magnitudes and Frequency of Floods of Streams in Indiana”, WRI 84-4134, USGS, Indianapolis, IN.

Hosking, J.R.M., and J.R. Wallis (1993). Some Statistics Useful in Regional Frequency Analysis, Water Resources Research, 29, 271-281.

Hosking, J.R.M. and J.R. Wallis (1997). Regional Frequency Analysis, Cambridge University Press, Cambridge CB2 2RU, U.K.

Hosking, J.R.M., J. R. Wallis and E.F. Wood (1985). An Appraisal of the Regional Flood Frequency Procedure in the UK Flood Studies Report, Hydrol. Sci. Jour., Vol. 30, No. 1, pp. 85-109.

Jin, M., and J.R. Stedinger (1989). Flood Frequency Analysis with Regional and Historical Information", Water Resources Research, Vol. 25, No. 5, pp. 925-936.

Iblings, M.L. and Rao, A.R. (2003). Regionalization of Indiana Watersheds for Flood Flow Predictions. III. Use of Precipitation and Flow Data for Regionalization of Watersheds, Interim Report FHWA/IN/JTRP-2002/3, No.2, JTRP, School of Civil Engineering, Purdue University, West Lafayette, IN 47907, pp. 98.

Kite, G.W. (1977). Frequency and Risk Analysis in Hydrology, Water Resources, Publications, Fort Collins, CO.

Landwehr, J.M., G.D. Tasker and R.D. Jarrett (1987). Discussion of Relative Accuracy of Log Pearson III Procedures, by J.R. Wallis and E.F. Wood, J. Hydraul. Eng., Vol. 111, No. 7, pp. 1206-1210.

McCuen, R.H. (1993). Microcomputer Applications in Statistical Hydrology, Prentice Hall, Englewood Cliffs, NJ.

McCormick, D.L. and A.R. Rao (1995). Outlier Detection in Indiana Flood Data, Tech. Rept. CE-EHE-95-04, School of Civil Engineering, Purdue University, W. Lafayette, IN 47907 , pp. 132.

Potter, K. W. (1987). Research on Flood Frequency Analysis, 1983-1986, Reviews of Geophysics, Vol. 25, No. 2, pp. 113-118. 
Potter, K.W., and D.P. Lettenmaier, A Comparison of Reginal Flood Frequency Estimation Methods Using a Resampling Method, Water Resources Research, Vol. 26, No. 3, pp. 415424.

Rao, A.R. and K.H. Hamed (1997). Regional Frequency Analysis of Wabash River Flood Data by L-Moments, ASCE Journal of Hydrologic Engineering, Vol. 2, No. 4, pp. 169-180.

Rao, A. Ramachandra and Khaled H. Hamed (2000). Flood Frequency Analysis, CRC Press LLc, Boca Raton, FL.

Rao, A.R., S. Ernst, and G.D. Jeong, (2002). Regionalization of Indiana Watersheds for Flood Flow Predictions. I. Results from L-Moment Based Method, Interim report FHWA/IN/JTRP-2002/3, JTRP, School of Civil Engineering, Purdue University, W. Lafayette, IN 47907, pp. 98.

Singh, V.P. and K. Singh (1988). Parameter Estimation for TPLN Distribution for Flood frequency Analysis, Water Resources Bulletin, Vol. 23, No. 6, pp. 1185-1191.

Srinivas, V.V. and A. R. Rao (2002). Regionalization of Indiana Watersheds for Flood Flow Predictions. II. Regionalization of Indiana Watersheds by Hybrid Cluster Analysis, Interim report FHWA/IN/JTRP-2002/3, JTRP, School of Civil Engineering, Purdue University, W. Lafayette, IN 47907, pp. 98.

Srinivas, V.V. and A.R. Rao (2003). Regionalization of Indiana Watersheds for Flood Flow Predictions. IV. Regionalization of Indiana Watersheds by Fuzzy Cluster Analysis, Interim report FHWA/IN/JTRP-2002/3, JTRP, School of Civil Engineering, Purdue University, W. Lafayette, IN 47907, pp. 98.

Stedinger, J. R. and Tasker, G. D. (1985). Regional Hydrologic Analysis 1.: Ordinary, Weighted, and Generalized Least Squares Compared, Water Resourc. Res., v. (22)5: p. 785793.

Stedinger, J.R., and G.D. Tasker (1985). Regional Hydrologic Regression, 1. Ordinary, Weighted and Generalized Least Squares Compared, Water Resources Research, Vol. 21, No. 9, pp. 1421-1432.

Stedinger, J.R., Vogel, R.M. and E. Foufoula-Geogiou, E., (1993). Frequency Analysis of Extreme Events, in "Handbook of Hydrology", ed. D.R. Maidment, McGraw-Hill, New York, NY, pp. 18.1-18.66.

Tasker, G.D., and J.R. Stedinger (1986). Estimating Generalized Skew with Weighted Least Squares Regression, J. Water Resour. Plann. Manage., Vol. 112, NO. 2, pp. 225-237.

Tasker, G.D., and J.R. Stedinger (1989). An Operational GLS Model for Hydrologic Regression, J. Hydrol., Vol. 111, pp. 361-375. 
Thomas, D.M., and M.A. Benson (1970). Generalization of Streamflow Characteristics from Drainage-Basin Characteristics, U.S. Geological Survey, Water Supply Paper 1975, U.S. Department of the Interior, Washington D.C.

U.S. Water Resources Council (1982). Guidelines for Determining Flood Flow Frequency, Bulletin 17B (revised), Hydrology Committee, Water Resources Research Council, Washington.

Wallis, J.R. and E.F. Wood (1985). Relative Accuracy of Log Pearson III Procedures, J. Hydraul. Eng., Vol. 111, No. 7, pp. 1043-1056 [with discussion and closure, J. Hydraul. Eng., Vol. 113, No. 7, pp. 1205-1214.]

Yevjevich, V. (1972). Probability and Statistics in Hydrology, Water Resources Publications, Fort Collins, CO.

Zempleni, A. (1991). Goodness-of-fit for Generalized Extreme Value Distributions, Technical Report, University of Sheffield. 